UNIVERSIDADE DE SÃO PAULO

FACULDADE DE ECONOMIA, ADMINISTRAÇÃO E CONTABILIDADE DEPARTAMENTO DE ADMINISTRAÇÃO PROGRAMA DE PÓS-GRADUAÇÃO EM ADMINISTRAÇÃo

A LIQUIDEZ E OS MODELOS DE PRECIFICAÇÃO DE ATIVOS - UM ESTUDO EMPÍRICO NO MERCADO ACIONÁRIO BRASILEIRO DE 1995 A 2011

Adriano Mussa

Orientador: Prof. Dr. José Roberto Securato 
Prof. Dr. João Grandino Rodas Reitor da Universidade de São Paulo

Prof. Dr. Reinaldo Guerreiro

Diretor da Faculdade de Economia, Administração e Contabilidade

Prof. Dr. Adalberto Américo Fischmann

Chefe do Departamento de Administração

Prof. Dr. Lindolfo Galvão de Albuquerque Coordenador do Programa de Pós-Graduação em Administração 


\section{A LIQUIDEZ E OS MODELOS DE PRECIFICAÇÃO DE ATIVOS - UM ESTUDO EMPÍRICO NO MERCADO ACIONÁRIO BRASILEIRO DE 1995 A 2011}

Tese apresentada ao Programa de PósGraduação em Administração da Faculdade de Economia, Administração e Contabilidade da Universidade de São Paulo, para obtenção do título de Doutor em Ciências.

Orientador: Prof. Dr. José Roberto Securato

\section{Versão Corrigida}

(versão original disponível na Faculdade de Economia, Administração e Contabilidade)

\section{SÃO PAULO}




\section{FICHA CATALOGRÁFICA}

Elaborada pela Seção de Processamento Técnico do SBD/FEA/USP

\section{Mussa, Adriano}

A liquidez e os modelos de precificação de ativos : um estudo empírico no mercado acionário brasileiro de 1995 a 2011 / Adriano Mussa. - São Paulo, 2012.

$168 \mathrm{p}$.

Tese (Doutorado) - Universidade de São Paulo, 2012.

Orientador: José Roberto Securato.

1. Finanças 2. Ações 3. Custo de capital I. Universidade de São Paulo. Faculdade de Economia, Administração e Contabilidade II. Título.

CDD - 332 
A Deus.

A minha esposa Carla e ao meu filho Gabriel, razões da minha vida. Aos meus pais, Luiz e Cleide, por tudo o que sou e pela dedicação e amor de toda uma vida. 


\section{AGRADECIMENTOS}

Ao Prof. Dr. José Roberto Securato, pela confiança que depositou em mim, pela valiosa orientação deste trabalho, pelo aprendizado único que obtive em suas disciplinas durante o curso de pós-graduação e demais projetos nos quais pude fazer parte de sua equipe, pelo privilégio de termos publicado trabalhos em conjunto e pelas inúmeras oportunidades que me concedeu.

Ao Prof. Dr. Rubens Famá, por ter feito parte da banca de qualificação e ter dado contribuições importantíssimas para o desenvolvimento desta tese, por ser fonte inesgotável de inspiração acadêmica, pelo privilégio de termos publicado trabalhos em conjunto e por ter me ensinado, desde os tempos do mestrado, a importância da paciência e da persistência no desenvolvimento da vida acadêmica.

A Profa. Dra. Rosana Tavares, por ter feito parte da banca de qualificação, pelas sugestões importantíssimas para o desenvolvimento desta tese, pelo privilégio de termos trabalhado juntos, pelas oportunidades que me abriu, pelas conversas enriquecedoras e pelos conselhos de sempre.

Ao Prof. Dr. Flávio Kezan Málaga, pela revisão cuidadosa desta tese, pelas contribuições enriquecedoras, por ter sido peça fundamental e determinante no meu desenvolvimento como docente, sendo sempre um espelho de excelência, pelos momentos de descontração e pelas oportunidades concedidas.

Ao Prof. Dr. Ricardo Humberto Rocha, pelas contribuições para o desenvolvimento deste trabalho, pelos valiosos ensinamentos de cada dia e pelas inúmeras oportunidades que me ofertou.

Ao Prof. Dr. José Odálio dos Santos, por ter me direcionado nos caminhos para a vida acadêmica e por seus conselhos sempre otimistas.

Ao Prof. Dr. Eliseu Martins, fonte de inspiração contínua, quem me proporcionou o privilégio inigualável de cursar duas disciplinas no programa de pós-graduação.

Aos demais professores do programa de pós-graduação da FEA/USP, especialmente à Profa. Dra. Maria Aparecida Gouvêa, Prof. Dr. José Roberto Savóia e ao Prof. Dr. Fábio Frezatti, pelo aprendizado proporcionado durante o programa.

Aos amigos Prof. Dr. Márcio Luiz Borinelli, Prof. Dr. José Carlos Luxo, Prof. Dr. Rafael Paschoarelli Veiga, Prof. Dr. Edson Ferreira de Oliveira, Prof. Dr. Leonel Molero Pereira e Prof. Dr. Eduardo Pozzi, pelo convívio e oportunidades de aprendizado que me proporcionaram. 
Ao André Rocha, por todo o auxílio na preparação das bases de dados desta tese.

À Saint Paul, representada pelo Prof. Dr. José Cláudio Securato, por todo o apoio técnico no desenvolvimento desta tese.

À Alexandra Venâncio dos Santos, com quem tenho o privilégio de trabalhar, por seu apoio e amizade incondicionais.

Aos colegas do programa de pós-graduação da FEA/USP André Saito, Ricardo Serra, Bolívar Godinho, Bruna Lousada Pereira, Marcela Galeno e Daniel Bergmann, pelo companheirismo, pelos momentos de descontração, pelo privilégio de termos cursado disciplinas em conjunto e pelas discussões sempre enriquecedoras. 


\section{RESUMO}

O trabalho seminal de Amihud e Mendelson (1986) abriu caminho para uma grande quantidade de pesquisas no âmbito internacional sugerindo que a liquidez poderia ser um fator relevante na explicação dos retornos das ações. A premissa central é que ativos menos líquidos devem apresentar taxas de retornos superiores a dos ativos mais líquidos, por representarem mais riscos a seus detentores. Assim, o objetivo principal da presente tese consistiu em verificar se há prêmios pela liquidez no mercado acionário brasileiro com o uso de uma vasta quantidade de medidas de liquidez, formas de cálculo e períodos de retenção das carteiras, bem como se o modelo de precificação de ativos de 2-fatores de Liu (2006) formado pelo beta de mercado e pelo fator liquidez - é válido para o mercado acionário brasileiro e, em caso positivo, se é superior ao CAPM, ao modelo dos 3-fatores de Fama e French (1993) e ao modelo dos 4-fatores de Carhart (1997), na explicação das variações dos retornos cross-section das carteiras de ações. Para isso, foram usadas todas as ações listadas na BM\&FBOVESPA, de 1995 a 2011. Os procedimentos metodológicos para obtenção das variáveis e testes para verificação da existência de prêmios pela liquidez seguiram, essencialmente, o estudo de Liu (2006). Os procedimentos para validação e comparação dos modelos de precificação de ativos foram efetuados seguindo o modelo de testes preditivo de Fama e MacBeth (1973). Foram testadas doze medidas de liquidez, dentre as mais recorrentes adotadas na literatura internacional. Os resultados encontrados evidenciaram fortes coeficientes de correlação entre muitas medidas, o que levou à manutenção dos testes com as medidas menos correlacionadas entre si: Índice de Negociabilidade da BM\&FBOVESPA, Turnover, Return-to-Volume e Coeficiente de Variação do Volume Financeiro. Dentre estas, observou-se a existência de prêmio pela liquidez estatisticamente significante no mercado acionário brasileiro, na maioria das estratégias testadas, com $\mathrm{o}$ uso do Índice de Negociabilidade da BM\&FBOVESPA e com o Coeficiente de Variação do Volume Financeiro. Esses resultados indicaram a existência de relação consistente e negativa entre o retorno das carteiras e a liquidez das ações e relação positiva entre a volatilidade da liquidez e o retorno das carteiras. Os prêmios encontrados com o uso do Índice de Negociabilidade da BM\&FBOVESPA mostraram-se robustos aos testes de subamostras, subperíodos e efeitos sazonais. Em relação aos testes empíricos dos modelos de precificação de ativos, o modelo dos 2-fatores mostrou-se válido para explicação das variações dos retornos cross-section das ações no mercado brasileiro. O fator liquidez revelou-se complementar ao fator beta de mercado, aumentando o poder de explicação do modelo quando comparado ao CAPM, especialmente nas carteiras compostas por ações de baixa liquidez. $\mathrm{O}$ modelo de 2-fatores mostrou-se também superior aos modelos 3-fatores e 4-fatores. Os resultados mantiveram-se robustos aos testes efetuados quanto a possíveis vieses de seleção do período amostral. Assim, mesmo que nenhum dos modelos tenha se apresentado suficiente na explicação das variações cross-section dos retornos no mercado acionário brasileiro, os resultados parecem indicar que a liquidez é uma direção especialmente promissora para a continuidade das pesquisas sobre o tema. 


\begin{abstract}
The seminal study of Amihud and Mendelson (1986) opened the way to a large quantity of researches in international environment suggesting that liquidity may be an important risk factor to explain stock returns. The central premise is that the less liquid assets should present higher rates of return than the most liquid assets, because they are riskier assets. Thus, the main objective of this thesis is to check if there is liquidity premium in the Brazilian stock market through the use of a vast amount of liquidity measures, forms of calculation and portfolios retention periods, as well as, to check if the 2-factor pricing model developed by Liu (2006) - formed by the market beta and the liquidity factor - is valid for the Brazilian stock market. If so, it tests whether the 2-factor model is superior to the CAPM, the 3-factor model of Fama and French (1993) and the 4-factor model of Carhart (1997), in explaining the cross-section variations of assets portfolio returns. For this purpose, this study used all shares listed on the BM\&FBOVESPA from 1995 to 2011. The methodological procedures for the variables construction and tests to verify the existence of liquidity premiums followed the study of Liu (2006). The procedures for validation and comparison of asset pricing models followed the predictive tests model of Fama and MacBeth (1973). This thesis tested 12 liquidity measures, among which were the most recurrent adopted in the international literature. The results showed strong correlations between many measures, which led to the maintenance of those with less correlation: BM\&FBOVESPA Negotiability Index, Turnover, Return-to-Volume and Coefficient of Variation of Financial Volume. Among these, it was observed the existence of a statistically significant premium for liquidity in the Brazilian stock market, in most of the tested strategies, using the BM\&FBOVESPA Negotiability Index and the Coefficient of Variation of Financial Volume. These results indicate that there is a consistent and negative relationship between portfolio returns and shares liquidity and a positive relationship between liquidity volatility and portfolio returns. Prizes found using the BM\&FBOVESPA Negotiability Index were robust to tests of subsamples, subperiods and seasonal effects. Regarding the asset pricing models empirical testing, the 2-factors model proved to be a valid explanation for the cross-section variations of returns of the shares in the Brazilian market. The liquidity factor proved to complement the market beta, increasing the explanatory power of the model when compared to the CAPM, especially in portfolios composed of stocks with low liquidity. The 2-factor model was even superior to the 3-factor and 4-factor models. The results have not changed even after the robustness tests regarding possible sample period selection biases. So even though none of the models has been shown enough in explaining the cross-section variations of stock returns in the Brazilian market, the results seem to indicate that liquidity is a particularly promising direction for continued research on the topic.
\end{abstract}




\section{SUMÁRIO}

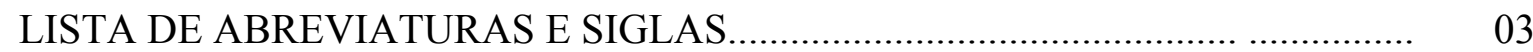

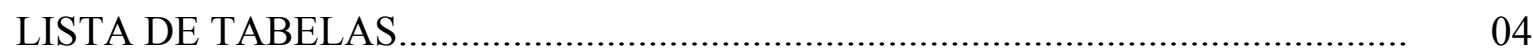

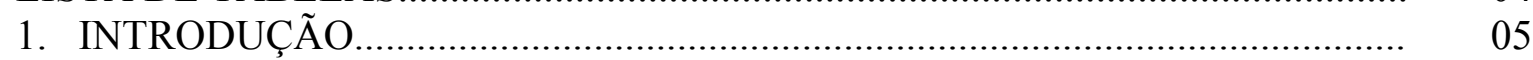

1.1 Situação problema..................................................................................... 05

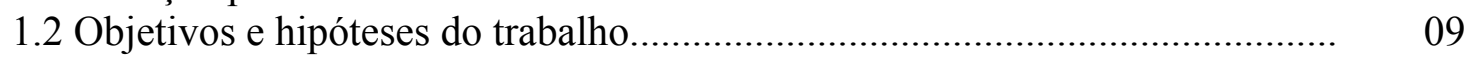

1.3 Justificativa do tema e ineditismo da pesquisa.......................................... 12

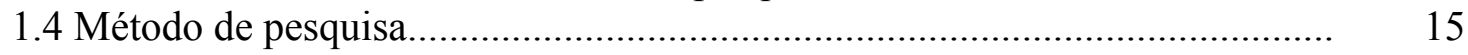

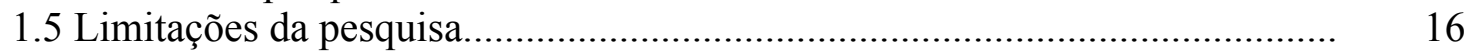

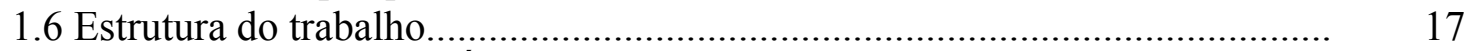

2. FUNDAMENTAÇÃO TEÓRICA........................................................................ 19

2.1 O Capital Asset Pricing Model - CAPM e a Arbitrage

Pricing Theory - APT................................................. 19

2.1.1 O CAPM - Capital Asset Pricing Model............................. 19

2.1.2 A APT - Arbitrage Pricing Theory.............................. 20

2.2 Hipótese de mercados eficientes e a identificação de anomalias..................... 23

2.3 Identificação dos efeitos tamanho e valor e o modelo dos 3 -fatores
de Fama e French (1993)............................................................................ 25

2.3.1 Testes empíricos do CAPM e a identificação das anomalias
efeito tamanho e valor..................................................................... 25

2.3.2 As possíveis causas das anomalias efeito tamanho e efeito valor.......... $\quad 28$

2.3.3 Alguns testes empíricos do CAPM e a identificação das anomalias efeito tamanho e valor no mercado brasileiro........................................... $\quad 29$

2.3.4 O modelo de 3-fatores.......................................................................... 29

2.3.5 Estudos dos fatores tamanho e valor posteriores ao de

2.3.6 Estudos do modelo dos 3-fatores no mercado acionário brasileiro....... 33

2.4 Identificação do efeito momento e o modelo dos 4-fatores de Carhart (1997).................................................................................. 35

2.4.1 A identificação do efeito momento........................................................ 35

2.4.2 O modelo de 4-fatores.......................................................................... 36

2.4.3 Estudos posteriores ao de Carhart (1997)................................................ 39

2.4.4 Estudos sobre o modelo de 4-fatores no mercado brasileiro.................... $\quad 40$

2.5 Liquidez e o modelo de 2-fatores..................................................................... 41

2.5.1 Detalhamento dos principais trabalhos sobre liquidez............................ 42

2.5.2 As possíveis causas do prêmio pela liquidez............................................ 60

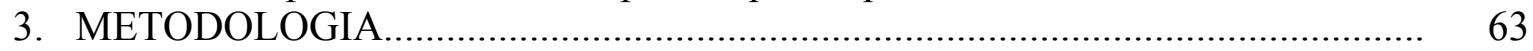

3.1 População e amostra.................................................................................... 64

3.2 Coleta de dados....................................................................................... 65

3.3 Cálculo e testes das medidas e prêmios pela liquidez..................................... 66

3.3.1 Detalhamento das medidas de liquidez............................................... 66

3.3.2 Procedimento para verificação dos prêmios pela liquidez................... 70

3.3.3 Testes de robustez dos prêmios pela liquidez...................................... 71

3.4 Procedimentos de testes dos modelos de precificação de ativos..................... $\quad 72$

3.4.1 Cálculo das variáveis dependentes.................................................... 73

3.4.2 Obtenção dos prêmios pelos fatores de risco

3.4.3 Procedimento dos testes estatísticos............................................... 77 
3.4.4 Teste de robustez dos modelos de precificação de ativos..................... 79

4. ANÁLISE DOS DADOS E RESULTADOS..................................................... 81

4.1 Testes dos prêmios pela liquidez.................................................................... $\quad 81$

4.1.1 Estatística descritiva e correlação entre as medidas de liquidez.......... 81

4.1.2 Os prêmios pela liquidez.................................................................. 87

4.1.3 Testes de robustez dos prêmios pela liquidez................................... 94

4.1.3.1 Testes de subamostras............................................................. 94

4.1.3.2 Testes de subperíodos e efeitos sazonais................................... 98

4.2 Testes dos modelos de precificação de ativos................................................. 99

4.2.1 Análise das variáveis dependentes e independentes........................... 100

4.2.2 Sensibilidade dos excessos de retornos aos fatores de risco................. 103

4.2.3 Resultados dos testes dos modelos de precificação de ativos................. 106

4.2.4 Testes de robustez dos modelos de precificação de ativos.................... 110

4.3 Análise das hipóteses da pesquisa.................................................................... 113

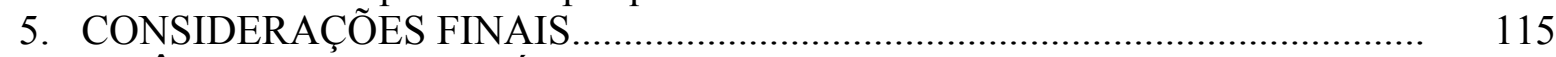

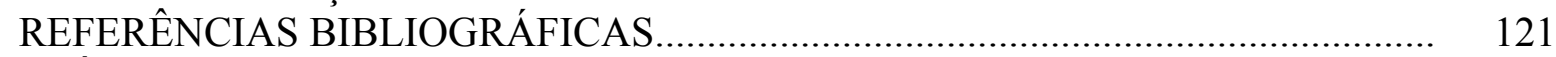

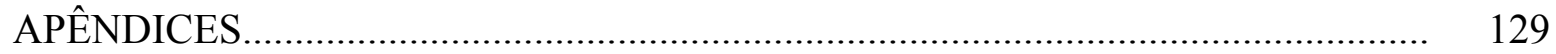




\section{LISTA DE ABREVIATURAS E SIGLAS}

Adj. $R^{2}$

AMEX:

APT:

$b$ :

B:

B/M:

BM\&FBOVESPA:

CAPM:

COMPUSTAT:

CVTOx:

CVVOLx:

DPTOx:

DPVOLx:

$h$ :

$H M L$ :

Ibovespa:

ILIQ:

$l$ :

$\mathrm{L} / \mathrm{P}$ :

LCAPM:

LIQ:

MKT:

NASDAQ:

NEG $x$ :

NTDx:

NYSE:

ON:

PN:

Prêmio LIQ:

QNx:

QTx:

RtoVx:

$\mathrm{Rm}$ :

Rlr ou Rf:

$s:$

$\mathrm{S}:$

SMB:

Teste $t$ :

TOx:

VM:

VOLx:

VZPx:

w:

WinMLos: coeficiente de determinação ajustado

American Stock Exchange

Arbitrage Princing Theory

coeficiente do fator beta de mercado

carteira formada por ações de menor liquidez

índice book-to-market

Bolsa de Mercadorias e Futuros e Bolsa de Valores de São Paulo

Capital Asset Pricing Model

Standard \& Poor's COMPUSTAT

Coeficiente de Variação do Turnover

Coeficiente de Variação do Volume Financeiro

Desvio-padrão do Turnover

Desvio-padrão do Volume Financeiro

coeficiente do fator índice $\mathrm{B} / \mathrm{M}$

prêmio pelo fator índice B/M - High Minus Low

índice da Bolsa de Valores de São Paulo

iliquidez

coeficiente do fator liquidez

índice Lucro/Preço

Liquidity Capital Asset Pricing Model

liquidez

fator beta de mercado ou prêmio pelo fator mercado

NASDAQ Stock Exchange

Índice de Negociabilidade da BM\&FBOVESPA

Número de dias sem transações

New York Stock Exchange

ações ordinárias

ações preferenciais

prêmios pelo fator (i)liquidez

Quantidade de Negócios

Quantidade de Títulos

Return-to-Volume

retorno da carteira de mercado

retorno do ativo livre de risco

coeficiente do fator tamanho

carteira formada por ações de maior liquidez

prêmio pelo fator tamanho - Small Minus Big

teste de médias one sample $t$

Turnover

valor de mercado

Volume Financeiro

Volume Zero Padronizado

coeficiente do fator momento

prêmio pelo fator momento - Winner Minus Looser 


\section{LISTA DE TABELAS}

Tabela $1-$

Estatísticas descritivas das ações da amostra

82

Tabela $2-$

Matriz de correlação entre as medidas de liquidez.

86

Tabela 3 -

Desempenho das carteiras classificadas conforme o

Índice de Negociabilidade.

89

Tabela 4

Desempenho das carteiras classificadas conforme o Turnover.

Tabela 5

Desempenho das carteiras classificadas conforme o

Return-To-Volume

Tabela 6 - Desempenho das carteiras classificadas conforme o Coeficiente de Variação do Volume

Tabela 7 - Análise de subamostras com carteiras classificadas conforme o Índice de Negociabilidade da BM\&FBOVESPA e a estratégia $6 \times 6$

Tabela 8 - Análise de subamostras segregadas conforme o índice B/M com carteiras classificadas conforme o Índice de Negociabilidade da BM\&FBOVESPA e a estratégia $6 \times 6$, considerando o período de 1995 a 2007

Tabela 9 - $\quad$ Análise de subperíodos e efeitos sazonais com carteiras classificadas conforme o Índice de Negociabilidade da BM\&FBOVESPA e a estratégia $6 \times 6$

Tabela 10 - Estatísticas descritivas das variáveis dependentes: excesso de retorno mensal das carteiras

Tabela 11 - Estatísticas descritivas e matriz de correlação das variáveis independentes.

Tabela 12 - Sensibilidade dos excessos de retornos aos fatores de risco

Tabela 13 - Resultados das regressões cross-sections dos modelos CAPM, 2-fatores, 3-fatores e 4-fatores

Tabela 14 - Resultados das regressões cross-sections dos modelos CAPM, 2-fatores, 3-fatores e 4-fatores com exclusão dos interceptos.

Tabela 15 - Teste de robustez dos modelos - resultados das regressões cross-sections dos modelos CAPM, 2-fatores, 3-fatores e 4-fatores com variações dos períodos de within-sample e out-of-sample. 


\section{INTRODUÇÃO}

\subsection{Situação Problema}

Os modelos de precificação de ativos formam um assunto bastante discutido e pesquisado em finanças. Sua importância é facilmente observada em vários ramos de estudos. A previsão de retornos, a mensuração do custo do capital próprio, as questões de como o risco é mensurado, como é recompensado e quanto risco a assumir, são fundamentais em decisões de investimentos e financiamentos.

Além disso, o tema apresenta importância crescente para a contabilidade brasileira rumo à convergência com as normas internacionais, principalmente no que se refere à questão de qual taxa utilizar para os cálculos de valor presente nos testes de recuperabilidade dos ativos especialmente o Pronunciamento Técnico CPC (Comitê de Pronunciamentos Contábeis) 01 Redução ao Valor Recuperável de Ativos.

Sharpe (1964), Lintner (1965) e Mossin (1966), baseados nos trabalhos de Markowitz (1952) e de Tobin (1958), desenvolveram o modelo denominado Capital Asset Pricing Model CAPM. O CAPM é um dos modelos mais utilizados no mundo até hoje para mensuração do custo do capital próprio, sendo que seus estudos ocuparam parte dos trabalhos acadêmicos durante mais de três décadas. Por esse modelo, o retorno de qualquer ativo é determinado pelo retorno do ativo livre de risco e pelo prêmio de mercado multiplicado pelo fator beta de mercado, que mede a sensibilidade dos retornos do ativo em relação à carteira de mercado. Trata-se, portanto, de um modelo de fator único, o beta de mercado, que seria o fator de explicação da diferença de retorno exigido entre os ativos, numa relação linear.

Diversos autores passaram a testar empiricamente a validade do CAPM. Muitos pesquisadores, nos primeiros estudos, encontraram evidências no sentido de validação do modelo. Entre eles, podem-se citar Black, Jensen e Scholes (1972) e Fama e MacBeth (1973). Porém, o desenvolvimento dos testes trouxe o debate sobre suas deficiências, principalmente devido ao surgimento de novas evidências de que parte da variação nos retornos esperados dos ativos não está relacionada ao beta de mercado (FAMA e FRENCH, 2004). 
Ross (1976) propôs um novo enfoque multifatorial para explicar a formação de preços dos ativos, baseado nos conceitos de arbitragem. Esse novo enfoque deu origem a Arbitrage Pricing Theory - APT. Grinblatt e Titman (2005, p.181) destacam que existem três maneiras de estimar os fatores comuns em um modelo multifatorial: i) utilizar um procedimento estatístico, como uma análise fatorial, para determinar as carteiras fatoriais, que são carteiras de títulos criadas para imitar fatores; ii) utilizar variáveis macroeconômicas, como mudanças nas taxas de juros e mudanças na atividade econômica, na condição de aproximações para fatores; iii) utilizar características da empresa, como seu tamanho, para criar carteiras que ajam como aproximações para os fatores.

Essa terceira opção utiliza carteiras selecionadas com base nas anomalias de retornos passados. Basu (1977), Banz (1981), Stattman (1980), Lakonishok e Shapiro (1986) e Fama e French (1992) são exemplos de alguns estudos que identificaram ineficiências do CAPM e terminaram por caracterizar anomalias de mercado.

Por sua vez, Fama e French (1993), baseados em estudos anteriores, sugeriram que novas variáveis, relacionadas às anomalias identificadas, fossem agregadas ao CAPM, na constituição de um modelo multifatorial que utilizasse as características da empresa como fatores de risco. Esse modelo ficou conhecido como modelo de 3-fatores que, segundo os autores, poderia explicar significativamente os retornos das ações. Os fatores de risco do modelo são o beta de mercado, conforme definido pelo CAPM; o tamanho da empresa, definido pelo valor de mercado do patrimônio líquido; e o índice book-to-market - B/M, definido pela relação entre o valor contábil e de mercado do patrimônio líquido.

Alguns estudos sobre o modelo dos 3-fatores foram efetuados no mercado acionário brasileiro, dentre os quais se destacam Málaga e Securato (2004), Lucena e Pinto (2005) e Almeida e Eid (2010). Esses trabalhos, de forma geral, foram favoráveis à validação do modelo de 3-fatores, outrossim, evidenciaram que os modelos não foram suficientes na explicação das variações dos retornos das ações.

Conforme concluíram Fama e French (1996), o modelo de 3-fatores captura a maior parte das anomalias não assimiladas pelo fator beta de mercado, exceto a anomalia denominada efeito momento. Um grande número de estudos, iniciados por Jegadeesh e Titman (1993), demonstrou que estratégias de momento, que envolvem a compra (venda) de ações que 
tiveram um bom (mau) desempenho nos últimos meses, tendem a produzir retornos anormais positivos durante períodos subsequentes. Os resultados de Jegadeesh e Titman (1993) foram corroborados por Fama e French (1996) e Jegadeesh e Titman (2001) para o mercado norteamericano, por Rouwenhorst (1998) para o mercado europeu e por Rouwenhorst (1999) para os mercados emergentes.

Uma vez identificado o fator de risco momento, alguns estudos, sendo pioneiro o trabalho de Carhart (1997), passaram a adicioná-lo ao modelo dos 3-fatores de Fama e French (1993), construindo o que ficou conhecido como modelo dos 4-fatores. Em seu estudo, Carhart (1997) encontrou evidências empíricas para afirmar a superioridade do modelo dos 4-fatores em relação ao modelo dos 3-fatores e ao CAPM, na explicação dos retornos.

Mussa et al (2007) testaram o modelo dos 4-fatores no mercado acionário brasileiro, também encontrando evidências de sua validação e de superioridade em relação ao CAPM e ao modelo dos 3-fatores, utilizando modelo de testes de regressões em séries temporais, mesma técnica adotada por Fama e French (1993). Contudo, Mussa et al (2009), ao utilizarem regressões em duas etapas, séries temporais e cross-section, conforme metodologia de Fama e Macbeth (1973), não encontraram significância estatística para os fatores tamanho e momento, além de indicarem que nenhum dos modelos testados foi suficiente na explicação do retorno das ações.

Em paralelo, desde o final da década de 1960, a liquidez vem sendo objeto de estudo de vários acadêmicos, principalmente na literatura internacional. Especialmente, o artigo seminal de Amihud e Mendelson (1986), abriu caminho para uma grande quantidade de pesquisas sugerindo que a liquidez pode ser um fator relevante na explicação dos retornos das ações. A premissa central é que ativos menos líquidos devem apresentar taxas de retornos superiores às dos ativos mais líquidos, por representarem mais riscos a seus detentores. Apesar de Fama e French (1993) sugerirem que a liquidez estaria contida no fator tamanho, as pesquisas empíricas têm demonstrado que o fator liquidez é relevante na explicação dos retornos das ações, mesmo depois de controlado pelos fatores de Fama e French (1993) - tamanho e índice B/M - e de Carhart (1997) - momento. Alguns exemplos são os estudos de Brennan et al (1998), Datar et al (1998), Chordia et al (2001), Liu (2006) e Keene e Petersen (2007). 
A liquidez é comumente descrita como um conceito multidimensional: a habilidade de negociar grandes quantidades de ativos, rapidamente, a um baixo custo e com pequeno impacto nos preços (BLACK, 1971; LIU, 2006). Conforme essa definição, pode-se notar a dificuldade de observação direta da liquidez e a existência de pelo menos quatro dimensões que a compõem: i) quantidade; ii) velocidade; iii) custo e iv) impacto nos preços. Desse contexto, decorre, ao longo dos anos, a criação e testes de distintas medidas de liquidez, para tentar capturar suas diferentes dimensões.

Uma vez identificado o fator de risco liquidez, alguns estudos mais recentes como os de Acharya e Pedersen (2005) e Liu (2006), passaram a adicioná-lo ao beta de mercado do CAPM, construindo o que ficou conhecido como Liquidity CAPM - LCAPM ou modelo de 2-fatores. Esses dois trabalhos, de maneira geral, evidenciaram a validade do modelo de 2fatores e sua superioridade em relação aos modelos CAPM, 3-fatores de Fama e French (1993) e 4-fatores de Carhart (1997). Ressalte-se que o trabalho de Acharya e Pedersen (2005) testou o fator liquidez em conjunto com os fatores tamanho e índice B/M. Já, o estudo de Liu (2006) incluiu o fator momento, além dos fatores já mencionados.

Há poucos estudos brasileiros sobre o tema, dentre os quais se podem mencionar Sanvicente e Minardi (1998), Bruni e Famá (1998), Vieira e Milach (2008), Correia et al (2008) e Machado e Medeiros (2011). Entretanto, nesses, as evidências sobre a existência de prêmio pela liquidez, bem como sua validade para uso em modelos de precificação de ativos têm sido controversas, variando conforme o período, o método estatístico e, principalmente, as medidas de liquidez e seus respectivos métodos de cálculo. Ressalte-se que esses trabalhos se concentraram em algumas poucas quantidades de medidas de liquidez e sem quaisquer variações de períodos para cálculo das medidas e retenção das carteiras, bem como escassos testes de robustez dos prêmios pela liquidez.

Com base no exposto acima, observa-se uma lacuna na literatura nacional de estudos mais aprofundados sobre a liquidez e seu papel em modelos de precificação de ações. Dessa forma, o problema a ser investigado nesta tese pode ser resumido com as seguintes questões:

- Haveria prêmio pelo fator liquidez no mercado acionário brasileiro?

- Quais medidas de liquidez - e suas dimensões - seriam capazes de capturar esse prêmio e qual o período de sua dissipação? 
- Esse prêmio seria robusto em relação a: i) diferentes subamostras para controle dos efeitos tamanho, índice B/M e momento; ii) efeitos sazonais e iii) subperíodos?

- Esse prêmio, em conjunto com o fator beta de mercado - que forma o modelo de 2-fatores seria significante na explicação dos retornos cross-section dos ativos no mercado acionário brasileiro?

- Seria o modelo dos 2-fatores superior aos modelos CAPM, 3-fatores de Fama e French (1993) e 4-fatores de Carhart (1997) na explicação dos retornos cross-section dos ativos, para o mercado acionário brasileiro?

\subsection{Objetivos e hipóteses do trabalho}

O objetivo principal deste trabalho consiste em verificar se há prêmios pela liquidez no mercado acionário brasileiro, testando diferentes medidas de liquidez, formas de cálculo e períodos de retenção, bem como se o modelo de 2-fatores - formado pelo beta de mercado e pelo fator liquidez - é válido para o mercado acionário brasileiro e, em caso positivo, se é superior ao CAPM, ao modelo dos 3-fatores de Fama e French (1993) e ao modelo dos 4fatores de Carhart (1997), na explicação das variações dos retornos cross-section das carteiras de ações.

Com base nos objetivos definidos no parágrafo anterior, as hipóteses testadas nesta pesquisa estão detalhadas na Ilustração 1 a seguir e podem ser separadas em dois grandes grupos: o primeiro grupo, que compreende as hipóteses de I a V, refere-se a testes sobre a existência dos prêmios pelos fatores liquidez, beta de mercado, tamanho, índice B/M e momento no mercado acionário brasileiro. Especificamente, a hipótese I tem como propósito verificar a existência de prêmio pelo fator liquidez no mercado acionário brasileiro, com o uso de uma vasta gama de medidas de liquidez, períodos de cálculo e de retenção das carteiras. Já, as hipóteses II, III e IV têm como objetivos verificar a robustez dos prêmios pela liquidez em relação a subamostras, efeito sazonal e subperíodos, respectivamente. Dessa forma, elas só serão testadas se H1,I for aceita, ou seja, se for verificada a existência de prêmio pelo fator liquidez no mercado acionário brasileiro. A hipótese $\mathrm{V}$, por sua vez, tem como propósito verificar a existência de prêmios pelos demais fatores utilizados como variáveis explicativas das variações dos retornos das ações nos modelos de precificação de ativos testados nesta pesquisa: beta de mercado, tamanho, índice B/M e momento. Assim, trata-se de uma hipótese 
independente das hipóteses de I a IV. Vale a ressalva de que cada um dos fatores - mercado, tamanho, índice B/M e momento - será examinado separadamente.

O segundo grupo de hipóteses, por sua vez, compreende as hipóteses VI e VII e têm como objetivo testar o modelo de 2-fatores e compará-lo com os modelos CAPM, 3-fatores e 4fatores. Especificamente, a hipótese VI tem como objetivo testar a validade do modelo de 2fatores, composto pelos fatores beta de mercado e liquidez, no mercado acionário brasileiro. Por fim, a hipótese VII objetiva comparar o modelo de 2-fatores com os modelos CAPM, 3fatores e 4-fatores e, portanto, somente será verificada se H1,VI for aceita, ou seja, se for constatada a validade do modelo de 2-fatores no mercado acionário brasileiro. 
Grupo 1 - Hipóteses para verificação de prêmios pelos fatores

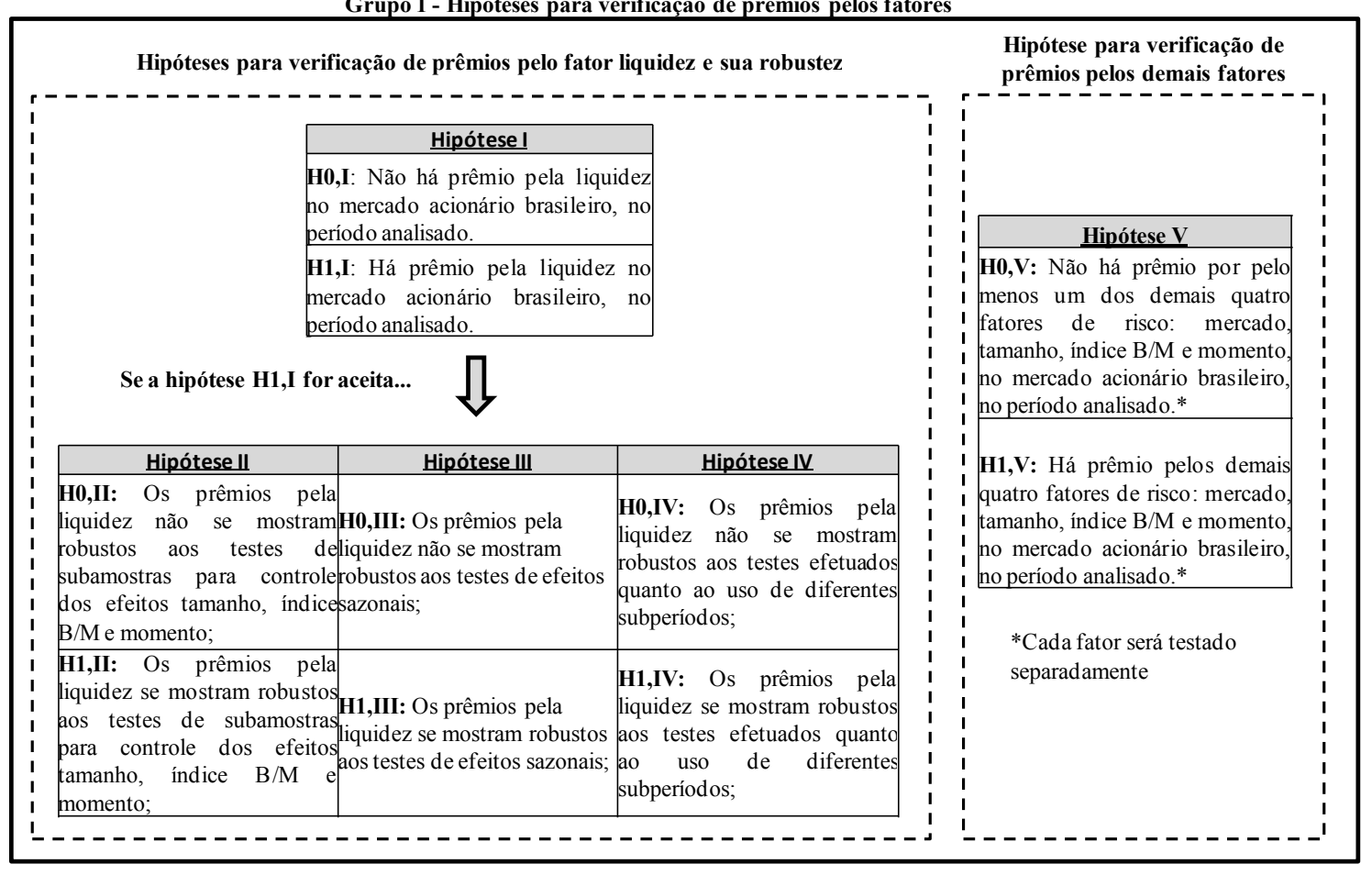

Grupo 2 - Hipóteses para testes dos modelos de precificação de ativos

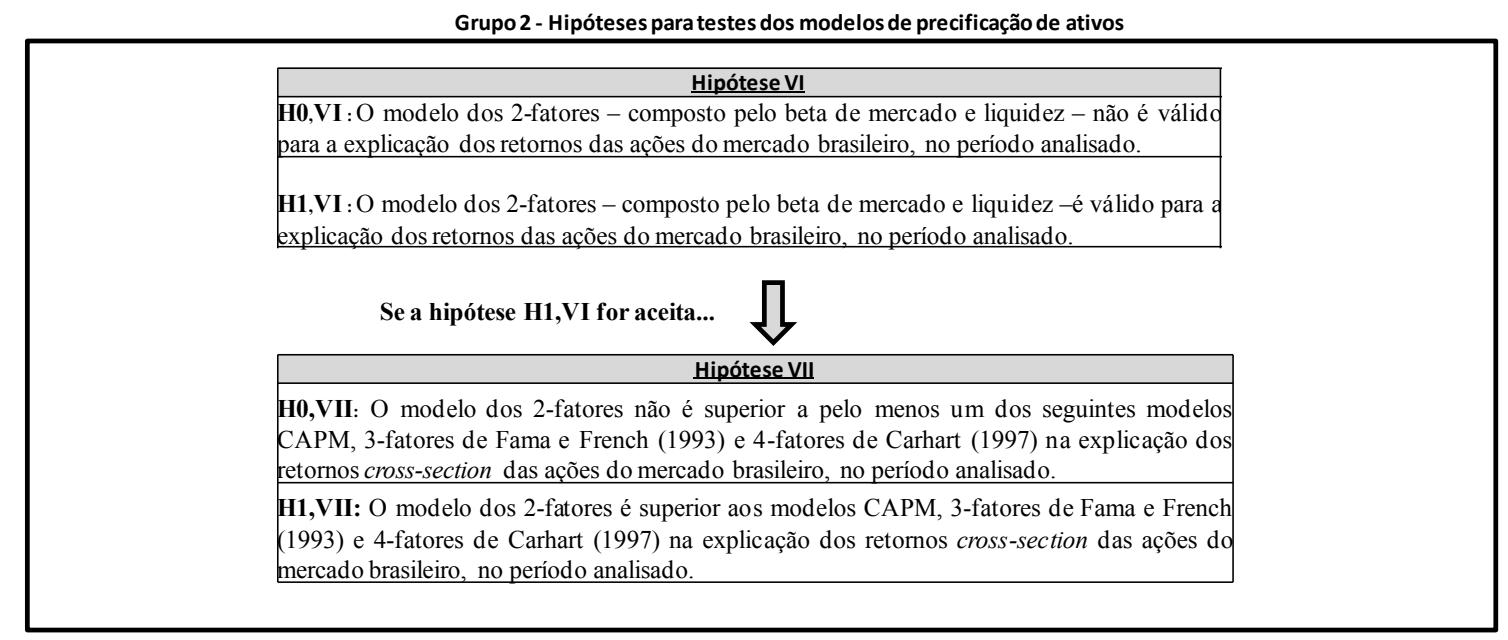

Ilustração 1 - Detalhamento das hipóteses da pesquisa 


\subsection{Justificativa do tema e ineditismo da pesquisa}

Lee (2011) destaca que, até o momento, a importância potencial da liquidez não foi explorada de forma extensiva em mercados internacionais como o foi no mercado norte-americano, havendo espaço para pesquisas que aprofundem e tragam novas evidências sobre o tema, pois é exatamente nos mercados emergentes que o efeito da liquidez deveria ser mais forte.

Bekaert et al (2007) destacam o tema ao afirmarem que baixa liquidez é um dos principais motivos que impede investidores estrangeiros de investir nos mercados emergentes, reforçando a importância de estudos sobre liquidez em mercados como o brasileiro.

Modelos de precificação de ativos são utilizados em atividades que exigem determinação do retorno esperado de ações, tais como avaliação de empresas, mensuração e reconhecimento de ativos para fins contábeis e seleção e construção de carteiras de investimento. Dessa forma, modelos inadequados podem levar a decisões equivocadas. Assim, o fato de nenhum modelo de precificação de ativos ter se mostrado suficiente na explicação dos retornos das ações, reforça a justificativa da escolha do tema, bem como destaca a importância do teste da validade do modelo de 2-fatores no mercado acionário brasileiro.

Além disso, ao se considerar que o aumento da quantidade de variáveis tende a distanciar os modelos do uso prático no cotidiano dos negócios, o modelo de 2-fatores, se validado, pode ser uma boa alternativa quando comparado a modelos de mais fatores como os de Fama e French (1993) e Carhart (1997).

São poucos os estudos sobre liquidez e sua relação com o retorno das ações no mercado brasileiro e o presente trabalho apresenta claras diferenças em relação a esses, conforme apresentado no Quadro 1 abaixo. 
Quadro 1 - Comparação da presente tese com os demais trabalhos efetuados sobre liquidez e sua relação com a precificação de ativos no mercado acionário brasileiro

O quadro abaixo compara, nos aspectos mais relevantes, a presente tese com os principais trabalhos efetuados sobre a relação da liquidez com o retorno das ações no mercado acionário brasileiro. A coluna Medidas de liquidez descreve quais medidas de liquidez foram utilizadas em cada estudo. As colunas Períodos de formação e Períodos de retenção, mostram quais diferentes períodos de cálculo das medidas e retenção das carteiras foram considerados. Demais variáveis consideradas dizem respeito a outras variáveis estudadas em conjunto com a liquidez. As demais colunas contêm títulos autoexplicativos.

\begin{tabular}{|c|c|c|c|c|c|c|}
\hline Trabalho & Medidas de liquidez & $\begin{array}{c}\text { Períodos } \\
\text { de } \\
\text { formação }\end{array}$ & $\begin{array}{l}\text { Períodos } \\
\text { de } \\
\text { retenção }\end{array}$ & $\begin{array}{c}\text { Testes de } \\
\text { robustez } \\
\text { dos prêmios } \\
\text { pela } \\
\text { liquidez } \\
\end{array}$ & $\begin{array}{c}\text { Demais } \\
\text { variáveis } \\
\text { consideradas }\end{array}$ & $\begin{array}{l}\text { Período } \\
\text { estudado }\end{array}$ \\
\hline $\begin{array}{l}\text { Sanvicente e } \\
\text { Minardi } \\
(1998)\end{array}$ & $\begin{array}{l}\text { - Índice de Negociabilidade da } \\
\text { BM\&FBOVESPA }\end{array}$ & 4 meses & 4 meses & Nenhum & $\begin{array}{l}\text { Beta de } \\
\text { mercado }\end{array}$ & $\begin{array}{l}\text { De } 1994 \text { a } \\
1998\end{array}$ \\
\hline $\begin{array}{l}\text { Bruni e Famá } \\
\text { (1998) }\end{array}$ & $\begin{array}{l}\text { - Índice de Negociabilidade da } \\
\text { BM\&FBOVESPA }\end{array}$ & 12 meses & $\begin{array}{c}12 \\
\text { meses }\end{array}$ & Nenhum & $\begin{array}{l}\text { Beta de } \\
\text { mercado }\end{array}$ & $\begin{array}{c}\text { De } 1988 \text { a } \\
1996\end{array}$ \\
\hline $\begin{array}{l}\text { Vieira e } \\
\text { Milach } \\
(2008)\end{array}$ & $\begin{array}{l}\text { - Volume Financeiro } \\
\text { - Quantidade de Títulos } \\
\text { - Quantidade de Negócios } \\
\text { - Turnover } \\
\text { - Return- to-Volume }\end{array}$ & 1 mês & 1 mês & $\begin{array}{l}\text { Efeito } \\
\text { janeiro }\end{array}$ & $\begin{array}{l}\text { Beta de } \\
\text { mercado, } \\
\text { volatillidade } \\
\text { dos retornos, } \\
\text { tamanho e } \\
\text { dividend yield }\end{array}$ & $\begin{array}{l}\text { De } 1995 \text { a } \\
2005\end{array}$ \\
\hline $\begin{array}{l}\text { Correia et al } \\
\quad(2008)\end{array}$ & $\begin{array}{l}\text { - Volume Financeiro } \\
\text { - Quantidade de Negócios } \\
\text { - Turnover }\end{array}$ & 1 mês & 1 mês & Nenhum & $\begin{array}{c}\text { Beta de } \\
\text { mercado, } \\
\text { tamanho e } \\
\text { índice } \mathrm{B} / \mathrm{M}\end{array}$ & $\begin{array}{l}\text { De } 1995 \text { a } \\
2004\end{array}$ \\
\hline $\begin{array}{l}\text { Machado e } \\
\text { Medeiros } \\
(2011)\end{array}$ & $\begin{array}{l}\text { - Índice de Negociabilidade da } \\
\text { BM\&FBOVESPA } \\
\text { - Volume Financeiro } \\
\text { - Quantidade de Negócios } \\
\text { - Turnover } \\
\text { - Volume Zero Padronizado. }\end{array}$ & 12 meses & $\begin{array}{c}12 \\
\text { meses }\end{array}$ & $\begin{array}{l}\text { Efeito } \\
\text { janeiro }\end{array}$ & $\begin{array}{c}\text { Beta de } \\
\text { mercado, } \\
\text { tamanho, } \\
\text { índice } \mathrm{B} / \mathrm{M} \mathrm{e} \\
\text { momento }\end{array}$ & $\begin{array}{l}\text { De } 1995 \text { a } \\
2008\end{array}$ \\
\hline $\begin{array}{l}\text { A presente } \\
\text { tese }\end{array}$ & $\begin{array}{l}\text { - Volume Financeiro } \\
\text { - Quantidade de Negócios } \\
\text { - Quantidade de Títulos } \\
\text { - Número de Dias Sem } \\
\text { Transações } \\
\text { - Return-to-Volume } \\
\text { - Turnover } \\
\text { - Volume Zero Padronizado } \\
\text { - Índice de Negociabilidade da } \\
\text { BM\&FBOVESPA } \\
\text { - Desvio-padrão do Turnover } \\
\text { - Desvio-padrão do Volume } \\
\text { - Coeficiente de Variação do } \\
\text { Turnover } \\
\text { - Coeficiente de Variação do } \\
\text { Volume }\end{array}$ & $\begin{array}{l}1,3,6 \mathrm{e} \\
12 \text { meses }\end{array}$ & $\begin{array}{c}1,3,6 \mathrm{e} \\
12 \\
\text { meses }\end{array}$ & $\begin{array}{c}\text { Efeito } \\
\text { janeiro, } \\
\text { Subamostras } \\
\text { - controle } \\
\text { dos efeitos } \\
\text { tamanho, } \\
\text { índice B/M e } \\
\text { momento - e } \\
\text { Subperíodos. }\end{array}$ & $\begin{array}{c}\text { Beta de } \\
\text { mercado, } \\
\text { tamanho, } \\
\text { índice } \mathrm{B} / \mathrm{M} \text { e } \\
\text { momento }\end{array}$ & $\begin{array}{l}\text { De } 1995 \text { a } \\
\quad 2011\end{array}$ \\
\hline
\end{tabular}


Conforme já mencionado no item 1.1, os resultados evidenciados nos trabalhos brasileiros sobre o tema liquidez trouxeram resultados controversos a respeito do papel da liquidez na explicação dos retornos das ações, sendo que algumas pesquisas apresentaram evidências favoráveis e outras desfavoráveis à existência de prêmio pela liquidez, sua relação com o retorno das ações, bem como a validade do seu uso em modelos de precificação de ativos. Os resultados favoráveis podem ser observados em Bruni e Famá (1998), Vieira e Milach (2008) e Machado e Medeiros (2011), enquanto os desfavoráveis em Sanvicente e Minardi (1998) e Correia et al (2008).

Nota-se, no Quadro 1, que o presente trabalho faz uso da mais vasta quantidade de medidas de liquidez já empregada em pesquisas nacionais, o que se justifica pela divergência de resultados verificados até agora no mercado nacional e pela característica multidimensional que permeia o termo liquidez. Até mesmo no âmbito internacional, somente trabalhos mais recentes como o de Lam e Tam (2011) testaram quantidade semelhante de medidas e períodos de cálculo e retenção das carteiras.

Trabalhos anteriores focaram apenas em um período para a formação das medidas e para retenção das ações na carteira. Múltiplos períodos para a retenção das carteiras são importantes para verificação da persistência e da dissipação do prêmio pela liquidez (LIU, 2006).

Os trabalhos realizados até o momento concentraram-se essencialmente em verificar se os prêmios pela liquidez eram robustos ao efeito janeiro, como foi feito por Vieira e Milach (2008) e Machado e Medeiros (2011). O presente trabalho, além desse efeito sazonal e seguindo a linha de Liu (2006), faz uso de outros testes de robustez dos prêmios como: i) subamostras para controle dos efeitos das variáveis tamanho, índice B/M e momento nos prêmios pela liquidez e; ii) subperíodos para verificar os possíveis efeitos da seleção amostral.

Observa-se, também, que, somente no estudo de Machado e Medeiros (2011), a liquidez foi estudada em conjunto com os efeitos tamanho, índice B/M e momento, além do beta de mercado, na formação dos modelos de precificação de ativos. Porém, destaca-se que o referido estudo trabalhou apenas com regressões em séries temporais, o que, conforme será discutido no Capítulo 3, é uma metodologia menos recomendada para esse tipo de testes por não refletir de forma adequada a realidade dos investidores. Afora isso, os autores 
adicionaram o fator liquidez ao modelo de 4-fatores de Carhart (1997), formando um modelo com uso de cinco fatores simultâneos, o que aumenta a sua complexidade e dificulta a aplicabilidade prática.

\subsection{Método de pesquisa}

Marconi e Lakatos (1996, p. 16-17 e 2000, p.76) destacam que toda pesquisa nasce de algum problema teórico e/ou prático e que a natureza do problema direciona o método ou tipo de pesquisa científica utilizada.

Martins (2002, p.33) ressalta que a bibliografia sobre metodologia científica apresenta diferentes classificações de tipos de estudos, que costumam variar conforme o enfoque epistemológico. $\mathrm{O}$ autor apresenta um levantamento dos principais tipos de estudos utilizados nas ciências sociais (MARTINS, 2002, p. 34-39) e, de acordo com essa tipologia, a presente pesquisa pode ser classificada como: bibliográfica, descritiva, correlacional, estatística e empírico-analítica.

Marconi e Lakatos (1996, p.17) destacam que:

[...] toda pesquisa deve basear-se em uma teoria, que serve de ponto de partida para a investigação bem sucedida de um problema. A teoria, sendo instrumento de ciência, é utilizada para conceituar os tipos de dados a serem analisados.

A pesquisa bibliográfica ou fundamentação teórica deste trabalho está evidenciada no Capítulo 2, no qual há um levantamento das principais definições, correntes teóricas e evidências empíricas relativas ao tema liquidez e modelos de precificação de ativos.

A pesquisa descritiva é apresentada no Capítulo 4 com a análise descritiva das principais características das ações de empresas brasileiras de capital aberto em relação à liquidez, beta de mercado, tamanho, índice B/M, momento e retorno.

A pesquisa correlacional, estatística e empírico-analítica caracteriza-se pelo uso de técnicas quantitativas para coleta, tratamento e análise dos dados, bem como pelo emprego de técnicas 
estatísticas para a verificação das relações de causalidade entre as variáveis. No Capítulo 4 são realizadas análises estatísticas de significância das correlações entre as diferentes medidas de liquidez, entre as medidas de liquidez e os retornos das ações e entre as medidas de liquidez e os fatores beta de mercado, tamanho, índice B/M e momento. No mesmo capítulo são verificadas as significâncias estatísticas e a robustez dos prêmios pela liquidez. Por fim, empregam-se regressões lineares múltiplas para testes de validade e do poder explicativo dos modelos de precificação de ativos, bem como para a comparação entre os diferentes modelos testados.

\subsection{Limitações da pesquisa}

Bornholt (2007) destaca a existência de dois problemas ou limitações principais no modelo dos 3-fatores de Fama e French (1993), que podem ser estendidos para o modelo de 4-fatores de Carhart (1997) e 2-fatores de Liu (2006) abordados nesta tese. A primeira limitação, também ressaltada por Fama e French (2004), é que o método usado para a construção dos fatores é conduzido empiricamente e os fatores devem ser conhecidos ad-hoc, havendo ausência de fundamentação teórica para suportar a utilização das variáveis. A segunda é que a aplicação prática do modelo tem limitações, devido à necessidade de se encontrar uma estimação segura das sensibilidades dos fatores e dos prêmios pelos riscos, além da inclusão de muitas variáveis distanciarem os modelos da aplicabilidade prática.

Conforme destacado por Grinblatt e Titman (2005), os modelos APT que utilizam características da empresa como fatores de risco têm a desvantagem de que as carteiras são selecionadas com base nas anomalias encontradas em retornos passados, podendo talvez não serem boas para explicar retornos futuros.

Outra limitação a ser apontada é a quantidade relativamente pequena de ações disponíveis no mercado brasileiro para a formação das carteiras deste estudo, quando comparada aos estudos sobre o mercado acionário de países desenvolvidos como o norte-americano. Esse fato pode acarretar a exclusão justamente das ações menos líquidas enviesando os resultados, bem como a criação de carteiras pouco diversificadas, levando a prejuízos na estimação de modelos APT. 


\subsection{Estrutura do trabalho}

O capítulo 2 é dedicado à fundamentação teórica do tema. Os assuntos abordados são: os modelos CAPM e APT; hipótese de mercados eficientes e a identificação de anomalias; testes empíricos do CAPM; a identificação dos efeitos tamanho e valor e a criação do modelo de 3fatores; a identificação do fator momento e a criação do modelo de 4-fatores; e, finalmente, a liquidez e sua relação com os modelos de precificação de ativos.

O capítulo 3 detalha a metodologia dos testes utilizados. Inicialmente, são descritos os procedimentos para a coleta dos dados, bem como a população e tratamentos amostrais. Posteriormente, são abordados os cálculos e procedimentos de testes das medidas e prêmios pela liquidez, bem como os testes para verificação da sua robustez. Na sequência, são abordados os passos metodológicos para a criação das variáveis e testes estatísticos para os modelos de precificação de ativos.

O capítulo 4 é destinado à análise dos dados e resultados em face dos objetivos propostos e hipóteses a serem testadas. São analisadas as medidas de liquidez, os prêmios pela liquidez e os resultados dos testes de robustez. Seguidos da apresentação dos resultados das regressões para teste dos modelos de precificação de ativos, bem como as comparações entre eles.

Finalizando, o capítulo 5 apresenta as considerações finais sobre os resultados obtidos, além de sugestões para pesquisas posteriores. Concluindo com os apêndices contendo os dados utilizados para o cálculo das medidas, formação das carteiras, cálculos dos retornos, prêmios de risco e regressões, bem como tabelas que foram suprimidas do corpo do texto com o intuito de torná-lo mais fluido. 


\section{FUNDAMENTAÇÃO TEÓRICA}

Nesse capítulo são abordados os modelos CAPM e APT, a hipótese de mercados eficientes, os testes empíricos do CAPM, o desenvolvimento dos modelos 3-fatores de Fama e French (1993) e 4-fatores de Carhart (1997) e, principalmente, o papel da liquidez como fator de risco e sua posterior inclusão em modelos de precificação de ativos - Liquidity CAPM (LCAPM) ou modelo de 2-fatores.

\subsection{O Capital Asset Pricing Model - CAPM e a Arbitrage Pricing Theory - APT}

A tese de doutorado de Frank Knight, finalizada em Cornell em 1916 e publicada como livro em 1921 - Risk, uncertainty and profit - é considerada por Bernstein (1997) como a primeira obra de maior importância a lidar explicitamente com a tomada de decisões sob condições de incerteza. Knight (1921) baseia a sua análise na distinção entre risco e incerteza e questiona a capacidade dos cálculos de probabilidade e das avaliações empíricas das frequências de ocorrências passadas, de refletir a realidade e o futuro dos homens, sua natureza experimental e criativa diante do desconhecido.

Apesar da importância desses e de outros estudos anteriores, o ponto de partida teórico desta tese é o CAPM desenvolvido por Sharpe (1964), Lintner (1965) e Mossin (1966), com base nos trabalhos de Markowitz (1952) e de Tobin (1958).

Dessa forma, nesse subcapítulo são apresentados os modelos CAPM e APT. Ressalve-se que os resultados dos principais testes empíricos do CAPM e a identificação de fatores de risco adicionais ao beta de mercado que compõem os modelos APT utilizados nesta tese, são descritos separadamente nos subcapítulos $2.3,2.4$ e 2.5 .

\subsubsection{O CAPM - Capital Asset Pricing Model}

Sharpe (1964), Lintner (1965) e Mossin (1966), com base no legado de Markowitz (1952) e Tobin (1958), desenvolveram o Capital Asset Pricing Model - CAPM, modelo de precificação de fator de risco único, ou seja, o beta de mercado, que, por meio de uma relação 
linear expressa na Equação 1, conseguiria explicar a diferença de retorno exigido entre os ativos. A linearidade da fórmula do CAPM indica que títulos com betas mais elevados apresentam maior risco e devem pressupor retornos esperados superiores.

$$
E\left(R_{i}\right)=R_{l r}+\beta_{i} *\left[E(R m)-R_{l r}\right]
$$

Em que:

$\boldsymbol{E}\left(\boldsymbol{R}_{i}\right)$ é a expectativa de retorno do ativo $i$;

$\boldsymbol{R}_{l r}$ é o retorno do ativo livre de risco;

$\boldsymbol{\beta}_{i}$ é o beta de mercado do ativo $i$, ou seja, a covariância do retorno do ativo $i$ com o retorno de mercado, dividido pela variância do retorno de mercado;

$\boldsymbol{E}\left(\boldsymbol{R}_{\boldsymbol{m}}\right)$ é o retorno esperado da carteira de mercado.

Grinblatt e Titman (2005) apontam que, além das premissas necessárias para a construção da teoria de carteiras de Markowitz (1952), o CAPM foi desenvolvido com base em suposições adicionais como a existência de muitos investidores, todos com aversão a riscos, que dispõem das mesmas informações e têm as mesmas expectativas em relação a risco, retorno e covariância dos ativos. Além disso, presume que a economia não tem restrição ao investimento ou empréstimo, inclusive em ativo livre de risco, e há ausência de impostos e custos de transação. Fama e French (2004) destacam que essas suposições talvez tenham simplificado demais a realidade, o que pode ser a explicação de boa parte dos problemas identificados em testes empíricos do modelo, que serão abordados com mais detalhes nos subcapítulos subsequentes, e terminaram por abrir espaço para o desenvolvimento de modelos APT.

\subsubsection{A APT - Arbitrage Pricing Theory}

O modelo APT desenvolvido por Ross (1976) pode ser visto como mais genérico, uma alternativa ao CAPM. A principal diferença entre eles é que o APT pressupõe que os retornos dos ativos são gerados por uma série de fatores. Além disso, o APT exige hipóteses menos restritivas em relação ao comportamento do investidor. Grinblatt e Titman (2005) destacam 
que a flexibilidade do APT permite explicar melhor os retornos passados, apesar de acabar oferecendo menos orientação sobre a estimação das taxas esperadas futuras de retorno.

As principais pressuposições do APT de Ross (1976) são quatro: i) os retornos podem ser descritos pelo modelo fatorial; ii) não há oportunidades de arbitragem; iii) existe um número amplo de ativos, de tal forma que é possível criar carteiras que diversifiquem o risco específico das empresas; iv) os mercados financeiros não possuem atrito.

Fama e French (2004) afirmam que, para modelos derivados do APT, o necessário é que as carteiras adicionais sejam bem diversificadas e que sejam suficientemente diferentes da carteira de mercado. Na mesma linha, Grinblatt e Titman (2005) destacam que a esperança é que o APT possa capturar aspectos adicionais de risco, além daqueles absorvidos pelo beta de mercado, melhorando a explicação das variações dos retornos dos ativos.

Ross (1976, p.353) apresenta o APT em formato bastante abrangente e destaca que o modelo pode ser expresso em vários formatos distintos. Um dos formatos mais intuitivos e recorrentes na literatura é o sugerido por Grinblatt e Titman (2005, p.180) e Copeland et al (2005, p.219), no qual o APT é expresso na forma de retornos esperados, conforme apresentado na Equação 2 a seguir:

$$
\widetilde{r}_{i}=\alpha_{i}+B_{i 1} * \widetilde{F}_{1}+B_{i 2} * \widetilde{F}_{2}+\ldots+B_{i K} * \widetilde{F}_{K}+\widetilde{\mathrm{E}}_{i}
$$

Em que:

$\sim$

$\boldsymbol{r}_{i}$ é a taxa aleatória de retorno do ativo $i$;

$\alpha_{i}$ é a taxa de retorno do ativo $i$, se todos os fatores de risco forem iguais a zero;

$\boldsymbol{B}_{i K}$ é a sensibilidade da taxa de retorno do ativo $i$ ao fator de risco $K$;

$\boldsymbol{F}_{\boldsymbol{k}}$ é o fator de risco $K$;

$\sim$

$\boldsymbol{E}_{\boldsymbol{i}}$ é o componente aleatório, com média zero e eliminado pela diversificação.

Da equação do APT, pode-se inferir, segundo Brealey e Myers (2003), que, ao se atribuir o valor zero aos indicadores de sensibilidade, o prêmio pelo ativo será nulo. Uma carteira 
diversificada que seja construída para não ter sensibilidade aos fatores será, por essência, livre de risco, devendo oferecer retorno similar ao do ativo livre de risco. Caso oferecesse um retorno superior, os investidores poderiam obter retornos sem risco, por meio de empréstimos de recursos à taxa livre de risco, aplicando tais recursos na carteira. Por outro lado, caso a carteira oferecesse um retorno inferior ao do ativo livre de risco, os investidores poderiam obter lucros sem risco, assumindo posições vendidas na carteira e compradas no ativo livre de risco. Essas posições são conhecidas como posições de arbitragem.

A pressuposição da equação do APT é que um número relativamente pequeno de fatores comuns, para os quais as ações têm sensibilidades distintas (betas), geram os retornos dos títulos. O erro da equação, $\boldsymbol{E}_{\boldsymbol{i}}$, representa componentes de risco específicos das empresas, que não são correlacionados, contribuindo para uma variância mínima no caso de carteiras bem diversificadas (GRINBLATT e TITMAN, 2005).

A magnitude dos betas do ativo descreve como se comporta a sensibilidade do retorno do título às mudanças dos fatores comuns. Grinblatt e Titman (2005) destacam que existem três formas distintas para se estimar ou construir os fatores, descritas no Quadro 2. Diante de tal flexibilidade nas formas de escolha dos fatores, fica evidente que uma das maiores desvantagens de modelos APT está relacionada à indefinição dos fatores.

Quadro 2 - Resumo das três maneiras para a construção de fatores em modelos APT

\begin{tabular}{|c|c|c|}
\hline Método de Estimação & Vantagens & Desvantagens \\
\hline $\begin{array}{l}\text { Análise fatorial - um procedimento } \\
\text { puramente estatístico para estimar } \\
\text { fatores e a sensibilidade dos } \\
\text { retornos a eles. }\end{array}$ & $\begin{array}{l}\text { Fornece a melhor estimativa } \\
\text { dos fatores, dados os seus } \\
\text { pressupostos. }\end{array}$ & $\begin{array}{l}\text { A pressuposição de que as covariâncias } \\
\text { são constantes é crucial e provavelmente } \\
\text { será violada na realidade; não nomeia } \\
\text { efetivamente os fatores. }\end{array}$ \\
\hline $\begin{array}{l}\text { Variáveis macroeconômicas } \\
\text { utiliza } \text { séries r temporais } \\
\text { macroeconômicas que captam } \\
\text { alterações na produtividade, taxas } \\
\text { de juros e inflação para que atuem } \\
\text { como aproximações para os fatores } \\
\text { que geram retornos acionários. }\end{array}$ & ação mais & $\begin{array}{l}\text { Implica que os fatores apropriados sejam } \\
\text { as alterações não antecipadas das macro- } \\
\text { variáveis. Pode ser difícil medir na prática } \\
\text { alterações não antecipadas das variáveis, } \\
\text { tais como produtividade agregada e } \\
\text { inflação. }\end{array}$ \\
\hline $\begin{array}{l}\text { Características da empresa - utiliza } \\
\text { características da empresa, como o } \\
\text { tamanho, sabendo do seu } \\
\text { relacionamento com os retornos } \\
\text { acionários, para formar as carteiras } \\
\text { de fator. }\end{array}$ & $\begin{array}{l}\text { Mais intuitiva que as } \\
\text { carteiras formadas pela } \\
\text { análise fatorial; sua formação } \\
\text { não requer covariâncias } \\
\text { constantes. }\end{array}$ & $\begin{array}{l}\text { Carteiras selecionadas com base nas } \\
\text { anomalias de retorno do passado, que só } \\
\text { são fatores porque explicam acidentes } \\
\text { históricos, podem não ser boas para } \\
\text { explicar retornos esperados no futuro. }\end{array}$ \\
\hline
\end{tabular}

FONTE: Grinblatt e Titman (2005, p. 181). 
Nos subcapítulos 2.3, 2.4 e 2.5 serão comentados alguns dos principais testes empíricos do CAPM que levaram à identificação de características das empresas incorporadas como fatores de risco comuns em modelos multifatoriais. Ressalte-se que, com exceção do CAPM, os demais modelos testados nesta tese - 2-fatores, 3-fatores e 4-fatores - podem ser considerados modelos APT que utilizam características das empresas como fatores de risco.

\subsection{Hipótese de mercados eficientes e a identificação de anomalias}

A hipótese de eficiência de mercado, que é geralmente envolvida na discussão a respeito das explicações das causas e definições das anomalias que acabam por gerar fatores adicionais ao beta de mercado em modelos APT, tem uma história relativamente longa na área de finanças. O conceito ou a ideia apareceu pela primeira vez no final do século XIX, embora ainda não usando os termos mercados eficientes (SHILLER, 1999). Já na década de 1960, surge o importante trabalho de Samuelson (1965) e a pesquisa não publicada de Harry Roberts de 1967, referenciada por Shiller (1999). Segundo Shiller (1999), é Roberts quem cunha a expressão hipótese de mercados eficientes e sugere o que pode ser considerado o embrião das formas de testes de eficiência que mais tarde seriam estruturadas por Fama (1970).

Num mercado eficiente, os preços refletem de forma total e instantânea toda a informação relevante disponível, significando que, quando os ativos são comercializados, os preços são sinais adequados para a alocação de capital (COPELAND et al, 2005). Fama (1970) afirma que nenhuma informação poderia trazer possibilidade de ganho anormal aos investidores, ou seja, retornos superiores ao retorno relativo ao risco de determinado ativo.

De acordo com Brealey e Myers (2003), em mercados eficientes, a compra ou a venda de qualquer ativo ao preço vigente no mercado, nunca será uma operação com um valor presente líquido positivo. Se a venda de um título proporcionar um valor presente líquido positivo ao vendedor, terá que proporcionar um valor presente líquido negativo ao comprador.

Fama (1970) propôs três formas de eficiência de mercado. A primeira delas, chamada de forma fraca de eficiência, mostra que os preços refletem toda a informação contida no registro dos preços passados. Se o mercado for eficiente na forma fraca, a utilização de informações sobre preços passados não é capaz de proporcionar lucros econômicos aos investidores. 
Pela forma semiforte de eficiência, os preços refletem não só o seu comportamento passado, como também o restante da informação publicada, tais como notícias específicas e anúncios sobre distribuição de lucros e dividendos. Os testes da forma semiforte procuram especificar a rapidez com que os preços dos ativos refletem as informações públicas.

Finalmente, há a eficiência na forma forte, na qual os preços refletem não só a informação pública, mas toda e qualquer informação, inclusive as chamadas informações privilegiadas. Os testes dessa forma de eficiência procuram detectar se algum investidor possui alguma informação privilegiada que não está totalmente refletida nos preços.

Fama (1970) enumerou três condições para a verificação da eficiência dos mercados: i) inexistência de custos de transação; ii) disponibilidade de toda a informação a custo zero a todos os participantes do mercado e iii) todos concordam quanto aos efeitos das informações nos preços atuais dos ativos, assim como em suas distribuições futuras.

Fama (1991) propôs alterações nas denominações das formas de eficiência de mercado. Os testes da forma fraca de eficiência passaram a ser chamados de testes de previsibilidade de retorno. Na segunda categoria, os testes passaram a se chamar estudos de evento. Por fim, na terceira categoria, o teste da forma forte, teve seu nome alterado para teste de informações privadas.

Testes da hipótese de mercados eficientes estão diretamente associados a uma das principais correntes para a definição do termo anomalia, que está relacionada a suas causas: a das finanças comportamentais. A visão desses é que as anomalias são motivadas por padrões documentados de comportamento irracional dos investidores, que são inconsistentes com a teoria de eficiência de mercado e as expectativas racionais de precificação de ativos. Alguns dos defensores dessa visão são DeBondt e Thaler (1987) e Lakonishok et al (1994).

Porém, existe uma segunda grande corrente para a definição do termo anomalia, a de riscos racionais, que pode ser resumida pela ideia de Fama e French (2004). Eles afirmam que anomalia é a nomenclatura normalmente utilizada para se referir aos fatores de risco identificados empiricamente e que não são capturados pelo beta de mercado do CAPM. 
Dessa forma, tamanho, índice B/M, momento e liquidez seriam anomalias pelo fato de testes empíricos demonstrarem que esses seriam fatores de risco adicionais ao CAPM.

Nas palavras de Fama e French (2004, p.40):

[...] quando testes rejeitam o CAPM, não se pode dizer se o problema é a premissa de que os preços são racionais (visão comportamentalista) ou o problema está relacionado a violações de outras premissas, que são também necessárias para produzir o CAPM (nossa posição).

É importante ressaltar, nesse ponto, que não faz parte do escopo da presente tese a discussão da polêmica que envolve a origem das anomalias, nem será tomada uma posição em favor de uma ou outra corrente. A identificação das anomalias tamanho, valor, momento e liquidez que originam os fatores de risco usados nesta tese nos modelos APT estão detalhadas nos subcapítulos 2.3, 2.4 e 2.5 .

\subsection{Identificação dos efeitos tamanho e valor e o modelo dos 3-fatores de Fama e French} (1993)

Esse subcapítulo descreve os testes empíricos do CAPM que originaram a identificação das anomalias tamanho e valor, além do modelo dos 3-fatores de Fama e French (1993) e os seus principais testes empíricos.

\subsubsection{Testes empíricos do CAPM e a identificação das anomalias efeito tamanho e valor}

Os primeiros testes empíricos do CAPM, como os de Black, Jensen e Scholes (1972) e Fama e MacBeth (1973), trouxeram evidências no sentido de validar o modelo.

Black, Jensen e Scholes (1972) buscaram validar a Security Market Line, testando se havia uma relação linear positiva entre o beta de mercado e o retorno das ações, por meio do método de carteiras. A amostra foi composta pelas ações listadas na New York Stock Exchange - NYSE entre 1926 e 1965. As conclusões validaram o modelo CAPM. 
Já o estudo de Fama e MacBeth (1973) testou de forma direta o CAPM, por meio do método de carteira e com utilização da técnica de testes em duas etapas - séries temporais e crosssectional - com a amostra compreendendo ações listadas na NYSE de 1926 a 1968. Os resultados não rejeitaram o CAPM.

Porém, a partir do final da década de 1970, alguns trabalhos empíricos trouxeram evidências de que o retorno das ações não seria totalmente explicado pelo beta de mercado. Assim, começaram a ser identificados outros fatores capazes de capturar parte do risco não absorvido pelo beta de mercado.

Roll (1977) criticou os testes empíricos do CAPM e concluiu que ninguém poderia testá-lo e validá-lo por meio de trabalhos empíricos, devido à impossibilidade de se obter ou mensurar a verdadeira carteira de mercado. No mesmo sentido, Penteado e Famá (2002) evidenciaram deficiências do uso do Ibovespa como referência para o retorno de mercado no Brasil, além de mostrarem que há grandes diferenças de resultados no uso do CAPM ao se variar o método de cálculo da carteira de mercado.

Um dos primeiros estudos a identificar anomalias não capturadas pelo CAPM foi o de Basu (1977). O autor testou o CAPM dividindo a amostra em carteiras, de acordo com o índice Preço/Lucro (P/L) das ações, no período de 1957 a 1971. Os resultados encontrados trouxeram evidências de que as carteiras contendo ações com os menores índices $\mathrm{P} / \mathrm{L}$ apresentavam maiores retornos ajustados ao risco do que carteiras formadas com ações de maiores índices P/L. Em outras palavras, os retornos futuros de ações com baixos índices P/L foram maiores do que o previsto pelo CAPM.

Stattman (1980) demonstrou que a razão book-to-market seria útil na explicação dos retornos cross-sectionals das ações do mercado norte-americano, de forma complementar ao beta de mercado. Mais especificamente, o autor documentou que ações com alto índice B/M apresentaram retornos médios mais elevados do que as ações com baixo índice B/M e essa diferença não foi capturada pelo beta de mercado. Essa relação entre o índice B/M e o retorno das ações ficou conhecida como efeito valor.

Banz (1981) estudou a relação entre o CAPM e a anomalia denominada efeito tamanho, por meio do método de carteiras, utilizando todas as ações ordinárias listada na NYSE, de 1926 a 
1975. Em suas conclusões observou que, na média, ações de empresas de pequeno porte, apresentavam retornos superiores àqueles observados em ações de empresas maiores. Esse comportamento anormal é o denominado efeito tamanho.

Já o estudo de Reinganum (1981) tinha como objetivo verificar se as ações listadas na NYSE e AMEX - American Stock Exchange, de 1962 a 1975, com diferentes betas, apresentavam retornos diferentes. Seus resultados não corroboraram a hipótese de que o beta de mercado era o único fator relevante, abrindo espaço para a existência de outros fatores que poderiam influenciar o retorno das ações.

Lakonishok e Shapiro (1986) testaram a influência do efeito tamanho na explicação das variações dos retornos das ações, também utilizando o método de carteiras, com a amostra composta por ações listadas na NYSE, de 1954 a 1981. Os seus resultados rejeitaram a significância do beta de mercado na explicação das variações dos retornos das ações. Os autores demonstraram que, para um período amostral mais recente, o poder explanatório do beta de mercado obtido por Black, Jensen e Scholes (1972) e Fama e MacBeth (1973), não mais existia.

No início da década de 1990, surge o importante estudo de Fama e French (1992). Os autores analisaram a influência conjunta das variáveis beta de mercado, tamanho, índice B/M, alavancagem e índice lucro/preço (L/P) na explicação dos retornos das ações listadas na NYSE, AMEX e NASDAQ Stock Exchange, NASDAQ, entre 1963 e 1990. Notaram que os estudos de Black, Jensen e Scholes (1972) e Fama e MacBeth (1973) concentraram suas amostras em período anterior a 1962 e, também, que as variáveis tamanho, índice Lucro/Preço $(\mathrm{L} / \mathrm{P})$, índice $\mathrm{B} / \mathrm{M}$ e alavancagem tinham poder de explicação das variações dos retornos das ações. Ademais, perceberam que tamanho e índice B/M pareciam absorver o papel das variáveis alavancagem e índice L/P. Dessa forma, os autores consideraram a possibilidade das variáveis tamanho e índice $\mathrm{B} / \mathrm{M}$ serem proxies de fatores de risco comuns aos retornos de todas as ações. O estudo de Fama e French (1993) adicionou esses fatores ao beta de mercado, constituindo o modelo de precificação de ativos batizado como modelo dos 3-fatores. 


\subsubsection{As possíveis causas das anomalias efeito tamanho e efeito valor}

Em relação às possíveis causas da ocorrência dos efeitos tamanho e valor, Keim (1983) verificou o relacionamento entre o efeito janeiro e o efeito tamanho, ao pesquisar as cotações diárias das ações negociadas na NYSE e AMEX, durante o período de 1963 a 1979. A análise da existência do efeito tamanho ao longo dos meses do ano permitiu concluir que esse é muito mais forte no mês de janeiro.

Fama e French (1992, 1993, 1995 e 2004) sugerem que a inclusão do efeito valor seria suportada pelo fato de as ações com alto índice B/M apresentarem, de forma persistente, baixos retornos sobre seus ativos, o que permitiria o surgimento de um risco adicional, que justificaria a posterior observação de maiores retornos. A inclusão do fator tamanho, por sua vez, teria argumento semelhante, pois ações de menor porte tendem a ser mais afetadas por ciclos econômicos recessivos, surgindo daí um risco adicional.

Black (1993) apresenta uma explicação bastante direta e polêmica para as evidências encontradas em relação à ocorrência dos efeitos tamanho e valor. O autor credita a existência dos efeitos a problemas com os dados amostrais, mais precisamente, ao processo de data mining.

Lakonishok et al (1994), por sua vez, argumentam que a anomalia de valor seria gerada por uma sobrerreação irracional de curto prazo ao indicador book-to-market. Empresas com alto índice B/M apresentariam, inicialmente, uma subvalorização e empresas com baixos índices apresentariam uma sobrevalorização. Ao longo do tempo, a ocorrência de maiores retornos para as empresas de maior índice B/M, representaria uma correção desta sobrerreação. Assim, conforme Fama e French (2004), a visão dos comportamentalistas é que o resultado desta sobrerreação está, apenas por acaso, correlacionada com as características das empresas, de tal forma que se pareça com uma questão de risco.

Kothari et al (1995) afirmam que a relação entre o retorno médio e o índice B/M é seriamente exagerada pelo viés de sobrevivência da amostra. Na mesma linha, Wang (2000) alega que o efeito tamanho é explicado, em grande parte, por inferências estatísticas espúrias, resultantes de viéses de sobrevivência das ações da amostra e não seriam uma anomalia. 


\subsubsection{Alguns testes empíricos do CAPM e a identificação das anomalias efeito tamanho e valor no mercado brasileiro}

Alguns testes empíricos do CAPM e de busca de evidências das anomalias também foram realizados para o mercado acionário brasileiro. Neves (1996) concluiu que as variáveis beta de mercado, índice P/L e índice B/M seriam significativas na explicação das variações dos retornos das ações. Horng (1997) rejeitou a hipótese de que o retorno das ações estaria relacionado positivamente ao beta de mercado. Bruni (1998) encontrou três fatores (índice $\mathrm{B} / \mathrm{M}$, endividamento e relação preço/vendas) que se mostraram significantes na explicação das variações dos retornos das ações. Já Mellone Jr. (1999) afirmou que existiria uma relação linear e positiva entre o beta de mercado e o retorno das ações, mas essa relação não seria significante. Finalmente, Braga (1999) e Costa Jr. e Neves (2000) caracterizaram a importância das variáveis tamanho e índice B/M, de forma complementar ao beta de mercado, na explicação do comportamento das variações dos retornos das ações.

\subsubsection{O modelo de 3-fatores}

Fama e French (1993), com base nas anomalias identificadas em estudos anteriores, formularam um modelo de precificação de ativos conhecido como modelo de 3-fatores que, de acordo com os autores, explicaria de maneira significativa as variações dos retornos dos ativos. Os três fatores são: o beta de mercado, conforme definido pelo CAPM; o tamanho da empresa, que é medido pelo valor de mercado das ações e tenta capturar a anomalia efeito tamanho e o índice B/M, que representa a relação entre o valor contábil e de mercado do patrimônio líquido e busca capturar a anomalia denominada efeito valor. Os autores incluíram nesse estudo tanto o mercado de bônus corporativo quanto o de ações.

O modelo pode ser expresso, matematicamente, por:

$$
R_{c i, t}-R_{l r t}=a+b\left[R_{m t}-R_{l r t}\right]+s\left[S M B_{t}\right]+h\left[H M L_{t}\right]+e_{i, t}
$$

Em que:

$\boldsymbol{R}_{C i, t}$ é o retorno da carteira $i$, no mês $t$; 
$\boldsymbol{R}_{l r t}$ é o retorno do ativo livre de risco no mês $t$;

$\boldsymbol{R}_{\boldsymbol{m} t}$ é o retorno da carteira de mercado no mês $t$;

$\boldsymbol{S M B}_{t}$ é o prêmio pelo fator tamanho no mês $t$ (Small Minus Big ou a diferença entre a média de retorno das ações de empresas de pequeno porte e a média de retorno das ações de empresas de grande porte);

$\boldsymbol{H M L}_{\boldsymbol{t}}$ é o prêmio pelo fator B/M no mês $t$ (High Minus Low ou a diferença entre a média de retorno das ações com alto índice B/M e a média de retorno das ações com baixo índice B/M); $\boldsymbol{e}_{i, t}$ é o resíduo do modelo referente à carteira $i$ no mês $t$.

Para a verificação da influência das variáveis sobre os retornos dos ativos, Fama e French (1993) criaram carteiras para replicar os fatores de risco relacionados às variáveis tamanho e índice B/M. O primeiro passo foi estimar os prêmios pelos fatores de risco. O segundo foi analisar o efeito desses fatores sobre os retornos das ações por meio de regressões temporais. O período amostral para as ações foi de 1963 a 1991. A amostra foi composta por todas as ações listadas na NYSE, AMEX e NASDAQ (a partir de 1972).

Para se obterem os valores para as variáveis dependentes e independentes, procedeu-se com os passos descriminados abaixo, iniciando com uma dupla ordenação independente, de acordo com os fatores tamanho e índice B/M.

Em junho de cada ano, a amostra foi classificada de acordo com o índice B/M das ações que a representavam. Após a ordenação, a amostra foi segregada em três grupos: 30\% inferiores (Low - L), os 40\% médios (Medium - M) e os 30\% superiores (High - H). Em seguida, a amostra foi classificada conforme o tamanho (valor de mercado das ações ordinárias). O valor mediano foi utilizado para separar as ações em dois grupos: Big - B e Small - S, que continham as empresas de maior e menor valor de mercado, respectivamente.

Após as duas ordenações independentes anteriores, como consequência da interseção dos grupos, foram criadas seis carteiras: $\mathrm{S} / \mathrm{L}, \mathrm{S} / \mathrm{M}, \mathrm{S} / \mathrm{H}, \mathrm{B} / \mathrm{L}, \mathrm{B} / \mathrm{M}$ e $\mathrm{B} / \mathrm{H}$. De julho do ano $t$ a junho de $t+1$, calculou-se o retorno mensal das seis carteiras por meio da ponderação, pelo valor de mercado da ação em relação ao valor de mercado da carteira, dos retornos das ações que as compunham. Mensalmente, calculou-se o prêmio pelo fator de risco tamanho - SMB, Small Minus Big -, pela diferença entre a média dos retornos das carteiras S e a média dos retornos das carteiras B. O prêmio pelo fator de risco índice B/M - HML, High Minus Low - 
foi obtido pela diferença entre a média dos retornos das carteiras $\mathrm{H}$ e a média dos retornos mensais das carteiras L. Finalmente, o prêmio pelo fator de risco mercado foi calculado pela diferença entre o retorno da carteira de mercado e a taxa livre de risco. O retorno da carteira de mercado foi calculado pela ponderação, pelo valor, dos retornos das ações amostrais. Esses prêmios mensais foram utilizados como variáveis independentes (ou explicativas) nas regressões temporais, para validação dos modelos.

Após os cálculos acima, Fama e French (1993) formaram 25 novas carteiras também em junho de cada ano. Para a construção dessas novas carteiras, os autores criaram cinco grupos para cada variável (tamanho e índice B/M). O excesso de retorno mensal dessas 25 carteiras em relação à taxa livre de risco foi a variável dependente das regressões lineares temporais. As carteiras foram, então, reformuladas em junho de cada ano, por meio da repetição das etapas acima.

Os principais resultados do estudo de Fama e French (1993) são resumidos a seguir:

- Foram encontrados prêmios positivos para todos os fatores de risco: mercado, tamanho e índice $\mathrm{B} / \mathrm{M}$;

- A maior parte das regressões das carteiras do modelo apresentaram interceptos estatisticamente iguais a zero, validando o modelo utilizado e indicando que os três fatores seriam proxies para os fatores de risco relevantes para os investidores;

- Todos os fatores de risco se mostraram significativos e pareceram se complementarem na explicação das variações dos retornos das carteiras;

- Os fatores de risco mostraram-se ortogonais;

- O modelo dos 3-fatores é válido para ser usado nas diversas decisões financeiras e é superior ao CAPM na explicação dos retornos das ações, no mercado norte-americano.

\subsubsection{Estudos dos fatores tamanho e valor posteriores ao de Fama e French (1993)}

Nos parágrafos seguintes, são apresentados estudos posteriores ao de Fama e French (1992 e 1993), que se dividiram em relação à validade do beta de mercado e ao poder de explicação do CAPM. Ressalte-se que os estudos que incluíram as variáveis tamanho e valor, mas que 
também adicionaram os efeitos momento ou a liquidez estão detalhados respectivamente nos subcapítulos 2.4 e 2.5 .

Black (1993) testou o CAPM também utilizando o método de carteira, para o período de 1926 a 1991 e, encontrou evidências de que as ações com betas menores alcançaram desempenho superior ao previsto pelo CAPM. O contrário ocorreu com ações com betas maiores. Concluiu que muitas das evidências de Fama e French (1992) decorreram do processo que ele chamou de data mining e que o CAPM deve, de qualquer forma, ser utilizado para guiar as decisões de investimento.

Chan e Lakonishok (1993) chegaram à conclusão de que o beta de mercado, apesar de não explicar toda a variação dos retornos das ações, pdoeria ser uma medida de risco adequada. Assim, haveria espaço para que outros fatores, possivelmente comportamentais, fossem adicionados ao beta de mercado, para melhorar o poder explicativo das variações dos retornos das ações.

Grinold (1993) concluiu que, independente da validação ou não do CAPM, o beta de mercado tem a sua importância e utilidade, principalmente devido à capacidade de mensurar o risco sistemático, sendo assim, um importante instrumento de risco.

Davis (1994) encontrou que as variáveis $\mathrm{B} / \mathrm{M}$, earnings to price e cash flow yield são significantes na explicação dos retornos das ações de empresas norte-americanas de 1940 a 1963. Já, tamanho, crescimento histórico e preço não são. A escolha de um período amostral anterior à base Standard \& Poor's COMPUSTAT foi motivada pelo interesse do autor de eliminar o minimizar vieses como o de sobrevivência.

Fama e French (1995) encontraram evidências de que empresas com baixo B/M são em média mais rentáveis do que empresas com alto $\mathrm{B} / \mathrm{M}$ por 4 anos antes e 5 anos após à formação das carteiras usadas no teste. Também verificaram que empresas maiores têm, persistentemente, rentabilidade maior do que empresas pequenas.

Kothari et al (1995) argumentam que os betas de retornos anuais produzem uma relação positiva mais forte entre o beta e a média de retornos, do que os betas de retornos mensais. 
Além disso, afirmam que a relação entre o retorno médio e o índice $\mathrm{B} / \mathrm{M}$ é seriamente exagerada pelo viés de sobrevivência da amostra.

Fama e French (2004), em resposta às críticas feitas à metodologia de seus estudos, afirmaram que o viés de sobrevivência não explica a relação entre o índice $\mathrm{B} / \mathrm{M}$ e o retorno médio. Contestaram o estudo de Kothari et al (1995), afirmando que betas anuais ou mensais produzem a mesma inferência sobre o prêmio de mercado. Argumentam, ainda, que o prêmio beta de mercado não salva o CAPM, trazendo evidências de que ele não é capaz de explicar os retornos esperados.

Fama e French (1998) encontraram evidências de que empresas com alto B/M tiveram retornos acima da média de mercado e acima das empresas com baixo B/M para ações das empresas de países ao redor do mundo, incluindo o Brasil. Também identificaram que empresas menores tendem a ter retornos maiores do que empresas maiores.

Fama e French (2004) enfatizam que, devido aos problemas empíricos do CAPM verificados nos diversos testes (sejam causados por excesso de simplificações das premissas ou por inviabilidade de se encontrar a verdadeira carteira de mercado), a maior parte das aplicações reais do modelo, por exemplo, para estimativa do custo do capital próprio ou avaliação de desempenho de carteiras administradas, não são válidas.

\subsubsection{Estudos do modelo dos 3-fatores no mercado acionário brasileiro}

Como consequência da publicação do artigo de Fama e French (1993), muitos autores passaram a testar, empiricamente, a validade do modelo dos 3-fatores nos mais diversos mercados. Dentre os principais trabalhos realizados tendo como objeto de estudo o mercado acionário brasileiro, podem-se citar Málaga e Securato (2004), Lucena e Pinto (2005) e Almeida e Eid (2010).

Málaga e Securato (2004) testaram a aplicação direta do modelo dos 3-fatores de Fama e French (1993) no mercado acionário brasileiro. Foram utilizadas cotações mensais de todas as ações listadas na BM\&FBOVESPA, no período de junho de 1995 a junho de 2003. A 
metodologia utilizada foi essencialmente a mesma adotada por Fama e French (1993), com exceção da quantidade de carteiras criadas para cálculo das variáveis dependentes.

Os principais resultados obtidos pelo estudo estão relacionados abaixo (MÁLAGA e SECURATO, 2004):

- o modelo dos 3-fatores foi válido para o mercado acionário brasileiro, sendo superior ao CAPM na explicação da variação dos retornos das carteiras;

- os dois fatores adicionais - tamanho e índice B/M - pareceram estar relacionados a fatores sistêmicos não captados pelo fator mercado;

- os 3-fatores mostraram-se significantes, complementando-se na explicação dos retornos de carteiras de diferentes características;

- o fator mercado explicou parte das variações de todas as carteiras testadas;

- o prêmio pelo tamanho - SMB - foi negativo, indicando que, no mercado brasileiro, empresas maiores parecem oferecer taxas de retornos superiores àquelas das empresas menores, contrapondo os resultados encontrados por Fama e French (1993), no mercado acionário norte-americano.

Lucena e Pinto (2005) realizaram testes empíricos de uma proposta de modificação do modelo dos 3-fatores no mercado acionário brasileiro. Após alguns testes sobre os resíduos do modelo original, os autores utilizaram técnicas autorregressivas heterocedásticas para tentar melhorar a aplicação do modelo de Fama e French (1993) em mercados emergentes, como o brasileiro. O modelo testado foi, então, o de Fama e French (1993) com a inclusão de componentes de variância condicional ARCH e GARCH. A amostra foi composta por 213 ações listadas na BM\&FBOVESPA, de julho de 1994 a agosto de 2004. Lucena e Pinto (2005, p.15) assinalam que o modelo dos 3-fatores "se mostra adequado para a previsão de retornos no mercado de capitais brasileiro" e ressaltam a importância das modificações citadas acima para amenizar os problemas com os resíduos das regressões.

Almeida e Eid (2010) estudaram a influência do índice B/M e seus componentes, de tamanho e do efeito das emissões líquidas de ações na explicação dos retornos de empresas do mercado acionário brasileiro de 1996 a 2008 e encontraram evidências da significância do índice B/M e do tamanho. 


\subsection{Identificação do efeito momento e o modelo dos 4-fatores de Carhart (1997)}

Esse subcapítulo descreve a identificação do efeito momento e sua posterior inclusão no modelo de 4-fatores.

\subsubsection{A identificação do efeito momento}

O efeito momento foi, inicialmente, identificado por Jegadeesh e Titman (1993) e indica que a estratégia de venda de ativos que tiveram um mau desempenho passado e a compra de ativos que tiveram um bom desempenho passado, leva a retornos anormais positivos, durante os meses subsequentes. Essa estratégia vai de encontro à hipótese de DeBondt e Thaler (1985 e 1987), de que estratégias contrárias é que são as geradoras de retornos anormais.

O estudo de Jegadeesh e Titman (1993) compreendeu o período de 1965 a 1989, analisando, detalhadamente, 32 estratégias de momento. Os resultados encontrados corroboraram a existência da possibilidade de ganhos anormais significantes no mercado acionário norteamericano em 31 das 32 estratégias estudadas.

As estratégias foram formadas considerando os 3, 6, 9 e 12 meses anteriores como períodos de formação das carteiras e os 3, 6, 9 e 12 meses subsequentes, como períodos de retenção das carteiras. A combinação dos quatro períodos de formação com os quatro de retenção totalizaram as 16 estratégias. Essas foram posteriormente duplicadas, ao se considerar a alternativa de se deixar o espaço de uma semana entre os períodos de formação e retenção.

Jegadeesh e Titman (1993) perceberam, também, que a rentabilidade das estratégias geradas no primeiro ano após a formação das carteiras se dissipava nos dois anos seguintes.

Alguns estudos passaram, então, a testar e corroborar a existência do efeito momento nos mercados acionários mundiais. Dentre eles, podem-se citar, Fama e French (1996) e Jegadeesh e Titman (2001) para o mercado norte-americano, Rouwenhorst (1998) para o mercado europeu, Rouwenhorst (1999) para os mercados emergentes, incluindo o Brasil. 
O estudo de Rouwenhorst (1999) utilizou 87 empresas brasileiras listadas na BM\&FBOVESPA, de 1982 a 1997, testando somente uma estratégia de momento: a 6x6, ou seja, retornos acumulados nos últimos 6 meses para o período de formação das carteiras e os 6 meses subsequentes como período de retenção. Apesar de ter encontrado um prêmio positivo com a estratégia de momento para a média dos países emergentes, a pesquisa chegou a um prêmio praticamente nulo no Brasil: $0,01 \%$ ao mês.

Em relação às possíveis causas do efeito momento, Daniel e Titman (1999) sugerem o excesso de confiança dos investidores. Os próprios Jegadeesh e Titman (2001) refizeram o estudo efetuado em 1993, ampliando o período amostral, e verificaram a persistência da anomalia no mercado norte-americano. Os autores também buscaram as possíveis causas do efeito momento, suportando a ideia de que a rentabilidade dessas estratégias pode estar relacionada a fatores comportamentais, mais especificamente, a uma sobrerreação, que é posteriormente corrigida, uma vez que se observa a dissipação da rentabilidade anormal dos retornos após um curto período de retenção.

Hong et al (2000) concluíram que as causas da estratégia de momento são consistentes com a hipótese de que informações específicas da empresa são difundidas apenas de forma gradual ao público investidor. Assim, quanto mais lento o processo de difusão das informações específicas da empresa, maior a intensidade do efeito momento. Dessa forma, o efeito momento estaria relacionado ao tamanho das empresas, pois quanto menor a empresa, mais lenta parece ser a difusão de informações específicas. Além disso, os autores encontraram que as ações com menor cobertura por parte dos analistas de mercado são as que apresentaram os maiores retornos motivados por estratégias de momento.

\subsubsection{O modelo de 4-fatores}

Fama e French (1996 e 2004) afirmam que o modelo dos 3-fatores captura a maior parte das anomalias, com exceção do efeito momento. Carhart (1997), em seu estudo de análise da persistência de desempenho de fundos mútuos de investimento, agregou a estratégia de momento de Jegadeesh e Titman (1993) ao modelo dos 3-fatores de Fama e French (1993), construindo o que ficou conhecido como modelo dos 4-fatores. 
O modelo dos 4-fatores pode, então, ser expresso pela equação abaixo:

$$
R_{c i, t}-R_{l r t}=a+b\left[R_{m t}-R_{l r t}\right]+s\left[S M B_{t}\right]+h\left[H M L_{t}\right]+w[\text { WinMLost }]+e_{i, t}
$$

Em que:

$\boldsymbol{R}_{C i, t}$ é o retorno da carteira $i$, no mês $t$;

$\boldsymbol{R}_{l r t}$ é o retorno do ativo livre de risco no mês $t$;

$\boldsymbol{R}_{\boldsymbol{m} t}$ é o retorno da carteira de mercado no mês $t$;

$\boldsymbol{S M B}_{t}$ é o prêmio pelo fator tamanho no mês $t$ (Small Minus Big ou a diferença entre a média de retorno das ações de empresas de pequeno porte e a média de retorno das ações de empresas de grande porte);

$\boldsymbol{H M L}_{\boldsymbol{t}}$ é o prêmio pelo fator B/M no mês $t$ (High Minus Low ou a diferença entre a média de retorno das ações com alto índice B/M e a média de retorno das ações com baixo índice B/M);

WinMLos $_{t}$ é o prêmio pelo fator momento no mês $t$ (Winner Minus Loser ou a diferença entre a média de retorno das ações de empresas que tiveram um alto desempenho passado e a média de retorno das ações de empresas que tiveram um baixo desempenho passado);

$\boldsymbol{e}_{i, t}$ é o resíduo do modelo referente à carteira $i$ no mês $t$.

Conforme Carhart (1997), o modelo dos 4-fatores é consistente com um modelo de equilíbrio de mercado, considerando a existência de quatro fatores de risco. Grinblatt e Titman (2005) destacam que modelos como esse são compostos por carteiras de custo zero (se autofinanciam), que podem ser vistos como um modelo de atribuição de desempenho, no qual os coeficientes e prêmios indicam a proporção do retorno que pode ser atribuído a: i) uma posição comprada em carteira de índices de valores ponderados e uma posição vendida em ativos livre de risco; ii) uma posição comprada em uma carteira de ações de alto índice B/M e uma posição vendida em ações com baixo índice B/M; iii) uma posição comprada em uma carteira de ações de baixa capitalização e uma posição vendida em uma carteira de ações de alta capitalização e, finalmente, iv) uma posição comprada em uma carteira de ações que tiveram um bom desempenho passado e uma posição vendida em uma carteira de ações que tiveram um mau desempenho passado.

Carhart (1997) empregou três modelos: o CAPM, o modelo dos 3-fatores e o modelo dos 4fatores, para a mensuração do desempenho de fundos mútuos do mercado norte-americano. 
Em sua metodologia, os fundos mútuos foram classificados em janeiro de cada ano, de 1963 a 1993, em carteiras formadas por decis, de pesos iguais, baseados nos retornos passados dos últimos 12 meses, desconsiderando o mês mais recente. Os fundos com os maiores retornos passados compuseram o primeiro decil e os fundos com os piores retornos passados compuseram o último decil. Posteriormente, os decis 1 e 10 foram divididos cada um em três, utilizando o mesmo critério. As carteiras foram mantidas por 12 meses e, então, reformuladas pela repetição das etapas descritas. Esse procedimento gerou uma série temporal de retornos mensais para cada decil.

Os prêmios pelos fatores de risco tamanho e índice B/M foram obtidos diretamente com Fama e French. Para a obtenção da variável WinMLos, todas as ações foram ordenadas de acordo com o desempenho acumulado do retorno no período $t-2$ e $t-12$. Na sequência, a amostra foi separada em três grupos: $30 \%$ superiores, $40 \%$ médios e $30 \%$ inferiores, de acordo com o retorno acumulado. O prêmio pelo fator de risco momento foi obtido pela diferença entre a média não ponderada dos retornos das ações do grupo superior e a média não ponderada dos retornos das ações do grupo inferior. As carteiras incluíam todas as ações listadas na NYSE, AMEX e NASDAQ e foram reformuladas mensalmente.

Os principais resultados do trabalho de Carhart (1997) estão resumidos abaixo:

- o modelo dos 4-fatores explicou consideravelmente as variações nos retornos dos fundos, sendo superior aos modelos CAPM e 3-fatores;

- os prêmios médios mensais pelos fatores de risco mostraram-se positivos e elevados;

- as correlações entre os prêmios pelos fatores de risco mostraram-se baixas;

- o modelo dos 4-fatores melhorou a média dos erros dos modelos, quando comparados ao CAPM e ao modelo dos 3-fatores de Fama e French (1993);

- o excesso de retorno mensal das carteiras decresceu à medida que se caminhou das carteiras com retornos acumulados superiores para as carteiras com os retornos acumulados inferiores;

- o CAPM não explicou o retorno relativo das carteiras e os betas de mercado se mantiveram praticamente constantes ao longo das carteiras. 


\subsubsection{Estudos posteriores ao de Carhart (1997)}

Como estudos posteriores ao de Carhart (1997), que também utilizaram o modelo dos 4fatores, pode-se citar Liew e Vassalou (2000) e L'Her et al (2004). Ressalte-se que os estudos que incluíram a variável momento em conjunto com a liquidez estão descritos no subcapítulo 2.5 .

A abordagem de Liew e Vassalou (2000) consistiu em relacionar a rentabilidade dos fatores mercado, índice $\mathrm{B} / \mathrm{M}$, tamanho e momento ao crescimento econômico de 10 países desenvolvidos, de 1978 a 1996. Os países incluídos foram Austrália, Canadá, França, Alemanha, Itália, Japão, Holanda, Suíça, Reino Unido e Estados Unidos. A metodologia foi um pouco diferente da metodologia utilizada por Fama e French (1993), pois devido à pequena quantidade de ações encontradas em alguns países da amostra, não foi possível proceder com ordenações independentes, somente com ordenações sequenciais.

Os resultados da pesquisa indicaram que os fatores índice $\mathrm{B} / \mathrm{M}$ e tamanho contêm informações significantes sobre o crescimento do PIB. O poder de explicação desses fatores mostrou-se independente do fator mercado. Os coeficientes dos fatores mercado, tamanho e índice B/M das regressões foram, em geral, positivos e com magnitude similares. Poucas evidências foram encontradas para suportar a presença do fator momento como fator explicativo do crescimento econômico dos países da amostra.

L'Her et al (2004) testaram os quatro fatores no mercado acionário canadense, utilizando a metodologia de Fama e French (1993) para a construção dos fatores de risco. A amostra compreendeu o período de julho de 1960 a abril de 2001. O prêmio médio anual obtido pelos fatores mercado, tamanho, índice B/M e momento foram, respectivamente, 4,52\%, 5,08\%, $5,09 \%$ e $16,07 \%$. Os autores verificaram que o retorno do fator tamanho foi substancialmente maior em janeiro, em comparação com os demais meses do ano. Já o fator momento foi sempre significante, exceto em janeiro, quando as carteiras de ações perdedoras superaram, em termos de retornos, as carteiras de ações vencedoras. Em relação ao fator índice B/M, não foi encontrada qualquer relação com os meses do ano. O retorno do fator book-to-market mostrou-se fortemente influenciado por oscilações macroeconômicas. Por fim, quanto à relação entre as políticas monetárias restritivas ou expansivas e a significância dos fatores, encontraram que os prêmios pelos fatores de risco tamanho e índice B/M são significantes 
somente em ambientes de expansão da política monetária, enquanto o fator momento não é significativamente afetado por alterações dessas políticas.

\subsubsection{Estudos sobre o modelo de 4-fatores no mercado brasileiro}

O estudo de Mussa et al (2007) teve o objetivo de investigar a validade do modelo de precificação de ativos dos 4-fatores no mercado acionário brasileiro usando a metodologia de formação de carteiras e regressão em séries temporais de Fama e French (1993). Foram usadas as ações listadas na BM\&FBOVESPA, de 1995 a 2007. Os resultados verificados apresentaram evidências de que o modelo dos 4-fatores é válido para o mercado acionário brasileiro, sendo superior ao modelo dos 3-fatores, e também ao CAPM, na explicação das variações dos retornos das ações da amostra. Porém, não foi encontrado um prêmio significativo pelo fator momento.

Mussa et al (2009) testaram e compararam os modelos CAPM, 3-fatores e 4-fatores a partir da metodologia de teste preditivo, utilizando duas etapas - regressões em séries temporais e cross-section - com erros-padrão calculados pela técnica de Fama e Macbeth (1973). Apesar de os resultados indicarem a superioridade do modelo 4-fatores em relação ao modelo 3fatores, e esse em relação ao CAPM, nenhum dos três modelos testados foram suficientes na explicação das variações dos retornos das ações do mercado brasileiro. Além do mais, foi encontrado que, contrário a algumas evidências empíricas que não utilizam a metodologia preditiva, os efeitos tamanho e momento parecem não estar presente no mercado de capitais brasileiro, enquanto há indícios da presença dos efeitos valor e relevância do mercado em explicar retornos esperados.

Flister et al (2011) estudaram a influência das anomalias momento, tamanho e índice B/M no retorno de empresas brasileiras de 1995 a 2008 e encontraram evidências de que o efeito momento não é significante, o efeito $\mathrm{B} / \mathrm{M}$ é significante e positivo e o efeito tamanho é significante e negativo. 


\subsection{Liquidez e o modelo de 2-fatores}

A liquidez é comumente descrita como a habilidade de negociar grandes quantidades de ativos, rapidamente, a um baixo custo e com pequeno impacto nos preços (BLACK, 1971; LIU, 2006). Conforme essa definição, pode-se notar quatro dimensões da liquidez: i) quantidade; ii) velocidade; iii) custo e iv) impacto nos preços.

Tendo como ponto de partida o trabalho seminal de Amihud e Mendelson (1986) ${ }^{1}$, há uma grande quantidade de pesquisas que suportam a hipótese de existência de prêmio pela liquidez e indicam, portanto, que a liquidez das ações afeta os seus retornos. A premissa central é que ativos menos líquidos devem apresentar taxas de retornos superiores às dos ativos mais líquidos, por representarem mais riscos a seus detentores. Essas pesquisas serão detalhadas no subcapítulo 2.5.1.

Nesse sentido, e considerando que nenhum dos modelos de precificação de ativos estudados até o momento se mostrou suficiente na explicação das variações dos retornos das ações, Acharya e Pedersen (2005) e Liu (2006) sugerem a adição do fator liquidez ao beta de mercado do CAPM, constituindo o que ficou conhecido como modelo de 2-fatores, que pode ser considerado um modelo APT representado, matematicamente, pela Equação 5 abaixo:

$$
E\left(r_{i}\right)-r_{f}=\beta_{m, i}\left[E\left(r_{m}\right)-r_{f}\right]+\beta_{l, i} E(\text { Liq })
$$

Em que:

$\boldsymbol{E}\left(\boldsymbol{r}_{\boldsymbol{i}}\right)$ é o retorno esperado da ação $i$;

$\boldsymbol{r}_{f}$ é o retorno do ativo livre de risco;

$\boldsymbol{E}\left(\boldsymbol{r}_{\boldsymbol{m}}\right)$ é o retorno esperado da carteira de mercado;

$\boldsymbol{E}($ Liq) é o retorno esperado do fator que é proxy da liquidez ou a diferença entre a média de retorno das ações de empresas de baixa liquidez e média de retorno das ações de empresa de alta liquidez;

$\boldsymbol{\beta}_{\mathbf{m}, \mathbf{i}} \mathbf{e} \boldsymbol{\beta}_{\mathbf{l}, \mathbf{i}}$ são os betas da ação $i$ do mercado e do fator liquidez, respectivamente.

\footnotetext{
${ }^{1}$ Apesar da importância dos estudos anteriores como os de Demsetz (1968), Tinic (1972), Tinic e West (1972), Benston e Hagerman (1974), Garman (1976), Branch e Freed (1977), Stoll (1978), Ho e Stoll (1981 e 1983), Copeland e Galai (1983), o trabalho de Amihud e Mendelson (1986) será considerado essencialmente o ponto de partida teórico sobre liquidez desta tese.
} 


\subsubsection{Detalhamento dos principais trabalhos sobre liquidez}

O Quadro 3 abaixo, apresenta um resumo dos principais trabalhos sobre liquidez e sua relação com a explicação dos retornos das ações desenvolvidos até o momento, incluindo: as medidas utilizadas e suas respectivas dimensões da liquidez, a amostra e as principais evidências. $\mathrm{O}$ detalhamento de cada pesquisa encontra-se na sequência do Quadro 3. Ressalte-se que a pesquisa de Liu (2006) é descrita com maiores detalhes pelo fato de a presente tese utilizar ,essencialmente, os procedimentos de Liu (2006) como referência.

Em linhas gerais, os primeiros trabalhos que relacionaram liquidez e retorno concentraram-se na dimensão custo de transação ao utilizar o bid-ask spread como proxy para a liquidez, sendo seminal o trabalho de Amihud e Mendelson (1986). Os autores encontraram uma relação positiva entre retorno e iliquidez.

Posteriormente, Petersen e Fialkowski (1994) e Brennan e Subrahmanyam (1996) levantaram preocupações relativas à eficácia do uso do bid-ask spread como medida de liquidez. De forma geral, os autores argumentam que muitas transações de grande volume ocorrem fora do bid-ask spread e muitas transações de pequeno volume ocorrem dentro do bid-ask spread, distorcendo a medida e seu uso em modelos de precificação de ativos.

Esses questionamentos levaram ao desenvolvimento de novas medidas de liquidez como: Volume Financeiro de transações de Brenann et al (1998), Turnover de Datar et al (1998), Desvio-padrão do Turnover e do Volume Financeiro de transações e o Coeficiente de Variação do Turnover e do Volume Financeiro de transações de Chordia et al (2001), todas com ênfase na dimensão quantidade de transações; a medida de iliquidez de Amihud (2002) Return-to-Volume - com foco na dimensão impacto nos preços e a medida de iliquidez de Liu (2006), Volume Zero Padronizado, que pode ser considerada multidimensional com ênfase na velocidade de transação.

Faz-se importante a menção de que as pesquisas na literatura internacional, de forma geral, suportam as evidências de Amihud e Mendelson (1986), ou seja, de que existe prêmio pela liquidez. Já, no Brasil, as pesquisas têm apresentado resultados controversos quanto à existência de prêmios pela liquidez, bem como sua validade em modelos de precificação de ativos. 
Quadro 3 - Resumo dos principais trabalhos sobre liquidez e sua relação com o retorno em mercados acionários

O quadro abaixo resume os principais trabalhos sobre liquidez e seu papel na explicação dos retornos das ações. $\mathrm{O}$ painel A apresenta os estudos efetuados tendo como objeto o mercado acionário norte-americano. O painel $\mathrm{B}$ traz os estudos efetuados nos demais mercados, incluindo as pesquisas efetuadas no mercado brasileiro. São informados os autores do estudo, as medidas de liquidez utilizadas e as respectivas dimensões da liquidez, além de informações sobre a amostra e um resumo das principais evidências encontradas. Maiores detalhes sobre os referidos estudos são apresentados após esse quadro, conforme a referência indicada na coluna Item.

\begin{tabular}{|c|c|c|c|c|c|}
\hline Item & Estudo & $\begin{array}{c}\text { Medidas de } \\
\text { liquidez } \\
\text { utilizadas }\end{array}$ & $\begin{array}{c}\text { Dimensão } \\
\text { da liquidez }\end{array}$ & Amostra & Principais evidências \\
\hline \multicolumn{6}{|c|}{ Painel A - Estudos no mercado norte-americano } \\
\hline a) & $\begin{array}{l}\text { Amihud e } \\
\text { Mendelson } \\
\text { (1986) }\end{array}$ & Bid-ask spread & $\begin{array}{l}\text { Custos de } \\
\text { transações }\end{array}$ & $\begin{array}{c}\text { Ações da NYSE } \\
\text { de } 1960 \text { a } 1980\end{array}$ & $\begin{array}{l}\text { Relação positiva entre o retorno } \\
\text { esperado das ações e a iliquidez } \\
\text { medida pelo bid-ask spread. O } \\
\text { bid-ask spread explica o efeito } \\
\text { tamanho da empresa. }\end{array}$ \\
\hline b) & $\begin{array}{c}\text { Eleswarapu } \\
\text { e Reiganum } \\
\text { (1993) }\end{array}$ & Bid-ask spread & $\begin{array}{l}\text { Custos de } \\
\text { transações }\end{array}$ & $\begin{array}{c}\text { Ações da NYSE } \\
\text { de } 1961 \text { a } 1990\end{array}$ & $\begin{array}{l}\text { Relação positiva entre o retorno } \\
\text { esperado das ações e a iliquidez } \\
\text { medida pelo bid-ask spread } \\
\text { somente significativa para os } \\
\text { meses de janeiro. O efeito tamanho } \\
\text { da empresa persiste mesmo depois } \\
\text { de controlado pelo bid-ask spread. }\end{array}$ \\
\hline c) & $\begin{array}{l}\text { Brennan et } \\
\text { al (1998) }\end{array}$ & $\begin{array}{l}\text { Volume } \\
\text { financeiro }\end{array}$ & $\begin{array}{c}\text { Quantidade } \\
\text { de transações }\end{array}$ & $\begin{array}{c}\text { Ações da NYSE, } \\
\text { AMEX e } \\
\text { NASDAQ de } \\
1966 \text { a } 1995\end{array}$ & $\begin{array}{l}\text { Relação forte, consistente e } \\
\text { negativa entre o Volume } \\
\text { Financeiro de transações e a média } \\
\text { dos retornos das ações, mesmo } \\
\text { depois de os retornos serem } \\
\text { ajustados pelos fatores de risco } \\
\text { beta de mercado, tamanho e índice } \\
\text { B/M. }\end{array}$ \\
\hline d) & $\begin{array}{l}\text { Datar et al } \\
\quad(1998)\end{array}$ & Turnover & $\begin{array}{c}\text { Quantidade } \\
\text { de transações }\end{array}$ & $\begin{array}{l}\text { Ações da NYSE } \\
\text { de } 1962 \text { a } 1991\end{array}$ & $\begin{array}{l}\text { Relação negativa entre o Turnover } \\
\text { e os retornos das ações não restrito } \\
\text { ao mês de janeiro e persistente } \\
\text { mesmo depois dos ajustes pelos } \\
\text { fatores de risco tamanho, índice } \\
\text { B/M e beta de mercado. }\end{array}$ \\
\hline e) & $\begin{array}{l}\text { Chordia et } \\
\text { al (2001) }\end{array}$ & $\begin{array}{l}\text { Variabilidade } \\
\text { do Volume } \\
\text { Financeiro e } \\
\text { do Turnover }\end{array}$ & $\begin{array}{c}\text { Variabilidade } \\
\text { da liquidez }\end{array}$ & $\begin{array}{c}\text { Ações da NYSE, } \\
\text { AMEX e } \\
\text { NASDAQ de } \\
1966 \text { a } 1995\end{array}$ & $\begin{array}{l}\text { Relação forte e negativa entre a } \\
\text { variabilidade do Volume } \\
\text { Financeiro e do Turnover com o } \\
\text { retorno das ações, mesmo depois } \\
\text { de controlados pelos fatores de } \\
\text { risco tamanho, índice B/M e } \\
\text { momento. }\end{array}$ \\
\hline f) & $\begin{array}{l}\text { Amihud } \\
(2002)\end{array}$ & $\begin{array}{l}\text { Return-to- } \\
\text { Volume }\end{array}$ & $\begin{array}{l}\text { Impacto nos } \\
\text { preços }\end{array}$ & $\begin{array}{c}\text { Ações da NYSE } \\
\text { de } 1964 \text { a } 1997\end{array}$ & $\begin{array}{l}\text { Tanto entre ativos quanto ao longo } \\
\text { do tempo, o retorno esperado é } \\
\text { função crescente da iliquidez } \\
\text { esperada medida pelo Return-to- } \\
\text { Volume. }\end{array}$ \\
\hline g) & $\begin{array}{l}\text { Acharya e } \\
\text { Pedersen } \\
(2005)\end{array}$ & $\begin{array}{l}\text { Return-to- } \\
\text { Volume }\end{array}$ & $\begin{array}{l}\text { Impacto nos } \\
\text { preços }\end{array}$ & $\begin{array}{c}\text { Ações da NYSE } \\
\text { e AMEX de } \\
1963 \text { a } 1999 .\end{array}$ & $\begin{array}{l}\text { A adição do fator liquidez ao } \\
\text { CAPM mostrou-se válida e o novo } \\
\text { modelo superior ao CAPM em } \\
\text { termos de explicação das variações } \\
\text { dos retornos das ações. Além } \\
\text { disso, o retorno esperado dos } \\
\text { ativos depende da liquidez } \\
\text { esperada, da covariância do seu } \\
\text { próprio retorno e da liquidez com } \\
\text { o retorno de mercado e liquidez. }\end{array}$ \\
\hline
\end{tabular}




\begin{tabular}{|c|c|c|c|c|c|}
\hline \multicolumn{6}{|c|}{$\begin{array}{c}\text { Quadro } 3 \text { - Resumo dos principais trabalhos sobre liquidez e sua relação com o retorno em mercados acionários. } \\
\text { Continuação. }\end{array}$} \\
\hline Item & Estudo & \begin{tabular}{|c|}
$\begin{array}{c}\text { Medidas de liquidez } \\
\text { utilizadas }\end{array}$ \\
\end{tabular} & \begin{tabular}{c|c|} 
Dimensão da \\
liquidez
\end{tabular} & Amostra & Principais evidências \\
\hline \multicolumn{6}{|c|}{ Painel A - Estudos no mercado norte-americano } \\
\hline h) & Liu (2006) & $\begin{array}{l}\text { Volume Zero } \\
\text { Padronizado, } \\
\text { Turnover, Return- } \\
\text { to-Volume e Bid- } \\
\text { ask spread }\end{array}$ & $\begin{array}{c}\text { Múltiplas, } \\
\text { com especial } \\
\text { ênfase à } \\
\text { velocidade } \\
\text { de transações }\end{array}$ & $\begin{array}{c}\text { Ações da NYSE, } \\
\text { AMEX e } \\
\text { NASDAQ de } 1960 \\
\text { a } 2003\end{array}$ & $\begin{array}{l}\text { Relação forte e negativa entre a } \\
\text { medida de liquidez proposta } \\
\text { Volume Zero Padronizado - e o } \\
\text { retorno das ações. Identificação } \\
\text { de forte prêmio pela liquidez. } \\
\text { Criação do modelo de 2-fatores } \\
\text { (beta de mercado e liquidez) que } \\
\text { se mostrou como explicativo do } \\
\text { retorno das ações e superior aos } \\
\text { modelos CAPM e 3-fatores de } \\
\text { Fama e French (1993). O prêmio } \\
\text { pela liquidez incorpora anomalias } \\
\text { documentadas relacionadas aos } \\
\text { fatores de risco tamanho, fluxo de } \\
\text { caixa, lucro, dividendos, preços } \\
\text { das ações e índice B/M. }\end{array}$ \\
\hline i) & $\begin{array}{l}\text { Keene e } \\
\text { Petersen } \\
(2007)\end{array}$ & $\begin{array}{l}\text { Volume financeiro, } \\
\text { Turnover, desvio- } \\
\text { padrão do Volume } \\
\text { Financeiro, desvio- } \\
\text { padrão do } \\
\text { Turnover, } \\
\text { coeficiente de } \\
\text { variação do } \\
\text { Volume Financeiro } \\
\text { e coeficiente de } \\
\text { variação do } \\
\text { Turnover. }\end{array}$ & $\begin{array}{c}\text { Quantidade } \\
\text { de transações } \\
\text { e } \\
\text { variabilidade } \\
\text { da liquidez }\end{array}$ & $\begin{array}{l}\text { Ações do mercado } \\
\text { norte-americano } \\
\text { de } 1963 \text { a } 2002 .\end{array}$ & $\begin{array}{l}\text { A liquidez é precificada e } \\
\text { constitui-se em parte da } \\
\text { explicação da variação dos } \\
\text { retornos das ações no mercado } \\
\text { norte-americano. Os outros } \\
\text { quatro fatores - beta de mercado, } \\
\text { tamanho, índice B/M e momento } \\
\text { - também se mostraram } \\
\text { importantes e a presença da } \\
\text { liquidez alterou o efeito deles. A } \\
\text { maioria dos interceptos } \\
\text { apresentou-se } \\
\text { indicando que ainda há parte da } \\
\text { variação dos retornos não } \\
\text { explicada por esses cinco fatores. }\end{array}$ \\
\hline j) & $\begin{array}{l}\text { Nguyen et } \\
\text { al (2007) }\end{array}$ & Turnover & $\begin{array}{c}\text { Quantidade } \\
\text { de transações }\end{array}$ & $\begin{array}{c}\text { Ações da NYSE, } \\
\text { AMEX e } \\
\text { NASDAQ de } 1963 \\
\text { a } 2004\end{array}$ & $\begin{array}{l}\text { As ações menos líquidas } \\
\text { demandam alto retorno e essa } \\
\text { relação não é capturada pelas } \\
\text { outras variáveis consideradas - } \\
\text { beta de mercado, tamanho e } \\
\text { índice B/M. }\end{array}$ \\
\hline \multicolumn{6}{|c|}{ Painel B - Estudos nos demais mercados } \\
\hline $\mathrm{k})$ & $\begin{array}{c}\text { Sanvicente e } \\
\text { Minardi } \\
\text { (1998) }\end{array}$ & $\begin{array}{l}\text { Índice de } \\
\text { Negociabilidade da } \\
\text { BM\&FBOVESPA }\end{array}$ & $\begin{array}{c}\text { Quantidade } \\
\text { de transações }\end{array}$ & $\begin{array}{c}\text { Ações da } \\
\text { BM\&FBOVESPA } \\
\text { de } 1994 \text { a } 1998\end{array}$ & $\begin{array}{l}\text { Associação positiva e significante } \\
\text { entre os retornos e a liquidez, } \\
\text { medida pelo Índice de } \\
\text { Negociabilidade } \\
\text { BM\&FBOVESPA. }\end{array}$ \\
\hline 1) & $\begin{array}{l}\text { Bruni e } \\
\text { Famá } \\
\text { (1998) }\end{array}$ & $\begin{array}{l}\text { Índice de } \\
\text { Negociabilidade da } \\
\text { BM\&FBOVESPA }\end{array}$ & $\begin{array}{c}\text { Quantidade } \\
\text { de transações }\end{array}$ & $\begin{array}{c}\text { Ações da } \\
\text { BM\&FBOVESPA } \\
\text { de } 1988 \text { a } 1997\end{array}$ & $\begin{array}{l}\text { Associação negativa } \\
\text { significante entre os retornos e a } \\
\text { liquidez, medida pelo Índice de } \\
\text { Negociabilidade } \\
\text { BM\&FBOVESPA. }\end{array}$ \\
\hline $\mathrm{m})$ & $\begin{array}{c}\text { Jung et al } \\
(2003)\end{array}$ & $\begin{array}{l}\text { Turnover, Volume } \\
\text { financeiro e a } \\
\text { variabilidade do } \\
\text { Turnover }\end{array}$ & $\begin{array}{c}\text { Quantidade } \\
\text { de transações } \\
\mathrm{e} \\
\text { variabilidade } \\
\text { da liquidez }\end{array}$ & $\begin{array}{c}\text { Ações de } 27 \\
\text { mercados } \\
\text { emergentes de } \\
1992 \text { a } 1999 .\end{array}$ & $\begin{array}{l}\text { O retorno das ações está } \\
\text { positivamente } \\
\text { com medidas agregadas de } \\
\text { liquidez. Os resultados } \\
\text { mostraram-se robustos mesmo } \\
\text { depois de controlados pelo beta } \\
\text { de mercado, tamanho e índice } \\
\text { price-to-book. }\end{array}$ \\
\hline
\end{tabular}




\begin{tabular}{|c|c|c|c|c|c|}
\hline \multicolumn{6}{|c|}{$\begin{array}{l}\text { Quadro } 3 \text { - Resumo dos principais trabalhos sobre liquidez e sua relação com o retorno em mercados acionários. } \\
\text { Continuação. }\end{array}$} \\
\hline Item & Estudo & \begin{tabular}{|c|}
$\begin{array}{c}\text { Medidas de liquidez } \\
\text { utilizadas }\end{array}$ \\
\end{tabular} & \begin{tabular}{|c|}
$\begin{array}{c}\text { Dimensão da } \\
\text { liquidez }\end{array}$ \\
\end{tabular} & Amostra & Principais evidências \\
\hline \multicolumn{6}{|c|}{$\begin{array}{l}\text { Painel B - Estudos nos demais mercados } \\
\end{array}$} \\
\hline n) & $\begin{array}{c}\text { Chan e Faff } \\
(2005)\end{array}$ & Turnover & $\begin{array}{l}\text { Quantidade } \\
\text { de transações }\end{array}$ & $\begin{array}{c}\text { Ações do mercado } \\
\text { australiano de } \\
1990 \text { a } 1998\end{array}$ & $\begin{array}{l}\text { Prêmios positivos } \\
\text { estatisticamente significantes } \\
\text { para os fatores beta de mercado, } \\
\text { tamanho, índice B/M e Turnover, } \\
\text { além de fortes evidências a favor } \\
\text { da validade do modelo composto } \\
\text { pelos quatro fatores. }\end{array}$ \\
\hline o) & $\begin{array}{c}\text { Bekaert et al } \\
\quad(2007)\end{array}$ & $\begin{array}{l}\text { Volume zero, Bid- } \\
\text { ask e Turnover }\end{array}$ & $\begin{array}{l}\text { Velocidade, } \\
\text { custos e } \\
\text { quantidade } \\
\text { de } \\
\text { transações. }\end{array}$ & $\begin{array}{c}\text { Ações de } 19 \\
\text { mercados } \\
\text { emergentes de } \\
1987 \text { a } 2003 .\end{array}$ & $\begin{array}{l}\text { A medida de liquidez proposta }- \\
\text { volume zero - prediz os retornos } \\
\text { de forma significante nesses } \\
\text { mercados. }\end{array}$ \\
\hline p) & $\begin{array}{l}\text { Vieira e } \\
\text { Milach } \\
(2008)\end{array}$ & $\begin{array}{l}\text { Volume } \\
\text { Financeiro, } \\
\text { Quantidade de } \\
\text { Títulos negociados, } \\
\text { Quantidade de } \\
\text { Negócios, } \\
\text { Turnover, spread e } \\
\text { Return-to-Volume }\end{array}$ & Múltiplas & $\begin{array}{c}\text { Ações da } \\
\text { BM\&FBOVESPA } \\
\text { de } 1995 \text { a } 2005\end{array}$ & $\begin{array}{l}\text { As médias dos coeficientes de } \\
\text { correlação entre as medidas de } \\
\text { liquidez foram positivas, porém } \\
\text { de baixa magnitude, denotando o } \\
\text { caráter multidimensional da } \\
\text { liquidez. Nos modelos de } \\
\text { precificação, a maioria dos } \\
\text { coeficientes das variáveis de } \\
\text { liquidez não foram significativas, } \\
\text { apenas as variáveis iliquidez e } \\
\text { spread apresentaram } \\
\text { significância. Os resultados não } \\
\text { se mostraram influenciados pelo } \\
\text { efeito janeiro. }\end{array}$ \\
\hline q) & $\begin{array}{c}\text { Correia et al } \\
(2008)\end{array}$ & $\begin{array}{l}\text { Turnover, Volume } \\
\text { Financeiro e } \\
\text { Quantidade de } \\
\text { Negócios }\end{array}$ & $\begin{array}{l}\text { Quantidade } \\
\text { de transações }\end{array}$ & $\begin{array}{c}\text { Ações da } \\
\text { BM\&FBOVESPA } \\
\text { de } 1995 \text { a } 2004\end{array}$ & $\begin{array}{l}\text { Existência de uma associação } \\
\text { linear, positiva e estatisticamente } \\
\text { significativa entre o retorno e a } \\
\text { liquidez das ações com todas as } \\
\text { medidas de liquidez testadas. }\end{array}$ \\
\hline r) & $\begin{array}{c}\text { Lam e Tam } \\
\quad(2011)\end{array}$ & \begin{tabular}{|l|} 
Turnover, Volume \\
financeiro, \\
volatilidade do \\
Turnove e do \\
Volume, medida de \\
liquidez de Pastor e \\
Stambaugh (2003), \\
Return-to-Volume \\
Volume Zero \\
Padronizado. \\
\end{tabular} & Múltiplas & $\begin{array}{c}\text { Ações do mercado } \\
\text { de Hong Kong de } \\
1981 \text { a } 2004\end{array}$ & $\begin{array}{l}\text { A liquidez é um importante fator } \\
\text { na precificação de ativos, mesmo } \\
\text { depois de controlada por outros } \\
\text { fatores de risco como o tamanho, } \\
\text { o índice } \mathrm{B} / \mathrm{M} \text { e o momento. O } \\
\text { melhor modelo encontrado foi o } \\
\text { composto pelos fatores beta de } \\
\text { mercado, tamanho, índice } \mathrm{B} / \mathrm{M} \text { e } \\
\text { liquidez. }\end{array}$ \\
\hline s) & Lee $(2011)$ & Return-to-Volume & $\begin{array}{l}\text { Impacto nos } \\
\text { preços }\end{array}$ & $\begin{array}{c}\text { Ações de } \\
\text { empresas de } 50 \\
\text { países } \\
\text { desenvolvidos e } \\
\text { emergentes de } \\
1988 \text { a } 2007 .\end{array}$ & $\begin{array}{l}\text { O risco pela liquidez é } \\
\text { precificado independente do risco } \\
\text { de mercado nos mercados } \\
\text { financeiros internacionais. } \\
\text { Adicionalmente, o mercado } \\
\text { norte-americano é um importante } \\
\text { direcionador do risco de liquidez } \\
\text { global. } \\
\text { O preço pela liquidez variou ao } \\
\text { longo dos países conforme } \\
\text { fatores como posições } \\
\text { geográficas e condições dos } \\
\text { ambientes econômico político. }\end{array}$ \\
\hline
\end{tabular}




\begin{tabular}{|c|c|c|c|l|}
\hline \multicolumn{2}{|c|}{ Quadro 3- Resumo dos principais trabalhos sobre liquidez e sua relação com o retorno em mercados } \\
acionários. Continuação.
\end{tabular}

\section{a) Amihud e Mendelson (1986)}

Amihud e Mendelson (1986) conduziram um estudo pioneiro para investigar o papel da liquidez em modelos de precificação de ativos usando o bid-ask spread como proxy para iliquidez.

A ideia principal dos autores é que liquidez, no caso custos de transação ou iliquidez, está entre os atributos primários dos planos de investimentos. Nesse contexto, a iliquidez pode ser medida pelo custo da execução imediata. Um investidor comumente se depara com um tradeoff: esperar para transacionar a um preço favorável ou insistir na execução imediata ao preço bid ou ask corrente. A cotação do preço ask inclui um prêmio para a compra imediata e 
o preço bid, de forma similar, reflete a concessão requerida para a venda imediata. Assim, o bid-ask spread é uma medida natural de iliquidez.

O modelo estudado prediz que ativos com alto spread apresentam altos retornos esperados e que existe um efeito clientela no qual os investidores com horizontes de longo prazo selecionam ativos com altos spreads. Além disso, o modelo prediz que os retornos esperados líquidos dos custos de transação aumentam com o horizonte do investimento e, consequentemente, ativos com altos spreads propiciam altos retornos para seus detentores. Assim, investidores com longos horizontes de investimentos podem ganhar por manter ativos com altos spreads.

A medida bid-ask spread usada foi a média entre o spread relativo no começo e no final do ano e a hipótese testada foi que o retorno esperado é uma função crescente e côncava do spread. O spread relativo foi definido pelo dollar spread dividido pela média dos preços bid e ask no final do ano. O spread usado foi a média dos spreads relativos no começo e final do ano de 1960 a 1980 para todas as ações da NYSE. A metodologia de testes usada foi semelhante à de Black, Jensen e Scholes (1972) e Fama e Macbeth (1973).

A hipótese mostrou-se consistente com as evidências empíricas: verificou-se uma relação positiva entre o retorno esperado e a iliquidez, em que o retorno da carteira média ajustada pelo risco aumentou de acordo com o crescimento do bid-ask spread e a relação retornospread diminuiu com o spread.

O estudo destaca a importância da microestrutura dos mercados em determinar o retorno dos ativos e provê uma conexão com o mercado de capitais. Os resultados sugerem que o aumento da liquidez pode reduzir o custo de capital. $\mathrm{Na}$ área de seleção de carteiras, os resultados podem guiar os investidores em balancear os custos de transação esperados contra os retornos esperados.

\section{b) Eleswarapu e Reiganum (1993)}

Eleswarapu e Reiganum (1993) refizeram o trabalho de Amihud e Mendelson (1986) com ajustes na estrutura da pesquisa empírica, permitindo que fosse excluída uma quantidade 
menor de ações da amostra e possibilitasse a exploração do potencial efeito sazonal mensal, o efeito janeiro, na relação entre retornos esperados das ações e o bid-ask spread.

A amostra foi composta por todas as ações listadas na NYSE de 1961 a 1990 e foram analisadas as relações cross-sectional entre os retornos mensais, betas de mercado e o bid-ask spread relativo. A medida de bid-ask spread foi a mesma usada por Amihud e Mendelson (1986), porém foi usada uma técnica de formação das carteiras menos restritiva, o que possibilitou a elevação do tamanho da amostra em $45 \%$ quando comparado ao estudo de Amihud e Mendelson (1986). Além disso, Eleswarapu e Reiganum (1993) afirmam que fortes restrições amostrais podem, efetivamente, excluir da amostra empresas pequenas, maquiando o efeito tamanho.

As evidências empíricas sugerem um forte componente sazonal no prêmio pela liquidez, uma vez que ele se mostrou positivo e estatisticamente significativo somente durante o mês de janeiro.

\section{c) Brennan et al (1998)}

Brennan et al (1998) investigaram se os retornos esperados das ações podem ser explicados por modelos construídos com base no fator beta de mercado e por outros oito fatores de risco: tamanho e índice B/M de Fama e French (1993); o preço da ação e Volume Financeiro de transações, que podem ser consideradas medidas de liquidez; três medidas de momento retornos passados - similares às utilizadas por Jegadeesh e Titman (1993) e Carhart (1997) e dividend yield.

A escolha do Volume Financeiro de transações como medida de liquidez foi justificada pelo fato de Petersen e Fialkowski (1994) evidenciarem que a medida bid-ask spread de Amihud e Mendelson (1986) não captura o spread efetivo e estava disponível somente em periodicidade anual na época da realização do estudo. Além disso, Stoll (1978) e Glosten e Harris (1988) trouxeram evidências que o Volume Financeiro de transações é um dos maiores indicadores da liquidez de mercado.

A amostra do estudo incluiu todas as ações listadas na NYSE, AMEX e NASDAQ de 1966 a 1995 e foram usadas ações individuais ao invés de carteiras para evitar o viés conhecido por 
data-snooping identificado por Roll (1977), Lo e MacKinlay (1990), Fama e French (1996) e Brennan et al (1995).

Os autores encontraram evidências para suportar o uso das medidas tamanho, índice B/M, momento e Volume Financeiro de transações (liquidez) como fatores de risco na explicação dos retornos das ações da amostra, mesmo depois do retorno ser ajustado pelos fatores de risco do modelo de Fama e French (1993). O Volume Financeiro de transações apresentou uma forte, persistente e negativa relação com a média dos retornos das ações, mesmo depois dos já mencionados ajustes, o que é consistente com a inclusão do prêmio pela liquidez em modelos de precificação de ativos.

\section{d) Datar et al (1998)}

Datar et al (1998) propuseram um teste alternativo ao modelo de liquidez de Amihud e Mendelson (1986) usando o Turnover - mensurado pelo número de ações negociadas dividido pelo número de ações outstanding - como proxy para liquidez.

Foram dois os motivos para os autores proporem uma nova medida de liquidez: i) a informação bid-ask spread é difícil de se obter em bases mensais por um longo período; ii) Petersen e Fialkowski (1994) mostraram que o spread cotado é uma proxy pobre para o efetivo spread.

As vantagens da nova medida proposta são essencialmente duas: i) há um forte apelo teórico, uma vez que Amihud e Mendelson (1986) provaram que, em equilíbrio, liquidez é altamente correlacionada com frequência de negociação; ii) os dados para cálculo são relativamente fáceis de se obterem, o que permite capturar a sua variação mensal e por longo horizonte temporal.

Com a amostra composta por empresas não financeiras listadas na NYSE de 1962 a 1991, os autores concluiram que os retornos das ações são funções decrescentes dos seus valores de Turnover e que essa relação persiste mesmo depois de os retornos serem controlados pelos fatores de risco tamanho, índice B/M e beta de mercado. Em contraste com os resultados de Eleswarapu e Reiganum (1993), os autores não encontraram evidências do efeito janeiro, uma 
vez que os retornos das ações se mostraram fortemente relacionados com Turnover ao longo de todos os meses do ano.

\section{e) Chordia et al (2001)}

Dada as evidências de estudos anteriores de que o nível de liquidez afeta o retorno das ações, Chordia et al (2001) trabalharam com a hipótese de que, num segundo momento, a liquidez poderia ser positivamente relacionada com os retornos dos ativos. Motivados por essa hipótese, os autores analisaram a relação entre os retornos esperados das ações e o nível e a volatilidade do trading activity como proxy para a liquidez.

A motivação para o uso da variabilidade do trading activity está baseada no fato de os agentes do mercado serem avessos ao risco e não desejarem fortes variações na liquidez do papel. Dessa forma, ações com grande variabilidade na liquidez deveriam apresentar altos retornos esperados.

A amostra foi composta por ações da NYSE, AMEX e NASDAQ de 1966 a 1995. Como medidas de trading activity foram usadas o Volume Financeiro negociado em dólares e o Turnover das ações.

Os resultados encontrados foram contrários às hipóteses levantadas: relação forte e negativa entre o retorno dos ativos e a variabilidade do Volume Financeiro de transações em dólares e do Turnover das ações, mesmo depois de controlados pelos efeitos tamanho, índice B/M, momento, nível de Volume Financeiro e Turnover. Esse efeito permaneceu mesmo depois dos testes de robustez dos modelos: i) testes separados para ações da NYSE, AMEX e NASDAQ e ii) verificação da existência de relações não lineares entre as medidas de liquidez e os retornos.

\section{f) Amihud (2002)}

Amihud (2002) aplicou a medida de liquidez conhecida como Return-to-Volume, dada pela a divisão do retorno absoluto diário da ação por seu volume diário negociado em dólares. Essa medida pode ser interpretada como uma resposta do preço associada com um dólar de volume, servindo, portanto, como uma proxy do impacto da liquidez nos preços. O próprio 
autor menciona que existem medidas de liquidez melhores como o bid-ask spread, porém seus cálculos dependem de dados indisponíveis ou disponíveis por um período muito curto, inviabilizando ou restringindo o seu uso em pesquisas acadêmicas.

Analisando ações da NYSE de 1964 a 1997 e usando tanto séries de tempo quanto relações cross-sections, o autor encontrou que o excesso de retorno: i) aumenta com a iliquidez esperada medida no período anterior e ii) diminui com a iliquidez inesperada do próprio período. Em outras palavras, tanto entre ativos quanto ao longo do tempo, o retorno esperado é função crescente da iliquidez esperada. Além disso, verificou que o efeito tamanho está relacionado a mudanças na liquidez agregada de mercado e que o fator liquidez afeta de forma forte o retorno das ações de empresas de pequeno porte.

\section{g) Acharya e Pedersen (2005)}

Acharya e Pedersen (2005) incluíram a medida de iliquidez de Amihud (2002) ao beta de mercado do CAPM constituindo o modelo batizado de Liquidity CAPM - LCAPM ou modelo de 2-fatores, conforme expresso pela Equação 5. A amostra foi composta por ações de empresas listadas na NYSE e AMEX de 1963 a 1999 e o uso de testes cross-section.

Em linhas gerais, os autores encontraram que o modelo se mostrou válido e superior ao CAPM tradicional em termos de explicação das variações dos retornos das ações da amostra. Evidenciaram, também, que o retorno esperado dos ativos depende da liquidez esperada, da covariância do seu próprio retorno e da liquidez com o retorno de mercado e liquidez. $\mathrm{O}$ modelo mostrou-se satisfatório quando as carteiras foram classificadas quanto à liquidez, variabilidade da liquidez e tamanho, mas falhou em explicar o efeito B/M.

\section{h) Liu (2006)}

Conforme Liu (2006), nos últimos anos os trabalhos acadêmicos sobre liquidez concentraramse em examinar a importância da liquidez em explicar o retorno cross-section das ações usando medidas de liquidez que focaram apenas uma das dimensões da liquidez. Assim, se a liquidez possui várias dimensões, concentrar-se em apenas uma é prover uma explicação apenas parcial dela. O autor ressalta que existem poucos estudos sobre a dimensão velocidade de transações. 
O trabalho de Liu (2006) compreendeu as ações ordinárias listadas nas bolsas NYSE, AMEX e NASDAQ de 1960 a 2003 e foi dividido em três partes. Na primeira é proposta uma nova medida de liquidez denominada standardized Turnover-adjusted number of zero daily trading volumes over the prior $x$ months - ou Volume Zero Padronizado, a qual capturaria múltiplas dimensões da liquidez, com especial ênfase na velocidade de transações, ou seja, continuidade de negociações e potencial atraso ou dificuldade em executar uma ordem. A nova medida de liquidez mostrou-se altamente correlacionada com as medidas de liquidez comumente utilizadas: Bid-ask spread, Turnover e Return-to-Volume.

A medida de Liu (2006) pode ser descrita pela fórmula abaixo:

$$
V Z P x=\left[Y+\frac{\frac{1}{(x-\text { monthsturnover })}}{\text { Deflator }}\right] \times \frac{21 x}{\text { NoTD }}
$$

Em que:

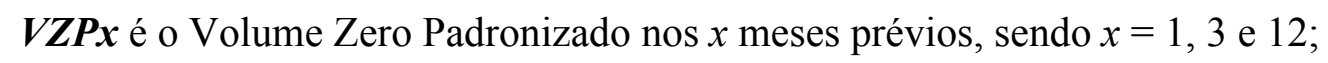

$\boldsymbol{Y}$ é a quantidade de dias com volume zero nos últimos $x$ meses, sendo $x=1,3 \mathrm{e} 12$, e captura a continuidade das transações e o potencial atraso ou dificuldade em executar uma ordem, ou seja, a dimensão velocidade da liquidez. A falta de transações indica o grau de iliquidez de uma ação. Em casos extremos de não transações, a medida captura lock-in-risk ou o risco da ação não poder ser vendida;

$\boldsymbol{x}$-months turnover é o Turnover nos $x$ meses prévios, sendo $x=1,3$ e 12, calculados pela soma do Turnover diário ao longo dos $x$ meses prévios. Turnover diário é o número de ações negociadas em 1 dia dividido pelo número de ações outstanding ao final do dia. É a dimensão da quantidade de transações. O autor justifica que o ajuste de Turnover permite distinguir ações que possuem o mesmo número de dias com volume zero nos últimos $x$ meses;

Deflator é escolhido de tal forma que: $0<\frac{1 /(x-\text { months turnover })}{\text { Deflator }}<1$;

NoTD é número total de dias de negociação no mercado ao longo dos $x$ meses prévios. Pelo fato de o número de dias de negociação nos meses variar de 15 a 23, a multiplicação pelo 
fator $\frac{21 x}{N O T D}$ padroniza o número de dias de negociação em 21 , o que faz a medida de liquidez comparável ao longo do tempo.

Como exemplo, o VZP1 pode ser interpretado como Volume Zero Padronizado ao longo dos 21 dias de transação anteriores e VZP12 como Volume Zero Padronizado ao longo dos 252 dias de transação anteriores.

A construção da medida $(V Z P)$ foi feita ao final de cada mês para cada ação individual com base em dados diários. Essa nova medida de liquidez captura múltiplas dimensões de liquidez, dando especial ênfase à velocidade de transação, o que a literatura vem ignorando ao longo dos anos.

Como principais resultados dessa primeira parte destacam-se: i) as ações que a nova medida de liquidez identificou como menos líquidas tendem a ser pequenas, value, de baixo Turnover, alto Bid-ask spread e alto Return-to-Volume, o que é consistente com a intuição; ii) a nova medida de liquidez pode prever o retorno das ações 1 ou mais anos para frente. $\mathrm{O}$ último decil das ações teve um desempenho superior em relação ao mais líquido dos decis por, em média, $0,682 \%$ por mês, considerando 12 meses de período de manutenção. Esse poder de predição não é específico de um subperíodo ou totalmente explicado pelo efeito janeiro, apesar do prêmio pela liquidez em janeiro ter sido cerca de $2 \%$ maior do que nos demais meses do ano; iii) para testar a robustez do prêmio pela liquidez encontrado com a nova medida, o autor efetuou os seguintes testes adicionais: a) análise de subamostra; b) ajustes pelo fatores de risco dos modelos CAPM e 3-fatores de Fama-French; c) análise de subperíodos e sazonalidade. O prêmio pela liquidez mostrou-se robusto em relação a todos esses testes adicionais.

Na segunda parte do artigo, o autor desenvolve um modelo de precificação de ativos de dois fatores: beta de mercado e liquidez que pode ser expresso pela Equação 5 do subcapítulo 2.5.1.

Os procedimentos estatísticos para a criação das carteiras e fatores de risco foram semelhantes aos adotados por Fama e French (1993) e Carhart (1997). No início de cada mês $t$, de julho de 1963 a julho de 2003, todas as ações da amostra foram classificadas em ordem ascendente 
baseado na medida de liquidez, VZP12. Então, foram criadas duas carteiras: i) low-liquidity, LL, que contém as ações menos líquidas e ii) high-liquidity, HL, que contém as ações mais líquidas. As duas carteiras LL e LH foram, então, mantidas por seis meses depois de sua formação. Então, o fator liquidez foi construído pelo lucro mensal de comprar \$1 de equally weighted LL e vender \$1 de equally weighted HL.

O fator liquidez mostrou-se com correlação forte e negativa com o mercado - quando a economia apresenta baixo desempenho, leva a liquidez a ser baixa e investidores requerem um alto prêmio pela liquidez para compensá-los. Na sequência, para examinar quão bem a carteira criada representa o fator risco de liquidez, o autor construiu uma medida de risco de liquidez geral de mercado e estimou as inovações na liquidez de mercado baseado na nova medida de liquidez proposta no artigo. A medida agregada de liquidez pareceu descrever as condições de liquidez do mercado e, obviamente, períodos de baixa liquidez são aqueles que seguem eventos econômicos e financeiros significativos como embargo do petróleo, crash da bolsa, entre outros. O modelo de 2-fatores de Liu (2006) apresentou-se superior ao CAPM e ao modelo de 3-fatores de Fama e French (1993).

$\mathrm{Na}$ terceira e última parte do estudo, Liu (2006) explorou o papel da liquidez em explicar as várias anomalias de preços documentadas pela literatura de finanças. $\mathrm{O}$ modelo de 2-fatores desenvolvido no artigo teve êxito em explicar as anomalias documentadas. Ele descreve o prêmio pela liquidez que tanto o CAPM quanto o modelo de 3-fatores falharam em capturar, além de incorporar os efeitos relativos a tamanho, índices B/M, cash-flow-to-price, earningsto-price, o dividend yield e investimentos contrários - momento. Em contraste, o CAPM foi pobre em explicar essas anomalias e o modelo de 3-fatores apenas apresentou um poder limitado nessas explicações. Em particular, além de falhar em capturar o prêmio pela liquidez, o modelo de 3-fatores não conseguiu explicar o efeito índice B/M. A conjectura de que o risco de liquidez captura risco de falência de forma mais direta que o tamanho ou índice B/M explica o melhor desempenho do modelo de 2-fatores.

\section{i) Keene e Petersen (2007)}

Keene e Petersen (2007) estudaram a importância da liquidez na explicação dos retornos das ações do mercado norte-americano com dados de 1963 a 2002, usando a metodologia de Fama e French (1993), ou seja, regressões em séries temporais. Os autores avaliaram a 
variável liquidez isoladamente e em conjunto com as variáveis beta de mercado, tamanho, índice B/M e momento, na construção de modelos de precificação de ativos.

As medidas de liquidez utilizadas foram: Volume Financeiro, Turnover, Desvio-padrão do Volume Financeiro, Desvio-padrão do Turnover, Coeficiente de Variação do Volume Financeiro e Coeficiente de Variação do Turnover, porém a maior parte dos resultados foram analisados considerando o Turnover.

Os principais resultados encontrados mostraram que a liquidez é precificada e constitui-se em parte da explicação da variação dos retornos das ações no mercado norte-americano. Os outros quatro fatores também se mostraram importantes e a presença da liquidez alterou o efeito deles. A maioria dos interceptos apresentou-se significante, indicando que ainda há parte da variação dos retornos não explicada por esses cinco fatores.

\section{j) Nguyen et al (2007)}

Nguyen et al (2007) levantaram a questão do CAPM capturar o risco pela liquidez e compararam esse modelo com um modelo de precificação composto pelas variáveis do modelo de Fama e French (1993) - beta de mercado, tamanho e índice B/M - mais a liquidez - usando a medida de Turnover proposta por Pastor e Stambaugh (2003).

Com amostra composta pelas ações da NYSE, AMEX e NASDAQ, de 1963 a 2004, os autores concluíram que as ações menos líquidas demandam alto retorno e que essa relação não é capturada pelas outras variáveis consideradas.

\section{k) Sanvicente e Minardi (1998)}

Baseado em depoimentos de gestores de fundos de ações bem classificados na análise efetuada pelo Instituto Brasileiro de Mercado de Capitais, que argumentaram que a razão de seu bom desempenho no primeiro trimestre de 1998 havia sido a ênfase em ações de segunda linha, Sanvicente e Minardi (1998) tiveram como objetivo comprovar se realmente existe um prêmio por falta de liquidez no mercado acionário brasileiro. Com dados da BM\&FBOVESPA de 11 quadrimestres, de setembro de 1994 a abril de 1998, por meio do método de carteiras, 
análise de correlações de postos de Spearman e regressões lineares, e tendo como medida de liquidez o Índice de Negociabilidade da BM\&FBOVESPA definido por Paula Leite e Sanvicente (1995), os autores concluíram que:

[...] ao contrário da crença explicitada na introdução, não parece haver prêmio por falta de liquidez, medida a liquidez da maneira usualmente praticada em nosso mercado. No período analisado, foram justamente as ações mais negociadas cuja rentabilidade foi mais elevada, ajustando-se a análise pela influência de diferenças de risco. Deste ponto de vista, portanto, não há evidências de que exista, em nosso mercado a anomalia proposta pelos administradores de fundos entrevistados pela imprensa no primeiro trimestre de 1998. (SANVICENTE e MINARDI, 1998, p. 10).

\section{l) Bruni e Famá (1998)}

Bruni e Famá (1998) avaliaram as ações negociadas na BM\&FBOVESPA, de 1988 a 1997. Utilizando como medida de liquidez o Índice de Negociabilidade da BM\&FBOVESPA, foram formadas 25 carteiras, recalculadas anualmente. Para cada carteira foram obtidos os retornos, os betas de mercado e o Índice de Negociabilidade médios. Na sequência, as variáveis foram utilizadas numa regressão cross-section. Os resultados mostraram uma associação negativa e significante entre os retornos e a liquidez, medida pelo Índice de Negociabilidade.

\section{m) Jung et al (2003)}

Jung et al (2003) documentaram o papel da liquidez em 27 mercados emergentes, de 1992 a 1999. Os autores encontraram que o retorno das ações está positivamente correlacionado com medidas agregadas de liquidez - Turnover e Volume Financeiro -, contrariando as evidências da maioria dos testes observados em mercados de países desenvolvidos. Os resultados mostraram-se robustos mesmo depois de controlados pelo beta de mercado, tamanho e índice price-to-book.

\section{n) Chan e Faff (2005)}

Chan e Faff (2005) analisaram a relação da liquidez com o retorno das ações no mercado australiano de 1990 a 1998, adicionando o fator liquidez - Turnover das ações - ao modelo de 
3-fatores de Fama e French (1993). Os autores encontraram prêmios positivos e estatisticamente significantes para os fatores beta de mercado, tamanho, índice B/M e liquidez (Turnover), além de fortes evidências a favor da validade do modelo de 4-fatores sugerido.

\section{o) Bekaert et al (2007)}

Bekaert et al (2007) estudaram a relação entre liquidez e retorno das ações em 19 mercados emergentes, incluindo o Brasil, de 1987 a 2003. Os autores utilizaram uma medida de liquidez de fácil obtenção baseada nos estudos de Lesmond (2005) e Lesmond et al (1999): the proportion of daily zero firm return averaged over the month, que se mostrou positivamente correlacionada com bid-ask spread e negativamente correlacionada com Turnover. Os autores encontraram evidências favoráveis no sentido de que a medida de liquidez adotada prediz os retornos de forma significante nos mercados estudados.

\section{p) Vieira e Milach (2008)}

Vieira e Milach (2008) buscaram descrever o comportamento das medidas de liquidez e iliquidez e avaliar o papel da liquidez na precificação das ações no mercado brasileiro de 1995 a 2005, usando regressões lineares por meio da metodologia de Fama e Macbeth (1973).

Os autores avaliaram diferentes medidas de liquidez: Volume Financeiro negociado, Quantidade de Títulos negociados, Quantidade de Negócios, Spread, Turnover e Return-toVolume. Vale a ressalva de que a medida de spread adotada não é o bid-ask spread usado na literatura internacional e sim a diferença entre preço máximo e mínimo da ação dividida pelo preço médio.

As médias dos coeficientes de correlação entre as medidas de liquidez foram positivas, porém de baixa magnitude, denotando o caráter multidimensional da liquidez.

Foram testados doze modelos, seis deles usando o beta de mercado e cada uma das medidas de liquidez/iliquidez como variáveis explicativas e os seis seguintes incorporaram aos modelos as variáveis valor de mercado, volatilidade e dividend yield. 
Nos modelos de precificação, a maioria dos coeficientes das variáveis de liquidez não foram significativas, apenas as variáveis iliquidez - Return-to-Volume e Spread apresentaram significância. Os resultados não se mostraram influenciados pelo efeito janeiro.

\section{q) Correia et al (2008)}

Correia et al (2008) verificaram se há efeitos da liquidez na determinação da rentabilidade de mercado das ações negociadas no mercado acionário brasileiro como fator adicional ao beta de mercado, ao índice valor patrimonial por ação dividido pelo preço e ao tamanho. A amostra compreendeu as ações da BM\&FBOVESPA, de 1995 a 2004. As medidas de liquidez utilizadas foram: Turnover, Volume Financeiro e Quantidade de Negócios.

Os resultados revelaram a existência de uma associação linear positiva e estatisticamente significativa entre o retorno e a liquidez das ações com todas as medidas de liquidez testadas, contrariando as evidências da maioria dos testes observados em mercados de países desenvolvidos e corroborando as evidência de Jung et al (2003) para países emergentes, incluindo o Brasil.

\section{r) Lam e Tam (2011)}

Lam e Tam (2011) estudaram o papel da liquidez na precificação dos retornos dos ativos no mercado de Hong Kong com dados de 1981 a 2004. Utilizaram nove das mais conhecidas medidas de liquidez - Turnover, Volume Financeiro, volatilidade do Turnover, volatilidade do Volume Financeiro, Coeficiente de Variação do Turnover, Coeficiente de Variação do Volume Financeiro, medida de liquidez de Pastor e Stambaugh (2003), o Return-to-Volume de Amihud (2002) e o Volume Zero Padronizado de Liu (2006).

Com metodologia de regressões em séries temporais, encontraram evidências de que a liquidez é um importante fator na precificação de ativos, mesmo depois de controlada por outros fatores de risco como o tamanho, o índice B/M e o momento. Testaram diferentes modelos de precificação de ativos compostos pelas várias combinações de fatores de risco: beta de mercado, tamanho, índice B/M, momento e liquidez. O melhor modelo foi o composto pelos fatores beta de mercado, tamanho, índice B/M e liquidez. Por outro lado, o fator momento não pareceu ser precificado no mercado de Hong Kong. 


\section{s) Lee (2011)}

Lee (2011) replicou o trabalho de Acharya e Pedersen (2005) em um nível global, com ações de 50 países desenvolvidos e emergentes, incluindo o Brasil, de 1988 a 2007. O autor encontrou evidências de que o risco pela liquidez é precificado independente do risco de mercado nos mercados financeiros internacionais. Adicionalmente, indicou que o mercado norte-americano é um importante direcionador do risco de liquidez global. O preço pela liquidez variou ao longo dos países conforme fatores como posições geográficas e condições dos ambientes econômico e político.

\section{t) Machado e Medeiros (2011)}

Machado e Medeiros (2011) verificaram a existência de prêmio pela liquidez no mercado acionário brasileiro de 1995 a 2008 e analisaram se a liquidez poderia ser um fator adicional aos fatores beta de mercado, tamanho, índice B/M e momento na explicação das variações dos retornos das ações. Foram testadas cinco medidas de liquidez - Turnover, Volume Financeiro, Quantidade de Negócios, Índice de Negociabilidade e a medida de Liu (2006), Volume Zero Padronizado - todas obtidas pela média anual dos valores mensais dos 12 meses anteriores aos de formação das carteiras. O período de retenção das ações nas carteiras também foi de 12 meses.

Os resultados encontrados mostraram que as variáveis Turnover e a medida de Liu (2006) não apresentaram prêmios significativos; as variáveis Quantidade de Negócios e Índice de Negociabilidade, significância marginal; e somente a variável Volume Financeiro apresentou prêmio significativo ao nível de $5 \%$, não restrito ao mês de janeiro. Todas as medidas de liquidez mostraram-se altamente correlacionadas, com exceção do Turnover.

Em relação aos testes de modelos de precificação de ativos, foram utilizadas regressões lineares múltiplas em séries de tempo e as principais conclusões foram que:

- o CAPM mostrou-se o modelo menos adequado na explicação dos retornos; 
- a inclusão dos fatores tamanho e índice B/M de Fama e French (1993), que foram significativos em todas as carteiras, aumentaram o poder explicativo do modelo de todas as carteiras quando comparado aos resultados do CAPM - em média 7\%;

- a inclusão do fator momento de Carhart (1997), que se mostrou significativo em todas as carteiras, aumentou o poder explicativo dos modelos quando comparado aos resultados do modelo de 3-fatores de Fama e French (1993) - em média 1,5\%;

- a inclusão da liquidez, que se mostrou significativa na maioria das carteiras, melhorou o poder explicativo do retorno das carteiras quando comparado aos resultados do modelo de 4-fatores de Carhart (1997) - em média 1,7\%. Em outras palavras, os resultados evidenciaram a superioridade do modelo de 5-fatores na explicação dos retornos das ações no mercado brasileiro.

\section{u) Lischewski e Voronkova (2012)}

Lischewski e Voronkova (2012) buscaram evidências de fatores que explicassem os retornos das ações em mercados emergentes, focando em mercados acionários de países da Europa Central e Oriental. Além de beta de mercado, tamanho, índice B/M, os autores estudaram se a liquidez era um fator de risco precificado, com base em dados de 1996 a 2009. As medidas de liquidez utilizadas foram: i) a proporção de dias com zero volume; ii) Turnover; iii) a medida de Liu (2006); iv) Return-to-Volume e v) Spread efetivo.

Os resultados encontrados suportam a relevância dos fatores beta de mercado, tamanho e índice B/M na explicação dos retornos das ações. Porém, contrariando os resultados obtidos em testes nos mercados desenvolvidos, os autores não encontraram evidências que suportassem a hipótese de que a liquidez seria um fator de risco em países emergentes.

\subsubsection{As possíveis causas do prêmio pela liquidez}

A literatura internacional conjectura algumas possíveis causas da existência de prêmios pela liquidez. Liu (2006) agrupou-as da seguinte forma:

i) a liquidez mostra-se relevante quando a economia estiver em recessão ou houver a expectativa de entrar (LIU, 2006; PASTOR e STAMBAUGH, 2003). Do ponto de vista 
de asset allocation, investidores com aversão ao risco preferem investir em ações menos arriscadas e mais líquidas se estão antecipando uma recessão. Essa argumentação parece consistente com: a) a noção de preferência pela liquidez de Hick (1967), que propõe que os investidores mantinham ativos financeiros não somente com o objetivo de retorno, mas também para facilitar ajustes na carteira motivados por alterações nas condições econômicas; b) Chordia et al (2005), que mostram que a liquidez está associada a políticas monetárias;

ii) a assimetria de informações pode criar iliquidez. Se investidores comuns tomam conhecimento de que existem investidores com informações privilegiadas no mercado, provavelmente optarão por não negociar, o que restringirá a liquidez do papel (BRENNAN e SUBRAHMANYAM, 1996).

iii) as próprias empresas podem causar iliquidez, à medida que os investidores evitem manter ações de empresas que apresentem grandes probabilidades de quebra ou possuam um corpo gerencial de competência questionável. 


\section{METODOLOGIA}

Nesse capítulo são descritos os procedimentos metodológicos utilizados nesta pesquisa. Inicialmente, são detalhadas população, amostra e coleta de dados. A sequência está separada em duas partes: i) procedimento para cálculo e testes das medidas e prêmios pela liquidez e ii) testes dos modelos de precificação de ativos. Os subitens dentro de cada uma dessas duas partes detalham as fórmulas e as variáveis utilizadas, os procedimentos de testes das medidas de liquidez e dos modelos de precificação de ativos, bem como os testes de robustez adotados.

Em linhas gerais, no presente estudo foram usadas todas as ações listadas na Bolsa de Valores do Estado de São Paulo - BM\&FBOVESPA, de julho de 1995 a novembro de 2011. A metodologia adotada para a verificação dos prêmios pela liquidez foi essencialmente a mesma utilizada por Liu (2006): formação de carteiras baseadas nas medidas de liquidez e posterior manutenção e cálculo dos retornos acumulados, sendo que o prêmio pela liquidez foi verificado pela diferença do retorno das carteiras menos líquidas e o retorno das carteiras mais líquidas. Foi utilizado o teste $t$ de comparação de médias - one sample $t$ - para estimativa da significância estatística dos prêmios. Na construção dos modelos de precificação de ativos, a metodologia de formação das carteiras foi também essencialmente a mesma utilizada por Liu (2006), ou seja, carteiras formadas com base em decis, conforme a liquidez das ações. O prêmio pelo fator liquidez foi calculado conforme a metodologia sugerida por Liu (2006). Os prêmios pelos fatores de risco beta de mercado, tamanho e índice B/M foram calculados essencialmente seguindo os procedimentos do estudo de Fama e French (1993). Os prêmios pelo fator de risco momento foram calculados considerando a estratégia de momento de Jegadeesh e Titman (1993) e Carhart (1997). Para teste e validação dos modelos de precificação foi utilizada a metodologia de regressões em duas etapas de Fama e Macbeth (1973), que é essencialmente a mesma adotada por Amihud e Mendelson (1986), Eleswarapu e Reiganum (1993), Brennan et al (1998), Datar et al (1998), Chordia et al (2001), Amihud (2002), Acharya e Pedersen (2005) e Nguyen et al (2007), em seus estudos sobre liquidez. A significância dos coeficientes de cada fator foi testada por meio da estatística $t$ nas regressões cross-sections. A comparação entre os modelos foi feita pela análise dos coeficientes dos fatores e pelos coeficientes de determinação ajustados, $\operatorname{Adj} . R^{2}$, das regressões. 


\subsection{População e Amostra}

A população analisada foi constituída por todas as ações listadas na BM\&FBOVESPA entre julho de 1995 e novembro de 2011. Utilizou-se esse período devido à maior estabilidade da economia brasileira após o Plano Real.

Foram efetuadas as seguintes exclusões:

i) Ações que não apresentavam cotações mensais consecutivas para o período de $x$ meses anteriores e $x$ meses posteriores ao do mês de cálculo das medidas de liquidez, em que $x$ pode assumir o valor de 1, 3, 6 e 12 meses, dependendo do horizonte temporal da medida empregada. Os meses anteriores foram necessários para o cálculo das medidas de liquidez e, os posteriores, para o cálculo dos retornos acumulados das carteiras. Optou-se por utilizar diferentes períodos de cálculos das medidas e retenção das carteiras, para evitar possíveis vieses de seleção amostral. Por exemplo, considerar 12 meses para cálculo das medidas e mais 12 meses para retenção das carteiras, iria requerer 24 meses de cotações mensais consecutivas, certamente levando à exclusão das ações menos líquidas, podendo distorcer os resultados da pesquisa.

ii) Para testes que envolveram valor de mercado - VM:

- para empresas que possuíam ações de classe ON - Ordinárias - e PN - Preferenciais -, adotou-se o mesmo procedimento de Málaga e Securato (2004), qual seja: calculou-se o valor de mercado pelo somatório das duas classes, $\mathrm{ON}$ e PN, apenas quando ambas estavam presentes na amostra. Caso contrário, considerou-se apenas o valor de mercado da classe do papel constante na amostra.

iii) Para testes que envolveram o índice $\mathrm{B} / \mathrm{M}$ :

- ações de empresas com Patrimônio Líquido negativo ao final de cada trimestre de cada ano; 
- ações de empresas financeiras devido a seu alto grau de endividamento, característico do setor. A exclusão decorre da influência que o endividamento tem sobre o índice B/M e do fato de o endividamento de empresas financeiras não ter o mesmo significado do endividamento de empresas não-financeiras.

Faz-se importante destacar que o período amostral foi levemente restringido ao longo dos procedimentos empíricos, dependendo da necessidade do uso de dados retroativos e futuros para cálculo das variáveis e manutenção das ações nas carteiras em determinado mês. Por exemplo, para cálculo das variáveis dependentes e independentes para os testes empíricos dos modelos de precificação de ativos foram considerados rebalanceamentos semestrais das carteiras - nos meses de junho e dezembro de cada ano. Assim, em cada um desses meses utilizaram-se os dados dos últimos 6 meses para cálculo das variáveis e criação das carteiras que, por sua vez, foram mantidas por mais 6 meses. Neste caso, o primeiro mês para cálculo das variáveis foi dezembro de 1995 (com a utilização de dados passados desde julho de 1995, início da amostra) e o último mês foi dezembro de 2010 (com as carteiras mantidas até junho de 2011).

Diante do tratamento detalhado acima, note-se que a amostra desta pesquisa não está livre do viés de sobrevivência. Porém, esse efeito foi bastante diminuído pelo fato de as carteiras serem rebalanceadas periodicamente e não mantidas iguais durante todo o período. $\mathrm{O}$ rebalanceamento foi mensal no caso dos testes para verificação dos prêmios pela liquidez e semestral no caso da construção das carteiras de ações e dos fatores de risco nos testes dos modelos de precificação de ativos.

\subsection{Coleta de dados}

Esta pesquisa utilizou-se dos dados secundários detalhados no Quadro 4, extraídos do banco de dados Economática ${ }^{\circledR}$ : 
Quadro 4 - Descrição dos dados utilizados na pesquisa

\begin{tabular}{|l|c|}
\hline \multicolumn{1}{|c|}{ Descrição dos dados } & Periodicidade \\
\hline Cotação do preço médio, mínimo, máximo e de fechamento das & \\
ações das empresas listadas na BM\&FBOVESPA & Diária \\
\hline Quantidade de negócios efetuados por ação & Diária \\
\hline Quantidade de ações outstanding por ação & Diária \\
\hline Quantidade de títulos negociados por ação & Diária \\
\hline Volume em Reais negociado por ação & Diária \\
\hline Patrimônio Líquido e demais dados contábeis por empresa & Trimestral \\
\hline Valor de mercado por ação & Diária \\
\hline Retorno da Caderneta de Poupança & Mensal \\
\hline Dividendos distribuídos por ação & Mensal \\
\hline Número de dias úteis & Mensal \\
\hline
\end{tabular}

Os cálculos estatísticos foram processados utilizando o sistema estatístico Statistical Package for Social Sciences (SPSS), versão 17.

\subsection{Cálculo e testes das medidas e prêmios pela liquidez}

Nos subcapítulos abaixo são detalhadas as medidas de liquidez utilizadas, bem como os procedimentos para teste da existência de prêmio pela liquidez.

\subsubsection{Detalhamento das medidas de liquidez}

A presente pesquisa testou uma vasta gama de medidas de liquidez mais comumente utilizadas na literatura internacional sobre o tema, considerando diferentes períodos para cálculos das medidas e para a retenção das carteiras. As medidas estão detalhadas no Quadro 5. Cada uma delas foi calculada mensalmente para todas as ações constantes da amostra. 
Quadro 5 - Detalhamento das medidas de liquidez utilizadas na pesquisa.

O quadro abaixo detalha as medidas de liquidez utilizadas na pesquisa. A coluna Medida denomina o nome da medida de liquidez. Detalhamento apresenta a explicação pormenorizada do cálculo das medidas e os Códigos são as diferentes medidas que se formam conforme o emprego dos $x$ meses prévios usados para cálculo, sendo $x=1,3,6$ e 12 meses. Por exemplo, VOL1, VOL3, VOL6 e VOL12, referem-se aos somatórios dos volumes financeiros negociados de determinada ação em Reais nos 1, 3, 6 e 12 meses prévios, respectivamente. A coluna Referências menciona quais estudos anteriores utilizaram a medida. LIQ/ILIQ indica se a medida é de liquidez ou de iliquidez, respectivamente. ** significa que a medida é de variabilidade da liquidez. Dimensão prioritária é a dimensão da liquidez que é prioritariamente capturada pela medida, conforme sugerido pelos autores que as desenvolveram ou as utilizaram. Ressalte-se que essas associações entre medida e dimensão prioritária podem conter distorções em função da multidimensionalidade que permeia o conceito de liquidez.

\begin{tabular}{|c|c|c|c|c|c|}
\hline Medida & Detalhamento & Códigos & Referências & $\begin{array}{l}\text { LIQ / } \\
\text { ILIQ }\end{array}$ & Dimensão prioritária \\
\hline Volume Financeiro & $\begin{array}{l}\text { Somatório do Volume Financeiro negociado de } \\
\text { determinada ação em reais nos } x \text { meses prévios. } \\
\text { Sendo que } x=1,3 \text {, } 6 \text { e } 12 \text { meses }\end{array}$ & $\begin{array}{l}\text { VOL1, } \\
\text { VOL3, } \\
\text { VOL6 e } \\
\text { VOL12 }\end{array}$ & $\begin{array}{c}\text { Brennan et al (1998), } \\
\text { Keene e Petersen } \\
(2007), \text { Jung et al } \\
\text { (2003), Vieira e } \\
\text { Milach (2008), } \\
\text { Correia et al (2008), } \\
\text { Lam e Tam (2011), } \\
\text { Machado e Medeiros } \\
\text { (2011) }\end{array}$ & LIQ & Quantidade de transações \\
\hline Quantidade de Negócios & $\begin{array}{l}\text { Somatório da Quantidade de Negócios efetuados nos } x \\
\text { meses prévios. } \\
\text { Sendo que } x=1,3,6 \text { e } 12 \text { meses }\end{array}$ & $\begin{array}{l}\text { QN1, QN3, } \\
\text { QN6 e } \\
\text { QN12 }\end{array}$ & $\begin{array}{l}\text { Vieira e Milach } \\
\text { (2008), Correia et al } \\
\text { (2008), Machado e } \\
\text { Medeiros (2011) }\end{array}$ & LIQ & Quantidade de transações \\
\hline Quantidade de Títulos & $\begin{array}{l}\text { Somatório da Quantidade de Títulos negociados nos } x \\
\text { meses prévios. } \\
\text { Sendo que } x=1,3,6 \text { e } 12 \text { meses }\end{array}$ & $\begin{array}{l}\text { QT1, QT3, } \\
\text { QT6 e } \\
\text { QT12 }\end{array}$ & $\begin{array}{l}\text { Vieira e Milach } \\
\quad(2008)\end{array}$ & LIQ & Quantidade de transações \\
\hline Número de dias sem transações & $\begin{array}{l}\text { Número de dias sem transações nos } x \text { meses prévios. } \\
\qquad \text { Sendo que } x=1,3,6 \text { e } 12 \text { meses }\end{array}$ & $\begin{array}{l}\text { NTD1, } \\
\text { NTD3, } \\
\text { NTD6 e } \\
\text { NTD12 }\end{array}$ & $\begin{array}{l}\text { Bekaert et al (2007), } \\
\text { Lischewski e } \\
\text { Voronkova (2012) }\end{array}$ & ILIQ & Velocidade de transações \\
\hline Return-to-Volume & $\begin{array}{c}\text { Para } \mathrm{x}=1 \text { mês: Retorno mensal da ação dividido pelo } \\
\text { somatório do volume negociado em Reais no mesmo mês. } \\
\begin{array}{c}\text { Para } \mathrm{x}= \\
3,6 \text { e } 12 \text { meses: Média do Return-to-Volume dos } \\
\text { 3, } 6 \text { e } 12 \text { meses prévios, respectivamente. }\end{array}\end{array}$ & $\begin{array}{l}\text { RtoV1, } \\
\text { RtoV3, } \\
\text { RtoV6 e } \\
\text { RtoV12 }\end{array}$ & $\begin{array}{c}\text { Amihud (2002), } \\
\text { Acharya e Pedersen } \\
\text { (2005), Liu (2006), } \\
\text { Lam e Tam (2011), } \\
\text { Lee (2011), } \\
\text { Lischewski e } \\
\text { Voronkova (2012) }\end{array}$ & ILIQ & Impacto nos preços \\
\hline
\end{tabular}




\begin{tabular}{|c|c|c|c|c|c|}
\hline Medida & Detalhamento & Códigos & Referências & $\begin{array}{l}\text { LIQ / } \\
\text { ILIQ }\end{array}$ & Dimensão prioritária \\
\hline Turnover & $\begin{array}{c}\text { Para } x=1 \text { mês: somatório da quantidade de ações } \\
\text { negociadas no mês dividido pela quantidade de ações } \\
\text { outstanding no último dia do mês. } \\
\text { Para } x=3,6 \text { e } 12 \text { meses: média do Turnover dos } 3,6 \text { e } 12 \\
\text { meses prévios, respectivamente. }\end{array}$ & $\begin{array}{c}\text { TO1, TO3, } \\
\text { TO6 e } \\
\text { TO12 }\end{array}$ & $\begin{array}{l}\text { Datar et al (1998), } \\
\text { Liu (2006), Keene e } \\
\text { Petersen (2007), } \\
\text { Nguyen et al (2007), } \\
\text { Jung et al (2003), } \\
\text { Chan e Faff (2005), } \\
\text { Bekaert et al (2007), } \\
\text { Vieira e Milach } \\
\text { (2008), Correia et al } \\
\text { (2008), Lam e Tam } \\
\text { (2011), Machado e } \\
\text { Medeiros (2011), } \\
\text { Lischewski e } \\
\text { Voronkova (2012) } \\
\end{array}$ & LIQ & Quantidade de transações \\
\hline Volume Zero Padronizado & 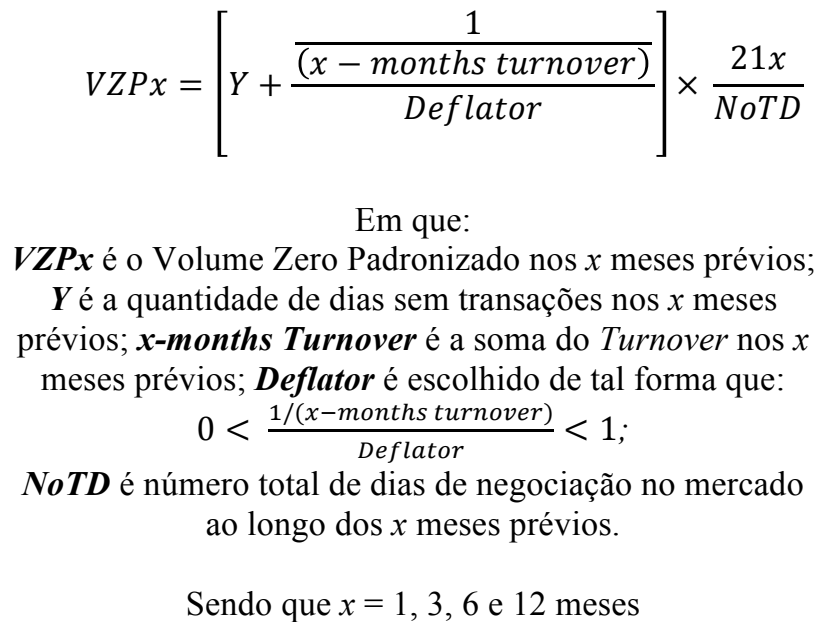 & $\begin{array}{l}\text { VZP1, } \\
\text { VZP3, } \\
\text { VZP6 e } \\
\text { VZP12 }\end{array}$ & $\begin{array}{c}\text { Liu (2006), Lam e } \\
\text { Tam (2011), Machado } \\
\text { e Medeiros (2011), } \\
\text { Lischewski e } \\
\text { Voronkova (2012) }\end{array}$ & ILIQ & $\begin{array}{l}\text { Múltiplas, com ênfase na } \\
\text { velocidade de transações }\end{array}$ \\
\hline
\end{tabular}




\begin{tabular}{|c|c|c|c|c|c|}
\hline \multicolumn{6}{|c|}{ Quadro 5 - Detalhamento das medidas de liquidez utilizadas na pesquisa. Continuação. } \\
\hline Medida & Detalhamento & Códigos & Referências & $\begin{array}{l}\text { LIQ / } \\
\text { ILIQ }\end{array}$ & Dimensão prioritária \\
\hline $\begin{array}{c}\text { Índice de Negociabilidade da } \\
\text { BM\&FBOVESPA }\end{array}$ & $\begin{array}{l}\qquad I N t=\sqrt{\frac{n i, t}{N, t} \times \frac{v i, t}{V, t}} \\
\text { IN,t é o Índice de Negociabilidade, no mês } t \text {; ni,t é o } \\
\text { número de negócios com a ação } i \text { no mercado à vista, no } \\
\text { mês } t ; \mathbf{N}, \mathbf{t} \text { é o número total de negócios no mercado à } \\
\text { vista, no mês } t \text {; vi,t é o volume financeiro gerado pelos } \\
\text { negócios com a ação } i \text { no mercado à vista, no mês } t ; \mathbf{V}, \mathbf{t} \text { é } \\
\text { o volume financeiro total do mercado à vista da } \\
\text { BM\&FBOVESPA, no mês } t \text {. }\end{array}$ & $\begin{array}{l}\text { NEG1, } \\
\text { NEG3, } \\
\text { NEG6 e } \\
\text { NEG12 }\end{array}$ & $\begin{array}{l}\text { Sanvicente e Minardi } \\
\text { (1998), Bruni e Famá } \\
\text { (1998), Machado e } \\
\text { Medeiros (2011) }\end{array}$ & LIQ & Quantidade de transações \\
\hline Desvio-padrão do Turnover & $\begin{array}{l}\text { Desvio-padrão do Turnover dos } x \text { meses prévios. } \\
\qquad \text { Sendo que } x=3,6 \text { e } 12 \text { meses }\end{array}$ & $\begin{array}{l}\text { DPTO3, } \\
\text { DPTO6 e } \\
\text { DPTO12 }\end{array}$ & $\begin{array}{l}\text { Chordia et al (2001), } \\
\text { Keene e Petersen } \\
(2007), \text { Jung et al } \\
(2003), \text { Lam e Tam } \\
(2011)\end{array}$ & $* *$ & Volatilidade da liquidez \\
\hline $\begin{array}{l}\text { Desvio-padrão do Volume } \\
\text { Financeiro }\end{array}$ & $\begin{array}{l}\text { Desvio-padrão do Volume Financeiro dos } x \text { meses } \\
\text { prévios. } \\
\text { Sendo que } x=3,6 \text { e } 12 \text { meses }\end{array}$ & $\begin{array}{l}\text { DPVOL3, } \\
\text { DPVOL6 e } \\
\text { DPVOL12 }\end{array}$ & $\begin{array}{l}\text { Chordia et al }(2001) \text {, } \\
\text { Keene e Petersen } \\
(2007), \text { Lam e Tam } \\
\text { (2011) }\end{array}$ & $* *$ & Volatilidade da liquidez \\
\hline $\begin{array}{c}\text { Coeficiente de Variação do } \\
\text { Turnover }\end{array}$ & $\begin{array}{l}\text { Coeficiente de Varição do Turnover dos } x \text { meses prévios. } \\
\qquad \text { Sendo que } x=3,6 \text { e } 12 \text { meses }\end{array}$ & $\begin{array}{l}\text { CVTO3, } \\
\text { CVTO6 e } \\
\text { CVTO12 }\end{array}$ & $\begin{array}{l}\text { Chordia et al }(2001) \text {, } \\
\text { Keene e Petersen } \\
(2007), \text { Lam e Tam } \\
(2011)\end{array}$ & $* *$ & Volatilidade da liquidez \\
\hline $\begin{array}{l}\text { Coeficiente de Variação do } \\
\text { Volume Financeiro }\end{array}$ & $\begin{array}{l}\text { Coeficiente de Variação do Volume Financeiro dos } x \\
\text { meses prévios. } \\
\text { Sendo que } x=3,6 \text { e } 12 \text { meses }\end{array}$ & $\begin{array}{c}\text { CVVOL3, } \\
\text { CVVOL6 } \\
\text { e } \\
\text { CVVOL12 }\end{array}$ & $\begin{array}{c}\text { Chordia et al }(2001) \text {, } \\
\text { Keene e Petersen } \\
(2007), \text { Lam e Tam } \\
(2011)\end{array}$ & $* *$ & Volatilidade da liquidez \\
\hline
\end{tabular}




\subsubsection{Procedimento para verificação dos prêmios pela liquidez}

Antes de se proceder com os testes para verificação dos prêmios pela liquidez, foram calculadas as correlações entre as diferentes medidas considerando cada um dos períodos de cálculo e manutenção das ações na carteira. Os resultados são apresentados no Apêndice 1. O objetivo foi a eliminação de medidas altamente correlacionadas entre si, visando à simplificação na sequência dos testes da pesquisa. Seguindo Sanvicente e Minardi (1998) e Liu (2006) optou-se por utilizar o teste de correlação de postos de Spearman, devido a grande quantidade de valores extremos presentes nas séries de dados, ocasionados pelo fato de as medidas de liquidez não serem padronizadas - sendo que a única exceção é o Volume Zero Padronizado (VZP) de Liu (2006).

Seguindo os mesmos passos de Liu (2006), no início de cada mês $t$, de julho de 1995 a novembro de 2011, todas as ações da amostra foram classificadas de forma independente conforme cada uma das medidas de liquidez mantidas na pesquisa. Assim, os passos descritos abaixo foram repetidos para cada medida de liquidez considerada. A amostra foi, então, separada em 10 carteiras formadas por decis conforme o valor da medida de liquidez adotada. Foram calculados os retornos acumulados equally weighted de cada carteira, considerando diferentes períodos de retenção - 1, 3, 6 e 12 meses. O cálculo dos retornos médios pelo método equally weighted é sugerido por Amihud (2002) e Pastor e Stambaugh (2003) e utilizado também por Liu (2006) para evitar que o retorno das carteiras seja fortemente influenciado por retornos de empresas de grandes portes as quais normalmente apresentam alta liquidez. Finalmente, foi calculada a diferença entre os retornos das carteiras extremas, ou seja, a de menor liquidez menos a de maior liquidez, para verificação da existência de prêmio pela liquidez. Seguindo Liu (2006), foi utilizada a estatística $t$ - teste one-sample $t$ para averiguação da significância dos prêmios.

Ressalte-se que, como as carteiras são reformuladas mensalmente, os procedimentos descritos acima capturam alterações na liquidez dos papéis ao longo do tempo. Essas alterações podem ser motivadas pela própria empresa emissora, como os splits e bônus, por exemplo. Em exemplo de split, a ação pode ganhar liquidez e migrar de uma carteira menos líquida para outra mais líquida já no mês subquente ao mês do split. 


\subsubsection{Testes de robustez dos prêmios pela liquidez}

Para a execução de testes de robustez dos prêmios pela liquidez foram efetuados três procedimentos independentes: i) análise de subamostras; ii) análise de subperíodos e iii) análise de sazonalidade.

A análise de subamostras constitui-se em separações independentes da amostra conforme o tamanho da empresa, o índice $B / M$ e o momento. De acordo com cada uma dessas variáveis, a amostra foi estratificada em cinco partes (quintis).

Vale ressaltar que, no caso das segregações com base no índice B/M, os procedimentos foram feitos de duas formas alternativas. A primeira considerou todo o período amostral, ou seja, de julho de 1995 a novembro de 2011. A segunda considerou o período anterior ao início das alterações da legislação contábil no rumo às normas internacionais de contabilidade, de julho de 1995 a dezembro de 2007. Esse procedimento fez-se necessário, pois as alterações contábeis podem ter ocasionado modificações no patrimônio líquido das empresas e, consequentemente, no índice B/M. O período amostral mais recente, de janeiro de 2008 a novembro de 2011, não foi usado para testes independentes dos demais, pois sobrariam quantidade insuficiente de dados para a execução dos testes estatísticos.

Em relação à análise de subperíodos, optou-se por separar a amostra em duas: i) de julho de 1995 a dezembro de 2002; ii) de janeiro de 2003 a novembro de 2011, devido às diferenças nos cenários macroeconômicos dos dois períodos.

Por sua vez, nos testes da verificação de feitos sazonais, buscou-se analisar se o prêmio pela liquidez encontrado estava restrito ao mês de janeiro, isto é, influenciado pelo efeito janeiro identificado por Keim (1983) e Eleswarapu e Reiganum (1993). Para tal, a amostra foi separada em duas: i) meses de janeiro e ii) meses diferentes de janeiro.

Dentro de cada subamostra, subperíodo ou sazonalidade, foram repetidos os procedimentos já descritos para a verificação da existência de prêmios pela liquidez. 


\subsection{Procedimentos de testes dos modelos de precificação de ativos}

O Quadro 6 apresenta os quatro modelos de precificação de ativos testados nesta tese, quais sejam: CAPM, 2-fatores de Liu (2006), 3-fatores de Fama e French (1993) e 4-fatores de Carhart (1997).

Os testes dos modelos foram conduzidos sobre carteiras de ações. A priori, estimaram-se as variáveis dependentes - excesso de retorno das carteiras em relação ao retorno do ativo livre de risco. As carteiras foram formadas com base em decis conforme a liquidez das ações, seguindo a metodologia de Liu (2006). Posteriormente, construiram-se as variáveis independentes - os prêmios pelos fatores de riscos mercado, liquidez, tamanho, índice B/M e momento. Os procedimentos para cômputo do fator liquidez foram essencialmente os mesmos utilizados por Liu (2006). Os procedimentos para a obtenção dos fatores de risco beta de mercado, tamanho e índice B/M foram essencialmente os mesmos adotados por Fama e French (1993). Por sua vez, o fator momento foi estimado seguindo Carhart (1997). Os testes para validação dos modelos, por sua vez, foram realizados de acordo com a metodologia de Fama e MacBeth (1973). Todos esses procedimentos metodológicos são descritos com maiores detalhes nos subcapítulos subsequentes. 
Quadro 6 - Modelos de precificação de ativos testados na pesquisa

O quadro abaixo detalha os quatro modelos testados na presente pesquisa, quais sejam: CAPM, 2-fatores de Liu (2006), 3-fatores de Fama e French (1993) e 4-fatores de Carhart (1997).

\begin{tabular}{|c|c|}
\hline Modelos & Formulação/Variáveis \\
\hline CAPM & $\begin{array}{l}R_{c i, t}-R_{l r t}=a+b\left[R_{m t}-R_{l r t}\right]+e_{i, t} \\
\text { Em que: } \\
\boldsymbol{R}_{C i, t} \text { é o retorno da carteira } i \text {, no mês } t \text {; } \\
\boldsymbol{R}_{l r t} \text { é o retorno do ativo livre de risco no mês } t \\
\boldsymbol{R}_{\boldsymbol{m} t} \text { é o retorno da carteira de mercado no mês } t \text {; } \\
\boldsymbol{e}_{i, t} \text { é o resíduo do modelo referente à carteira } i \text { no mês } t \text {. }\end{array}$ \\
\hline $\begin{array}{l}\text { 2-Fatores } \\
\text { Liu (2006) }\end{array}$ & $\begin{array}{l}R_{c i, t}-R_{l r t}=a+b\left[R_{m t}-R_{l r t}\right]+l\left[L I Q_{t}\right]+e_{i, t} \\
\text { Em que: } \\
\text { LIQt é o prêmio pelo fator liquidez no mês } t \text { (diferença entre a média de retorno } \\
\text { das ações de empresas de baixa liquidez e a média de retorno das ações de } \\
\text { empresas de alta liquidez, sendo a liquidez medida pelo Índice de Negociabilidade } \\
\text { da BM\&FBOVESPA, conforme explanado no Capítulo } 4 \text {. }\end{array}$ \\
\hline $\begin{array}{c}\text { 3-Fatores } \\
\text { Fama e French (1993) }\end{array}$ & 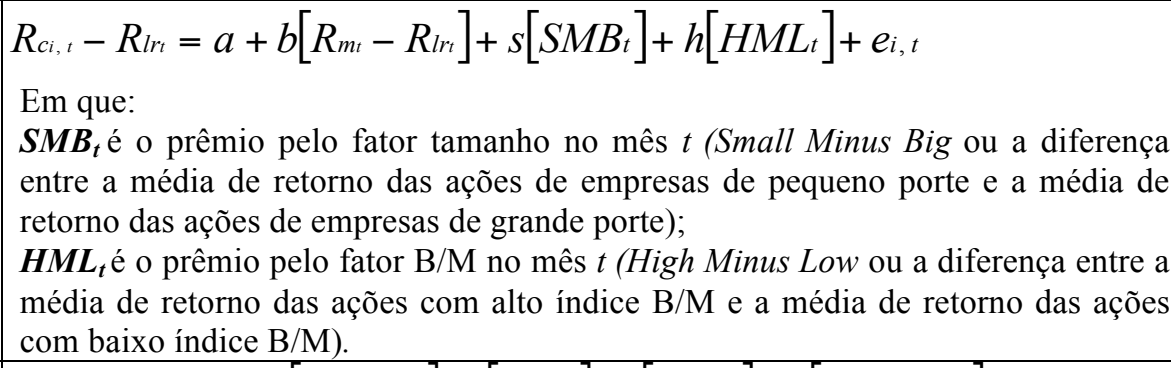 \\
\hline $\begin{array}{c}\text { 4-Fatores } \\
\text { Carhart (1997) }\end{array}$ & $\begin{array}{l}\quad R_{c i, t}-R_{l r_{t}}=a+b\left[R_{m t}-R_{l r_{t}}\right]+S\left[S M B_{t}\right]+h\left[H M L_{t}\right]+w[\text { WinMLost }]+e_{i, t} \\
\text { Em que: } \\
\text { WinMLos }_{t} \text { é o prêmio pelo fator momento no mês } t \text { (Winner Minus Loser ou a } \\
\text { diferença entre a média de retorno das ações de empresas que tiveram um alto } \\
\text { desempenho passado e a média de retorno das ações de empresas que tiveram um } \\
\text { baixo desempenho passado). }\end{array}$ \\
\hline
\end{tabular}

\subsubsection{Cálculo das variáveis dependentes}

A preparação das carteiras seguiu, essencialmente, a metodologia de Liu (2006). Nos meses de junho e dezembro de cada ano $t$, de 1995 a 2011, todas as ações da amostra foram separadas em decis baseados na liquidez das ações medida pelo Índice de Negociabilidade da BM\&FBOVESPA, calculado com base na média dos valores do índice nos 6 meses prévios (NEG6). A escolha do Índice de Negociabilidade da BM\&FBOVESPA (NEG6) será discutida em detalhes no Capítulo 4. Então, as carteiras foram mantidas por 6 meses e procedeu-se com o cálculo do retorno mensal equally weighted de cada uma das carteiras.

O excesso de retorno mensal de cada uma das 10 carteiras em relação à taxa livre de risco foi a variável dependente das regressões lineares. Adotou-se o retorno mensal da caderneta de 
poupança como uma aproximação para a taxa livre de risco, conforme sugerido por Barros et al (2003). Foram usados os retornos nominais das ações e do ativo livre de risco. Adicionalmente, os retornos foram deflacionados, mas como não houve quaisquer alterações significativas nos resultados e análises, esses dados foram suprimidos do texto, mas estão à disposição dos leitores mediante solicitação ao autor desta tese.

As 10 carteiras foram reformuladas a cada semestre, por meio da repetição das etapas acima. A escolha do rebalanceamento semestral foi motivada pelo fato de as estratégias de retenção das carteiras de 6 meses apresentarem prêmios pela liquidez mais moderados quando comparado com as estratégias de 1, 3 e 12 meses. Esse tema será discutido em detalhes no Capítulo 4. O mesmo procedimento foi adotado por Liu (2006).

\subsubsection{Obtenção dos prêmios pelos fatores de risco (variáveis independentes)}

Os prêmios pelo fator beta de mercado foram obtidos utilizando a equação abaixo:

$$
\text { Prêmio de Mercado } \mathrm{t}=\left[\sum_{\mathrm{i}=1}^{\mathrm{n}} \frac{V M_{i, t}}{V M_{M, t}}\left(R_{i, t}\right)\right]-R f_{t}
$$

Em que:

$\boldsymbol{R}_{i, t}$ é o retorno da ação $i$, pertencente à carteira de mercado, no mês $t$; $\boldsymbol{V} \boldsymbol{M}_{\boldsymbol{i}, t}$ é o valor de mercado da ação $i$, ao final do mês $t$;

$\boldsymbol{V M}_{\boldsymbol{M}, t}$ é o valor de mercado da carteira de mercado, considerando todas as ações da amostra, no mês $t$;

$\boldsymbol{R} \boldsymbol{f}_{\boldsymbol{t}}$ é o retorno do ativo livre de risco - caderneta de poupança - no mês $t$.

Os prêmios pelo fator liquidez foram calculados conforme a metodologia de Liu (2006). Em junho e dezembro de cada ano $t$, todas as ações da amostra foram classificadas conforme sua liquidez calculada pelo Índice de Negociabilidade da BM\&FBOVESPA médio dos últimos 6 meses (NEG6). As ações foram então separadas em dois grupos - LL (Low Liquidity) e HL (High Liquidity) - contendo cada um 50\% das ações da amostra. As carteiras foram, então, 
mantidas por 6 meses. O prêmio pelo fator liquidez foi obtido mensalmente pela seguinte expressão:

$$
\text { Prêmio LIQ }=\overline{R \operatorname{Riq1}}_{, t}-\overline{R \operatorname{Liq1}}_{{ }_{\text {, }}}
$$

Em que:

$\boldsymbol{R L i q 1 ,}{ }_{t}$ é o retorno médio equally weighted da carteira que contém as ações menos líquidas no mês $t$;

$\boldsymbol{R L i q 1 0 ,}$ é o retorno médio equally weighted da carteira que contém as ações mais líquidas no mês $t$.

Os prêmios pelos fatores tamanho e índice $\mathrm{B} / \mathrm{M}$ foram obtidos essencialmente conforme os procedimentos de Fama e French (1993). Já, o prêmio pelo fator momento foi obtido conforme procedido por Jegadeesh e Titman (1993) e Carhart (1997). Em junho e dezembro de cada ano $t$, de 1995 a 2011, calcularam-se os três fatores para cada ação da amostra utilizando-se as equações constantes do Quadro 7.

Quadro 7 - Fórmulas de cálculos das variáveis tamanho, índice B/M e momento O quadro abaixo apresenta as fórmulas para cálculo das variáveis tamanho, índice B/M e momento.

\begin{tabular}{|c|c|c|}
\hline Fatores & Fórmula & Detalhamento \\
\hline Tamanho & $V M_{i, t}=\sum P_{y, i, t} \times N_{y, i, t}$ & $\begin{array}{l}\boldsymbol{V} \boldsymbol{M}_{\boldsymbol{i}, \boldsymbol{t}} \text { é o valor de mercado da } \\
\text { empresa } i \text { no momento } t ; \boldsymbol{P}_{\boldsymbol{y}, \boldsymbol{i}, \boldsymbol{t}} \text { é o } \\
\text { preço da ação do tipo } y \text {, da empresa } i \\
\text { no momento } t \text {; } \\
\boldsymbol{N}_{\boldsymbol{y}, \boldsymbol{i}, \boldsymbol{t}} \text { é o número de ações do tipo } y \text {, } \\
\text { da empresa } i \text {, no momento } t \text {. }\end{array}$ \\
\hline Índice $\mathbf{B} / \mathbf{M}$ & $B / M_{i, t}=\frac{V C P L, t}{V M P L, t}$ & $\begin{array}{l}\boldsymbol{V} \boldsymbol{C}_{\boldsymbol{P L}, \boldsymbol{t}} \text { é o valor contábil do } \\
\text { patrimônio líquido em } t \text {; } \\
\boldsymbol{V M}_{\boldsymbol{P L , t} \text { é o valor de mercado do }} \\
\text { patrimônio líquido em } t \text {; }\end{array}$ \\
\hline Momento & Desempenho acumulado do retorno no período $t-2$ e $t-7$ & $\begin{array}{l}\text { Considerou-se a estratégia de } \\
\text { momento de } 6 \text { meses de Jegadeesh e } \\
\text { Titman (1993). }\end{array}$ \\
\hline
\end{tabular}

Posteriormente, as ações foram divididas em grupos: L (Low), M (Medium) e H (High), para o fator índice B/M; B (Big) e S (Small), para o fator tamanho e Los (Losers) e Win (Winners) para o fator momento. Após as três ordenações independentes realizadas conforme cada uma 
das três variáveis, foram construídas 12 carteiras decorrentes da interseção dos diversos grupos criados. Por exemplo, a carteira H/B/Los foi formada por ações com alto índice B/M, grandes no tamanho e perdedoras no retorno acumulado histórico. As demais carteiras seguem o mesmo raciocínio.

A equação apresentada abaixo foi utilizada para cálculo dos prêmios pelo fator tamanho (SMB):

$$
S M B_{t}=\overline{R_{S, t}}-\overline{R_{B, t}}
$$

Em que:

$\boldsymbol{S M B}_{\boldsymbol{t}}$ - Small Minus Big é o prêmio pelo fator tamanho no mês $t$;

$\boldsymbol{R}_{S, t}$ o retorno médio mensal das carteiras $\mathrm{S}$ no mês $t$;

$\boldsymbol{R}_{B, t} \mathbf{0}$ retorno médio mensal das carteiras B no mês $t$.

Os prêmios pelo fator índice B/M (HML) foram calculados conforme a seguinte equação:

$$
H M L_{t}=\overline{R_{H, t}}-\overline{R_{L, t}}
$$

Em que:

$\boldsymbol{H M L}_{\boldsymbol{t}}-$ High Minus Low é o prêmio mensal pelo fator de risco B/M no mês $t$;

$\boldsymbol{R}_{\boldsymbol{H}, \boldsymbol{t}}$ o retorno médio mensal das carteiras H no mês $t$;

$\boldsymbol{R} \boldsymbol{L}_{, t}$ o retorno médio mensal das carteiras L no mês $t$.

Por sua vez, os prêmios pelo fator momento (WinMLos) foram obtidos utilizando a equação apresentada na sequência:

$$
\text { WinMLoSt }_{t}=\overline{R_{W I N, t}}-\overline{R_{L O S, t}}
$$

Em que:

WinMLos $_{t}$ - Winner Minus Loser, corresponde ao prêmio mensal pelo fator de risco momento no mês $t$;

$\boldsymbol{R}_{W I N, t}$ é o retorno médio mensal das carteiras Win no mês $t$;

$\boldsymbol{R}_{L O S, t}$ é o retorno médio mensal das carteiras Los no mês $t$. 
Conforme já mencionado, todos os procedimentos acima foram repetidos a cada semestre nos meses de junho e dezembro de cada ano. A escolha do rebalanceamento semestral foi motivada pelo fato de as estratégias de retenção das carteiras de 6 meses apresentarem prêmio pela liquidez mais moderado quando comparado com as estratégias de 1, 3 e 12 meses, conforme será analisado no Capítulo 4. O mesmo procedimento foi adotado por Liu (2006). Consequentemente, para dar maior coerência aos cálculos, optou-se pela realização do rebalanceamento semestral também para todos os demais fatores. Outrossim, houve uma motivação adicional para o rebalanceamento semestral: a natureza ainda preponderantemente de curto prazo das operações financeiras brasileiras no período amostral considerado nesta tese.

Esses cinco prêmios mensais - beta de mercado, liquidez, tamanho, índice B/M e momento foram utilizados como variáveis explicativas das regressões para a obtenção dos betas dos fatores de risco que compõem os modelos testados nesta pesquisa.

\subsubsection{Procedimento dos testes estatísticos}

Elton et al. (2004) discutem vários procedimentos de testes do CAPM e modelos correlatos. Em essência, os testes envolvem o uso de regressões com séries temporais (primeiro passo) para estimação dos betas e o uso de regressões em cross-section (segundo passo) para testar as hipóteses resultantes dos modelos. Nesse caso, os betas (sensibilidades) estimados no primeiro passo são usados como variáveis explicativas nas regressões cross-section de segundo passo. Sendo assim, tem-se a metodologia desenvolvida por Fama e MacBeth (1973) de teste em duas etapas.

Ressalte-se que essa metodologia é essencialmente a mesma utilizada por grande parte dos estudos sobre liquidez e sua relação com os retornos das ações como o de Amihud e Mendelson (1986), Eleswarapu e Reiganum (1993), Brennan et al (1998), Datar et al (1998), Chordia et al (2001), Amihud (2002), Acharya e Pedersen (2005) e Nguyen et al (2007).

De acordo com Lakonishok e Shapiro (1986), essa metodologia tende a refletir mais adequadamente o comportamento dos investidores, uma vez que eles utilizam dados 
históricos para a estimação dos betas, com o objetivo de realizar seus investimentos futuros, além de não ter a desvantagem de superestimar a importância e a significância das variáveis explicativas dos testes contemporâneos, que utilizam unicamente regressões em séries temporais.

$\mathrm{Na}$ presente pesquisa, a primeira etapa de testes foi denominada within-sample e compreendeu o período de julho de 1995 a dezembro de 2003. A segunda, chamada de out-ofsample, compreendeu o período de janeiro de 2004 a novembro de 2011. O ponto de corte em 2003 pautou-se, principalmente, no balanceamento do número de observações entre as amostras. O subcapítulo 3.4.4 discute os testes de robustez efetuados em relação à esse critério de segregação da amostra.

Nessas regressões, as variáveis dependentes são as médias mensais dos prêmios pelo risco das carteiras calculado out-of-sample e as variáveis explicativas são os betas dos diversos fatores calculados within-sample, a partir das regressões em séries temporais. Espera-se que, no segundo passo, os valores dos interceptos sejam zero e os coeficientes das variáveis explicativas diferentes de zero.

Acrescente-se que nessa metodologia proposta por Fama e MacBeth (1973), os erros-padrão dos coeficientes das regressões cross-section não são obtidos pela metodologia convencional de Mínimos Quadrados Ordinários - MQO, por poderem produzir estimativas totalmente enviesadas, em virtude da incapacidade de se identificar o verdadeiro beta ou verdadeiras sensibilidades. No caso do CAPM, o beta obtido na regressão em séries temporais é uma estimativa do verdadeiro beta, ou seja, mesmo que existisse um beta verdadeiro e estável, tudo o que se teria é uma estimativa e essa estimativa pode até ser não enviesada, mas está sujeita a erro de amostragem. Dessa forma, qualquer erro na estimativa do beta fará com que o coeficiente beta na regressão cross-section seja enviesado para baixo e o intercepto seja enviesado para cima (ELTON et al, 2004, p.300). Acrescentando que, à medida que o verdadeiro valor do beta está positivamente correlacionado com a variância do resíduo, essa acabará funcionando como proxy do verdadeiro beta e o retorno ficará positivamente correlacionado com o risco residual (ELTON et al, 2004, p.300).

Catalogados esses possíveis problemas para testes dos modelos de retornos esperados, Fama e Macbeth (1973) indicaram as medidas para diminuir o erro amostral e a correlação, com 
qualquer defasagem, entre os resíduos da equação, ou seja, o risco residual: (i) medir betas de carteiras e não de títulos individuais e (ii) estimar os betas a partir de $n$ regressões crosssections mensais e usar o valor médio dos parâmetros como coeficiente da equação crosssection de todo o período (equação geral). Essa última indicação fícou conhecida como técnica de Fama e Macbeth (1973) para cômputo dos erros-padrão e foi empregada nesta pesquisa.

Ressalte-se que foram efetuados: (i) os testes de Kolmogorov-Smirnov para a verificação da normalidade das variáveis dependentes e independentes; (ii) os testes de Durbin-Watson para a averiguação de autocorrelação dos resíduos; bem como (iii) os testes de Fator de Inflação da Variância - FIV - para checar a existência de (multi)colinearidade entre as variáveis independentes.

\subsubsection{Teste de robustez dos modelos de precificação de ativos}

Para a execução de testes de robustez dos modelos de precificação de ativos foi efetuado o seguinte procedimento: utilizaram-se outros quatro períodos de within-sample e out-of-sample aumentando (diminuindo) o período de within-sample (out-of-sample) de 12 em 12 meses, para evitar possíveis problemas causados pela seleção amostral.

Adicionalmente, foram efetuados testes considerando somente o período anterior ao início das alterações da legislação contábil rumo às normas internacionais de contabilidade, de julho de 1995 a dezembro de 2007. Tal procedimento se fez necessário, pois as alterações contábeis podem ter ocasionado modificações no patrimônio líquido das empresas e, consequentemente, no índice B/M. Nesse caso, foi considerado como within-sample o período de julho de 1995 a junho de 2001 e out-of-sample o período de julho de 2001 a dezembro de 2007. O ponto de corte em 2001 pautou-se, principalmente, no balanceamento do número de observações entre as amostras. O período amostral mais recente, ou seja, de janeiro de 2008 a novembro de 2011, não foi usado para testes independentes dos demais, pois sobrariam quantidades insuficientes de dados para a execução dos testes estatísticos.

O Quadro 8 detalha todos os períodos de within-sample e out-of-sample utilizados nessa pesquisa: 
Quadro 8 - Detalhamento dos períodos de within-sample e out-of-sample utilizados nesta pesquisa para testes dos modelos de precificação de ativos

\begin{tabular}{|c|c|c|c|}
\hline Teste & Descrição & $\begin{array}{l}\text { Período } \\
\text { within-sample }\end{array}$ & $\frac{\text { Período }}{\text { out-of-sample }}$ \\
\hline Original & $\begin{array}{l}\text { Separação da amostra em within-sample e out- } \\
\text { of-sample pautada no balanceamento do número } \\
\text { de observações entre as amostras. }\end{array}$ & $\begin{array}{c}\text { Julho/1995 a } \\
\text { Dezembro/2003 }\end{array}$ & $\begin{array}{l}\text { Janeiro/2004 a } \\
\text { Novembro/2011 }\end{array}$ \\
\hline $\begin{array}{l}\text { Alternativo } \\
1\end{array}$ & $\begin{array}{c}\text { Menos } 12 \text { meses de within-sample e mais } 12 \\
\text { meses de out-of-sample. }\end{array}$ & $\begin{array}{c}\text { Julho/1995 a } \\
\text { Dezembro/2002 }\end{array}$ & $\begin{array}{c}\text { Janeiro/2003 a } \\
\text { Novembro/2011 }\end{array}$ \\
\hline $\begin{array}{l}\text { Alternativo } \\
\quad 2\end{array}$ & $\begin{array}{l}\text { Menos } 24 \text { meses de within-Sample e mais } 24 \\
\text { meses de out-of-sample em relação ao original. }\end{array}$ & $\begin{array}{c}\text { Julho/1995 a } \\
\text { Dezembro/2001 }\end{array}$ & $\begin{array}{c}\text { Janeiro/2002 a } \\
\text { Novembro/2011 }\end{array}$ \\
\hline $\begin{array}{l}\text { Alternativo } \\
3\end{array}$ & $\begin{array}{l}\text { Mais } 12 \text { meses de within-Sample e menos } 12 \\
\text { meses de out-of-sample em relação ao original }\end{array}$ & $\begin{array}{c}\text { Julho/1995 a } \\
\text { Dezembro/2004 }\end{array}$ & $\begin{array}{c}\text { Janeiro/2005 a } \\
\text { Novembro/2011 }\end{array}$ \\
\hline $\begin{array}{l}\text { Alternativo } \\
44\end{array}$ & $\begin{array}{l}\text { Mais } 24 \text { meses de within-Sample e menos } 24 \\
\text { meses de out-of-sample em relação ao original. }\end{array}$ & $\begin{array}{c}\text { Julho/1995 a } \\
\text { Dezembro/2005 }\end{array}$ & $\begin{array}{l}\text { Janeiro/2006 a } \\
\text { Novembro/2011 }\end{array}$ \\
\hline $\begin{array}{l}\text { Alternativo } \\
5\end{array}$ & $\begin{array}{l}\text { Período amostral anterior ao início das } \\
\text { alterações contábeis brasileiras no rumo às } \\
\text { normas internacionais. A separação da amostra } \\
\text { em within-sample e out-of-sample foi pautada } \\
\text { no balanceamento do número de observações } \\
\text { entre as amostras. }\end{array}$ & $\begin{array}{l}\text { Julho de } 1995 \text { a } \\
\text { Junho de } 2001\end{array}$ & $\begin{array}{l}\text { Julho de } 2001 \text { a } \\
\text { Dezembro de } 2007\end{array}$ \\
\hline
\end{tabular}




\section{ANÁLISE DE DADOS E RESULTADOS}

Esse capítulo apresenta a análise dos dados e resultados da pesquisa empírica. Na primeira parte, são analisados os resultados dos testes para verificação da existência de prêmios pela liquidez e inclui: as estatísticas descritivas e o sinal e a magnitude das correlações entre as diferentes medidas de liquidez utilizadas; os cálculos e a análise dos prêmios pela liquidez e o comportamento das medidas considerando os diferentes períodos para cálculo e manutenção das carteiras e os testes de robustez para os prêmios encontrados. Na segunda parte são testados os modelos de precificação de ativos propostos, abrangendo: a análise das variáveis dependentes e independentes; a sensibilidade dos excessos de retornos aos fatores de risco; os resultados dos testes dos modelos de precificação de ativos e os testes de robustez.

\subsection{Testes dos prêmios pela liquidez}

Esse subcapítulo é dedicado à análise da existência de prêmios pela liquidez no mercado acionário brasileiro. São analisadas as estatísticas descritivas e o sinal e a magnitude das correlações entre as diferentes medidas de liquidez utilizadas; os cálculos e a análise dos prêmios pela liquidez e o comportamento das medidas considerando os diferentes períodos para cálculo e manutenção das carteiras e os testes de robustez para os prêmios encontrados.

\subsubsection{Estatísticas descritivas e correlação entre as medidas de liquidez}

Conforme se pode observar na Tabela 1, a quantidade média de ações na amostra variou de 132 na estratégia $12 \times 12$ - 12 meses para cálculo das medidas e 12 meses para a retenção das carteiras - a 340 na estratégia 1x1 -1 mês para cálculo das medidas e 1 mês para retenção das carteiras. A quantidade de ações na carteira diminuiu à medida que se aumentou o período de manutenção das ações nela. Por exemplo, a estratégia 1x1 apresentou uma quantidade média de 340 ações, a 1x3 280 ações, a 1x6 239 ações e a 1×12 188 ações. O mesmo efeito se nota nas estratégias que consideraram 3, 6 e 12 meses como períodos de formação. A quantidade de ações da amostra diminuiu à medida que se aumentou o período para cálculo das medidas de liquidez. Por exemplo, quando se compara as estratégias 1x3, 3x3, 6x3 e 12x3, a quantidade de ações na amostra diminui, com uma quantidade média de 280, 248, 217 e 174 
ações, respectivamente. Essas evidências corroboram a suposição de que a formação das amostras é bastante sensível a restrições de períodos de cálculo das medidas e de retenção das carteiras, sendo que as estratégias mais restritivas podem levar à exclusão justamente das ações menos líquidas, enviesando os resultados dos testes.

Tabela 1 - Estatísticas descritivas das ações da amostra

Essa tabela apresenta a quantidade média, mínima e máxima de ações que permaneceram na amostra em cada uma das 16 estratégias consideradas. As 16 estratégias foram formadas considerando $x$ meses prévios para cálculos das medidas e $x$ meses posteriores para retenção das carteiras, sendo $x=1,3,6$ e 12 meses. Por exemplo, na estratégia $3 \times 6$ a exigência para permanência de ações na amostra foi cotações mensais consecutivas nos 3 meses anteriores e 6 meses posteriores ao do mês em análise. As demais estratégias seguiram o mesmo raciocínio.

\begin{tabular}{|c|c|c|c|}
\hline \multirow{2}{*}{ Estratégia } & \multicolumn{3}{|c|}{ Quantidade de ações na amostra } \\
\cline { 2 - 4 } & Média & Mínima & Máxima \\
\hline $\mathbf{1 x 1}$ & 340 & 266 & 446 \\
\hline $\mathbf{1 x 3}$ & 280 & 194 & 365 \\
\hline $\mathbf{1 x 1 2}$ & 239 & 163 & 315 \\
\hline $\mathbf{3 x 1}$ & 188 & 127 & 410 \\
\hline $\mathbf{3 x 3}$ & 288 & 202 & 381 \\
\hline $\mathbf{3 x 6}$ & 248 & 165 & 343 \\
\hline $\mathbf{3 x 1 2}$ & 216 & 148 & 289 \\
\hline $\mathbf{6 x 1}$ & 173 & 115 & 369 \\
\hline $\mathbf{6 x 3}$ & 245 & 167 & 344 \\
\hline $\mathbf{6 x 6}$ & 217 & 149 & 325 \\
\hline $\mathbf{6 x 1 2}$ & 193 & 130 & 250 \\
\hline $\mathbf{1 2 x 1}$ & 158 & 103 & 317 \\
\hline $\mathbf{1 2 x 3}$ & 191 & 131 & 289 \\
\hline $\mathbf{1 2 x 6}$ & 174 & 116 & 255 \\
\hline $\mathbf{1 2 x 1 2}$ & 158 & 103 & 225 \\
\hline
\end{tabular}

A Tabela 2 apresenta a média dos coeficientes de correlação de Spearman entre as diferentes medidas de liquidez, considerando as 16 estratégias. Os baixos valores de desvio-padrão de todas as médias observadas - de 0,01 (observado em várias correlações como a entre Volume Financeiro e Quantidade de Títulos) a 0,09 (observado entre as variáveis Desvio-padrão do Volume e Coeficiente de Variação do Volume) - indicam que houve pouca variação entre as correlações das medidas ao longo das 16 estratégias formadas por diferentes períodos de cálculo das medidas e retenção das carteiras. A tabela contendo as matrizes de correlações individuais para cada estratégia é apresentada no Apêndice 1. 
As correlações envolvendo as medidas Volume Financeiro, Quantidade de Negócios, Quantidade de Títulos, Turnover e Índice de Negociabilidade da BM\&FBOVESPA apresentaram sinais positivos entre si e negativos com as medidas de iliquidez: Número de Dias Sem Transação, Volume Zero Padronizado e Return-to-Volume. Por sua vez, as medidas de iliquidez também apresentaram correlações positivas entre si.

As medidas Desvio-padrão do Volume Financeiro e Desvio-padrão do Turnover apresentaram correlações positivas com as medidas de liquidez e negativas com as medidas de iliquidez, sinais contrários aos esperados caso se confirme a existência de prêmio pela liquidez com o uso das medidas Volume Financeiro, Quantidade de Negócios, Quantidade de Títulos, Índice de Negociabilidade da BM\&FBOVESPA e Turnover. Por sua vez, Coeficiente de Variação do Volume Financeiro e Coeficiente de Variação do Turnover apresentaram correlações negativas com as medidas de liquidez e positivas com as medidas de iliquidez, conforme o esperado, caso se observe prêmio com o uso das medidas Volume Financeiro, Quantidade de Negócios, Quantidade de Títulos, Índice de Negociabilidade da BM\&FBOVESPA e Turnover.

Da mesma forma que foi evidenciado no estudo de Liu (2006) para o mercado norteamericano, além de sinais coerentes com as expectativas, nota-se na Tabela 2 que muitas medidas de liquidez apresentaram fortes correlações entre si e, por esse motivo, fez-se necessária a eliminação de algumas para evitar redundâncias de testes no desenvolvimento desta pesquisa. As medidas que foram mantidas para as próximas etapas do trabalho foram: Índice de Negociabilidade da BM\&FBOVESPA, Turnover, Return-to-Volume e Coeficiente de Variação do Volume Financeiro. A explicação da sua escolha encontra-se nos parágrafos abaixo.

\section{- A escolha do Índice de Negociabilidade da BM\&FBOVESPA}

As medidas Volume Financeiro, Desvio-padrão do Volume Financeiro, Quantidade de Negócios, Quantidade de Títulos, Número de Dias Sem Transação e Índice de Negociabilidade da BM\&FBOVESPA apresentaram fortes correlações entre si - por exemplo, a correlação entre Índice de Negociabilidade da BM\&FBOVESPA e Volume Financeiro foi de 0,98 , sinalizando que elas capturam a mesma dimensão da liquidez ou dimensões que no mercado brasileiro se mostram altamente correlacionadas. 
O Índice de Negociabilidade da BM\&FBOVESPA foi a medida que apresentou as maiores correlações com as demais medidas mencionadas. Por esse motivo e por ela ser uma medida amplamente conhecida e divulgada no mercado nacional, desse ponto em diante do trabalho optou-se por prosseguir com Índice de Negociabilidade da BM\&FBOVESPA e a eliminação de Volume Financeiro, Desvio-padrão do Volume Financeiro, Quantidade de Negócios, Quantidade de Títulos e Número de Dias Sem Transação.

Na mesma linha, Vieira e Milach (2008) encontraram fortes correlações entre as medidas Quantidade de Negócios e Volume Financeiro. Por sua vez, Machado e Medeiros (2011) encontraram fortes correlações entre as variáveis Volume Financeiro, Índice de Negociabilidade da BM\&FBOVESPA e Quantidade de Negócios.

O Índice de Negociabilidade da BM\&FBOVESPA também apresentou forte correlação com o VM - valor de mercado, indicando que as ações mais líquidas são as que representam as empresas de porte maior. Esse fato corrobora a intuição de que as empresas menos líquidas são as de menor porte, o que também foi observado no mercado norte-americano por Liu (2006).

\section{- A escolha do Turnover}

As medidas Turnover, Desvio-padrão do Turnover e Volume Zero Padronizado apresentaram altas correlações entre si indicando que essas medidas parecem capturar a mesma dimensão da liquidez ou dimensões altamente correlacionadas. Exemplificando: a correlação entre Turnover e Valor Zero Padronizado foi de -0,99. Além disso, elas apresentaram baixas correlações com o Índice de Negociabilidade da BM\&FBOVESPA. Por esse motivo viu-se a necessidade de manter uma das medidas e escolheu-se Turnover por sua facilidade de cálculo quando comparada com Volume Zero Padronizado e Desvio-padrão do Turnover.

\section{- A escolha do Return-to-Volume}

Por sua vez, Return-to-Volume foi mantida por não apresentar forte correlação com qualquer outra medida, diferente do identificado por Liu (2006) no mercado norte-americano, sinalizando que a medida pode capturar diferente dimensão da liquidez. A maior correlação 
foi verificada com o Índice de Negociabilidade da BM\&FBOVESPA. Esse fato é consistente com a ideia de Amihud (2002), que afirma que Return-to-Volume captura a dimensão impacto nos preços, que é diferente da dimensão quantidade de transações supostamente capturada pelo Índice de Negociabilidade da BM\&FBOVESPA.

\section{- A escolha do Coeficiente de Variação do Volume Financeiro}

As medidas Coeficiente de Variação do Volume Financeiro e Coeficiente de Variação do Turnover apresentaram altas correlações entre si, 0,90. Apesar de apresentarem fortes correlações também com o Índice de Negociabilidade da BM\&FBOVESPA, -0,62 nos dois casos, optou-se por prosseguir com uma das duas medidas de variabilidade para verificar a existência no mercado acionário brasileiro de prêmio pela volatilidade da liquidez sugerido por Chordia et al (2001). Assim, optou-se pelo Coeficiente de Variação do Volume Financeiro por ser uma medida mais fácil de calcular quando comparada ao Coeficiente de Variação do Turnover.

Então, para a próxima etapa do trabalho - cálculo dos prêmios pela liquidez - foram selecionadas as medidas Índice de Negociabilidade da BM\&FBOVESPA, Turnover, Returnto- Volume e Coeficiente de Variação do Volume Financeiro. 
Tabela 2 -Matriz de correlação entre as medidas de liquidez

Essa tabela apresenta os coeficientes de correlação de Spearman para todas as medidas de liquidez utilizadas no presente estudo. As medidas de liquidez estão detalhadas no Quadro 5, Capítulo 3. VM é o valor de mercado das ações. No final de cada mês $t$, de julho de 1995 a novembro de 2011, foi calculado o coeficiente de correlação de Spearman cross-section sobre todas as ações da amostra e, posteriormente, foi calculada a média time-series dessas correlações. Os resultados são apresentados individualmente em 16 painéis no Apêndice 1, de acordo com a combinação de cada um dos $x$ meses de cálculo das medidas e $x$ meses de retenção das ações, em que $x$ é igual a 1, 3, 6 e 12 meses. Por exemplo, o painel B do Apêndice 1 apresenta os resultados para a estratégia 1x3, a qual contém ações que atendem ao seguinte requisito para cada mês $t$, de julho de 1995 a novembro de 2011: cotação mensal no mês corrente e nos 3 meses seguintes. Os dados apresentados na presente tabela, por sua vez, são as médias e os desvios-padrão (entre parênteses) dos valores de todos os demais painéis, de A a P do Apêndice 1.

\begin{tabular}{|c|c|c|c|c|c|c|c|c|c|c|c|c|}
\hline & VM & $\begin{array}{l}\text { Volume } \\
\text { Financeiro }\end{array}$ & $\begin{array}{l}\text { Quantidade } \\
\text { de Negócios }\end{array}$ & $\begin{array}{l}\text { Quantidade } \\
\text { de Títulos }\end{array}$ & $\left|\begin{array}{l}\text { Número de Dias } \\
\text { Sem Transação }\end{array}\right|$ & \begin{tabular}{|l} 
Return-to- \\
Volume
\end{tabular} & TurnOver & \begin{tabular}{|l|} 
Volume Zero \\
Padronizado
\end{tabular} & $\begin{array}{l}\text { Índice de } \\
\text { Negociabilidade }\end{array}$ & \begin{tabular}{|l|} 
Desvio- \\
Padrão do \\
TurnOver
\end{tabular} & \begin{tabular}{|l|} 
Desvio- \\
Padrão do \\
Volume
\end{tabular} & $\begin{array}{l}\text { Coeficiente } \\
\text { de Variação } \\
\text { do TurnOver }\end{array}$ \\
\hline \multirow{2}{*}{ Volume Financeiro } & 0,74 & & & & & & & & & & & \\
\hline & $(0,01)$ & & & & & & & & & & & \\
\hline \multirow{2}{*}{ Quantidade de Negócios } & 0,63 & 0,92 & & & & & & & & & & \\
\hline & $(0,01)$ & $(0,01)$ & & & & & & & & & & \\
\hline \multirow{2}{*}{ Quantidade de Títulos } & 0,42 & 0,66 & 0,68 & & & & & & & & & \\
\hline & $(0,01)$ & $(0,01)$ & $(0,01)$ & & & & & & & & & \\
\hline \multirow{2}{*}{ Número de Dias Sem Transação } & $-0,57$ & $-0,83$ & $-0,91$ & $-0,60$ & & & & & & & & \\
\hline & $(0,02)$ & $(0,02)$ & $(0,02)$ & $(0,02)$ & & & & & & & & \\
\hline \multirow{2}{*}{ Return-to-Volume } & 0,02 & $-0,05$ & $-0,09$ & $-0,06$ & 0,06 & & & & & & & \\
\hline & $(0,02)$ & $(0,02)$ & $(0,04)$ & $(0,03)$ & $(0,02)$ & & & & & & & \\
\hline \multirow{2}{*}{ TurnOver } & $-0,02$ & 0,31 & 0,27 & 0,61 & $-0,22$ & $-0,01$ & & & & & & \\
\hline & $(0,02)$ & $(0,04)$ & $(0,04)$ & $(0,01)$ & $(0,04)$ & $(0,02)$ & & & & & & \\
\hline \multirow{2}{*}{ Volume Zero Padronizado } & $-0,02$ & $-0,34$ & $-0,30$ & $-0,63$ & 0,27 & 0,01 & $-0,99$ & & & & & \\
\hline & $(0,02)$ & $(0,03)$ & $(0,03)$ & $(0,01)$ & $(0,03)$ & $(0,02)$ & $(0,01)$ & & & & & \\
\hline \multirow{2}{*}{ Índice de Negociabilidade } & 0,70 & 0,98 & 0,98 & 0,68 & $-0,89$ & $-0,07$ & 0,29 & $-0,33$ & & & & \\
\hline & $(0,01)$ & $(0,00)$ & $(0,00)$ & $(0,01)$ & $(0,02)$ & $(0,03)$ & $(0,04)$ & $(0,03)$ & & & & \\
\hline \multirow{2}{*}{ Desvio-Padrão do TurnOver } & $-0,13$ & 0,17 & 0,13 & 0,52 & $-0,09$ & $-0,02$ & 0,96 & $-0,94$ & 0,15 & & & \\
\hline & $(0,01)$ & $(0,03)$ & $(0,03)$ & $(0,01)$ & $(0,04)$ & $(0,01)$ & $(0,01)$ & $(0,01)$ & $(0,03)$ & & & \\
\hline \multirow{2}{*}{ Desvio-Padrão do Volume } & 0,72 & 0,97 & 0,88 & 0,64 & $-0,78$ & $-0,07$ & 0,29 & $-0,33$ & 0,93 & 0,21 & & \\
\hline & $(0,01)$ & $(0,01)$ & $(0,01)$ & $(0,00)$ & $(0,02)$ & $(0,02)$ & $(0,03)$ & $(0,03)$ & $(0,01)$ & $(0,04)$ & & \\
\hline \multirow{2}{*}{ Coeficiente de Variação do TurnOver } & $-0,45$ & $-0,58$ & $-0,61$ & $-0,43$ & 0,61 & $-0,01$ & $-0,18$ & 0,22 & $-0,62$ & 0,04 & $-0,42$ & \\
\hline & $(0,03)$ & $(0,05)$ & $(0,04)$ & $(0,03)$ & $(0,04)$ & $(0,01)$ & $(0,01)$ & $(0,02)$ & $(0,05)$ & $(0,03)$ & $(0,08)$ & \\
\hline \multirow{2}{*}{ Coeficiente de Variação do Volume } & $-0,47$ & $-0,58$ & $-0,61$ & $-0,40$ & 0,60 & $-0,00$ & $-0,16$ & 0,20 & $-0,62$ & 0,04 & $-0,40$ & 0,90 \\
\hline & $(0,04)$ & $(0,06)$ & $(0,05)$ & $(0,03)$ & $(0,05)$ & $(0,01)$ & $(0,02)$ & $(0,03)$ & $(0,06)$ & $(0,04)$ & $(0,09)$ & $(0,03)$ \\
\hline
\end{tabular}




\subsubsection{Os prêmios pela liquidez}

A Tabela 3 apresenta os retornos das carteiras e os prêmios pelas liquidez com o uso da medida Índice de Negociabilidade da BM\&FBOVESPA. Para todas as 16 estratégias, as 10 carteiras apresentaram retornos positivos e estatisticamente diferentes de zero. Em todas as estratégias, de forma geral, os retornos das carteiras aumentaram à medida que diminuiu a liquidez das carteiras. Os prêmios pela liquidez (B-S) mostraram-se positivos e estatisticamente diferentes de zero em todas as estratégias a $1 \%$ de significância, com exceção da estratégia $12 \times 1$, cujo prêmio de $1,53 \%$ ao mês se mostrou estatisticamente diferente de zero a $5 \%$ de significância. O maior prêmio foi encontrado pela estratégia $1 \times 1,4,48 \%$ ao mês, e o menor na estratégia $12 \times 1$, $1,53 \%$ ao mês. Assim, parece haver uma relação negativa entre liquidez e retorno: a liquidez medida pelo Índice de Negociabilidade da BM\&FBOVESPA parece ser precificada no mercado acionário brasileiro.

Apesar dos prêmios médios mensais serem bastante elevados, vale a ressalva de que a presente pesquisa não tem como objetivo definir estratégias de compra e venda de ações que possam resultar em ganhos anormais, uma vez que outros fatores, como custos de transação, devem ser levados em conta. Ressaltando que os procedimentos empíricos levaram à exclusão de ações que não apresentaram cotações mensais consecutivas por $x$ meses para cálculos das medidas e retenção das carteiras, sendo $x=1,3,6$ e 12 meses. Dessa forma, a amostra trabalhada ficou livre do risco conhecido como lock in risk, ou seja, o risco dos ativos não poderem ser vendidos a qualquer tempo.

Os retornos de B-S diminuíram à medida que se aumentou o período de retenção para as estratégias que consideraram 1 e 3 meses como períodos de cálculo da medida de liquidez. Por exemplo, os prêmios B-S das estratégias 1x1, 1x3, 1x6 e 1x12 foram, respectivamente, 4,48\%, $3,03 \%, 2,63 \%$ e $2,40 \%$ ao mês. Os retornos de B-S, em termos gerais, também diminuíram à medida que se aumentou o período de cálculo das medidas de liquidez. Por exemplo, os prêmios para as estratégias $1 \times 1,3 \times 1,6 \times 1$ e $12 \times 1$ foram de, respectivamente, 4,48\%, 2,95\%, $2,38 \%$ e $1,53 \%$. Esses fatos indicam que: i) os prêmios pela liquidez se dissipam ao longo do tempo e ii) quanto maior a restrição para a manutenção das ações na amostra menor o prêmio pela liquidez encontrado, o que pode ser resultado da exclusão justamente das ações menos líquidas em estratégias de maior horizonte temporal como a $12 \times 1$. 
Em linhas gerais, as evidências encontradas corroboram os resultados das pesquisas efetuadas com dados do mercado acionário norte-americano (AMIHUD e MENDELSON, 1986; BRENNAN et al, 1998 e LIU, 2006). Porém, a magnitude dos prêmios pela liquidez se mostrou muito mais forte no mercado brasileiro. Por exemplo os prêmios encontrados por Liu (2006) no mercado norte-americano variaram de $0,180 \%$ ao mês a $0,846 \%$ ao mês. Esse fato parece estar de acordo com a expectativa de Bekaert et al (2007) e Lee (2011), que afirmam que os prêmios pela liquidez deveriam ser mais elevados em mercados emergentes devido justamente à baixa liquidez dos papéis.

Machado e Medeiros (2011) encontraram prêmios menores pela liquidez no mercado acionário brasileiro utilizando o Volume Financeiro como proxy para a liquidez $(0,77 \%$ ao mês). Todavia, vale destacar que a diferença entre a magnitude dos prêmios pode ser motivada pela forte restrição amostral imposta pelos referidos autores, ao excluírem ações: i) que não apresentaram cotações mensais e consecutivas por 24 meses; ii) que apresentaram Patrimônio Líquido negativo em dezembro de cada ano; iii) de empresas financeiras. Essas restrições impostas certamente excluíram da amostra justamente as ações menos líquidas, podendo distorcer ou enviesar os resultados dos prêmios. Apenas como comparação, a quantidade média de ações da amostra em cada ano no estudo de Machado e Medeiros (2011) foi de 149, enquanto no presente estudo variou de 132 a 340, dependendo da estratégia utilizada. Afora que o rebalanceamento das carteiras no estudo de Machado e Medeiros (2011) foi feito a cada 12 meses, enquanto na presente pesquisa foi mensal, independente da estratégia utilizada.

A Tabela 4 mostra os retornos das carteiras e prêmios pela liquidez considerando o Turnover como medida de liquidez. Pode-se observar que os prêmios B-S se mostraram negativos, porém de baixa magnitude, em praticamente todas as estratégias, sendo que a única exceção foi a estratégia 1x1. O retorno médio ao longo das carteiras manteve-se praticamente estável em todas as estratégias. Exemplo, a estratégia $6 \times 3$ apresentou retornos médios em torno de $2 \%$ ao longo de todas as carteiras.. Os resultados corroboram os achados de Vieira e Milach (2008) e Machado e Medeiros (2011) para o mercado acionário nacional, mas não se identificam com as evidências encontradas para esta medida no mercado norte-americano (DATAR et al, 1998; LIU, 2006; BEKAERT et al, 2007). 
Tabela 3 - Desempenho das carteiras classificadas conforme o Índice de Negociabilidade

Essa tabela apresenta o desempenho das carteiras considerando todas as ações da amostra de 1995 a 2011 . No início de cada mês $t$, de julho de 1995 a novembro de 2011, as ações elegíveis da BM\&FBOVESPA foram classificadas conforme o Índice de Negociabilidade. Os critérios de seleção das medidas de liquidez são explicados no subcapítulo 4.1.1. Baseado nessa classificação, as ações foram agrupadas em 10 carteiras equally weighted e mantidas por $x$ meses $(x=1,3,6$ e 12 meses). $\mathbf{S}$ denota o decil que contém as ações mais líquidas (maiores valores de Índice de Negociabilidade), B denota o decil que contém as ações menos líquidas (menores valores de Índice de Negociabilidade) e B-S é a diferença entre B e S. A estratégia 1x1 refere-se a 1 mês para cálculo da medida de liquidez e 1 mês para retenção das carteiras. O mesmo raciocínio é válido para as demais estratégias. As entradas de dados são os retornos \% médios mensais das carteiras. Os valores entre parênteses são a estatística $t$ (teste onesample-t). * indica que o coeficiente/teste é significativo a $1 \%$; e $* *$ significativo a $5 \%$.

\begin{tabular}{|c|c|c|c|c|c|c|c|c|c|c|c|}
\hline Estratégia & S & D2 & D3 & D4 & D5 & D6 & D7 & D8 & D9 & B & B-S \\
\hline \multirow{2}{*}{$1 \times 1$} & $2,46^{*}$ & $2,72^{*}$ & $3,01^{*}$ & $3,42 *$ & $3,60 *$ & $4,48^{*}$ & $4,08^{*}$ & $4,44^{*}$ & $4,56^{*}$ & $6,93 *$ & $4,48 *$ \\
\hline & $(3,35)$ & $(3,83)$ & $(4,29)$ & $(5,06)$ & $(5,57)$ & $(4,84)$ & $(6,73)$ & $(7,40)$ & $(6,28)$ & $(7,13)$ & $(4,66)$ \\
\hline \multirow{2}{*}{$1 \times 3$} & $1,96^{*}$ & $2,07^{*}$ & $2,44 *$ & $2,80^{*}$ & $3,25^{*}$ & $3,46^{*}$ & $3,80^{*}$ & $3,97 *$ & $4,08^{*}$ & $5,08^{*}$ & $3,03 *$ \\
\hline & $(4,12)$ & $(4,20)$ & $(5,04)$ & $(5,62)$ & $(6,39)$ & $(6,93)$ & $(7,42)$ & $(8,36)$ & $(8,62)$ & $(8,70)$ & $(6,26)$ \\
\hline \multirow{2}{*}{$1 \times 6$} & $1,59^{*}$ & $1,81^{*}$ & $1,99^{*}$ & $2,44^{*}$ & $2,72 *$ & $2,91 *$ & $3,32 *$ & $3,46^{*}$ & $3,72 *$ & $4,14^{*}$ & $2,63 *$ \\
\hline & $(4,68)$ & $(5,04)$ & $(5,45)$ & $(6,40)$ & $(7,07)$ & $(7,57)$ & $(8,93)$ & $(9,62)$ & $(9,92)$ & $(9,63)$ & $(7,48)$ \\
\hline \multirow{2}{*}{$1 \times 12$} & $1,43^{*}$ & $1,45^{*}$ & $1,70^{*}$ & $2,13 *$ & $2,40 *$ & $2,62 *$ & $3,00 *$ & $2,92 *$ & $3,30^{*}$ & $3,65^{*}$ & $2,40 *$ \\
\hline & $(7,30)$ & $(6,90)$ & $(7,78)$ & $(8,95)$ & $(9,92)$ & $(10,48)$ & $(11,91)$ & $(11,85)$ & $(13,77)$ & $(13,71)$ & $(9,30)$ \\
\hline \multirow{2}{*}{$3 \times 1$} & $2,14^{*}$ & $2,21^{*}$ & $2,67^{*}$ & $2,66^{*}$ & $3,19 *$ & $3,33 *$ & $3,52 *$ & $4,38^{*}$ & $3,50^{*}$ & $5,09 *$ & $2,95 *$ \\
\hline & $(3,08)$ & $(3,23)$ & $(4,03)$ & $(4,02)$ & $(4,94)$ & $(4,94)$ & $(6,06)$ & $(4,23)$ & $(5,59)$ & $(8,04)$ & $(4,30)$ \\
\hline \multirow{2}{*}{$3 \times 3$} & $1,49 *$ & $1,76^{*}$ & $1,97^{*}$ & $2,42 *$ & $2,39 *$ & $3,05 *$ & $3,31 *$ & $2,99 *$ & $3,64^{*}$ & $4,13 *$ & $2,49 *$ \\
\hline & $(3,48)$ & $(4,02)$ & $(4,41)$ & $(5,47)$ & $(5,23)$ & $(6,54)$ & $(7,50)$ & $(7,35)$ & $(7,88)$ & $(9,30)$ & $(6,58)$ \\
\hline \multirow{2}{*}{$3 \times 6$} & $1,34^{*}$ & $1,50^{*}$ & $1,70^{*}$ & $2,07 *$ & $2,09 *$ & $2,81 *$ & $2,80^{*}$ & $3,02 *$ & $3,17^{*}$ & $3,72 *$ & $2,31 *$ \\
\hline & $(4,65)$ & $(4,87)$ & $(5,20)$ & $(6,09)$ & $(6,36)$ & $(7,88)$ & $(8,20)$ & $(9,27)$ & $(10,03)$ & $(10,37)$ & $(7,12)$ \\
\hline \multirow{2}{*}{$3 \times 12$} & $1,29^{*}$ & $1,41^{*}$ & $1,36^{*}$ & $2,11^{*}$ & $2,22 *$ & $2,38^{*}$ & $2,79^{*}$ & $2,88^{*}$ & $2,84^{*}$ & $3,40 *$ & $2,26^{*}$ \\
\hline & $(6,87)$ & $(7,13)$ & $(6,67)$ & $(9,06)$ & $(9,61)$ & $(10,10)$ & $(11,29)$ & $(11,91)$ & $(13,22)$ & $(15,50)$ & $(12,17)$ \\
\hline \multirow{2}{*}{$6 \times 1$} & $1,59^{*}$ & $1,76^{*}$ & $1,87^{*}$ & $2,44^{*}$ & $2,00 *$ & $3,10 *$ & $2,56^{*}$ & $2,51^{*}$ & $4,18^{*}$ & $3,96^{*}$ & $2,38 *$ \\
\hline & $(2,51)$ & $(2,71)$ & $(3,17)$ & $(4,07)$ & $(3,45)$ & $(4,45)$ & $(5,15)$ & $(5,44)$ & $(3,57)$ & $(6,01)$ & $(3,11)$ \\
\hline \multirow{2}{*}{$6 \times 3$} & $1,23^{*}$ & $1,42 *$ & $1,52 *$ & $1,88^{*}$ & $2,02 *$ & $2,48^{*}$ & $2,75^{*}$ & $2,61^{*}$ & $3,11^{*}$ & $3,30 *$ & $1,87 *$ \\
\hline & $(3,33)$ & $(3,46)$ & $(3,69)$ & $(4,63)$ & $(4,96)$ & $(5,94)$ & $(6,44)$ & $(7,11)$ & $(7,18)$ & $(9,28)$ & $(5,23)$ \\
\hline \multirow{2}{*}{$6 \times 6$} & $1,17^{*}$ & $1,25^{*}$ & $1,46^{*}$ & $1,79 *$ & $2,06^{*}$ & $2,27^{*}$ & $2,77^{*}$ & $2,70^{*}$ & $2,73^{*}$ & $3,05 *$ & $1,76^{*}$ \\
\hline & $(4,43)$ & $(4,39)$ & $(4,90)$ & $(5,33)$ & $(6,50)$ & $(7,08)$ & $(8,55)$ & $(8,68)$ & $(9,29)$ & $(11,61)$ & $(7,42)$ \\
\hline \multirow{2}{*}{$6 \times 12$} & $1,28^{*}$ & $1,31^{*}$ & $1,41^{*}$ & $1,67^{*}$ & $2,26^{*}$ & $2,48^{*}$ & $2,72 *$ & $2,65^{*}$ & $2,59 *$ & $3,24 *$ & $2,08 *$ \\
\hline & $(6,81)$ & $(6,72)$ & $(7,00)$ & $(7,45)$ & $(9,29)$ & $(10,78)$ & $(10,94)$ & $(11,78)$ & $(12,30)$ & $(15,64)$ & $(12,11)$ \\
\hline \multirow{2}{*}{$12 \times 1$} & $1,56^{*}$ & $1,68^{*}$ & $1,69^{*}$ & $2,44^{*}$ & $2,35^{*}$ & $2,08^{*}$ & $2,94 *$ & $2,41^{*}$ & $3,95^{*}$ & $3,09 *$ & $1,53 * *$ \\
\hline & $(2,48)$ & $(2,66)$ & $(2,75)$ & $(2,86)$ & $(4,24)$ & $(3,81)$ & $(5,50)$ & $(4,75)$ & $(2,72)$ & $(4,71)$ & $(2,13)$ \\
\hline \multirow{2}{*}{$12 \times 3$} & $1,35^{*}$ & $1,32^{*}$ & $1,55^{*}$ & $1,97 *$ & $2,22 *$ & $2,03 *$ & $2,76^{*}$ & $2,73^{*}$ & $2,41^{*}$ & $3,30^{*}$ & $1,77^{*}$ \\
\hline & $(3,76)$ & $(3,46)$ & $(3,40)$ & $(4,52)$ & $(5,54)$ & $(5,12)$ & $(7,34)$ & $(7,11)$ & $(7,22)$ & $(7,47)$ & $(4,06)$ \\
\hline \multirow{2}{*}{$12 \times 6$} & $1,32^{*}$ & $1,23^{*}$ & $1,53^{*}$ & $1,75^{*}$ & $2,20 *$ & $2,23 *$ & $2,78^{*}$ & $2,85^{*}$ & $2,36^{*}$ & $3,36^{*}$ & $1,93 *$ \\
\hline & $(4,93)$ & $(4,54)$ & $(4,80)$ & $(5,55)$ & $(6,64)$ & $(6,85)$ & $(9,08)$ & $(9,87)$ & $(8,56)$ & $(10,89)$ & $(6,60)$ \\
\hline \multirow{2}{*}{$12 \times 12$} & $1,46^{*}$ & $1,19^{*}$ & $1,66^{*}$ & $1,37 *$ & $2,38 *$ & $2,36^{*}$ & $2,50^{*}$ & $2,77^{*}$ & $2,72 *$ & $3,18^{*}$ & $1,78 *$ \\
\hline & $(7,79)$ & $(6,18)$ & $(7,99)$ & $(6,17)$ & $(9,72)$ & $(10,66)$ & $(10,18)$ & $(12,34)$ & $(13,25)$ & $(15,14)$ & $(8,99)$ \\
\hline
\end{tabular}




\section{Tabela 4 - Desempenho das carteiras classificadas conforme o Turnover}

Essa tabela apresenta o desempenho das carteiras considerando todas as ações da amostra de 1995 a 2011 . No início de cada mês $t$, de julho de 1995 a novembro de 2011, as ações elegíveis da BM\&FBOVESPA foram classificadas conforme o Turnover. Os critérios de seleção das medidas de liquidez são explicados no subcapítulo 4.1.1. Baseado nessa classificação, as ações foram agrupadas em 10 carteiras equally weighted e mantidas por $x$ meses ( $x=1,3,6$ e 12 meses). $\mathbf{S}$ denota o decil que contém as ações mais líquidas (maiores valores de Turnover), B denota o decil que contém as ações menos líquidas (menores valores de Turnover) e B-S é a diferença entre B e S. A estratégia 1x1 refere-se a 1 mês para cálculo da medida de liquidez e 1 mês para retenção das carteiras. $O$ mesmo raciocínio é válido para as demais estratégias. As entradas de dados são os retornos \% médios mensais das carteiras. Os valores entre parênteses são a estatística $t$ (teste one-sample $t$ ). * indica que o coeficiente/teste é significativo a $1 \%$; e $* *$ significativo a $5 \%$.

\begin{tabular}{|c|c|c|c|c|c|c|c|c|c|c|c|}
\hline & $\mathbf{S}$ & D2 & D3 & D4 & D5 & D6 & D7 & D8 & D9 & B & B-S \\
\hline \multirow{2}{*}{$1 \times 1$} & $4,30^{*}$ & $3,65^{*}$ & $3,27^{*}$ & $4,09 *$ & $3,59 *$ & $4,23^{*}$ & $3,86^{*}$ & $3,85^{*}$ & $4,00 *$ & $4,86^{*}$ & 0,57 \\
\hline & $(5,93)$ & $(5,45)$ & $(5,35)$ & $(6,00)$ & $(5,87)$ & $(4,73)$ & $(6,25)$ & $(5,65)$ & $(5,89)$ & $(5,65)$ & $(\mathbf{0 , 8 5})$ \\
\hline \multirow{2}{*}{$1 \times 3$} & $3,50^{*}$ & $3,14 *$ & $3,18^{*}$ & $3,52^{*}$ & $3,39^{*}$ & $3,41^{*}$ & $3,23^{*}$ & $3,14 *$ & $3,10^{*}$ & $3,49^{*}$ & $-0,24$ \\
\hline & $(6,78)$ & $(6,05)$ & $(6,57)$ & $(7,58)$ & $(7,21)$ & $(6,81)$ & $(6,69)$ & $(6,56)$ & $(6,78)$ & $(6,55)$ & $(0,66)$ \\
\hline \multirow{2}{*}{$1 \times 6$} & $3,11^{*}$ & $2,70^{*}$ & $2,78^{*}$ & $3,08^{*}$ & $2,89 *$ & $3,03^{*}$ & $2,66^{*}$ & $2,80^{*}$ & $2,76^{*}$ & $2,61^{*}$ & $-0,98 *$ \\
\hline & $(8,17)$ & $(6,76)$ & $(7,26)$ & $(8,74)$ & $(8,34)$ & $(8,17)$ & $(7,28)$ & $(7,34)$ & $(7,71)$ & $(6,97)$ & $(3,47)$ \\
\hline \multirow{2}{*}{$1 \times 12$} & $2,68^{*}$ & $2,47^{*}$ & $2,58^{*}$ & $2,98^{*}$ & $2,65^{*}$ & $2,62 *$ & $2,44^{*}$ & $2,28^{*}$ & $2,30^{*}$ & $1,89^{*}$ & $-1,67 *$ \\
\hline & $(10,48)$ & $(10,07)$ & $(10,34)$ & $(12,19)$ & $(12,03)$ & $(11,69)$ & $(10,90)$ & $(9,25)$ & $(10,34)$ & $(8,60)$ & $(7,01)$ \\
\hline \multirow{2}{*}{$3 \times 1$} & $3,26^{*}$ & $3,01^{*}$ & $3,07 *$ & $3,39^{*}$ & $3,20^{*}$ & $3,11^{*}$ & $3,95^{*}$ & $3,40^{*}$ & $3,12 *$ & $3,14^{*}$ & $-0,12 *$ \\
\hline & $(4,85)$ & $(4,75)$ & $(4,76)$ & $(5,60)$ & $(5,59)$ & $(5,50)$ & $(3,71)$ & $(4,96)$ & $(5,09)$ & $(4,97)$ & $(0,25)$ \\
\hline \multirow{2}{*}{$3 \times 3$} & $2,90^{*}$ & $2,68^{*}$ & $2,58^{*}$ & $2,92 *$ & $2,68 *$ & $3,05^{*}$ & $2,65^{*}$ & $2,61 *$ & $2,70^{*}$ & $2,48^{*}$ & $-0,68^{*}$ \\
\hline & $(6,39)$ & $(5,67)$ & $(5,51)$ & $(7,24)$ & $(6,56)$ & $(6,66)$ & $(6,51)$ & $(5,80)$ & $(6,54)$ & $(5,71)$ & $(2,19)$ \\
\hline \multirow{2}{*}{$3 \times 6$} & $2,75^{*}$ & $2,28^{*}$ & $2,35^{*}$ & $2,86^{*}$ & $2,65^{*}$ & $2,32 *$ & $2,58^{*}$ & $2,22 *$ & $2,48^{*}$ & $1,97^{*}$ & $-1,41^{*}$ \\
\hline & $(8,18)$ & $(6,23)$ & $(6,87)$ & $(9,03)$ & $(8,54)$ & $(7,69)$ & $(8,11)$ & $(6,54)$ & $(8,01)$ & $(6,34)$ & $(4,74)$ \\
\hline \multirow{2}{*}{$3 \times 12$} & $2,38^{*}$ & $2,39^{*}$ & $2,39^{*}$ & $2,90 *$ & $2,47 *$ & $2,27^{*}$ & $2,40^{*}$ & $1,92^{*}$ & $2,17^{*}$ & $1,61^{*}$ & $-1,64 *$ \\
\hline & $(9,73)$ & $(9,96)$ & $(9,72)$ & $(12,49)$ & $(12,24)$ & $(11,37)$ & $(10,92)$ & $(8,50)$ & $(10,53)$ & $(8,05)$ & $(7,02)$ \\
\hline \multirow{2}{*}{$6 \times 1$} & $2,87^{*}$ & $2,22 *$ & $2,23 *$ & $2,44^{*}$ & $3,17^{*}$ & $2,56^{*}$ & $3,69^{*}$ & $1,99^{*}$ & $2,58^{*}$ & $2,08^{*}$ & $-0,79$ \\
\hline & $(4,71)$ & $(3,74)$ & $(4,18)$ & $(4,91)$ & $(5,51)$ & $(5,06)$ & $(3,09)$ & $(3,54)$ & $(3,58)$ & $(3,76)$ & $(1,66)$ \\
\hline \multirow{2}{*}{$6 \times 3$} & $2,46^{*}$ & $2,32 *$ & $2,16^{*}$ & $2,44 *$ & $2,54 *$ & $2,30 *$ & $2,58^{*}$ & $1,77^{*}$ & $2,33^{*}$ & $1,53^{*}$ & $-1,27 *$ \\
\hline & $(5,90)$ & $(5,32)$ & $(5,28)$ & $(6,58)$ & $(7,15)$ & $(6,47)$ & $(5,76)$ & $(4,42)$ & $(6,14)$ & $(4,29)$ & $(4,11)$ \\
\hline \multirow{2}{*}{$6 \times 6$} & $2,28^{*}$ & $2,30 *$ & $2,10^{*}$ & $2,60 *$ & $2,38^{*}$ & $2,09 *$ & $2,29 *$ & $1,66^{*}$ & $2,18^{*}$ & $1,49^{*}$ & $-1,52 *$ \\
\hline & $(7,09)$ & $(6,76)$ & $(6,65)$ & $(8,89)$ & $(8,56)$ & $(7,77)$ & $(7,21)$ & $(5,97)$ & $(7,43)$ & $(5,74)$ & $(4,85)$ \\
\hline \multirow{2}{*}{$6 \times 12$} & $2,26^{*}$ & $2,28^{*}$ & $2,35^{*}$ & $2,84 *$ & $2,34 *$ & $2,32 *$ & $2,20^{*}$ & $1,73^{*}$ & $1,87^{*}$ & $1,54^{*}$ & $-1,84^{*}$ \\
\hline & $(9,26)$ & $(9,44)$ & $(9,65)$ & $(12,21)$ & $(13,00)$ & $(11,19)$ & $(9,89)$ & $(8,30)$ & $(9,22)$ & $(8,22)$ & $(6,12)$ \\
\hline \multirow{2}{*}{$12 \times 1$} & $2,31^{*}$ & $2,44^{*}$ & $2,14^{*}$ & $2,97^{*}$ & $2,48 *$ & $2,45^{*}$ & $3,56^{*}$ & $1,85^{*}$ & $2,39^{*}$ & $1,54^{*}$ & $-0,77$ \\
\hline & $(3,66)$ & $(4,21)$ & $(3,89)$ & $(4,70)$ & $(4,85)$ & $(4,93)$ & $(2,40)$ & $(3,45)$ & $(2,98)$ & $(2,84)$ & $(1,70)$ \\
\hline \multirow{2}{*}{$12 \times 3$} & $2,10^{*}$ & $2,28^{*}$ & $2,42 *$ & $2,68^{*}$ & $2,37 *$ & $2,10^{*}$ & $2,47^{*}$ & $1,72^{*}$ & $1,96^{*}$ & $1,62 *$ & $-0,80$ * \\
\hline & $(5,00)$ & $(5,38)$ & $(5,78)$ & $(7,33)$ & $(7,03)$ & $(5,96)$ & $(5,06)$ & $(4,84)$ & $(4,80)$ & $(4,54)$ & $(2,56)$ \\
\hline \multirow{2}{*}{$12 \times 6$} & $2,08^{*}$ & $2,35^{*}$ & $2,44^{*}$ & $2,76^{*}$ & $2,49 *$ & $2,10^{*}$ & $2,24 *$ & $1,83^{*}$ & $1,85^{*}$ & $1,55^{*}$ & $-1,24^{*}$ \\
\hline & $(6,47)$ & $(7,08)$ & $(7,38)$ & $(9,31)$ & $(9,13)$ & $(7,91)$ & $(6,84)$ & $(6,70)$ & $(6,23)$ & $(5,89)$ & $(3,77)$ \\
\hline \multirow{2}{*}{$12 \times 12$} & $2,28^{*}$ & $2,34 *$ & $2,41 *$ & $2,86^{*}$ & $2,63 *$ & $2,14^{*}$ & $2,01^{*}$ & $1,81^{*}$ & $1,77^{*}$ & $1,38^{*}$ & $-1,53^{*}$ \\
\hline & $(9,53)$ & $(9,13)$ & $(10,45)$ & $(13,40)$ & $(13,61)$ & $(10,40)$ & $(9,07)$ & $(9,00)$ & $(8,73)$ & $(7,55)$ & $(7,06)$ \\
\hline
\end{tabular}


A Tabela 5, por sua vez, apresenta os retornos das carteiras e prêmios pela liquidez considerando o Return-to-Volume como medida de liquidez. É possível observar tanto prêmios B-S positivos quanto negativos ao longo das estratégias, não sendo possível identificar consistência nos prêmios. Além disso, a maior parte dos prêmios não se mostrou estatisticamente diferente de zero pelo teste $t$. Assim, ou a medida não é uma boa proxy para a dimensão impacto nos preços, ou essa dimensão parece não ser precificada no mercado acionário brasileiro. Os resultados não corroboram os achados de Amihud (2002) e Liu (2006) para o mercado norte-americano.

Finalmente, a Tabela 6 apresenta os retornos das carteiras e prêmios pela liquidez considerando o Coeficiente de Variação do Volume como medida de risco. Para todas as 12 estratégias, as 10 carteiras apresentaram retornos positivos e estatisticamente diferentes de zero, com exceção das estratégias 3x1, 6x1 e 6x3. Os prêmios pela liquidez (B-S) mostraram-se positivos e, em quase todas as estratégias, estatisticamente diferentes de zero. $\mathrm{O}$ maior prêmio foi encontrado pela estratégia $12 \times 6,1,55 \%$ ao mês, e o menor pela estratégia $3 \times 1,0,42 \%$ ao mês. Os prêmios para as estratégias que consideraram 12 meses para cálculo das medidas foram os que apresentaram maiores prêmios, o que é condizente com a natureza da medida - de dispersão - e a sua consequente necessidade de um longo horizonte temporal para cômputo. Nessas estratégias de mais longo prazo, como por exemplo a $12 \times 12$, o retorno das carteiras aumentou à medida que se aumentou o Coeficiente de Variação do Volume Financeiro negociado. Dessa forma, parece haver uma relação positiva entre volatilidade da liquidez e retorno, ou seja, a volatilidade da liquidez parece ser precificada no mercado acionário brasileiro. Esses resultados são contrários aos encontrados por Chordia et al (2001) para o mercado norte-americano, mas estão de acordo com as expectativas dos referidos autores. Segundo Chordia et al (2001) o motivo dessa relação positiva está no fato de os agentes do mercado serem avessos ao risco e não desejarem fortes variações na liquidez do papel. Desta forma, ações com grande variabilidade na liquidez deveriam apresentar altos retornos esperados. 
Tabela 5 - Desempenho das carteiras classificadas conforme o Return-to-Volume

Essa tabela apresenta o desempenho das carteiras considerando todas as ações da amostra de 1995 a 2011 . No início de cada mês t, de julho de 1995 a novembro de 2011, as ações elegíveis da BM\&FBOVESPA são classificadas conforme o Return-to-Volume. Os critérios de seleção das medidas de liquidez são explicados no subcapítulo 4.1.1 Baseado nessa classificação, as ações são agrupadas em 10 carteiras equally weighted e mantidas por $x$ meses $(x=1,3,6$ e 12 meses). $\mathbf{S}$ denota o decil que contém as ações mais líquidas (menores valores de Return-to-Volume), B denota o decil que contém as ações menos líquidas (maiores valores de Return-to-Volume) e B-S é a diferença entre $\mathbf{B}$ e $\mathbf{S}$. A estratégia 1x1 refere-se a 1 mês para cálculo da medida de liquidez e 1 mês para a retenção das carteiras. O mesmo raciocínio é válido para as demais estratégias. As entradas de dados são os retornos \% médios mensais das carteiras. Os valores entre parênteses são a estatística $t$ (one-sample $t$ ). * indica que o coeficiente/teste é significativo a $1 \%$ e $* *$ significativo a $5 \%$.

\begin{tabular}{|c|c|c|c|c|c|c|c|c|c|c|c|}
\hline & S & D2 & D3 & D4 & D5 & D6 & D7 & D8 & D9 & B & B-S \\
\hline \multirow{2}{*}{$1 \times 1$} & $6,89^{*}$ & $3,92 *$ & $2,74^{*}$ & $2,53^{*}$ & $2,73 *$ & $2,99 *$ & $3,6^{*}$ & $4,11 *$ & $4,98^{*}$ & $3,88^{*}$ & $-3,02 *$ \\
\hline & $(9,38)$ & $(5,44)$ & $(4,31)$ & $(3,68)$ & \begin{tabular}{|l|}
$(4,23)$ \\
\end{tabular} & $(4,60)$ & $(5,42)$ & $(6,46)$ & $(5,43)$ & $(5,44)$ & $(5,59)$ \\
\hline \multirow{2}{*}{$1 \times 3$} & $4,47^{*}$ & $3,22 *$ & $2,46^{*}$ & $2,23^{*}$ & $2,42 *$ & $2,71^{*}$ & $3,01 *$ & $3,58^{*}$ & $3,97 *$ & $4,53^{*}$ & $-0,78$ \\
\hline & $(8,18)$ & $(6,52)$ & $(5,07)$ & $(4,49)$ & \begin{tabular}{|l|}
$(4,92)$ \\
\end{tabular} & $(5,83)$ & $(6,31)$ & $(7,44)$ & $(8,49)$ & $(8,45)$ & $(1,05)$ \\
\hline \multirow{2}{*}{$1 \times 6$} & $3,78^{*}$ & $2,45^{*}$ & $2,23^{*}$ & $1,85^{*}$ & $2,16^{*}$ & $2,29 *$ & $2,57 *$ & $3,22 *$ & $3,51^{*}$ & $3,96^{*}$ & $\mathbf{0 , 3 0}$ \\
\hline & $(9,42)$ & $(6,98)$ & $(6,12)$ & $(5,07)$ & $(5,80)$ & $(6,45)$ & $(7,19)$ & $(8,81)$ & $(9,33)$ & $(9,92)$ & $(0,99)$ \\
\hline \multirow{2}{*}{$1 \times 12$} & $3,04^{*}$ & $2,33^{*}$ & $1,97^{*}$ & $1,74^{*}$ & $1,91^{*}$ & $1,94^{*}$ & $2,15^{*}$ & $2,72 *$ & $3,19 *$ & $3,58^{*}$ & 0,36 \\
\hline & $(12,01)$ & $(9,62)$ & $(8,67)$ & $(8,01)$ & $(8,25)$ & $(9,18)$ & $(9,18)$ & $(11,43)$ & $(12,85)$ & $(13,53)$ & $(1,09)$ \\
\hline \multirow{2}{*}{$3 \times 1$} & $5,04^{*}$ & $3,20 *$ & $2,30^{*}$ & $1,74^{*}$ & $2,33^{*}$ & $3,04 *$ & $3,43^{*}$ & $3,78^{*}$ & $4,10^{*}$ & $3,47^{*}$ & $-1,57^{*}$ \\
\hline & $(7,18)$ & $(3,10)$ & $(3,55)$ & $(2,71)$ & $(3,53)$ & $(4,66)$ & $(5,43)$ & $(5,47)$ & $(6,91)$ & $(5,79)$ & $(2,94)$ \\
\hline \multirow{2}{*}{$3 \times 3$} & $3,27^{*}$ & $2,34^{*}$ & $1,82^{*}$ & $1,7^{*}$ & $1,86^{*}$ & $2,36^{*}$ & $2,90 *$ & $3,22 *$ & $3,64^{*}$ & $3,92^{*}$ & $\mathbf{0 , 3 0}$ \\
\hline & $(7,03)$ & $(5,40)$ & $(4,20)$ & $(3,74)$ & $(4,22)$ & $(5,54)$ & $(6,41)$ & $(7,39)$ & $(7,81)$ & $(9,15)$ & $(0,73)$ \\
\hline \multirow{2}{*}{$3 \times 6$} & $2,81^{*}$ & $2,07 *$ & $1,48^{*}$ & $1,69^{*}$ & \begin{tabular}{|l|}
$1,82 *$ \\
\end{tabular} & $2,09 *$ & $2,38 *$ & $2,76^{*}$ & $3,37 *$ & $3,74^{*}$ & $0,79 * *$ \\
\hline & $(8,26)$ & $(6,28)$ & $(4,57)$ & $(5,19)$ & \begin{tabular}{|l|}
$(5,72)$ \\
\end{tabular} & $(6,76)$ & $(7,32)$ & $(8,10)$ & $(10,33)$ & $(10,56)$ & $(2,22)$ \\
\hline \multirow{2}{*}{$3 \times 12$} & $2,65^{*}$ & $2,10^{*}$ & $1,59^{*}$ & $1,77^{*}$ & $1,86^{*}$ & $1,82 *$ & $2,06^{*}$ & $2,47^{*}$ & $3,00 *$ & $3,30^{*}$ & $\mathbf{0 , 3 4}$ \\
\hline & $(11,45)$ & $(8,59)$ & $(7,05)$ & $(8,24)$ & $(8,87)$ & $(9,23)$ & $(9,55)$ & $(11,12)$ & $(12,71)$ & $(13,65)$ & $(1,14)$ \\
\hline \multirow{2}{*}{$6 \times 1$} & $3,49^{*}$ & $2,45 * *$ & $1,60^{*}$ & $1,55^{*}$ & $1,68 *$ & $2,60^{*}$ & $2,58^{*}$ & $3,36^{*}$ & $3,46^{*}$ & $3,15^{*}$ & $-0,34$ \\
\hline & $(5,35)$ & $(2,10)$ & $(2,79)$ & $(2,56)$ & \begin{tabular}{|l|}
$(2,60)$ \\
\end{tabular} & $(4,15)$ & $(4,64)$ & $(6,20)$ & $(5,52)$ & $(6,01)$ & $(0,61)$ \\
\hline \multirow{2}{*}{$6 \times 3$} & $2,46^{*}$ & $2,32 *$ & $2,16^{*}$ & $2,44^{*}$ & $2,54 *$ & $2,30 *$ & $2,58 *$ & $1,77^{*}$ & $2,33^{*}$ & $1,53^{*}$ & $-1,27^{*}$ \\
\hline & $(5,90)$ & $(5,32)$ & $(5,28)$ & $(6,58)$ & \begin{tabular}{|l|}
$(7,15)$ \\
\end{tabular} & $(6,47)$ & $(5,76)$ & $(4,42)$ & $(6,14)$ & $(4,29)$ & $(4,11)$ \\
\hline \multirow{2}{*}{$6 \times 6$} & $2,28^{*}$ & $2,30 *$ & $2,10^{*}$ & $2,60^{*}$ & $2,38 *$ & $2,09^{*}$ & $2,29 *$ & $1,66^{*}$ & $2,18^{*}$ & $1,49^{*}$ & $-1,52 *$ \\
\hline & $(7,09)$ & $(6,76)$ & $(6,65)$ & $(8,89)$ & $(8,56)$ & $(7,77)$ & $(7,21)$ & $(5,97)$ & $(7,43)$ & $(5,74)$ & $(4,85)$ \\
\hline \multirow{2}{*}{$6 \times 12$} & $2,42 *$ & $2,00^{*}$ & $1,71^{*}$ & $1,59^{*}$ & $1,63 *$ & $1,66^{*}$ & $1,91^{*}$ & $2,37^{*}$ & $2,93 *$ & $3,33^{*}$ & $\mathbf{0 , 6 0 * *}$ \\
\hline & $(10,75)$ & $(8,29)$ & $(7,39)$ & $(7,44)$ & $(7,93)$ & $(8,33)$ & $(9,62)$ & $(11,36)$ & $(13,12)$ & $(13,92)$ & $(2,14)$ \\
\hline \multirow{2}{*}{$12 \times 1$} & $2,91^{*}$ & $1,84^{*}$ & $1,68^{*}$ & $1,73^{*}$ & $1,89^{*}$ & $2,18^{*}$ & $2,05^{*}$ & $4,09^{*}$ & $3,18^{*}$ & $2,57^{*}$ & $-0,34$ \\
\hline & $(4,07)$ & $(3,67)$ & $(2,98)$ & $(2,77)$ & $(3,03)$ & $(3,27)$ & $(3,80)$ & $(2,76)$ & $(4,48)$ & $(5,69)$ & $(\mathbf{0 , 5 3 )}$ \\
\hline \multirow{2}{*}{$12 \times 3$} & $2,42^{*}$ & $1,99 *$ & $1,80^{*}$ & $1,46^{*}$ & \begin{tabular}{|l|}
$1,61^{*}$ \\
\end{tabular} & $1,81 *$ & $2,01 *$ & $2,41^{*}$ & $3,21^{*}$ & $2,91^{*}$ & 0,21 \\
\hline & $(5,88)$ & $(5,30)$ & $(4,24)$ & $(3,58)$ & $(3,83)$ & $(4,53)$ & $(5,63)$ & $(6,84)$ & $(6,57)$ & $(8,20)$ & $(0,62)$ \\
\hline \multirow{2}{*}{$12 \times 6$} & $2,36^{*}$ & $2,22 *$ & $1,89^{*}$ & $1,52^{*}$ & $1,49 *$ & $1,62^{*}$ & $2,02 *$ & $2,30^{*}$ & $2,93 *$ & $3,25^{*}$ & $\mathbf{0 , 3 7}$ \\
\hline & $(7,47)$ & $(6,91)$ & $(5,90)$ & $(4,81)$ & $(4,93)$ & $(5,50)$ & $(7,47)$ & $(8,34)$ & $(9,62)$ & $(11,03)$ & $(0,96)$ \\
\hline \multirow{2}{*}{$12 \times 12$} & $2,53^{*}$ & $2,42 *$ & $2,02 *$ & $1,64^{*}$ & $1,67^{*}$ & $1,61^{*}$ & $1,66^{*}$ & $2,12 *$ & $2,63 *$ & $3,20^{*}$ & $\mathbf{0 , 2 3}$ \\
\hline & $(10,25)$ & $(9,82)$ & $(7,81)$ & $(8,00)$ & $(8,04)$ & $(7,60)$ & $(8,69)$ & $(11,03)$ & $(13,12)$ & $(14,45)$ & $(0,69)$ \\
\hline
\end{tabular}


Tabela 6 - Desempenho das carteiras classificadas conforme o Coeficiente de Variação do Volume

Essa tabela apresenta o desempenho das carteiras considerando todas as ações da amostra de 1995 a 2011 . No início de cada mês $t$, de julho de 1995 a novembro de 2011, as ações elegíveis da BM\&FBOVESPA são classificadas conforme o Coeficiente de Variação do Volume Financeiro. Os critérios de seleção das medidas de liquidez são explicados no subcapítulo 4.1.1. Baseado em cada classificação, as ações são agrupadas em 10 carteiras equally weighted e mantidas por $x$ meses ( $x=1,3,6$ e 12 meses). $\mathbf{S}$ denota o decil que contém as ações mais líquidas (menores valores de Coeficiente de Variação do Volume Financeiro), B denota o decil que contém as ações menos líquidas (maiores valores de Coeficiente de Variação do Volume Financeiro) e B-S é a diferença entre $\mathbf{B}$ e $\mathbf{S}$. A estratégia $3 \times 1$ refere-se a 3 mês para cálculo da medida de liquidez e 1 mês para retenção das carteiras. O mesmo raciocínio é válido para as demais estratégias. As entradas de dados são os retornos \% médios mensais das carteiras. Os valores entre parênteses são a estatística $t$ (one-sample $t$ ). * indica que o coeficiente/teste é significativo a $1 \%$ e ** significativo a $5 \%$.

\begin{tabular}{|c|c|c|c|c|c|c|c|c|c|c|c|}
\hline & $\mathbf{S}$ & D2 & D3 & D4 & D5 & D6 & D7 & D8 & D9 & B & B-S \\
\hline \multirow{2}{*}{$3 \times 1$} & $2,84^{*}$ & $2,65^{*}$ & $3,14^{*}$ & $2,78^{*}$ & $3,19^{*}$ & $3,10 *$ & $4,43^{*}$ & $3,74^{*}$ & $3,35^{*}$ & $3,25^{*}$ & 0,42 \\
\hline & $(3,86)$ & $(4,26)$ & $(5,20)$ & $(4,40)$ & $(5,56)$ & $(5,09)$ & $(4,16)$ & $(6,14)$ & $(5,41)$ & $(5,06)$ & $(0,67)$ \\
\hline \multirow{2}{*}{$3 \times 3$} & $2,07 *$ & $2,29 *$ & $2,40^{*}$ & $2,39^{*}$ & $2,75^{*}$ & $2,77^{*}$ & $3,35^{*}$ & $2,99^{*}$ & $3,03^{*}$ & $3,12 *$ & $0,90 *$ \\
\hline & $(4,78)$ & $(5,38)$ & $(5,62)$ & $(5,44)$ & $(6,53)$ & $(6,43)$ & $(6,81)$ & $(7,20)$ & $(7,21)$ & $(7,04)$ & $(2,81)$ \\
\hline \multirow{2}{*}{$3 \times 6$} & $1,94^{*}$ & $2,03 *$ & $2,13 *$ & $2,30^{*}$ & $2,48^{*}$ & $2,43^{*}$ & $2,88^{*}$ & $2,59 *$ & $2,75^{*}$ & $2,95^{*}$ & 0,93* \\
\hline & $(6,40)$ & $(6,51)$ & $(6,89)$ & $(6,99)$ & $(7,76)$ & $(7,33)$ & $(8,41)$ & $(8,03)$ & $(8,52)$ & $(8,79)$ & $(3,76)$ \\
\hline \multirow{2}{*}{$3 \times 12$} & $1,87^{*}$ & $1,91^{*}$ & $2,08^{*}$ & $2,07^{*}$ & $2,25^{*}$ & $2,41^{*}$ & $2,36^{*}$ & $2,56^{*}$ & $2,52 *$ & $2,86^{*}$ & $1,00 *$ \\
\hline & $(9,33)$ & $(8,96)$ & $(9,94)$ & $(9,28)$ & $(10,47)$ & $(11,48)$ & $(10,06)$ & $(11,10)$ & $(11,07)$ & $(11,69)$ & $(4,50)$ \\
\hline \multirow{2}{*}{$6 \times 1$} & $2,10^{*}$ & $1,90^{*}$ & $2,32 *$ & $2,21^{*}$ & $2,72^{*}$ & $3,53^{*}$ & $2,32^{*}$ & $3,21^{*}$ & $3,18^{*}$ & $2,39^{*}$ & 0,30 \\
\hline & $(3,50)$ & $(3,41)$ & $(4,19)$ & $(4,12)$ & $(3,64)$ & $(2,97)$ & $(4,58)$ & $(5,38)$ & $(5,54)$ & $(4,80)$ & $(0,55)$ \\
\hline \multirow{2}{*}{$6 \times 3$} & $1,66^{*}$ & $1,73^{*}$ & $1,87^{*}$ & $1,97^{*}$ & $2,45^{*}$ & $2,53^{*}$ & $2,33^{*}$ & $2,49^{*}$ & $2,87^{*}$ & $2,50^{*}$ & 0,66 \\
\hline & $(4,45)$ & $(4,85)$ & $(4,78)$ & $(4,92)$ & $(5,82)$ & $(5,81)$ & $(5,95)$ & $(6,35)$ & $(7,06)$ & $(6,61)$ & $(1,91)$ \\
\hline \multirow{2}{*}{$6 \times 6$} & $1,52^{*}$ & $1,63^{*}$ & $1,79^{*}$ & $1,85^{*}$ & $2,47^{*}$ & $2,19^{*}$ & $2,2 *$ & $2,31 *$ & $2,77^{*}$ & $2,71^{*}$ & $1,19 *$ \\
\hline & $(5,78)$ & $(6,07)$ & $(6,13)$ & $(6,22)$ & $(7,58)$ & $(7,61)$ & $(7,28)$ & $(7,67)$ & $(9,04)$ & $(8,73)$ & $(5,22)$ \\
\hline \multirow{2}{*}{$6 \times 12$} & $1,61^{*}$ & $1,65^{*}$ & $2,04 *$ & $1,89^{*}$ & $2,11^{*}$ & $2,40^{*}$ & $2,32^{*}$ & $2,43^{*}$ & $2,64 *$ & $2,70^{*}$ & $1,24 *$ \\
\hline & $(8,80)$ & $(8,31)$ & $(9,18)$ & $(9,24)$ & $(9,18)$ & $(11,43)$ & $(10,64)$ & $(10,91)$ & $(11,11)$ & $(11,88)$ & $(6,60)$ \\
\hline \multirow{2}{*}{$12 \times 1$} & $1,64^{*}$ & $1,80^{*}$ & $2,20^{*}$ & $2,10^{*}$ & $3,62^{*}$ & $2,14 *$ & $2,42 *$ & $2,68^{*}$ & $2,41^{*}$ & $3,01^{*}$ & $1,38 * *$ \\
\hline & $(2,86)$ & $(3,01)$ & $(3,93)$ & $(3,79)$ & $(2,43)$ & $(3,78)$ & $(4,83)$ & $(4,11)$ & $(4,75)$ & $(4,04)$ & $(2,22)$ \\
\hline \multirow{2}{*}{$12 \times 3$} & $1,42^{*}$ & $1,55^{*}$ & $1,97^{*}$ & $2,36^{*}$ & $2,07^{*}$ & $2,29 *$ & $2,20^{*}$ & $2,42 *$ & $2,66^{*}$ & $2,91^{*}$ & $1,47^{*}$ \\
\hline & $(3,98)$ & $(4,26)$ & $(5,11)$ & $(5,06)$ & $(5,78)$ & $(6,10)$ & $(5,79)$ & $(6,18)$ & $(6,33)$ & $(6,67)$ & $(4,68)$ \\
\hline \multirow{2}{*}{$12 \times 6$} & $1,30^{*}$ & $1,55^{*}$ & $1,76^{*}$ & $2,33^{*}$ & $2,28^{*}$ & $2,26^{*}$ & $2,31^{*}$ & $2,40^{*}$ & $2,72 *$ & $2,83^{*}$ & $1,55^{*}$ \\
\hline & $(5,08)$ & $(5,81)$ & $(6,18)$ & $(6,85)$ & $(8,12)$ & $(7,72)$ & $(7,51)$ & $(7,67)$ & $(8,85)$ & $(8,78)$ & $(6,28)$ \\
\hline \multirow{2}{*}{$12 \times 12$} & $1,46^{*}$ & $1,48^{*}$ & $1,80^{*}$ & $2,00^{*}$ & $2,31^{*}$ & $2,41^{*}$ & $2,37^{*}$ & $2,53^{*}$ & $2,52 *$ & $2,84^{*}$ & $1,53^{*}$ \\
\hline & $(7,95)$ & $(7,94)$ & $(8,05)$ & $(9,24)$ & $(10,57)$ & $(10,72)$ & $(10,02)$ & $(10,66)$ & $(11,44)$ & $(13,17)$ & $(7,80)$ \\
\hline
\end{tabular}


Apesar das evidências da precificação da variabilidade do Volume Financeiro no mercado acionário brasileiro, devido ao fato de o Coeficiente de Variação do Volume Financeiro ser uma medida de volatilidade da liquidez e dada a forte correlação encontrada entre esea medida e o Índice de Negociabilidade da BM\&FBOVESPA, -0,62, desse ponto da pesquisa em diante optou-se por não prosseguir com o Coeficiente de Variação do Volume Financeiro.

Assim, as próximas seções abordam testes de robustez dos prêmios pela liquidez encontrados com a medida Índice de Negociabilidade da BM\&FBOVESPA. Bem como, desse ponto em diante, optou-se por considerar apenas a estratégia $6 \times 6$, pelo fato de ser a estratégia que apresentou prêmios de magnitudes intermediárias, quando comparada com as estratégias mais curtas e mais longas, tanto para o cálculo das medidas quanto para a formação das carteiras.

\subsubsection{Testes de robustez dos prêmios pela liquidez}

Esse subcapítulo analisa os resultados dos testes de robustez dos prêmios pela liquidez. Inicialmente, são apresentados e analisados os testes de subamostras e, posteriormente, os testes de subperíodos e de efeitos sazonais.

\subsubsection{Testes de subamostras}

A Tabela 7 apresenta os resultados dos testes de subamostras estratificadas com base em: tamanho (VM - Valor de Mercado), índice B/M e momento. Cada subamostra para VM, índice B/M e momento contém $1 / 3$ das ações da amostra no início de cada período de retenção. Então, em cada subamostra, no início de cada mês $t$, de julho de 1995 a novembro de 2011, as ações elegíveis foram classificadas conforme o Índice de Negociabilidade da BM\&FBOVESPA, calculado com base na média dos valores do índice nos 6 meses prévios (NEG6). Baseado nessa classificação, as ações foram agrupadas em 5 carteiras com retornos calculados equally weighted e mantidas por 6 meses. Dessa forma, foi considerada a estratégia 6x6. Os painéis $\mathrm{A}, \mathrm{B}$ e $\mathrm{C}$ referem-se às subamostras estratificadas com base em $\mathrm{VM}$, índice B/M e momento, respectivamente. 
Tabela 7 - Análise de subamostras com carteiras classificadas conforme o Índice de Negociabilidade da BM\&FBOVESPA e a estratégia $6 \times 6$.

Essa tabela apresenta a análise de subamostras estratificadas com base em: VM (Valor de Mercado ou tamanho), índice B/M e momento. Cada subamostra para VM, índice B/M e momento contém 1/3 das ações da amostra no início de cada período de retenção. Por exemplo, para as 3 subamostras baseadas em VM, o Low-VM contém o terço das ações com menores VM no início de cada período de retenção; o Medium-VM contém o terço médio das ações baseado em VM no início de cada período de retenção; e o $\boldsymbol{H i g h} \boldsymbol{V} \boldsymbol{V}$ contém o terço das ações com maiores VM no início de cada período de retenção. Então, em cada subamostra, no início de cada mês $t$, de julho de 1995 a novembro de 2011, as ações elegíveis foram classificadas conforme o Índice de Negociabilidade da BM\&FBOVESPA, calculado com base na média dos valores do índice nos 6 meses prévios (NEG6). Baseado nessa classificação, as ações foram agrupadas em 5 carteiras com retornos calculados equally weighted e mantidas por 6 meses. Dessa forma, foi considerada a estratégia 6x6. Os painéis A, B e C referem-se às subamostras estratificadas com base em VM, índice B/M e momento, respectivamente. $\mathbf{S}$ denota o quintil que contém as ações mais líquidas (maiores valores de Índice de Negociabilidade da BM\&FBOVESPA) e B denota o quintil que contém as ações menos líquidas (menores valores de Índice de Negociabilidade da BM\&FBOVESPA) e B-S é a diferença entre B e S. Para cálculos que envolvam o índice B/M foram excluídas as ações de empresas financeiras e com Patrimônio Líquido negativo. Além disso, vale a ressalva de que os valores de índice $\mathrm{B} / \mathrm{M}$ foram calculados no final de cada trimestre e mantidos para os 2 meses subsequentes, devido à necessidade de uso do valor de Patrimônio Líquido das empresas que são divulgados em bases trimestrais. As entradas de dados são os retornos \% médios mensais das carteiras. Os valores entre parênteses são a estatística $t$ (one-sample $t) . *$ indica que o coeficiente/teste é significativo a $1 \%$ e ** significativo a $5 \%$

\begin{tabular}{|c|c|c|c|}
\hline \multicolumn{4}{|c|}{ Painel A - Subamostra VM } \\
\hline Carteira & Low-VM & Medium-VM & High-VM \\
\hline \multirow[b]{2}{*}{ B } & $3,09 *$ & $2,47 *$ & $2,22 *$ \\
\hline & $(10,49)$ & $(8,75)$ & $(7,48)$ \\
\hline \multirow[b]{2}{*}{ Q2 } & $2,48^{*}$ & $2,87 *$ & $1,81 *$ \\
\hline & $(8,16)$ & $(8,59)$ & $(7,27)$ \\
\hline \multirow[b]{2}{*}{ Q3 } & $2,42 *$ & $2,34 *$ & $1,53 *$ \\
\hline & $(6,91)$ & $(6,97)$ & $(5,89)$ \\
\hline \multirow[b]{2}{*}{ Q4 } & $2,85 *$ & $1,98 *$ & $1,23 *$ \\
\hline & $(7,97)$ & $(5,23)$ & $(4,69)$ \\
\hline \multirow[b]{2}{*}{$\mathbf{S}$} & $2,13 *$ & $1,34 *$ & $1,39 *$ \\
\hline & $(5,41)$ & $(3,72)$ & $(4,98)$ \\
\hline \multirow[b]{2}{*}{ B-S } & $0,95 *$ & $1,13 *$ & $\mathbf{0 , 8 3 *}$ \\
\hline & $(3,08)$ & $(4,25)$ & $(3,28)$ \\
\hline \multicolumn{4}{|c|}{ Painel B - Subamostra índice B/M } \\
\hline Carteira & $L o w-B / M$ & Medium-B/M & High-B/M \\
\hline \multirow[b]{2}{*}{ B } & $2,51 *$ & $2,39 *$ & $3,22 *$ \\
\hline & $(7,06)$ & $(8,56)$ & $(10,31)$ \\
\hline \multirow[b]{2}{*}{ Q2 } & $2,69 *$ & $2,51 *$ & $2,81 *$ \\
\hline & $(7,92)$ & $(8,10)$ & $(9,18)$ \\
\hline \multirow[b]{2}{*}{ Q3 } & $1,78^{*}$ & $2,06^{*}$ & $2,50 *$ \\
\hline & $(5,80)$ & $(6,97)$ & $(6,87)$ \\
\hline \multirow[b]{2}{*}{ Q4 } & $1,47 *$ & $1,60 *$ & $2,27 *$ \\
\hline & $(5,05)$ & $(5,10)$ & $(5,72)$ \\
\hline \multirow[b]{2}{*}{$\mathbf{S}$} & $1,41 *$ & $1,32 *$ & $1,65^{*}$ \\
\hline & $(5,30)$ & $(4,56)$ & $(5,05)$ \\
\hline \multirow[b]{2}{*}{ B-S } & $1,10 *$ & $1,08 *$ & $1,57 *$ \\
\hline & $(3,81)$ & $(5,26)$ & $(5,18)$ \\
\hline
\end{tabular}




\begin{tabular}{|c|c|c|c|}
\hline \multicolumn{4}{|c|}{ Painel C - Subamostra momento } \\
\hline Carteira & Low-Momento & Medium-Momento & High-Momento \\
\hline \multirow{2}{*}{ 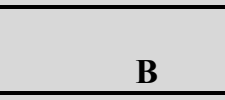 } & $2,50^{*}$ & $2,99 *$ & $3,08^{*}$ \\
\hline & $(7,61)$ & $(10,27)$ & $(10,32)$ \\
\hline \multirow[b]{2}{*}{ Q2 } & $2,34^{*}$ & $2,53 *$ & $3,05^{*}$ \\
\hline & $(6,31)$ & $(8,69)$ & $(9,34)$ \\
\hline \multirow[b]{2}{*}{ Q3 } & $1,75^{*}$ & $2,04 *$ & $2,78^{*}$ \\
\hline & $(4,72)$ & $(6,74)$ & $(8,75)$ \\
\hline \multirow[b]{2}{*}{ Q4 } & $1,40^{*}$ & $1,64 *$ & $2,29^{*}$ \\
\hline & $(3,99)$ & $(5,44)$ & $(7,62)$ \\
\hline \multirow[b]{2}{*}{$\mathbf{S}$} & $0,91^{*}$ & $1,49^{*}$ & $1,38^{*}$ \\
\hline & $\begin{array}{l}(2,68) \\
\end{array}$ & $(5,69)$ & $(4,72)$ \\
\hline \multirow[b]{2}{*}{ B-S } & $1,59 *$ & 1,50 * & $1,70^{*}$ \\
\hline & $(4,97)$ & $(6,57)$ & $(6,45)$ \\
\hline
\end{tabular}

Os resultados da Tabela 7 evidenciam que as diferenças de retorno entre as carteiras menos líquidas (B) e as mais líquidas (S) foram positivas e estatisticamente diferentes de zero em todas as subamostras. Esse fato corrobora as evidências encontradas por Liu (2006) no mercado norte-americano: os fatores tamanho, índice B/M e momento não parecem capazes de capturar ou explicar o fator liquidez.

Observa-se no Painel A que os menores prêmios pela liquidez foram encontrados na subamostra High-VM-0,83\% -, o que parece bastante coerente com a intuição, uma vez que as empresas com maior valor de mercado tendem a ser as mais líquidas. Resultados semelhantes foram encontrados por Liu (2006). Porém, na pesquisa de Liu (2006), a subamostra High-VM não apresentou prêmio estatisticamente significante pela liquidez.

O painel B mostra que o prêmio pela liquidez se manteve positivo e estatisticamente diferente de zero nas subamostras criadas com base no índice B/M. Semelhante ao encontrado por Liu (2006) para o mercado norte-americano, a subamostra que apresentou o maior prêmio médio foi a High-BM.

O painel C, por sua vez, mostra que os prêmios pela liquidez se mostraram estatisticamente positivos também nas 3 subamostras que consideram o retorno passado - momento - como critério de segregação. Essas evidências são semelhantes à de Liu (2006), mas contrárias às de Lee e Swaminathan (2000), ambas para o mercado norte-americano. Lee e Swaminathan (2000) mostraram que a liquidez - medida pelo turnover - só afeta retornos futuros de carteiras perdedoras, isto é, que apresentam fraco desempenho passado nos últimos 6 meses. 
Em linhas gerais, os resultados da Tabela 7 mostram que no mercado brasileiro os prêmios pela liquidez são mais pronunciados em empresas de tamanho médio - Medium- $M V$, com altos índices $\mathrm{B} / \mathrm{M}$ - High-B/M, altos retornos passados - High-Momento e que, entretanto, os prêmios encontrados não parecem ser direcionados por quaisquer desses fatores.

Adicionalmente, para se verificar a influência dos efeitos das alterações da legislação contábil nos cálculos do índice $\mathrm{B} / \mathrm{M}$, os testes apresentados no painel $\mathrm{B}$ foram refeitos considerando o período anterior ao início das modificações contábeis, ou seja, de julho de 1995 a dezembro de 2007. Os resultados são apresentados na Tabela 8.

A análise da Tabela 8 permite observar que, apesar de haver encontrado prêmios em geral com magnitudes inferiores aos encontrados com a amostra que considerou todo o período amostral, os prêmios mantiveram-se fortes - de $0,99 \%$ a $1,31 \%$ ao mês - e estatisticamente significativos nas três subamostras criadas com base no índice B/M.

Tabela 8 - Análise de subamostras segregadas conforme o índice B/M com carteiras classificadas conforme o Índice de Negociabilidade da BM\&FBOVESPA e a estratégia 6x6, considerando o período de 1995 a 2007.

Essa tabela apresenta a análise de subamostras estratificadas com base em: índice B/M no período de julho de 1995 a dezembro de 2007, ou seja, anterior ao início do processo de alteração da legislação contábil brasileira no rumo às normas internacionais de contabilidade. Cada subamostra para índice B/M contém 1/3 das ações da amostra no início de cada período de retenção. Então, em cada subamostra, no início de cada mês $t$, de julho de 1995 a dezembro de 2007, as ações elegíveis foram classificadas conforme o Índice de Negociabilidade da BM\&FBOVESPA calculado com base na média dos valores do índice nos 6 meses prévios (NEG6). Baseado nessa classificação, as ações foram agrupadas em 5 carteiras com retornos calculados equally weighted e mantidas por 6 meses. Dessa forma, foi considerada a estratégia 6x6. S denota o quintil que contém as ações mais líquidas (maiores valores de Índice de Negociabilidade da BM\&FBOVESPA) e B denota o quintil que contém as ações menos líquidas (menores valores de Índice de Negociabilidade da BM\&FBOVESPA) e B-S é a diferença entre $\mathbf{B}$ e $\mathbf{S}$. Foram excluídas as ações de empresas financeiras e com Patrimônio Líquido negativo, devido às distorções que elas podem causar no índice B/M. Além disso, vale a ressalva de que os valores de índice $\mathrm{B} / \mathrm{M}$ foram calculados no final de cada trimestre e mantidos para os 2 meses subsequentes, devido à necessidade de uso do valor de Patrimônio Líquido das empresas que são divulgados em bases trimestrais. As entradas de dados são os retornos \% médios mensais das carteiras. Os valores entre parênteses são a estatística $t$ (one-sample $t) . *$ indica que o coeficiente/teste é significativo a $1 \% \mathrm{e} * *$ significativo a $5 \%$

\begin{tabular}{|c|c|c|c|}
\hline & Low-B/M & Medium-B/M & High-B/M \\
\hline \multirow[b]{2}{*}{ B } & $2,72^{*}$ & $2,89^{*}$ & $2,81^{*}$ \\
\hline & $(6,51)$ & $(9,16)$ & $(7,45)$ \\
\hline \multirow[b]{2}{*}{ Q2 } & $2,74^{*}$ & $3,04^{*}$ & $1,88^{*}$ \\
\hline & $(7,11)$ & $(7,91)$ & $(4,84)$ \\
\hline \multirow[b]{2}{*}{ Q3 } & $1,56^{*}$ & $2,27^{*}$ & $1,78^{*}$ \\
\hline & $(4,59)$ & $(6,21)$ & $(4,54)$ \\
\hline \multirow[b]{2}{*}{ Q4 } & $1,27 *$ & $1,95^{*}$ & $1,44^{*}$ \\
\hline & $(3,83)$ & $(5,41)$ & $(4,36)$ \\
\hline \multirow[b]{2}{*}{ S } & $1,41^{*}$ & $1,91^{*}$ & $1,81^{*}$ \\
\hline & $(4,77)$ & $(6,94)$ & $(5,89)$ \\
\hline \multirow[b]{2}{*}{ B-S } & $1,31^{*}$ & $0,99 *$ & $1,00^{*}$ \\
\hline & $(3,89)$ & $(3,35)$ & $(2,99)$ \\
\hline
\end{tabular}




\subsubsection{Testes de subperíodos e efeitos sazonais}

A Tabela 9 apresenta a análise de subperíodos e efeitos sazonais para a verificação de possíveis vieses por seleção de período amostral e existência do efeito janeiro. Os resultados da Tabela 9, painel A, mostram que os prêmios pela liquidez não parecem estar restritos ao mês de janeiro no mercado acionário brasileiro, pois com a exclusão dos meses de janeiro da amostra continuam se observando prêmios pela liquidez estatisticamente diferentes de zero e de elevada magnitude - média de 1,91\% ao mês. Essas evidências, fortalecem os achados de Vieira e Milach (2008) e Machado e Medeiros (2011) para o mercado acionário brasileiro e de Datar et al (1998) e Liu (2006) para o mercado norte-americano, bem como contrariam as evidências de Eleswarapu e Reinganum (1993), também para o mercado norte-americano. Em relação à magnitude do prêmio, com a amostra completa o prêmio médio mensal foi menor, de $1,76 \%$, conforme pôde ser visto na Tabela 3. O fato de o prêmio médio mensal pela liquidez ter sido maior com a exclusão dos meses de janeiro difere do estudo de Liu (2006), que encontrou um forte efeito sazonal nos prêmios pela liquidez no mês de janeiro. Essa diferença pode ser motivada por evidências da ausência do efeito janeiro no mercado acionário brasileiro encontradas por Costa Jr (1990).

\section{Tabela 9 - Análise de subperíodos e efeitos sazonais com carteiras classificadas conforme o Índice de} Negociabilidade da BM\&FBOVESPA e a estratégia 6x6.

Essa tabela apresenta a análise de subperíodos - para a verificação da existência de vieses causados por seleção do período amostral - e do efeito janeiro. Para a verificação da existência do efeito janeiro os meses de janeiro foram excluídos da amostra (Painel A). De forma independente, para a verificação da existência de vieses por seleção de período amostral, a amostra foi separada em duas: i) de 1995 a 2002 e ii) de 2003 a 2011 , sendo que a escolha da data de corte foi motivada pelas diferenças nos cenários macroeconômicos dos dois períodos (Painel B). Então, em cada subamostra, no início de cada mês $t$, as ações elegíveis foram classificadas conforme o Índice de Negociabilidade da BM\&FBOVESPA calculado com base na média dos valores do índice nos 6 meses prévios (NEG6). Baseado nessa classificação, as ações foram agrupadas em 10 carteiras equally weighted e mantidas por 6 meses. Dessa forma, foi considerada a estratégia 6x6. S denota o quintil que contém as ações mais líquidas (maiores valores de Índice de Negociabilidade da BM\&FBOVESPA) e B denota o quintil que contém as ações menos líquidas (menores valores de Índice de Negociabilidade da BM\&FBOVESPA) e B-S é a diferença entre $\mathbf{B}$ e $\mathbf{S}$. As entradas de dados são os retornos \% médios mensais das carteiras. Os valores entre parênteses são a estatística $t$ (one-sample $t$ ). * indica que o coeficiente/teste é significativo a $1 \%$; e ** significativo a $5 \%$

Painel A - Efeito janeiro

\begin{tabular}{|c|c|c|c|c|c|c|c|c|c|c|c|}
\hline & S & D2 & D3 & D4 & D5 & D6 & D7 & D8 & D9 & B & B-S \\
\hline $\begin{array}{c}\text { Exclusão } \\
\text { dos meses } \\
\text { de janeiro }\end{array}$ & $1,16^{*}$ & $1,21 *$ & $1,45^{*}$ & $1,74^{*}$ & $2,04 *$ & $2,21^{*}$ & $2,70^{*}$ & $2,72 *$ & $2,61 *$ & $3,08^{*}$ & $\mathbf{1 , 9 1 *}$ \\
\cline { 2 - 14 } & $(4,17)$ & $(4,02)$ & $(4,58)$ & $(4,91)$ & $(6,06)$ & $(6,55)$ & $(8,08)$ & $(8,22)$ & $(9,18)$ & $(10,95)$ & $(8,11)$ \\
\hline
\end{tabular}

Painel B - Subperíodos

\begin{tabular}{|c|c|c|c|c|c|c|c|c|c|c|c|}
\hline & $\mathbf{S}$ & D2 & D3 & D4 & D5 & D6 & D7 & D8 & D9 & B & B-S \\
\hline \multirow{2}{*}{$\begin{array}{c}\text { de } 1995 \text { a } \\
2002 \\
\end{array}$} & os & 0,71 &, $98^{*}$ & $1,37^{*}$ & $1,67^{*}$ & 1,8 & 2,4 & 2,0 & 1,9 & $2,23 *$ & $1,40^{*}$ \\
\hline & $(2,21)$ & $(1,67)$ & $(2,22$ & $(2,87)$ & $(3,91)$ & $(4$ & $(4$ & $(4$, & $(4$, & $(7$ & $(4,37)$ \\
\hline \multirow{2}{*}{$\begin{array}{c}\text { de } 2003 \text { a } \\
2011\end{array}$} & $1,49 *$ & $1,78^{*}$ & $1,94 *$ & $2,20 *$ & $2,44^{*}$ & $2,70^{*}$ & $3,10 *$ & $3,31 *$ & $3,52 *$ & $3,87^{*}$ & $2,38 *$ \\
\hline & $(4,11)$ & $(4,85)$ & $(4,93)$ & $(4,70)$ & $(5,25)$ & $(5,96)$ & $(7,35)$ & $(7,39)$ & $(8,85)$ & $(9,52)$ & $(7,95)$ \\
\hline
\end{tabular}


O painel B da Tabela 9 mostra que o prêmio pela liquidez parece não estar restrito a subperíodos amostrais, pois se observam prêmios estatisticamente diferentes de zero tanto no subperíodo de 1995 a 2002, 1,40\% ao mês, quanto no subperíodo mais recente, de 2003 a 2011 , de $2,38 \%$ ao mês.

Na sequência, o subcapítulo 4.2 apresenta e analisa os testes dos modelos de precificação de ativos: CAPM, 2-fatores, 3-fatores e 4-fatores.

\subsection{Testes dos modelos de precificação de ativos}

Esse subcapítulo apresenta e analisa os resultados dos testes de modelos de precificação de ativos: CAPM, 2-fatores, 3-fatores e 4-fatores. Inicialmente são analisadas as variáveis dependentes - excesso de retorno mensal em relação ao retorno do ativo livre de risco - e independentes - fatores dos modelos. Em seguida, são analisadas as sensibilidades dos excessos de retornos aos fatores de risco, considerando a primeira etapa do procedimento de testes - regressões temporais. Posteriormente, são analisados os resultados das regressões de segunda etapa - cross-section - que são efetivamente as análises de validade e comparação entre os modelos de precificação de ativos. Seguindo-se, então, a discussão dos resultados dos testes de robustez.

Os dados de excesso de retornos mensais das carteiras, bem como os resultados dos cálculos dos prêmios mensais de cada fator - beta de mercado, liquidez, tamanho, índice B/M e momento - utilizados nesse capítulo da presente pesquisa para a realização dos testes dos modelos de precificação de ativos são apresentados nos Apêndices 2 e 3, respectivamente.

Vale nesse ponto ressaltar os resultados dos testes de (i) Kolmogorov-Smirnov para a verificação da normalidade das variáveis dependentes e independentes; (ii) Durbin-Watson para a averiguação de autocorrelação dos resíduos; (iii) de Fator de Inflação da Variância (FIV) para checagem da existência de (multi)colinearidade entre as variáveis independentes. Os resultados são apresentados no Apêndice 4 e não alteram a validade dos procedimentos estatísticos desta pesquisa, nem se mostram impeditivos para a análise, uma vez que: 
i) os p-values dos testes de normalidade de Kolmogorov-Smirnov mostraram-se superiores a 5\% em todas as variáveis da pesquisa, fato que não permite a rejeição da hipótese de normalidade das séries;

ii) os resultados do teste de autocorrelação dos resíduos de Durbin-Watson mantiveram-se ao redor de 2 - entre 1,54 e 2,21 - em todos os modelos testados, indicando baixa probabilidade de correlação temporal dos resíduos;

iii) os valores de FIV variam entre 1,08 e 1,38, o que indica uma baixa possibilidade da existência de (multi)colinearidade entre os fatores em todos os modelos testados.

\subsubsection{Análise das variáveis dependentes e independentes}

A quantidade média de ações que permaneceram na amostra para a formação das carteiras com base nos decis formados conforme o índice de Negociabilidade da BM\&FBOVESPA das ações foi de 188, com variação de 133 a 296 ao longo dos meses da amostra. Cada carteira formada, por sua vez, continha um décimo das ações da amostra em cada mês de formação. Dessa forma, a quantidade média de ações em cada carteira foi de 18,8, variando de 13 a 30 . Vaihekoski (2004) sugere que, para fins de testes de modelos de precificação de ativos, as carteiras sejam formadas com no mínimo 4 ações. Assim, a quantidade de ações utilizada em cada carteira nesta pesquisa satisfez essa condição.

A Tabela 10 apresenta os valores médios dos excessos de retornos mensais de cada carteira, formada com base em decis baseados na medida de liquidez - Índice de Negociabilidade da BM\&FBOVESPA. As médias dos excessos de retornos mensais de todas as carteiras foram positivas, sendo que em 9 das 10 carteiras a média se mostrou estatisticamente diferente de zero. A única exceção foi a carteira mais líquida $\mathrm{S}$, que apresentou média de $0,96 \%$ estatisticamente não diferente de zero. O excesso de retorno médio variou de $0,96 \%$ - carteira $\mathrm{S}$ - a 3,00\% ao mês - carteira B. Conforme o esperado e em linha com o verificado nos subcapítulos anteriores deste trabalho, o excesso de retorno médio mensal aumentou à medida que se diminuiu a liquidez das carteiras, confirmando o fato de as ações menos líquidas apresentarem maiores retornos, por representarem maiores riscos a seus detentores. 
Tabela 10 - Estatísticas descritivas das variáveis dependentes: excesso de retorno mensal das carteiras A tabela abaixo apresenta as estatísticas descritivas dos excessos de retornos mensais das carteiras, que são as variáveis dependentes das regressões lineares para testes dos modelos de precificação de ativos. Para a formação das carteiras, em junho e dezembro de cada ano $t$, de julho de 1995 a novembro de 2011 - todas as ações elegíveis da amostra foram classificadas conforme o Índice de Negociabilidade da BM\&FBOVESPA, calculado com base na média dos valores do índice nos 6 meses prévios (NEG6). Baseado nessa classificação, as ações foram agrupadas em 10 carteiras - decis - com retornos calculados equally weighted e mantidas por 6 meses. Dessa forma, foi considerada a estratégia $6 \times 6$. S denota o decil que contém as ações mais líquidas (maiores valores de Índice de Negociabilidade da BM\&FBOVESPA) e B denota o decil que contém as ações menos líquidas (menores valores de Índice de Negociabilidade da BM\&FBOVESPA) e B-S é a diferença entre $\mathbf{B}$ e $\mathbf{S}$. Os procedimentos são repetidos semestralmente, conforme efetuado por Liu (2006). Para cálculo do excesso de retorno mensal, é apurada a diferença entre o retorno mensal de cada carteira e o retorno mensal do ativo livre de risco - caderneta de poupança. *ao lado da estatística $t$ do teste one-sample $t$ indica que o coeficiente/teste é significativo a $1 \%$; e $* *$ significativo a $5 \%$.

\begin{tabular}{|l|c|c|c|c|c|c|c|c|c|c|}
\hline $\begin{array}{c}\text { Excesso de } \\
\text { Retorno } \\
\text { Mensal }\end{array}$ & S & D2 & D3 & D4 & D5 & D6 & D7 & D8 & D9 & B \\
\hline Média \% & 0,96 & 1,23 & 1,38 & 1,81 & 1,82 & 2,33 & 2,58 & 2,26 & 2,66 & 3,00 \\
\hline Estatística $\boldsymbol{t}$ & $(1,42)$ & $(2,00)^{* *}$ & $(1,94)^{* *}$ & $(2,67)^{*}$ & $(2,90)^{*}$ & $(3,87)^{*}$ & $(3,00)^{*}$ & $(4,26)^{*}$ & $(3,76)^{*}$ & $(4,50)^{*}$ \\
\hline $\begin{array}{l}\text { Desvio- } \\
\text { padrão \% }\end{array}$ & 9,17 & 9,38 & 8,79 & 9,20 & 8,55 & 8,19 & 11,66 & 7,20 & 7,20 & 9,04 \\
\hline Mínimo \% & $-36,01$ & $-37,31$ & $-27,20$ & $-31,87$ & $-30,06$ & $-25,94$ & $-30,29$ & $-23,58$ & $-20,49$ & $-17,73$ \\
\hline Máximo \% & 24,57 & 41,43 & 28,15 & 26,44 & 35,83 & 25,23 & 115,47 & 26,15 & 26,69 & 79,43 \\
\hline
\end{tabular}

O Painel A da Tabela 11 apresenta as estatísticas descritivas das variáveis independentes dos modelos de precificação de ativos - os fatores beta de mercado (MKT), liquidez (LIQ), tamanho (SMB), índice B/M (HML) e momento (WinMLos).

O prêmio médio pelo fator liquidez (LIQ), de $0,99 \%$, foi estatisticamente diferente de zero com $1 \%$ de significância. Os prêmios pelos fatores beta de mercado (MKT), de 1,47\%, e índice $\mathrm{B} / \mathrm{M}(\mathrm{HML})$, de $0,66 \%$, foram significativos a $5 \%$. Os prêmios pelos fatores tamanho (SMB) e momento (WinMLos), de $0,65 \%$ e $0,40 \%$, respectivamente, não se mostraram estatisticamente significativos. Os prêmios pelos fatores encontrados nesta pesquisa para o mercado acionário brasileiro foram em geral maiores do que os verificados no estudo de Liu (2006) para o mercado norte-americano, o que é coerente com a intuição e expectativa devido à diferença de maturidade e estabilidade entre os mercados. Quanto ao ranking dos prêmios, no estudo de Liu (2006) o maior prêmio encontrado foi em relação ao fator liquidez, seguido do beta de mercado, índice B/M e tamanho. 
Tabela 11 - Estatísticas descritivas e matriz de correlação das variáveis independentes A tabela abaixo apresenta as estatísticas descritivas - Painel A - e a matriz de correlação de Spearman - Painel B - das variáveis dependentes desta pesquisa, ou seja, os fatores de risco beta de mercado (MKT), liquidez (LIQ), tamanho (SMB), índice B/M (HML) e momento (WinMLos), de julho de 1995 a novembro de 2011. Em linhas gerais, o fator liquidez foi calculado conforme a metodologia de Liu (2006). Os fatores beta de mercado, tamanho e índice B/M foram calculados conforme a metodologia de Fama e French (1993). O fator momento foi calculado conforme a metodologia de Carhart (1997). O Capitulo 3 desta tese detalha os procedimentos metodológicos adotados para o cálculo dos fatores. Para cálculos que envolvem o índice B/M foram excluídas as ações de empresas financeiras e com Patrimônio Líquido negativo. As entradas de dados no Painel B são os coeficientes de correlação de Spearman entre as variáveis. Em ambos os painéis * indica que o coeficiente/teste é significativo a $1 \% \mathrm{e}^{* *}$ significativo a $5 \%$.

\begin{tabular}{|c|c|c|c|c|c|}
\hline \multicolumn{6}{|c|}{ Painel A - Estatísticas descritivas } \\
\hline & MKT & LIQ & SMB & HML & WinMLos \\
\hline Média \% & 1,47 & 0,99 & 0,65 & 0,66 & 0,40 \\
\hline Estatística $t$ & $(2,40)^{* \star}$ & $(3,01)^{*}$ & $(1,63)$ & $(2,20)^{\star \star}$ & $(1,23)$ \\
\hline Desvio-padrão \% & 8,31 & 4,45 & 5,44 & 4,07 & 4,39 \\
\hline Mínimo \% & $-39,71$ & $-9,23$ & $-18,97$ & $-20,03$ & $-17,60$ \\
\hline Máximo \% & 28,56 & 18,08 & 18,21 & 14,12 & 15,04 \\
\hline \multicolumn{6}{|c|}{ Painel B - Coeficientes de correlação de Spearman } \\
\hline & MKT & LIQ & SMB & HML & WinMLos \\
\hline MKT & 1 & & & & \\
\hline LIQ & $-0,52 *$ & 1 & & & \\
\hline SMB & $-0,29 *$ & $0,49 *$ & 1 & & \\
\hline HML & $-0,01$ & $-0,09$ & $-0,21 * *$ & 1 & \\
\hline WinMLos & $-0,21^{*}$ & 0,13 & $0,19^{* *}$ & $-0,23 * *$ & 1 \\
\hline
\end{tabular}

A significância dos prêmios encontrados nesta pesquisa para os fatores beta de mercado (MKT), tamanho (SMB) e momento (WinMLos) corroboram as evidências encontradas em estudos anteriores efetuados no mercado acionário brasileiro por Málaga e Securato (2004), Mussa et al (2009) e Machado e Medeiros (2011). O mesmo se observa em relação aos resultados do prêmio pelo fator liquidez (LIQ) quando comparado com a pesquisa de Machado e Medeiros (2011). Já, quanto ao fator B/M (HML) observam-se algumas diferenças em relação aos estudos anteriores efetuados no mercado acionários brasileiro. $\mathrm{O}$ fator índice B/M (HML) apresentou prêmios positivos, porém estatisticamente não significantes nas pesquisas de Málaga e Securato (2004) e Mussa et al (2009). Já, na pesquisa de Machado e Medeiros (2011) evidenciou-se um prêmio negativo e com significância estatística. Essas divergências podem estar relacionadas com as diferenças metodológicas entre os estudos no que se refere à construção das carteiras, períodos amostrais, bem como frequências de rebalanceamento das carteiras. 
O painel B da Tabela 11 apresenta os coeficientes de correlação de Spearman entre as variáveis independentes dos modelos de precificação de ativos - os fatores beta de mercado (MKT), liquidez (LIQ), tamanho (SMB), índice B/M (HML) e momento (WinMLos). A correlação negativa, de $-0,52$, observada entre beta de mercado (MKT) e liquidez (LIQ) parece refletir o estado natural da liquidez: o mercado é menos líquido em períodos de queda do mercado e investidores passam a requerer altos retornos para compensar os riscos da baixa liquidez. O mesmo fato foi observado por Liu (2006) no mercado acionário norte-americano.

A correlação entre os fatores liquidez (LIQ) e tamanho (SMB) foi positiva de 0,49 , o que está de acordo com a expectativa de que ações de empresas de menor porte são também as menos líquidas. A relativa força de correlação entre essas variáveis pode explicar a correlação negativa entre o beta de mercado (MKT) e o tamanho (SMB), -0,29. No entanto, o fato de a correlação entre liquidez (LIQ) e tamanho (SMB) ser ainda distante de 1 reforça a suposição de inabilidade do fator tamanho de capturar completamente o fator liquidez. Esses resultados contrariam os resultados encontrados por Liu (2006) - que encontrou correlação negativa de 0,15 entre o fator liquidez (LIQ) e o tamanho (SMB) -, porém justificam os resultados esperados pelo referido autor.

Diferente do verificado no estudo de Liu (2006), as correlações entre os fatores liquidez (LIQ) e índice B/M (HML) e entre beta de mercado (MKT) e índice B/M (HML) foram praticamente nulas no mercado acionário brasileiro, sendo de $-0,09$ e $-0,01$, respectivamente. Por sua vez, o fator momento (WinMLos) apresentou baixos coeficientes de correlação com todas as demais variáveis.

O próximo subcapítulo apresenta e analisa a sensibilidade dos excessos de retornos aos fatores de risco nas regressões temporais.

\subsubsection{Sensibilidade dos excessos de retornos aos fatores de risco}

A Tabela 12 apresenta os resultados das regressões em séries temporais considerando todo o período amostral. Nessa tabela demonstram-se as sensibilidades dos excessos de retorno mensal dos fatores em cada modelo testado: CAPM, 2-fatores, 3-fatores e 4-fatores. 
As sensibilidades dos excessos de retorno mensal dos fatores em cada modelo considerando somente os períodos within-sample - original e alternativos indicado no Quadro 8 do Capítulo 3 - são apresentados no Apêndice 5. Ao se analisar a tabela do Apêndice 5, não se observam alterações significativas nos resultados quando comparados com os dados da Tabela 12, que utiliza todo o período amostral.

Tabela 12 - Sensibilidade dos excessos de retornos aos fatores de risco

A tabela abaixo apresenta os resultados das regressões procedidas em séries temporais, considerando todo o período amostral e as 10 carteiras formadas com base em decis conforme o Índice de Negociabilidade da BM\&FBOVESPA (NEG6). O excesso de retorno mensal equally weighted de cada carteira calculado em relação ao retorno do ativo livre de risco - caderneta de poupança - foi considerada a variável dependente das regressões temporais. $\mathbf{S}$ denota o decil que contém as ações mais líquidas (maiores valores de Índice de Negociabilidade da BM\&FBOVESPA) e B denota o decil que contém as ações menos líquidas (menores valores de Índice de Negociabilidade da BM\&FBOVESPA). As variáveis independentes foram os prêmios pelos fatores beta de mercado, liquidez, tamanho, índice B/M e momento, nos respectivos modelos em que cada fator é incluído. $\mathrm{O}$ fator liquidez foi calculado essencialmente conforme a metodologia de Liu (2006). Os fatores beta de mercado, tamanho e índice B/M foram calculados essencialmente conforme procedido por Fama e French (1993). Por sua vez, o fator momento foi estimado conforme os métodos de Carhart (1997). O Capítulo 3 apresenta detalhes de cálculos de cada fator. Para cálculos que envolvem o índice B/M foram excluídas as ações de empresas financeiras e com Patrimônio Líquido negativo. Os coeficientes dos fatores beta de mercado, tamanho, índice $\mathrm{B} / \mathrm{M}$, momento e liquidez são identificados na coluna Coef. da tabela por $b, s, h, w$ e $l$, respectivamente, em cada um dos modelos testados: CAPM, 2-fatores, 3-fatores e 4-fatores. Na tabela são reportados os coeficientes dos fatores e entre parênteses a estatística $t$. * indica que o coeficiente é significativo a $1 \%$ e $* *$ significativo a $5 \%$.

\begin{tabular}{|c|c|c|c|c|c|c|c|c|c|c|c|}
\hline Modelo & Coef. & $\mathbf{S}$ & D2 & D3 & D4 & D5 & D6 & D7 & D8 & D9 & B \\
\hline \multirow{2}{*}{ CAPM } & \multirow{2}{*}{$b$} & 1,05 & 1,03 & 0,93 & 0,94 & 0,81 & 0,72 & 0,95 & 0,55 & 0,50 & 0,49 \\
\hline & & $(43,38)^{*}$ & $(29,85)^{*}$ & $(24,63)^{*}$ & $(22,00)^{*}$ & $(17,22)^{*}$ & $(3,04)^{*}$ & $(12,38)^{*}$ & $(11,13)^{*}$ & $(9,57)^{*}$ & $(6,81)^{*}$ \\
\hline \multirow{4}{*}{ 2-Fatores } & \multirow{2}{*}{$b$} & 0,97 & 0,97 & 0,87 & 0,97 & 0,86 & 0,90 & 1,27 & 0,79 & 0,74 & 0,95 \\
\hline & & $(35,18)^{*}$ & $(23,46)^{*}$ & $(19,21)^{*}$ & $(18,64)^{*}$ & $(15,09)^{*}$ & $(16,11)^{*}$ & $(15,15)^{*}$ & $(15,27)^{*}$ & $(13,27)^{*}$ & $(14,61)^{*}$ \\
\hline & \multirow{2}{*}{$l$} & 0,28 & 0,19 & 0,18 & 0,10 & 0,17 & 0,60 & 1,05 & 0,78 & 0,78 & 1,49 \\
\hline & & $(5,48)^{*}$ & $(2,39) * *$ & $(2,07)^{* *}$ & $(1,03)$ & $(1,98)^{* *}$ & $(5,71)^{*}$ & $(6,71)^{*}$ & $(8,11)^{*}$ & $(7,52)^{*}$ & $(12,34)^{*}$ \\
\hline \multirow{6}{*}{ 3-Fatores } & \multirow{2}{*}{$b$} & 1,06 & 1,08 & 1,04 & 1,12 & 0,98 & 0,93 & 1,07 & 0,75 & 0,68 & 0,67 \\
\hline & & $(41,33)^{*}$ & $(29,88)^{*}$ & $(30,25)^{*}$ & $(33,25)^{*}$ & $(24,77)^{*}$ & $(24,45)^{*}$ & $(13,21)^{*}$ & $(19,03)^{*}$ & $(14,54)^{*}$ & $(9,50)^{*}$ \\
\hline & \multirow{2}{*}{$s$} & 0,05 & 0,21 & 0,45 & 0,70 & 0,69 & 0,83 & 0,48 & 0,79 & 0,70 & 0,73 \\
\hline & & $(1,18)$ & $(3,62)^{*}$ & $(8,39)^{*}$ & $(13,09)^{*}$ & $(10,97)^{*}$ & $(13,77)^{*}$ & $(3,75)^{*}$ & $(12,68)^{*}$ & $(9,43)^{*}$ & $(6,05)^{*}$ \\
\hline & \multirow{2}{*}{$h$} & 0,17 & 0,20 & 0,37 & 0,31 & 0,39 & 0,34 & 0,26 & 0,33 & 0,41 & 0,26 \\
\hline & & $(3,47)^{*}$ & $(2,89)^{*}$ & $(5,51)^{*}$ & $(4,66)^{*}$ & $(5,07)^{*}$ & $(4,56)^{*}$ & $(1,67)$ & $(4,38)^{*}$ & $(4,47)^{*}$ & $(1,81)$ \\
\hline \multirow{8}{*}{ 4-Fatores } & \multirow{2}{*}{$\boldsymbol{b}$} & 1,07 & 1,07 & 1,03 & 1,10 & 0,96 & 0,91 & 1,05 & 0,74 & 0,68 & 0,66 \\
\hline & & $(40,62)^{*}$ & $(29,03)^{*}$ & $(29,41)^{*}$ & $(32,65)^{*}$ & $(24,15)^{*}$ & $(23,78)^{*}$ & $(12,59)^{*}$ & $(18,41)^{*}$ & $(14,23)^{*}$ & $(9,01)^{*}$ \\
\hline & \multirow{2}{*}{$\boldsymbol{S}$} & 0,05 & 0,21 & 0,45 & 0,70 & 0,70 & 0,84 & 0,48 & 0,79 & 0,70 & 0,74 \\
\hline & & $(1,12)$ & $(3,67)^{*}$ & $(8,37)^{*}$ & $(13,56)^{*}$ & $(11,34)^{*}$ & $(14,15)^{*}$ & $(3,74)^{*}$ & $(12,73)^{*}$ & $(9,44)^{*}$ & $(6,57)^{*}$ \\
\hline & \multirow{2}{*}{$h$} & 0,19 & 0,18 & 0,35 & 0,25 & 0,33 & 0,29 & 0,21 & 0,31 & 0,42 & 0,21 \\
\hline & & $(3,65)^{*}$ & $(2,45)$ & $(4,86)^{*}$ & $(3,72)^{*}$ & $(4,17)^{*}$ & $(3,88)^{*}$ & $(1,27)$ & $(3,86)^{*}$ & $(4,42)^{*}$ & $(1,47)$ \\
\hline & \multirow{2}{*}{$\boldsymbol{w}$} & 0,05 & $-0,08$ & $-0,08$ & $-0,19$ & $-0,22$ & $-0,16$ & $-0,19$ & $-0,08$ & 0,04 & $-0,17$ \\
\hline & & $(1,14)$ & $(1,26)$ & $(1,23)$ & $(3,01)^{*}$ & $(3,03)^{*}$ & $(2,34)^{* *}$ & $(1,27)$ & $(1,14)$ & $(0,49)$ & $(1,28)$ \\
\hline
\end{tabular}


No modelo CAPM, bem como em todos os fatores em que foi incluído, os coeficientes do fator beta de mercado mostraram-se estatisticamente significantes para todas as 10 carteiras. Os baixos valores dos coeficientes $b$ no CAPM nas carteiras menos líquidas (D8, D9 e B) parecem sinalizar as restrições do beta de mercado em explicar os retornos das ações menos líquidas. Fato semelhante ao identificado por Liu (2006) no mercado norte-americano.

No modelo de 2-fatores, o fator liquidez apresentou coeficientes válidos estatisticamente em 9 das 10 carteiras testadas, sendo exceção a carteira D4. Os coeficientes do beta de mercado (MKT) apresentaram-se maiores e mais próximos de 1 quando foi adicionado o fator liquidez (LIQ). O fator liquidez (LIQ) apresentou coeficientes maiores nas carteiras menos líquidas, justamente as carteiras em que o CAPM parece ter apresentado menos eficiência na explicação das variações dos retornos das carteiras de ações. Dessa forma, os dois fatores parecem se complementar na explicação das variações dos retornos das ações no mercado brasileiro.

Por sua vez, no modelo dos 3-fatores, os fatores tamanho (SMB) e índice B/M (HML) apresentaram coeficientes estatisticamente significativos respectivamente em 9 e 8 das 10 carteiras testadas. Semelhante ao observado no modelo de 2-fatores e ao evidenciado por Fama e French (1993) e Málaga e Securato (2004), os coeficiente do beta de mercado (MKT) mostraram-se maiores e mais próximos de 1 com a adição dos demais fatores. Segundo Fama e French (1993) esse fenômeno estaria relacionado à correlação dos demais fatores com o beta de mercado (MKT). O fator tamanho (SMB) apresentou coeficientes mais expressivos nas carteiras de menor liquidez, o que é coerente com a intuição e com as suposições de Fama e French (1993) de que esse fator pode capturar uma parcela da liquidez. O coeficiente do fator índice $\mathrm{B} / \mathrm{M}$ apresentou valores baixos em todas as carteiras testadas.

O comportamento dos fatores que compõem o modelo dos 3-fatores - beta de mercado, tamanho e índice B/M - parece não ter se alterado significativamente com a inclusão do fator momento, na constituição do modelo dos 4-fatores. O fator momento, por sua vez, apresentou coeficientes significativos em apenas 3 das 10 carteiras, parecendo não ter um papel representativo na explicação dos retornos das carteiras de ações no mercado brasileiro. 
O subcapítulo subsequente apresenta, avalia e compara os resultados dos testes dos modelos de precificação de ativos propriamente ditos por meio da análise das regressões de segunda etapa - cross-sections.

\subsubsection{Resultados dos testes dos modelos de precificação de ativos}

A Tabela 13 apresenta os resultados das regressões cross-section dos quatro modelos testados neste trabalho: CAPM, 2-fatores, 3-fatores e 4-fatores. Os valores dos interceptos dos quatro modelos foram altamente significativos a $1 \%$, indicando que eles não se mostram suficientes na explicação do excesso de retorno cross-section das carteiras no mercado acionário brasileiro.

Tabela 13 - Resultados das regressões cross-sections dos modelos CAPM, 2-fatores, 3-fatores e 4-fatores $\mathrm{O}$ excesso de retorno mensal de cada carteira em relação ao retorno do ativo livre de risco - caderneta de poupança - foi considerada a variável dependente das regressões cross-section procedidas com a amostra out-ofsample - de janeiro de 2004 a novembro de 2011. As variáveis independentes foram os betas dos diversos fatores - beta de mercado, liquidez, tamanho, índice B/M e momento - calculados within-sample, a partir de regressões em séries temporais, de julho de 1995 a dezembro de 2003. O fator liquidez foi calculado essencialmente conforme a metodologia de Liu (2006). Os fatores beta de mercado, tamanho e índice B/M foram calculados essencialmente conforme procedido por Fama e French (1993). Por sua vez, o fator momento foi estimado conforme os métodos de Carhart (1997). Para cálculos que envolvem o índice B/M foram excluídas as ações de empresas financeiras e com Patrimônio Líquido negativo. Os coeficientes dos fatores beta de mercado, liquidez, tamanho, índice B/M e momento são identificados na tabela por $\boldsymbol{b}, \boldsymbol{l}, \boldsymbol{s}, \boldsymbol{h}$ e $\boldsymbol{w}$, respectivamente. Na tabela são reportados os coeficientes das regressões e entre parênteses a estatística $t$. O $\boldsymbol{R}^{2} \boldsymbol{A d j}$. retorna o coeficiente de determinação ajustado, sendo o teste relevante dado pela estatística $F$ (teste conjunto dos parâmetros do modelo). *indica que o coeficiente/teste é significativo a $1 \%$ e ** significativo a $5 \%$. Os errospadrão para cômputo do $t$-estatístico foram calculados conforme a técnica de Fama e MacBeth (1973).

\begin{tabular}{|c|c|c|c|c|c|c|c|}
\hline Modelo & Intercepto & $b$ & $l$ & $s$ & $h$ & $w$ & $R^{2}$ Adj. \\
\hline \multirow[t]{2}{*}{ CAPM } & 4,15 & $-3,07$ & & & & & $0,52 *$ \\
\hline & $(4,24) *$ & $(3,25) *$ & & & & & \\
\hline \multirow[t]{2}{*}{ 2-Fatores } & 3,45 & $-2,50$ & 1,42 & & & & $0,87 *$ \\
\hline & $(3,72) *$ & $(2,92) *$ & $(3,37) *$ & & & & \\
\hline \multirow[t]{2}{*}{ 3-Fatores } & 6,26 & $-4,48$ & & 2,03 & $-4,82$ & & $0,75 *$ \\
\hline & $(3,28) *$ & $(2,63) *$ & & $(2,42)^{* *}$ & $(2,03) * *$ & & \\
\hline \multirow[t]{2}{*}{ 4-Fatores } & 6,77 & $-4,95$ & & 0,99 & $-3,56$ & 0,04 & $0,72 * *$ \\
\hline & $(2,78) *$ & $(2,33)^{* *}$ & & $(0,65)$ & $(1,47)$ & $(0,01)$ & \\
\hline
\end{tabular}


No modelo CAPM, o beta de mercado mostrou-se significativo a $1 \%$. Esse resultado corrobora as evidências encontradas por Liu (2006) para o mercado acionário norteamericano, mas contraria os resultados encontrados por Mussa et al (2009) para o mercado acionário brasileiro, uma vez que os referidos autores encontraram que o beta de mercado não era estatisticamente significativo no teste $t$. Observa-se, também, que o poder de explicação médio do modelo - $R^{2} A d j$ - foi de aproximadamente $52 \%$, bastante superior aos $3 \%$ encontrado por Mussa et al (2009). Essas disparidades podem ser explicadas pela diferença de períodos amostrais entre os dois estudos, pois a pesquisa de Mussa et al (2009) considerou o período de junho de 1995 a junho de 2007. Além disso, a presente pesquisa realizou rebalanceamentos semestrais das carteiras e retornos calculados equally weighted, enquanto Mussa et al (2009) realizaram rebalanceamentos anuais e retornos value weighted.

Com a inclusão do fator liquidez ao beta de mercado do CAPM, constitui-se o modelo de 2fatores. Nesse, observa-se, na Tabela 13, que tanto o beta de mercado quanto o fator liquidez se mostraram estatisticamente significativos a $1 \%$ e observou-se um substancial aumento do poder de explicação do modelo - Adj $R 2$ - que passou a ser de aproximadamente $87 \%$. Também se observou uma diminuição do valor do intercepto de 4,15 no CAPM para 3,45 no modelo de 2-fatores - mesmo que o valor ainda seja elevado e estatisticamente significativo. Esses resultados evidenciam ou sugerem a validade do modelo de 2-fatores para explicação das variações cross-section dos excessos de retorno das ações no mercado brasileiro, mas o alto valor de intercepto sinaliza que o modelo não se mostra suficiente nessa explicação. Liu (2006) encontrou resultados semelhantes para o mercado acionário norte-americano no que diz respeito aos coeficientes dos fatores, mas com a diferença de que o intercepto do modelo se mostrou não significante em boa parte das carteiras testadas.

Por sua vez, no modelo de 3-fatores, os coeficientes de todas as variáveis mostraram-se significativos, apesar de que os coeficientes dos fatores tamanho e índice B/M foram significativos somente a $5 \%$. O poder médio de explicação do modelo foi de $75 \%$. Em contraste com esses resultados, Mussa et al (2009) não encontraram significância para o fator tamanho e evidenciaram significância parcial para o fator índice B/M. Porém, apesar da indicação de resultados favoráveis à validade do modelo dos 3-fatores no mercado acionário brasileiro, esse modelo não se mostrou consistente nos testes de robustez discutidos mais adiante no subcapítulo 4.2.4. 
Por fim, o modelo dos 4-fatores apresentou coeficiente significativo no teste $t$ somente para o fator beta de mercado e $R^{2}$ Adj de $72 \%$, com significância de 5\%. Resultados semelhantes foram encontrados por Mussa et al (2009) também para o mercado acionário brasileiro. Dessa forma, o modelo dos 4-fatores não se mostra válido para a explicação das variações crosssection dos retornos das ações no mercado brasileiro.

Antes de se prosseguir para a análise dos testes de robustez dos modelos com as alterações dos períodos de within-sample e out-of-sample, faz-se necessária a observação de que os sinais dos coeficientes $b$ - fator beta de mercado - foram negativos em todos os modelos testados. Duas possíveis causas para esses sinais negativos podem ser levantadas: i) há excessos de retornos mensais das carteiras na amostra out-of-sample com valores negativos; ii) os elevados valores dos interceptos podem distorcer os sinais dos coeficientes.

O Apêndice 2 apresenta os excessos de retornos mensais das 10 carteiras usadas nesta pesquisa em relação ao retorno mensal da caderneta de poupança. Nele é possível observar que há uma quantidade relevante de meses e carteiras com valores negativos $-38 \%$ das observações. Ao se analisar cada coeficiente das regressões cross-section - que foram omitidos por serem tabelas com quantidades muito grandes de dados, mas que podem ser disponibilizadas aos leitores mediante solicitação ao autor desta tese-, note-se que em 63\% das vezes em que aparecem valores negativos para o coeficiente do fator beta de mercado, eles ocorrem justamente quando os excessos de retorno mensais das carteiras são negativos. Porém, os valores médios dos retornos das carteiras out-of-sample são positivos, o que sinaliza que os valores negativos das variáveis dependentes podem não ser a única causa dos coeficientes betas serem negativos.

Para se investigar a segunda hipótese levantada - impacto da elevada magnitude dos interceptos no sinal do coeficiente beta de mercado - os testes da Tabela 13 foram refeitos com a exclusão dos interceptos. Os resultados são apresentados na Tabela 14. 
Tabela 14 - Resultados das regressões cross-sections dos modelos CAPM, 2-fatores, 3-fatores e 4-fatores com exclusão dos interceptos

O excesso de retorno mensal de cada carteira em relação ao retorno do ativo livre de risco - caderneta de poupança - foi considerada a variável dependente das regressões cross-section procedidas com a amostra out-ofsample - de janeiro de 2004 a novembro de 2011 - com a exclusão dos interceptos. As variáveis independentes foram os betas dos diversos fatores - beta de mercado, liquidez, tamanho, índice B/M e momento - calculados within-sample, a partir de regressões em séries temporais, de julho de 1995 a dezembro de 2003. O fator liquidez foi calculado essencialmente conforme a metodologia de Liu (2006). Os fatores beta de mercado, tamanho e índice B/M foram calculados essencialmente conforme procedido por Fama e French (1993). Por sua vez, o fator momento foi estimado conforme os métodos de Carhart (1997). Para cálculos que envolvem o índice B/M foram excluídas as ações de empresas financeiras e com Patrimônio Líquido negativo. Os coeficientes dos fatores beta de mercado, tamanho, índice B/M, momento e liquidez são identificados na tabela por $\boldsymbol{b}, \boldsymbol{l}, \boldsymbol{s}, \boldsymbol{h}$ e $\boldsymbol{w}$, respectivamente e as regressões da segunda etapa foram procedidas com a exclusão dos interceptos. Na tabela são reportados os coeficientes das regressões e entre parênteses a estatística $t$. ${ }^{*}$ indica que o coeficiente/teste é significativo a $1 \% \mathrm{e}^{* *}$ significativo a $5 \%$. Os erros-padrão para cômputo do $t$-estatístico foram calculados conforme a técnica de Fama e MacBeth (1973).

\begin{tabular}{llllll}
\hline Modelo & $b$ & $l$ & $s$ & $h$ & $w$
\end{tabular}

CAPM 1,86

2-Fatores

$1,12 \quad 1,11$

$(2,01)^{* *} \quad(2,86) *$

$\begin{array}{llrr}\text { 3-Fatores } & 0,04 & 1,93 & 2,87\end{array}$

$(0,06) \quad(2,32) * * \quad(1,53)$

$\begin{array}{llcrr}\text { 4-Fatores } & 0,03 & 2,58 & 1,71 & 0,64\end{array}$

$(0,04) \quad(2,09)^{* *} \quad(0,58) \quad(0,24)$

Observa-se, na Tabela 14, que, com a exclusão dos interceptos, os sinais dos coeficientes do fator beta de mercado passaram a ser positivos em todos os modelos testados - porém com significância estatística apenas nos modelos CAPM e 2-fatores. Esses resultados parecem indicar que a manutenção dos interceptos alteram os sinais dos coeficientes do fator beta de mercado, sinalizando que a elevada magnitude dos interceptos parecem explicar os sinais negativos dos coeficientes $b$. Essas evidências da substancial importância dos interceptos corroboram a afirmação de que nenhum dos modelos testados nesta tese se mostra suficiente na explicação das variações dos retornos cross-section das ações no mercado brasileiro.

Adicionalmente, nota-se na Tabela 14 que o coeficiente do fator índice B/M também mudou de sinal e tornou-se positivo, da mesma forma que foi verificado com o fator beta de mercado. Porém, o referido fator perdeu sua significância estatística. 


\subsubsection{Testes de robustez dos modelos de precificação de ativos}

Para que se pudessem minimizar os possíveis prejuízos causados pela definição arbitrária dos períodos de within-sample e out-of-sample e dar maior robustez aos procedimentos empíricos, os testes dos modelos foram refeitos considerando outros quatro períodos de separação da amostra, aumentando (diminuindo) o período de within-sample (out-of-sample) de 12 em 12 meses. Adicionalmente, foi testado o período amostral anterior ao início das alterações contábeis brasileiras no rumo às normas internacionais, ou seja, com data final da amostra em dezembro de 2007. Nesse último caso, a separação da amostra em within-sample e out-ofsample foi pautada no balanceamento do número de observações entre as amostras. Os resultados são apresentados na Tabela 15.

Ao se variarem os períodos amostrais, observa-se na Tabela 15 que todos os interceptos de todos os modelos apresentam elevada significância estatística, corroborando as evidências iniciais de que nenhum dos modelos se mostra suficiente na explicação das variações crosssection dos retornos das ações no mercado brasileiro.

Em relação ao modelo CAPM, observaram-se pouquíssimas alterações de resultados quando comparados aos resultados iniciais. O coeficiente do fator beta de mercado manteve-se estatisticamente significante em todos os períodos e o poder de explicação do modelo $-R^{2} A d j$ - variou pouco em relação ao obtido nos primeiros testes (0,52\%), oscilando de $45 \%$ a $51 \%$.

Em relação ao modelo de 2-fatores, também não se observaram alterações relevantes de resultados quando comparados aos testes iniciais. Os coeficientes dos dois fatores - beta de mercado e liquidez - mantiveram-se estatisticamente significantes em todos os períodos e o poder de explicação do modelo - $R^{2} A d j$ - variou pouco em relação ao inicial $(0,87 \%)$ oscilando de $82 \%$ a $95 \%$-, e mantendo-se em patamar superior em relação a todos os demais modelos testados neste trabalho. Essas evidências atestam a validade do modelo de 2-fatores na explicação das variações cross-sections dos retornos no mercado acionário brasileiro, bem como a superioridade desse modelo quando comparado aos modelos CAPM, 3-fatores e 4fatores. De acordo com Liu (2006, p.634), “o estado natural da liquidez e a conjectura de que o risco pela liquidez captura distress risk mais diretamente do que os fatores tamanho e índice $\mathrm{B} / \mathrm{M}$, explicam o desempenho mais favorável do modelo de 2-fatores". Porém, ressalve-se que, conforme observado no subcapítulo anterior, os altos valores dos interceptos do modelo 
indicam que ele não se mostra suficiente na explicação das variações cross-section dos retornos das ações no mercado brasileiro.

Por sua vez, o modelo dos 3-fatores foi o que apresentou maior instabilidade aos testes de robustez. O coeficiente do fator beta de mercado não se mostrou significativo em dois períodos amostrais. O coeficiente $h$, relativo ao fator índice B/M, não se mostrou significativo em nenhuma das variações dos períodos amostrais, diferente dos resultados obtidos nos testes iniciais. O coeficiente $s$, referente ao fator tamanho, não se mostrou válido em três dos cinco períodos alternativos, também diferente dos resultados obtidos no primeiro teste. Observa-se também uma queda acentuada no $R^{2} A d j$, variando de $61 \%$ a $71 \%$, sendo que no teste inicial o valor foi de $0,75 \%$. Esses resultados diferem bastante dos resultados encontrados nos testes iniciais desta tese, porém parecem estar alinhados com os resultados encontrados por Mussa et al (2009).

Por fim, em relação ao modelo de 4-fatores também não se observaram grandes modificações em relação aos testes iniciais. Os coeficientes de todos os fatores, exceto o beta de mercado, não se mostraram estatisticamente significativos em nenhum dos períodos alternativos. $\mathrm{O} R^{2}$ Adj também variou muito pouco, oscilando de $62 \%$ a $72 \%$, sendo que no teste inicial o valor foi de $0,72 \%$. Esses resultados corroboram os achados de Mussa et al (2009). 
Tabela 15 - Teste de robustez dos modelos - resultados das regressões cross-sections dos modelos CAPM, 2-fatores, 3-fatores e 4-fatores com variações dos períodos de within-sample e out-of-sample

Nessa tabela é simulada a robustez dos modelos em diferentes períodos de within-sample e out-of-sample, conforme indicado no Quadro 8, do Capítulo 3 como Alternativo de 1 a 5 . O período within-sample representa o período de cálculo das sensibilidades dos fatores para as 10 carteiras formadas com base no Índice de Liquidez da BM\&FBOVESPA (NEG6). O período out-of-sample representa o período de cálculo das regressões crosssection. Nessas últimas, o excesso de retorno mensal de cada carteira (decil formado com base no Índice de Liquidez da BM\&FBOVESPA) em relação ao retorno do ativo livre de risco - caderneta de poupança - foi considerada a variável dependente das regressões. As variáveis independentes foram os betas dos diversos fatores - beta de mercado, liquidez, tamanho, índice B/M e momento - calculados within-sample, a partir de regressões em séries temporais. O fator liquidez foi calculado essencialmente conforme a metodologia de Liu (2006). Os fatores beta de mercado, tamanho e índice B/M foram calculados essencialmente conforme procedido por Fama e French (1993). Por sua vez, o fator momento foi estimado conforme os métodos de Carhart (1997). Para cálculos que envolvem o índice B/M foram excluídas as ações de empresas financeiras e com Patrimônio Líquido negativo. Os coeficientes dos fatores beta de mercado, tamanho, índice B/M, momento e liquidez são identificados na tabela por $\boldsymbol{b}, \boldsymbol{l}, \boldsymbol{s}, \boldsymbol{h}$ e $\boldsymbol{w}$, respectivamente Na tabela são reportados os coeficientes das regressões e entre parênteses a estatística $t$. O $\boldsymbol{R}^{2} \boldsymbol{A d j}$. retorna o coeficiente de determinação ajustado, sendo o teste relevante dado pela estatística $\mathrm{F}$ (teste conjunto dos parâmetros do modelo). * indica que o coeficiente/teste é significativo a $1 \%$ e $* *$ significativo a $5 \%$. Os erros-padrão para cômputo do $t$-estatístico foram calculados conforme a técnica de Fama e MacBeth (1973).

\begin{tabular}{|c|c|c|c|c|c|c|c|c|c|}
\hline $\begin{array}{l}\text { Within- } \\
\text { sample }\end{array}$ & $\begin{array}{l}\text { Out-of- } \\
\text { sample }\end{array}$ & Modelo & Intercepto & $b$ & $l$ & $s$ & $\boldsymbol{h}$ & $w$ & $R^{2} A d j$. \\
\hline & & CAPM & 4,06 & $-2,41$ & & & & & $0,47 *$ \\
\hline & & & $(4,68)^{*}$ & $(2,98)^{*}$ & & & & & \\
\hline Jul/1995 & Jan/2003 & 2-Fatores & 3,44 & $-1,96$ & & & & & $0,88^{*}$ \\
\hline $\mathbf{a}$ & $\mathbf{a}$ & & $(4,15)^{*}$ & $(2,63)^{*}$ & $(3,29)^{*}$ & & & & \\
\hline \multirow[t]{6}{*}{ Dez/2002 } & Nov/2011 & 3-Fatores & 4,32 & $-2,56$ & & 1,49 & $-1,72$ & & $0,61 * *$ \\
\hline & & & $(3,58)^{*}$ & $(2,36)^{* *}$ & & $(1,86)$ & $(0,89)$ & & \\
\hline & & 4-Fatores & 6,21 & $-4,05$ & & 0,16 & $-1,76$ & $-1,27$ & 0,62 \\
\hline & & & $(2,74) *$ & $(2,09)^{* *}$ & & $(0,13)$ & $(0,92)$ & $(0,69)$ & \\
\hline & & CAPM & 3,81 & $-2,30$ & & & & & $0,48 *$ \\
\hline & & & $(4,79)^{*}$ & $(2,93)^{*}$ & & & & & \\
\hline Jul/1995 & Jan/2002 & 2-Fatores & 3,22 & $-1,89$ & 1,24 & & & & $0,95^{*}$ \\
\hline $\mathbf{a}$ & $\mathbf{a}$ & & $(4,27)^{*}$ & $(2,63)^{*}$ & $(3,27)^{*}$ & & & & \\
\hline \multirow[t]{6}{*}{ Dez/2001 } & Nov /2011 & 3-Fatores & 3,12 & $-1,86$ & & 0,86 & 0,93 & & $0,61 * *$ \\
\hline & & & $(2,91)^{*}$ & $(2,07)^{* *}$ & & $(1,18)$ & $(0,52)$ & & \\
\hline & & 4-Fatores & 5,50 & $-3,67$ & & $-0,48$ & 0,00 & $-2,00$ & 0,64 \\
\hline & & & $(2,74) *$ & $(2,20)^{* *}$ & & $(0,47)$ & $(0,01)$ & $(1,39)$ & \\
\hline & & CAPM & 3,39 & $-2,42$ & & & & & $0,45^{*}$ \\
\hline & & & $(3,91)^{*}$ & $(2,98)^{*}$ & & & & & \\
\hline Jul/1995 & Jan/2005 & 2-Fatores & 2,32 & $-1,42$ & 1,13 & & & & $0,82 *$ \\
\hline $\mathbf{a}$ & $\mathbf{a}$ & & $(2,56)^{* *}$ & $(2,03)^{* *}$ & $(3,03)^{*}$ & & & & \\
\hline \multirow[t]{4}{*}{ Dez/2004 } & Nov/2011 & 3-Fatores & 4,07 & $-2,71$ & & 1,83 & $-3,48$ & & $0,64 * *$ \\
\hline & & & $(2,52)^{* *}$ & $(1,91)$ & & $(2,22)^{* *}$ & $(1,51)$ & & \\
\hline & & 4-Fatores & 4,44 & $-3,06$ & & 0,56 & $-1,90$ & $-1,24$ & 0,62 \\
\hline & & & $(2,58)^{* *}$ & $(2,05)^{* *}$ & & $(0,55)$ & $(0,89)$ & $(0,63)$ & \\
\hline
\end{tabular}




\begin{tabular}{|c|c|c|c|c|c|c|c|c|c|}
\hline $\begin{array}{l}\text { Within- } \\
\text { sample }\end{array}$ & $\begin{array}{l}\begin{array}{l}\text { Out-of- } \\
\text { sample }\end{array} \\
\end{array}$ & Modelo & Intercepto & $b$ & $l$ & $s$ & $h$ & $w$ & $R^{2} A d j$. \\
\hline & & CAPM & $\begin{array}{c}3,96 \\
(4,02)^{*}\end{array}$ & $\begin{array}{c}-3,01 \\
(3,40)^{*}\end{array}$ & & & & & $0,46^{*}$ \\
\hline $\begin{array}{c}\mathrm{Jul} / \mathbf{1 9 9 5} \\
\mathrm{a}\end{array}$ & $\begin{array}{c}\mathrm{Jan} / 2006 \\
\mathrm{a}\end{array}$ & 2-Fatores & $\begin{array}{c}2,63 \\
(2,48)^{* *}\end{array}$ & $\begin{array}{c}-1,75 \\
(2,13)^{* *}\end{array}$ & $\begin{array}{c}1,37 \\
(3,49)^{*}\end{array}$ & & & & $0,82 *$ \\
\hline \multirow[t]{3}{*}{ Dez/2005 } & Nov/2011 & 3-Fatores & $\begin{array}{c}4,27 \\
(2,33)^{* *}\end{array}$ & $\begin{array}{l}-2,99 \\
(1,83)\end{array}$ & & $\begin{array}{c}2,26 \\
(2,46)^{* *}\end{array}$ & $\begin{array}{l}-3,72 \\
(1,42)\end{array}$ & & $0,65 * *$ \\
\hline & & 4-Fatores & $\begin{array}{c}5,40 \\
(2,61)^{* *}\end{array}$ & $\begin{array}{c}-4,02 \\
(2,22)^{* *}\end{array}$ & & $\begin{array}{l}-0,19 \\
(0,14)\end{array}$ & $\begin{array}{l}-0,93 \\
(0,38)\end{array}$ & $\begin{array}{l}-3,67 \\
(1,52)\end{array}$ & $0,70 * *$ \\
\hline & & CAPM & $\begin{array}{c}4,69 \\
(4,53)^{*}\end{array}$ & $\begin{array}{c}-2,65 \\
(2,35)^{* *}\end{array}$ & & & & & $0,51^{*}$ \\
\hline $\begin{array}{c}\text { Jul/1995 } \\
\text { a }\end{array}$ & $\begin{array}{c}\mathrm{Jul} / 2001 \\
\mathrm{a}\end{array}$ & 2-Fatores & $\begin{array}{c}4,12 \\
(4,31)^{*}\end{array}$ & $\begin{array}{c}-2,27 \\
(2,22)^{* *}\end{array}$ & $\begin{array}{c}1,34 \\
(2,52)^{* *}\end{array}$ & & & & $0,94 *$ \\
\hline \multirow[t]{2}{*}{ Jun/2001 } & Dez/2007 & 3-Fatores & $\begin{array}{c}3,89 \\
(2,60)^{*}\end{array}$ & $\begin{array}{c}-2,41 \\
(2,15)^{* *}\end{array}$ & & $\begin{array}{c}0,73 \\
(0,94)\end{array}$ & $\begin{array}{c}2,06 \\
(0,83)\end{array}$ & & $0,71 * *$ \\
\hline & & 4-Fatores & $\begin{array}{c}6,28 \\
(2,06)^{* *}\end{array}$ & $\begin{array}{c}-4,24 \\
(1,67)\end{array}$ & & $\begin{array}{l}-0,64 \\
(0,42)\end{array}$ & $\begin{array}{c}1,19 \\
(0,49)\end{array}$ & $\begin{array}{l}-2,24 \\
(1,04)\end{array}$ & $0,72 * *$ \\
\hline
\end{tabular}

\subsection{Análise das hipóteses da pesquisa}

Baseado na análise dos dados e resultados efetuada nos subcapítulos anteriores, o Quadro 9 abaixo apresenta a decisão quanto à aceitação ou rejeição das hipóteses nulas formuladas no Capítulo 1. 


\section{Quadro 9 - Análises das hipóteses formuladas}

O quadro abaixo apresenta a análise das hipóteses formuladas no Capítulo 1 desta pesquisa. Para cada hipótese são analisadas a rejeição ou aceitação da hipótese nula, suportadas pelas evidências encontradas na pesquisa.

\begin{tabular}{|c|c|c|}
\hline Hipótese & Hipótese Nula & Decisão e evidências encontradas \\
\hline I & $\begin{array}{l}\text { Ho,: Não há prêmio pela liquidez no } \\
\text { mercado acionário brasileiro, no } \\
\text { período analisado. }\end{array}$ & $\begin{array}{l}\text { Rejeita-se } \mathbf{H}_{0, \mathrm{I}} \text { e aceita-se } \mathbf{H}_{1, \mathrm{I}} \text {, pois foram evidenciados prêmios } \\
\text { positivos e estatisticamente significativos pela liquidez no } \\
\text { mercado acionário brasileiro com o uso da medida Índice de } \\
\text { Negociabilidade da BM\&FBOVESPA. }\end{array}$ \\
\hline II & $\begin{array}{l}\mathbf{H}_{0, \mathrm{II}}: \text { Os prêmios pela liquidez não se } \\
\text { mostram robustos aos testes de } \\
\text { subamostras para controle dos efeitos } \\
\text { tamanho, índice B/M e momento. }\end{array}$ & $\begin{array}{l}\text { Rejeita-se } \mathbf{H}_{0, \text { II }} \text { e aceita-se } \mathbf{H}_{1, \mathrm{II}} \text {, pois os prêmios pela liquidez se } \\
\text { mantiveram estatisticamente positivos e significativos mesmo } \\
\text { após a separação da amostra em subamostras para controles dos } \\
\text { efeitos tamanho, índice } \mathrm{B} / \mathrm{M} \text { e momento. }\end{array}$ \\
\hline III & $\begin{array}{l}\mathbf{H}_{0, \text { III }} \text { Os prêmios pela liquidez não se } \\
\text { mostram robustos aos testes de efeitos } \\
\text { sazonais. }\end{array}$ & $\begin{array}{l}\text { Rejeita-se } \mathbf{H}_{0, \mathrm{III}} \text { e aceita-se } \mathbf{H}_{1, \mathrm{III}} \text {, pois os prêmios pela liquidez } \\
\text { se mantiveram estatisticamente positivos e significativos } \\
\text { mesmo após a separação da amostra em meses de janeiro e } \\
\text { meses diferentes de janeiro. }\end{array}$ \\
\hline IV & $\begin{array}{l}\mathbf{H}_{0, \mathbf{I V}} \text { : Os prêmios pela liquidez não se } \\
\text { mostram robustos aos testes efetuados } \\
\text { quanto ao uso de diferentes } \\
\text { subperíodos. }\end{array}$ & $\begin{array}{l}\text { Rejeita-se } \mathbf{H}_{0, \mathrm{IV}} \text { e aceita-se } \mathbf{H}_{1, \mathrm{IV}} \text {, pois os prêmios pela liquidez } \\
\text { se mantiveram estatisticamente positivos e significativos } \\
\text { mesmo após a separação da amostra em diferentes subperíodos. }\end{array}$ \\
\hline V & $\begin{array}{l}\mathbf{H}_{0, \mathrm{~V}} \text { : Não há prêmio por pelo menos } \\
\text { um dos demais quatro fatores de risco: } \\
\text { mercado, tamanho, índice } \mathrm{B} / \mathrm{M} \mathrm{e} \\
\text { momento, no mercado acionário } \\
\text { brasileiro, no período analisado. }\end{array}$ & $\begin{array}{l}\text { Aceita-se } \mathbf{H}_{0, \mathbf{v}} \text { e rejeita-se } \mathbf{H}_{\mathbf{1}, \mathbf{v}} \text { uma vez que não foi encontrado } \\
\text { prêmio estatisticamente significativo pelos fatores de risco } \\
\text { tamanho e momento. }\end{array}$ \\
\hline VI & $\begin{array}{l}\mathbf{H}_{\mathbf{0 , V I}}: \text { O modelo dos 2-fatores - } \\
\text { composto pelo beta de mercado e } \\
\text { liquidez - não é válido para a } \\
\text { explicação dos retornos das ações do } \\
\text { mercado brasileiro, no período } \\
\text { analisado. }\end{array}$ & $\begin{array}{l}\text { Rejeita-se } \mathbf{H}_{0, \mathrm{VI}} \text { e aceita-se } \mathbf{H}_{1, \mathrm{VI}} \text {, pois os coeficientes dos } \\
\text { fatores do modelo - beta de mercado e liquidez - apresentaram- } \\
\text { se estatisticamente significantes nos resultados das regressões } \\
\text { cross-section, mesmo após a realização dos testes de robustez } \\
\text { com variações dos períodos de within-sample e out-of-sample. } \\
\text { Porém, é importante a ressalva de que os valores dos } \\
\text { interceptos foram bastante elevados em todos os testes, } \\
\text { indicando que o modelo não se mostra suficiente na explicação } \\
\text { das variações dos retornos cross-section das ações no mercado } \\
\text { brasileiro. }\end{array}$ \\
\hline VII & $\begin{array}{l}\mathbf{H}_{0, \mathrm{VII}} \text { : O modelo dos 2-fatores não é } \\
\text { superior a pelo menos um dos } \\
\text { seguintes modelos: CAPM, 3-fatores } \\
\text { de Fama e French (1993) e 4-fatores de } \\
\text { Carhart (1997) na explicação dos } \\
\text { retornos cross-section das ações do } \\
\text { mercado brasileiro, no período } \\
\text { analisado. }\end{array}$ & $\begin{array}{l}\text { Rejeita-se } \mathbf{H}_{\mathbf{0}, \mathrm{VII}} \text { e aceita-se } \mathbf{H}_{\mathbf{1}, \mathbf{V I I}} \text {, uma vez que o modelo dos 2- } \\
\text { fatores apresentou os maiores coeficientes de determinação } \\
\text { ajustado - } R^{2} A d j \text { - dentre os modelos testados, tanto nos testes } \\
\text { iniciais quanto nos testes de robustez dos modelos com } \\
\text { variações dos períodos de within-sample e out-of-sample. Além } \\
\text { disso, no modelo de 3-fatores a significância dos coeficientes } \\
\text { dos fatores apresentou muita instabilidade nos testes de } \\
\text { robustez dos modelos. O modelo de 4-fatores, por sua vez, não } \\
\text { apresentou coeficientes estatisticamente significativos tanto nos } \\
\text { testes iniciais quanto nos testes de robustez. }\end{array}$ \\
\hline
\end{tabular}




\section{CONSIDERAÇÕES FINAIS}

O objetivo principal deste trabalho foi verificar se há prêmios pela liquidez no mercado acionário brasileiro com o uso de uma vasta quantidade de medidas de liquidez, formas de cálculo e períodos de retenção, bem como averiguar se o modelo de 2-fatores - formado pelo beta de mercado e pelo fator liquidez - seria válido para o mercado acionário brasileiro e, em caso positivo, se seria superior ao CAPM, ao modelo dos 3-fatores de Fama e French (1993) e ao modelo dos 4-fatores de Carhart (1997), na explicação das variações dos retornos crosssection das carteiras de ações, considerando todas as ações listadas na BM\&FBOVESPA, de julho de 1995 a novembro de 2011.

A metodologia adotada para a verificação dos prêmios pela liquidez foi essencialmente a mesma utilizada por Liu (2006): formação de carteiras baseadas nas medidas de liquidez e posterior manutenção e cálculo dos retornos acumulados, sendo que o prêmio pela liquidez foi verificado pela diferença do retorno das carteiras menos líquidas e o retorno das carteiras mais líquidas. Foi utilizado o teste $t$ de comparação de médias - one sample $t$ - para estimativa da significância estatística dos prêmios. Da mesma forma, para a construção dos modelos de precificação de ativos, a metodologia de formação das carteiras foi essencialmente a utilizada por Liu (2006), ou seja, carteiras criadas com base decis formados conforme a medida de liquidez Índice de Negociabilidade da BM\&FBOVESPA, utilizando a estratégia 6x6, (6 meses passados para cálculo da medida de liquidez e 6 meses futuros como períodos de retenção). O prêmio pela liquidez foi calculado também conforme a metodologia sugerida por Liu (2006). Os prêmios pelos fatores de risco mercado, tamanho e índice B/M foram calculados seguindo os procedimentos do estudo de Fama e French (1993). Por sua vez, os prêmios pelo fator de risco momento foram calculados considerando a estratégia de momento de 12 meses de Jegadeesh e Titman (1993) e Carhart (1997). Para teste e validação dos modelos de precificação foi utilizada a metodologia de regressões em duas etapas de Fama e Macbeth (1973), que é essencialmente a mesma adotada por Amihud e Mendelson (1986), Eleswarapu e Reiganum (1993), Brennan et al (1998), Datar et al (1998), Chordia et al (2001), Amihud (2002), Acharya e Pedersen (2005) e Nguyen et al (2007) em seus estudos sobre liquidez. A significância de cada fator foi testada por meio da estatística $t$. A validade dos modelos foi verificada pela análise do teste $t$ dos coeficientes de cada fator e a comparação entre os modelos utilizou-se dos coeficientes de determinação ajustados, $\operatorname{Adj} . R^{2}$, das regressões cross-section. 
As medidas de liquidez utilizadas nesta tese foram doze: Volume Financeiro, Quantidade de Negócios, Quantidade de Títulos, Número de Dias Sem Transação, Return-To-Volume, TurnOver, Volume Zero Padronizado, Índice de Negociabilidade da BM\&FBOVESPA, Desvio-padrão do TurnOver, Desvio-padrão do Volume, Coeficiente de Variação do TurnOver e Coeficiente de Variação do Volume. Para cada medida foram considerados 1, 3, 6 e 12 meses de períodos de cálculo e formação das carteiras e 1, 3, 6 e 12 meses como período de retenção das carteiras, ou seja, 16 estratégias. Motivado pelos altos coeficientes de correlação entre as medidas, optou-se por prosseguir com o cálculo dos prêmios das medidas Índice de Negociabilidade da BM\&FBOVESPA, TurnOver, Return-To-Volume e Coeficiente de Variação do Volume Financeiro.

Para a medida Índice de Negociabilidade da BM\&FBOVESPA, em todas as estratégias, de forma geral, os retornos das carteiras aumentaram à medida que diminuiu a liquidez das carteiras. Os prêmios pela liquidez (B-S) mostraram-se positivos e estatisticamente diferentes de zero em todas as estratégias. Dessa forma, parece haver uma relação negativa entre liquidez e retorno, ou seja, a liquidez medida pelo Índice de Negociabilidade da BM\&FBOVESPA parece ser precificada no mercado acionário brasileiro, corroborando parte das evidências encontradas no mercado norte-americano. As medidas TurnOver, Return-ToVolume, por sua vez, não apresentaram prêmios consistentes. Por fim, foram evidenciados prêmios significativos para o Coeficiente de Variação do Volume Financeiro, principalmente nas estratégias que consideraram 12 meses para período de cálculo, o que é consistente com a natureza da medida - de dispersão - e a sua consequente necessidade de um longo horizonte temporal para cômputo. Assim, parece haver uma relação positiva entre volatilidade da liquidez e retorno e, assim, a volatilidade da liquidez parece ser precificada no mercado acionário brasileiro. O motivo dessa relação positiva está no fato de os agentes do mercado serem avessos ao risco e não desejarem fortes variações na liquidez do papel. Dessa forma, ações com grande variabilidade na liquidez deveriam apresentar altos retornos esperados.

Porém, dado o alto nível de correlação encontrado entre o Índice de Negociabilidade da BM\&FBOVESPA e o Coeficiente de Variação do Volume Financeiro, -0,62, optou-se por prosseguir com os testes utilizando somente a primeira medida e a estratégia 6x6 (6 meses para cálculo da medida e formação das carteiras e 6 meses para retenção das carteiras). A escolha da estratégia $6 x 6$ foi motivada pelo fato de esta estratégia apresentar prêmio de 
magnitude intermediária quando comparadas com estratégias de horizonte temporal mais curto e mais longo.

Os prêmios pela liquidez encontrados com o uso da medida Índice de Negociabilidade da BM\&FBOVESPA apresentaram-se robustos aos testes de subamostras. A liquidez parece não ser explicada completamente pelo fator tamanho, pois se observaram prêmios significativos e positivos mesmo na subamostra formada por empresas de pequeno porte. Os prêmios também mostraram-se consistentes aos testes de subperíodos e sazonalidade (efeito janeiro).

Os prêmios pelos fatores beta de mercado (MKT), e índice B/M (HML) foram positivos e significativos a 5\%. Os prêmios pelos fatores tamanho (SMB) e momento (WinMLos) não se mostraram estatisticamente significativos, apesar de positivos. Os dois maiores prêmios médios foram encontrados para os fatores beta de mercado (MKT) e liquidez (LIQ), de 1,47\% e $0,99 \%$, respectivamente.

A correlação negativa, -0,52, observada entre beta de mercado (MKT) e liquidez (LIQ) parece refletir o estado natural da liquidez: o mercado é menos líquido em períodos de queda do mercado e investidores passam a requerer altos retornos para compensar os riscos da baixa liquidez. O mesmo fato foi observado por Liu (2006) no mercado acionário norte-americano. A correlação entre os fatores liquidez (LIQ) e tamanho (SMB) foi positiva, 0,49, o que está de acordo com a expectativa de que ações de empresas de menor porte são também as menos líquidas. A relativa força de correlação entre essas variáveis pode explicar a correlação negativa entre o beta de mercado (MKT) e o tamanho (SMB). No entanto, o fato de a correlação entre liquidez (LIQ) e tamanho (SMB) ser ainda distante de 1 reforça a ideia de inabilidade do fator tamanho de capturar completamente o fator liquidez.

Em relação aos testes dos modelos de precificação de ativos nas regressões cross-section, pôde-se verificar que:

- nenhum dos modelos se mostrou suficiente na explicação das variações dos retornos cross-section das ações no mercado acionário brasileiro, uma vez que os interceptos foram elevados e significantes estatisticamente, alterando inclusive os sinais dos coeficientes dos fatores beta de mercado e índice B/M; 
- o modelo CAPM apresentou coeficientes estatisticamente significativos para o fator beta de mercado, mesmo em todas as variações dos períodos de within-sample e out-of-sample. O $R^{2} A d j$. variou de $45 \%$ a $52 \%$;

- o modelo dos 2-fatores apresentou coeficientes estatisticamente significativos para os dois fatores - beta de mercado e liquidez - em todas as variações dos períodos de withinsample e out-of-sample sugerindo a validade do modelo de 2-fatores para explicação das variações cross-section das ações no mercado brasileiro. O $R^{2} A d j$. do modelo foi bastante elevado - o mais alto dentre os modelos testados - variando de $82 \%$ a $95 \%$;

- o modelo dos 3-fatores, por sua vez, apresentou coeficientes estatisticamente significativos em todas as variações dos períodos de within-sample e out-of-sample somente para o fator beta de mercado. A significância dos demais fatores - tamanho e índice $\mathrm{B} / \mathrm{M}$ - oscilou bastante ao longo dos períodos testados. O $R^{2}$ Adj. variou de $61 \%$ a $75 \%$;

- no modelo dos 4-fatores, a adição dos fator momento parece não ter alterado o comportamento dos fatores tamanho e índice B/M. O fator momento não se mostrou significativo em nenhuma das variações dos períodos de within-sample e out-of-sample. $\mathrm{O}$ $R^{2}$ Adj. oscilou de $62 \%$ a $72 \%$.

Em suma, o modelo dos 2-fatores mostrou-se válido e superior aos modelos CAPM, 3-fatores e 4-fatores na explicação das variações cross-section dos retornos das ações no mercado brasileiro. Fama e French (1996) pontuaram que o modelo dos 3-fatores parece não ser suficiente na explicação do retorno dos ativos e sugeriram pesquisas futuras por um modelo mais completo. Apesar de o modelo dos 2-fatores também não ter se mostrado suficiente na explicação dos retornos cross-section das ações no mercado brasileiro, o relativo sucesso do modelo evidenciado nesta tese, sugere que o risco pela liquidez pode ser uma direção especialmente promissora para a continuidade das pesquisas sobre o tema.

Em face dos resultados encontrados, vale destacar algumas ressalvas ou limitações desta pesquisa. Conforme já mencionado no subcapítulo 1.5, a principal delas é que, diferente do que ocorre com o modelo CAPM, tanto no modelo 2-fatores, quanto nos modelos 3-fatores e 4-fatores, não há justificativa teórica que defina de forma exata as variáveis explicativas, o que acaba sendo feito de forma arbitrária. Outrossim, apesar das evidências da existência e da consistência dos prêmios pela liquidez, é importante ressalvar que a presente pesquisa não teve como objetivo definir estratégias de compra e venda de ações que possam resultar em 
ganhos anormais, uma vez que outros fatores devem ser levados em consideração como, por exemplo, os custos de transação. Além disso, os procedimentos empíricos levaram à exclusão de ações que não apresentaram cotações mensais consecutivas por $x$ meses para cálculos das medidas e $x$ meses para retenção das carteiras, sendo $x=1,3,6$ e 12 meses. Dessa forma, a amostra trabalhada ficou livre do risco conhecido como lock in risk, ou seja, o risco dos ativos não poderem ser vendidos a qualquer tempo. Finalmente, apesar da presente tese utilizar grande quantidade de testes alternativos para verificação da robustez dos modelos de precificação de ativos, vale a ressalva de que os resultados dos testes empíricos podem ser sensíveis à metodologia empregada, especialmente no que se refere ao processo de criação das variáveis dependentes e independentes.

Assim sendo, os resultados encontrados talvez tenham despertado mais questionamentos do que conclusões, mas, sem dúvida, contribuíram para o desenvolvimento de pesquisas futuras, dentre as quais podem-se citar:

- a extensão do estudo variando-se critérios utilizados na metodologia, tanto na formação das carteiras, como no cálculo dos fatores de risco;

- seguindo Liu (2006), a investigação do papel específico da liquidez na explicação das demais anomalias de mercado documentadas pela literatura como cash-flow-to-price, earnings-to-price e dividend yield;

- a construção de medidas de liquidez agregadas, seguindo Amihud (2002) e Liu (2006), para tentar averiguar a capacidade da medida de liquidez em capturar a liquidez geral do mercado, bem como possibilitar o estudo do impacto de grandes movimentos que afetam a liquidez da bolsa de valores brasileira, como a entrada e saída de recursos de investidores estrangeiros;

- o estudo do papel da liquidez na explicação dos retornos dos ativos de renda fixa;

- o estudo do papel da liquidez na formação de preços futuros das ações nos mercados derivativos. 


\section{REFERÊNCIAS BIBLIOGRÁFICAS}

ACHARYA, Viral V.; PEDERSEN, Lasse H. Asset pricing with liquidity risk. Journal of Financial Economics. [S.I.], v. 77, p.375-410, 2005

ALMEIDA, Juliano R.; EID, William. Estimando o retorno das ações com decomposição do índice book-to-market: evidências na bovespa. Revista Brasileira de Finanças. Rio de Janeiro, RJ, v.8, n.4, p. 417-441, 2010

AMIHUD, Yakov. Illiquidity and stocks returns: cross-section and time-series effects. Journal of Financial Markets. [S.I.], v.5, p.31-56, 2002

AMIHUD, Yakov.; MENDELSON, Haim. Liquidity and stock returns. Financial Analysts Journal. [S.I.], v.42, n.3, p. 43-48, May-June 1986.

BANZ, Rolf W. The relationship between return and market value of common stock. Journal of Financial Economics, [S.I.], v. 9, n. 1, p. 3-18, March 1981.

BARROS, L. de C.; FAMÁ, R.; SILVEIRA, H. P. Aspectos da teoria de portfolio em mercados emergentes: uma análise de aproximações para a taxa livre de risco no Brasil. In: SEMEAD, 6, 2003, São Paulo. Anais...São Paulo: Universidade de São Paulo, 2003.

BASU, Sanjoy. Investment performance of common stocks in relation to their price earnings ratios: a test of the efficient market hypothesis. The Journal of Finance, [S.I.], v. 32, n. 3, p. 663-682, June 1977.

BEKAERT, Geert; HARVEY, Campbell R.; LUNDBLAD, Christian. Liquidity and expected returns: lessons from emerging markets. The Review of Financial Studies. [S.I.], v.20, n.5, p.1783-1830, 2007

BENSTON, George.J.; HAGERMAN, Robert L. Determinants of the bid-ask spreads in the over-the-counter market. Journal of Financial Economics, [S.I.], v. 1, p.353-364, 1974.

BERNSTEIN, Peter L. Desafio aos deuses: a fascinante história do risco. 17.ed. Rio de Janeiro: Elsevier, 1997.

BLACK, Fisher. Towards a fully automated exchange. Financial Analysts Journal. [S.I.], V. 24, n. 4, p.29-35, 1971

BLACK, Fisher. Beta and return. Journal of Portfolio Management,[S.I.], v. 20, p.8-18, 1993

BLACK, Fisher; JENSEN, Michael C.; SCHOLES, Myron. The capital asset pricing model: some empirical testes. Studies in the Theory of Capital Markets, [S.I.]: Praeger, 1972.

BORNHOLT, Graham N. Extending the capital asset pricing model: the reward beta approach. Journal of Accounting and Finance, [S.I.], v. 47, p. 69-83, 2007. 
BRAGA, C. Risco e retorno das ações de valor e de crescimento brasileiras nos anos 90. Rio de Janeiro, 1999. Dissertação (Mestrado em Administração) - Instituto COPPEAD de Administração da Universidade Federal do Rio de Janeiro.

BRANCH, Ben; FREED, Walter. Bid-ask spreads on the AMEX and the big board. The Journal of Finance, [S.I.], v. 32, p.159-164, March 1977

BREALEY, Richard A.; MYERS, Stewart C. Principles of corporate finance. 7.ed. New York: McGraw Hill, 2003.

BRENNAN, Michael J.; CHORDIA, Tarun; SUBRAHMANYAM, Avinidhar. Investment analysis and price formation in securities markets. Journal of Financial Economics. [S.I.], v. 38, p.361-382, 1995

BRENNAN, Michael J.; CHORDIA, Tarun; SUBRAHMANYAM, Avinidhar. Alternative factor specifications, security characteristics, and the cross-section of expected stock return. Journal of Financial Economics. [S.I.], v.49, p. 345-373, 1998.

BRENNAN, Michael J.; SUBRAHMANYAM, Avanidhar. Market microstrucuture and asset pricing: on the compensation of illiquidity in stock returns. Journal of Financial Economics. [S.I.], v. 41, p. 441-464, 1996.

BRUNI, Adriano L. Risco, retorno e equilíbrio: uma análise do modelo de precificação de ativos financeiros na avaliação de ações negociadas na bovespa (1988-1996). São Paulo, 1998. Dissertação (Mestrado em Administração) - Programa de Pós-Graduação em Administração, Faculdade de Economia, Administração e Contabilidade da Universidade de São Paulo.

BRUNI, Adriano L; FAMÁ, Rubens. Liquidez e avaliação de ativos financeiros: evidências empíricas na bovespa (1988-1996). In: ENCONTRO ANUAL DA ASSOCIAÇÃO NACIONAL DOS PROGRAMAS DE PÓS-GRADUAÇÃO EM ADMINISTRAÇÃOENANPAD, 22, Foz do Iguaçu, 1998. Anais...Foz do Iguaçu: ANPAD, 1998.

CARHART, Mark M. On persistence in mutual fund performance. The Journal of Finance, [S.I.], v. 52, n. 1, p.57-82, March 1997

CHAN, Louis C.; LAKONISHOK, Josef. Are reports of beta's death premature? Journal of Portfolio Management, [S.I.], v. 19, p.51-62, 1993.

CHAN, Howard W.; FAFF, Robert W. Asset pricing and the illiquidity premium. The Financial Review. [S.I.], v. 40, p.429-458, 2005

CHORDIA, Tarun; SARKAR, Asani; SUBRAHMANYAM, Avanidhar. An empirical analysis of stock and bond market liquidity. Review of Financial Studies. [S.I.], v.18, p.85129,2005

CHORDIA, Tarun; SUBRAHMANYAM, Avanidhar; ANSHUMAN, V. Ravi. Trading activity and expected returns. Journal of Financial Economics. [S.I.], v. 59, p.3-32, 2001 
COPELAND, Thomas E.; GALAI, Dan. Information effects on the bid-ask spread. The Journal of Finance, [S.I.], v. 38, p. 1457-1469, 1983

COPELAND, Thomas E.; WESTON, J. Fred.; SHASTRI, Kuldeep. Financial theory and corporate policy. 4. ed. New York: Addison Wesley, 2005.

CORREIA, Laise F.; AMARAL, Hudson F.; BRESSAN, Aureliano A. O efeito da liquidez sobre a rentabilidade de mercado das ações negociadas no mercado acionário brasileiro. Revista de Administração e Contabilidade da Unisinos. [S.I.], v.5, n.2, p.109-119, maio/agosto 2008

COSTA Jr, Newton Carneiro A. Sazonalidades do ibovespa. Revista de Administração de Empresas, [S.I.], n. 30, p.79-84, 1990.

COSTA Jr., Newton. C. A.; NEVES, Maria Beatriz E. Variáveis fundamentais e retornos das ações. Revista Brasileira de Economia, [S.I.], v.54, n. 1, p.123-137, jan-mar 2000.

DANIEL, Kent; TITMAN, Sheridan. Market efficiency in an irrational world. Financial Analysts Journal, [S.I.], v. 55, n. 6, p.28-40, November/December 1999.

DATAR, Vinay T.; NAIK, Narayan Y.; RADCLIFFE R. Liquidity and stock returns: an alternative test. Journal of Financial Markets. [S.I.], v. 1, p.203-219, 1998

DAVIS, Jamel L. The cross section of realized stock returns: the pre-COMPUSTAT evidence. The Journal of Finance, [S.I.], v.49, p. 1579-1593, 1994

DEBONDT, Werner F. M.; THALER, Richard H. Does the stock market overreact? The Journal of Finance, [S.I.], v.40, n.3, p.793-805, July 1985.

DEBONDT, Werner F. M.; THALER, Richard H. Further evidence on investor over-reaction and stock market seasonality. The Journal of Finance, [S.I.], v.42, p.557-581, July 1987.

DEMSETZ, Harold. The cost of transacting. Quarterly Journal of Economics, [S.I.], v. 82, p.33-53, 1968.

ELESWARAPU, Venkat R.; REINGANUM, Marc R. The seasonal behavior of the liquidity premium in asset pricing. Journal of Financial Economics. [S.I.], v. 34, p. 373-386, 1993

ELTON, E. J.; GRUBER, M. J.; BROWN, S. J.; GOETZMANN, W. N. Moderna teoria de carteiras e análise de investimentos. São Paulo: Atlas, 2004

FAMA, Eugene F. Efficient capital markets: a review of theory and empirical work. The Journal of Finance, [S.I.], v. 25, n. 2, p.383-417, May 1970.

FAMA, Eugene F. Efficient capital markets: II. The Journal of Finance, [S.I.], v. 46, n. 5 p.1575-1618, December 1991.

FAMA, Eugene F..; MACBETH, James D. Risk, return and equilibrium: empirical testes. The Journal of Political Economy, [S.I.], v. 81, n. 3, p.607-636, May-June 1973. 
FAMA, Eugene F.; FRENCH, Kenneth R. The cross-section of expected stock returns. Journal of Finance,[S.I.], v. 47, n. 2, p.427-465, June 1992.

FAMA, Eugene F.; FRENCH, Kenneth R. Common risk factors in the returns on stocks and bonds. Journal of Financial Economics, [S.I.], v. 33, n. 1, p.3-56, February 1993.

FAMA, Eugene F.; FRENCH, Kenneth R. Size and book-to-market factors in earnings and returns. Journal of Financial Economics, [S.I.], v. 50, n. 1, p.131-155, March 1995.

FAMA, Eugene F.; FRENCH, Kenneth R. Multifactor explanation of asset pricing anomalies. The Journal of Finance, [S.I.], v. 51, n. 1, p.55-84, March 1996

FAMA, Eugene F..; FRENCH, Kenneth R. Value versus growth: the international evidence. The Journal of Finance, [S.I.], v. 53, n. 6, p.1975-1999, december 1998.

FAMA, Eugene F.; FRENCH, Kenneth R. The capital asset pricing model: theory and evidence. Journal of Economic Perspectives, [S.I.], v. 18, n. 3, p.25-46, 2004.

FLISTER, Frederico V.; BRESSAN, Aureliano A.; AMARAL, Hudson F. CAPM condicional no mercado brasileiro: um estudo dos efeitos momento, tamanho e book-to-market entre 1995 e 2008. Revista Brasileira de Finanças. Rio de Janeiro, RJ, v.9, n.1, p.105-129, março 2011

GARMAN, Mark B. Market microstructure. Journal of Financial Economics, [S.I.], v. 3, p.257-275, 1976

GLOSTEN, Lawrence R.; HARRIS, Lawrence. Estimating the components of the bid/ask spread. Journal of Financial Economics, [S.I.], v21, p.123-142, 1988

GRINBLATT, Mark; TITMAN, Sheridan. Mercados financeiros e estratégia corporativa. 2.ed. Porto Alegre: Bookman, 2005.

GRINOLD, Richard C. Is beta dead again? Financial Analyst Journal, [S.I.], v. 49, n. 4 , p.28-34, July/August 1993.

HICK, John. Critical essays in monetary theory. Oxford University Press: Oxford, 1967

HO, Thomas.; STOLL, Hans R. Optimal dealer pricing under transactions and return uncertainty. Journal of Financial Economics, [S.I.], v. 9, p.47-73, 1981.

HO, Thomas; STOLL, Hans R. The dynamics of dealer markets under competition. The Journal of Finance, [S.I.], v. 38, p.1053-1074, 1983.

HONG, Harrison; LIM, Terence; STEIN, Jeremy C. Bad news travels slowly: size, analyst coverage, and the profitability of momentum strategies. The Journal of Finance, [S.I.], v. 55, n. 1, p.265-295, February 2000.

HORNG, Wang J. Testes de validade do capital asset pricing model no mercado acionário de São Paulo - um estudo indicativo do poder de teste da metodologia de Fama e MacBeth. São Paulo, 1997. Dissertação (Mestrado em Administração) - Escola de Administração de Empresas de São Paulo da Fundação Getúlio Vargas. 
JEGADEESH, Narasimhan; TITMAN, Sheridan. Returns to buying winners and selling losers: implications for stock market efficiency. The Journal of Finance, [S.I.], v. 48, n. 1, p.65-91, March 1993.

JEGADEESH, Narasimhan; TITMAN, Sheridan. Profitability of momentum strategies: an evaluation of alternative explanations. The Journal of Finance, [S.I.], v. 56, n. 2, p.699-720, April 2001.

JUNG, Sang-Gyung; MARATHE, Achla; SHAWKY, Hany A. Liquidity and stock returns in emerging equity markets. Emerging Markets Review. [S.I.], v.4, p.1-24, 2003

KEENE, Marvin A.; PETERSEN, David R. The importance of liquidity as a factor in asset pricing. The Journal of Financial Research. [S.I.], v. 30, n.1, p.91-109, 2007

KEIM, Donald B. Size-related anomalies and stock return seasonality: further empirical evidence. Journal of Financial Economics, [S.I.], v. 12, p. 13-32, June 1983.

KNIGHT, Frank H. Risk, uncertainty, and profit. The library of economics and liberty, 1921. Disponível em www.econlib.org/library/Knight/knRUP.html. Acesso em: 12 Nov. 2011.

KOTHARI, S. P.; SHANKEN, Jay; SLOAN, Richard G. Another look at the cross-section of expected stock returns. The Journal of Finance, [S.I.], v. 50, n.1, p. 185-224, March 1995.

L'HER, Jean-François.; MASMOUD, Tarek; SURET, Jean-Marc. Evidence to support the four-factor pricing model from the Canadian stock market. Journal of International

Financial Markets, Institutions and Money. [S.I.], v. 14, n. 4, p.313-328, 2004.

LAKONISHOK, Josef; SHAPIRO, Alan C. Systematic risk, total risk and size as determinants of stock market returns. Journal of Banking and Finance, [S.I.], v. 10, n. 1, p. 115-132, March 1986.

LAKONISHOK, Josef; SHLEIFER, Andrei.; VISHNY, Robert W. Contrarian investment, extrapolation, and risk. The Journal of Finance, [S.I.], v. 49, n. 5, p. 1541-1578, December 1994.

LAM, Keith; TAM, Lewis. Liquidity and asset pricing: evidence from the Hong Kong stock markets. Journal of Banking and Financem [S.I.], v.35, n.9, 2011

LEE, Kuan-Hiu. The world price of liquidity risk. Journal of Financial Economics. [S.I.], v. 99, p. 136-161, 2011

LEE, Charles M. C.; SWAMINATHAN, Bhaskaran. Price momentum and trade volume. The Journal of Finance, [S.I.], v.55, n.5, p. 2017-2069, October, 2000

LESMOND, David A. Liquidity of emerging markets. Journal of Financial Economics. [S.I.], v.77, p.411-452, 2005

LESMOND, David A.; OGDEN, Joseph P.; TRZCINKA, Charles A. A new estimate of transaction costs. The Review of Financial Studies. [S.I.], v.12, n.5, p.1113-1141, 1999 
LIEW, Jim K. S.; VASSALOU, Maria. Can book-to-market, size and momentum be risk factors that predict economic growth? Journal of Financial Economics, [S.I.], v. 57, n. 2, p.221-245, 2000.

LINTNER, John. The valuation of risk assets and the selection of risky investments in stock portfolios and capital budgets. The Review of Economics and Statistics. [S.I.], v. 47, n.1, p. 13-37, February 1965

LISCHEWSKI, Judith; VORONKOVA, Svitlana. Size, value and liquidity. Do they really matter on an emerging market stock market? Emerging Markets Review. [S.I.], v. 13, p. 825,2012

LIU, Weimin. A liquidity-augmented capital asset pricing model. Journal of Financial Economics. [S.I.], v.82, p.631-671, 2006

LO, Andrew W.; MACKINLAY, A. Craig. Data-snooping biases in tests of financial asset pricing models. Review of Financial Studies, [S.I.], v.3, p.431-468, 1990

LUCENA, Pierri; PINTO, Antonio Carlos F. Estudo de anomalias no mercado brasileiro de ações através de uma modificação no modelo de Fama e French. In: Encontro Anual da Associação Nacional dos Programas de Pós-graduação em Administração - ENANPAD, 29, 2005, Brasília. Anais... Brasília: ANPAD, 2005.

MACHADO, Márcio A. V.; MEDEIROS, Otávio R. Modelos de precificação de ativos e o efeito da liquidez: evidências empíricas no mercado acionário brasileiro. Revista Brasileira de Finanças. Rio de Janeiro, v. 9, n.3, set. 2011

MÁLAGA, Flávio K.; SECURATO, Jose Roberto. Aplicação do modelo dos três fatores de Fama e French no mercado acionário brasileiro - um estudo empírico do período 1995-2003. In: Encontro Anual da Associação Nacional dos Programas de Pós-graduação em Administração - ENANPAD, 28, 2004, Curitiba. Anais...Curitiba: ANPAD, 2004.

MARCONI, Marina de Andrade; LAKATOS, Eva Maria. Técnicas de pesquisa: planejamento e execução de pesquisas, elaboração, análise e interpretação de dados. $3^{\mathrm{a}}$. Ed. São Paulo: Atlas, 1996.

MARCONI, Marina de Andrade; LAKATOS, Eva Maria. Metodologia científica. $3^{\text {a }}$. Ed. São Paulo: Atlas, 2000.

MARKOWITZ, Harry M. Portfolio selection. The Journal of Finance. [S.I.], v. 7, p. 77-91, March 1952

MARTINS, Gilberto de A. Manual para elaboração de monografias e dissertações. $3^{\mathrm{a}}$. Ed., São Paulo: Atlas, 2002.

MELLONE Jr., Geraldo. Beta: problemas e evidência empírica. São Paulo, 1999.

Dissertação (Mestrado em Administração) - Programa de Pós-Graduação em Administração, Faculdade de Economia, Administração e Contabilidade da Universidade de São Paulo. 
MOSSIN, Jan. Equilibrium in capital asset market. Econometrica. [S.I.], v. 34, p. 768-783, 1966

MUSSA, Adriano; ROGERS, Pablo; SECURATO, José Roberto. Modelos de retornos esperados no mercado brasileiro: testes empíricos utilizando metodologia preditiva. Revista de Ciências da Administração. Florianópolis, SC, v.11, n.23, p.192-216, jan-abr 2009

MUSSA, Adriano; SANTOS, José Odálio; FAMA, Rubens. A adição do fator de risco momento ao modelo de precificação de ativos dos três fatores de Fama e French, aplicado ao mercado acionário brasileiro. In: Congresso USP de Controladoria e Contabilidade, 7, 2007, São Paulo. Anais...São Paulo: USP, 2007

NEVES, Maria Beatriz E. Utilização do beta, índice $\mathbf{P} / \mathbf{L}$, valor de mercado e valor contábil na relação risco-retorno no mercado acionário brasileiro. Rio de Janeiro, 1996. Dissertação (Mestrado em Administração) - Instituto COPPEAD de Administração da Universidade Federal do Rio de Janeiro.

NGUYEN, Duong; MISHRA, Suchismita; PRAKASH, Arun; GHOSH, Dilip K. Liquidity and asset pricing under the three-moment CAPM paradigm. The Journal of Financial Research. [S.I.], v.30, n.3, p.379-398, 2007

PASTOR, Lubos; STAMBAUGH, Robert F. Liquidity risk and expected returns. Journal of Political Economy. [S.I.], v.111, n.3, p.642-685, June 2003

PAULA LEITE, Helio; SANVICENTE, Antonio Z. Índice bovespa: um padrão para os investimentos brasileiros. São Paulo: Atlas, 1995.

PETERSEN, Mitchell A.; FIALKOWSKI, David. Posted versus effective spreads: good prices or bad quotes?. Journal of Financial Economics, [S.I.], v.35, p.269-292, 1994

PENTEADO, Marco Antonio de Barros; FAMÁ, Rubens. Será que o beta que temos é o beta que queremos? Caderno de Pesquisas em Administração. São Paulo, SP, v. 09, n. 03, p. 115 , jul-set 2002.

REINGANUM, Mark. Misspecifications of capital asset pricing: empirical anomalies based on earnings' yields and market values. Journal of Financial Economics, [S.I.], v. 9, n.1, p. 19-46, 1981.

ROLL, Richard A. A critique of the asset pricing theory's test: part I: on past and potential testability of the theory. Journal of Financial Economics, [S.I.], v. 4, p. 129-176, March 1977.

ROSS, Stephen A. The arbitrage theory of capital asset pricing. Journal of Economic Theory, [S.I.], v. 13, p.341-360, 1976.

ROUWENHORST, K. Geert. International momentum estrategies. The Journal of Finance, [S.I.], v. 53, n. 1, p.267-284, February 1998.

ROUWENHORST, K. Geert. Local return factors and Turnover in emerging stock markets. The Journal of Finance, [S.I.], v. 54, n. 4, p.1439-1464, August 1999. 
SAMUELSON, Paul. Proof that properly anticipated prices fluctuate randomly. Industrial Management Review, Cambridge: Massachusetts Institute of Technology, v. 6, p.41-49, 1965.

SANVICENTE, Antonio Z.; MINARDI, Andrea M.F. A liquidez é relevante no mercado de ações? Resenha BMF, n.128, p.35-55, 1998

SHARPE, William F. Capital asset prices: a theory of market equilibrium under conditions of risk. Journal of Finance, [S.I.], v. 19, p.425-443, September 1964.

SHILLER, Robert. Human behavior and the efficiency of the financial system. In: J. Taylor and M. Woodford (org.), Handbook of Macroeconomics, Amsterdam: Elsevier, 1999.

STATTMAN, Denis. Book values and stock returns. The Chicago MBA: A Journal of Selected Papers, [S.I], v. 4, p. 25-45. 1980.

STOLL, Hans. The pricing of dealer services: an empirical study of NASDAQ stocks. The Journal of Finance. [S.I.], v. 33, p.1152-1173, 1978

TINIC, Seha M. The economics of liquidity services. Quarterly Journal of Economics, [S.I.], v. 86, p.79-93, 1972.

TINIC, Seha M.; WEST, Richard R. Competition and the pricing of dealer service in the over-the-counter stock market. Journal of Financial and Quantitative Analysis, [S.I.], v. 7, p.1707-1727, 1972.

TOBIN, James. Liquidity preference as behavior toward risk. The Review of Economic Studies. [S.I.], v. 25, n. 2, p.65-86, February 1958

VAIHEKOSKI,Mika.Portfolio Construction for tests of asset pricing models. Financial Markets, Institutions \& Instruments, [S.I.], v. 13, p.1-39, 2004

VIEIRA, Kelmara M.; MILACH, Felipe T. Liquidez/iliquidez no mercado brasileiro: comportamento no período 1995-2005 e suas relações com o retorno. Revista de Administração e Contabilidade da Unisinos. [S.I.], v. 5, n.1, p.5-16, 2008

WANG, Xiaozu. Size effect, book-to-market effect, and survival. Journal of Multinational Financial Management, [S.I.], v. 10, p.257-273, 2000 


\section{APÊNDICES}

APÊNDICE 1 - MATRIZES DE CORRELAÇÃO ENTRE AS MEDIDAS DE LIQUIDEZ

APÊNDICE 2 - EXCESSOS DE RETORNOS MENSAIS DAS CARTEIRAS E RETORNO MENSAL DA CADERNETA DE POUPANÇA

APÊNDICE 3 - $\quad$ VALORES (PRÊMIOS) MENSAIS DOS FATORES DE RISCO

APÊNDICE 4 - TESTES DE NORMALIDADE, AUTOCORRELAÇÃO E (MULTI)COLINEARIDADE DAS VARIÁVEIS

APÊNDICE 5 - $\quad$ SENSIBILIDADE DOS EXCESSOS DE RETORNOS AOS

FATORES DE RISCO CONSIDERANDO AS AMOSTRAS WITHIN-

SAMPLE 


\section{APÊNDICE 1 - MATRIZES DE CORRELAÇÃO ENTRE AS MEDIDAS DE LIQUIDEZ}

A tabela abaixo apresenta os coeficientes de correlação de Spearman para todas as medidas de liquidez utilizadas no presente estudo. As medidas de liquidez estão explicadas com detalhes no Quadro 5 do Subcapítulo 3.3.1. VM é o valor de mercado das ações. No final de cada mês $t$, de julho de 1995 a novembro de 2011 , foi calculado o coeficiente de correlação de Spearman cross-section sobre todas as ações da amostra e, posteriormente, foi calculada a média time-series dessas correlações. Os resultados são apresentados individualmente nos 16 painéis abaixo, de $\mathbf{A}$ a $\mathbf{P}$, de acordo com a combinação de cada um dos $x$ meses de cálculo das medidas e $x$ meses de retenção das ações, em que $x$ é igual a 1, 3, 6 e 12 meses. Por exemplo, o painel B apresenta os resultados para a estratégia 1x3, a qual contém ações que atendem ao seguinte requisito para cada mês $t$, de julho de 1995 a novembro de 2011: cotação mensal no mês corrente e nos 3 meses seguintes.

\begin{tabular}{|c|c|c|c|c|c|c|c|c|c|c|c|c|}
\hline \multicolumn{13}{|c|}{ Painel A - 1X1 } \\
\hline & VM & $\begin{array}{c}\text { Volume } \\
\text { Financeiro } \\
\text { (VOL1) } \\
\end{array}$ & $\begin{array}{c}\text { Quantidade } \\
\text { de Negócios } \\
\text { (QN1) }\end{array}$ & $\begin{array}{c}\text { Quantidade } \\
\text { de Títulos } \\
\text { (QT1) }\end{array}$ & $\begin{array}{l}\text { Número de } \\
\text { Dias Sem } \\
\text { Transação } \\
\text { (NTD1) }\end{array}$ & $\begin{array}{l}\text { Return-to- } \\
\text { Volume } \\
\text { (RtoV1) }\end{array}$ & $\begin{array}{l}\text { Turnover } \\
\text { (TO1) }\end{array}$ & $\begin{array}{c}\text { Volume Zero } \\
\text { Padronizado } \\
\text { (VZP1) }\end{array}$ & $\begin{array}{c}\text { Índice de } \\
\text { Negociabilidade } \\
\text { (NEG3) }\end{array}$ & $\begin{array}{l}\text { Desvio- } \\
\text { Padrão do } \\
\text { Turnover } \\
\text { (DPTO3) }\end{array}$ & $\begin{array}{l}\text { Desvio- } \\
\text { Padrão do } \\
\text { Volume } \\
\text { (DPVOL3) }\end{array}$ & $\begin{array}{c}\text { Coeficiente } \\
\text { de Variação } \\
\text { do Turnover } \\
\text { (CVTO3) }\end{array}$ \\
\hline $\begin{array}{l}\text { Volume Financeiro } \\
\text { (VOL1) }\end{array}$ & 0,72 & & & & & & & & & & & \\
\hline $\begin{array}{l}\text { Quantidade de } \\
\text { Negócios (QN1) }\end{array}$ & 0,61 & 0,91 & & & & & & & & & & \\
\hline $\begin{array}{l}\text { Quantidade de } \\
\text { Títulos (QT1) }\end{array}$ & 0,39 & 0,68 & 0,70 & & & & & & & & & \\
\hline $\begin{array}{l}\text { Número de Dias } \\
\text { Sem Transação } \\
\text { (NTD1) }\end{array}$ & $-0,54$ & $-0,83$ & $-0,93$ & $-0,64$ & & & & & & & & \\
\hline $\begin{array}{l}\text { Return-to-Volume } \\
\text { (RtoV1) }\end{array}$ & 0,01 & $-0,01$ & $-0,03$ & $-0,02$ & 0,03 & & & & & & & \\
\hline Turnover (TO1) & 0,02 & 0,39 & 0,34 & 0,63 & $-0,31$ & 0,01 & & & & & & \\
\hline $\begin{array}{l}\text { Volume Zero } \\
\text { Padronizado (VZP1) }\end{array}$ & $-0,03$ & $-0,40$ & $-0,35$ & $-0,63$ & 0,32 & $-0,01$ & $-1,00$ & & & & & \\
\hline $\begin{array}{l}\text { Índice de } \\
\text { Negociabilidade } \\
\text { (NEG1) }\end{array}$ & 0,67 & 0,97 & 0,98 & 0,70 & $-0,92$ & $-0,02$ & 0,37 & $-0,38$ & & & & \\
\hline
\end{tabular}




\begin{tabular}{|c|c|c|c|c|c|c|c|c|c|c|c|c|}
\hline \multicolumn{13}{|c|}{ Painel B - 1X3 } \\
\hline & VM & $\begin{array}{l}\text { Volume } \\
\text { Financeiro } \\
\text { (VOL1) }\end{array}$ & $\begin{array}{c}\text { Quantidade } \\
\text { de Negócios } \\
\text { (QN1) }\end{array}$ & $\begin{array}{l}\text { Quantidade } \\
\text { de Títulos } \\
\text { (QT1) }\end{array}$ & $\begin{array}{l}\text { Número de } \\
\text { Dias Sem } \\
\text { Transação } \\
\text { (NTD1) }\end{array}$ & $\begin{array}{l}\text { Return-to- } \\
\text { Volume } \\
\text { (RtoV1) }\end{array}$ & $\begin{array}{l}\text { Turnover } \\
\text { (TO1) }\end{array}$ & $\begin{array}{c}\text { Volume Zero } \\
\text { Padronizado } \\
\text { (VZP1) }\end{array}$ & $\begin{array}{c}\text { Índice de } \\
\text { Negociabilidade } \\
\text { (NEG3) }\end{array}$ & $\begin{array}{l}\text { Desvio- } \\
\text { Padrão do } \\
\text { Turnover } \\
\text { (DPTO3) }\end{array}$ & $\begin{array}{l}\text { Desvio- } \\
\text { Padrão do } \\
\text { Volume } \\
\text { (DPVOL3) }\end{array}$ & $\begin{array}{c}\text { Coeficiente } \\
\text { de Variação } \\
\text { do Turnover } \\
\text { (CVTO3) }\end{array}$ \\
\hline $\begin{array}{l}\text { Volume Financeiro } \\
\text { (VOL1) }\end{array}$ & 0,73 & & & & & & & & & & & \\
\hline $\begin{array}{l}\text { Quantidade de } \\
\text { Negócios (QN1) }\end{array}$ & 0,62 & 0,92 & & & & & & & & & & \\
\hline $\begin{array}{l}\text { Quantidade de } \\
\text { Títulos (QT1) }\end{array}$ & 0,41 & 0,68 & 0,70 & & & & & & & & & \\
\hline $\begin{array}{l}\text { Número de Dias } \\
\text { Sem Transação } \\
\text { (NTD1) }\end{array}$ & $-0,54$ & $-0,82$ & $-0,91$ & $-0,63$ & & & & & & & & \\
\hline $\begin{array}{l}\text { Return-to-Volume } \\
\text { (RtoV1) }\end{array}$ & 0,00 & $-0,01$ & $-0,03$ & $-0,02$ & 0,02 & & & & & & & \\
\hline Turnover (TO1) & 0,00 & 0,37 & 0,32 & 0,62 & $-0,28$ & 0,02 & & & & & & \\
\hline $\begin{array}{l}\text { Volume Zero } \\
\text { Padronizado (VZP1) }\end{array}$ & $-0,02$ & $-0,37$ & $-0,33$ & $-0,63$ & 0,30 & $-0,01$ & $-1,00$ & & & & & \\
\hline $\begin{array}{l}\text { Índice de } \\
\text { Negociabilidade } \\
\text { (NEG1) }\end{array}$ & 0,69 & 0,97 & 0,98 & 0,70 & $-0,90$ & $-0,02$ & 0,35 & $-0,36$ & & & & \\
\hline
\end{tabular}




\begin{tabular}{|c|c|c|c|c|c|c|c|c|c|c|c|c|}
\hline \multicolumn{13}{|c|}{ Painel C - 1x6 } \\
\hline & VM & $\begin{array}{l}\text { Volume } \\
\text { Financeiro } \\
\text { (VOL1) }\end{array}$ & $\begin{array}{c}\text { Quantidade } \\
\text { de Negócios } \\
\text { (QN1) }\end{array}$ & $\begin{array}{l}\text { Quantidade } \\
\text { de Títulos } \\
\text { (QT1) }\end{array}$ & $\begin{array}{l}\text { Número de } \\
\text { Dias Sem } \\
\text { Transação } \\
\text { (NTD1) }\end{array}$ & $\begin{array}{l}\text { Return-to- } \\
\text { Volume } \\
\text { (RtoV1) }\end{array}$ & $\begin{array}{l}\text { Turnover } \\
\text { (TO1) }\end{array}$ & $\begin{array}{c}\text { Volume Zero } \\
\text { Padronizado } \\
\text { (VZP1) }\end{array}$ & $\begin{array}{c}\text { Índice de } \\
\text { Negociabilidade } \\
\text { (NEG3) }\end{array}$ & $\begin{array}{l}\text { Desvio- } \\
\text { Padrão do } \\
\text { Turnover } \\
\text { (DPTO3) }\end{array}$ & $\begin{array}{l}\text { Desvio- } \\
\text { Padrão do } \\
\text { Volume } \\
\text { (DPVOL3) }\end{array}$ & $\begin{array}{c}\text { Coeficiente } \\
\text { de Variação } \\
\text { do Turnover } \\
\text { (CVTO3) }\end{array}$ \\
\hline $\begin{array}{l}\text { Volume Financeiro } \\
\text { (VOL1) }\end{array}$ & 0,73 & & & & & & & & & & & \\
\hline $\begin{array}{l}\text { Quantidade de } \\
\text { Negócios (QN1) }\end{array}$ & 0,63 & 0,92 & & & & & & & & & & \\
\hline $\begin{array}{l}\text { Quantidade de } \\
\text { Títulos (QT1) }\end{array}$ & 0,42 & 0,68 & 0,69 & & & & & & & & & \\
\hline $\begin{array}{l}\text { Número de Dias } \\
\text { Sem Transação } \\
\text { (NTD1) }\end{array}$ & $-0,54$ & $-0,81$ & $-0,89$ & $-0,61$ & & & & & & & & \\
\hline $\begin{array}{l}\text { Return-to-Volume } \\
\text { (RtoV1) }\end{array}$ & $-0,00$ & $-0,02$ & $-0,03$ & $-0,02$ & 0,02 & & & & & & & \\
\hline Turnover (TO1) & $-0,01$ & 0,34 & 0,30 & 0,62 & $-0,25$ & 0,02 & & & & & & \\
\hline $\begin{array}{l}\text { Volume Zero } \\
\text { Padronizado (VZP1) }\end{array}$ & $-0,00$ & $-0,35$ & $-0,31$ & $-0,63$ & 0,27 & $-0,02$ & $-1,00$ & & & & & \\
\hline $\begin{array}{l}\text { Índice de } \\
\text { Negociabilidade } \\
\text { (NEG1) }\end{array}$ & 0,69 & 0,97 & 0,98 & 0,70 & $-0,88$ & $-0,02$ & 0,32 & $-0,33$ & & & & \\
\hline
\end{tabular}




\begin{tabular}{|c|c|c|c|c|c|c|c|c|c|c|c|c|}
\hline \multicolumn{13}{|c|}{ Painel D - 1x12 } \\
\hline & VM & $\begin{array}{c}\text { Volume } \\
\text { Financeiro } \\
\text { (VOL1) }\end{array}$ & $\begin{array}{c}\text { Quantidade } \\
\text { de Negócios } \\
\text { (QN1) }\end{array}$ & $\begin{array}{c}\text { Quantidade } \\
\text { de Títulos } \\
\text { (QT1) }\end{array}$ & $\begin{array}{l}\text { Número de } \\
\text { Dias Sem } \\
\text { Transação } \\
\text { (NTD1) }\end{array}$ & $\begin{array}{l}\text { Return-to- } \\
\text { Volume } \\
\text { (RtoV1) }\end{array}$ & $\begin{array}{l}\text { Turnover } \\
\text { (TO1) }\end{array}$ & $\begin{array}{c}\text { Volume Zero } \\
\text { Padronizado } \\
\text { (VZP1) }\end{array}$ & $\begin{array}{c}\text { Índice de } \\
\text { Negociabilidade } \\
\text { (NEG3) }\end{array}$ & $\begin{array}{l}\text { Desvio- } \\
\text { Padrão do } \\
\text { Turnover } \\
\text { (DPTO3) }\end{array}$ & $\begin{array}{l}\text { Desvio- } \\
\text { Padrão do } \\
\text { Volume } \\
\text { (DPVOL3) }\end{array}$ & $\begin{array}{c}\text { Coeficiente } \\
\text { de Variação } \\
\text { do Turnover } \\
\text { (CVTO3) }\end{array}$ \\
\hline $\begin{array}{l}\text { Volume Financeiro } \\
\text { (VOL1) }\end{array}$ & 0,73 & & & & & & & & & & & \\
\hline $\begin{array}{l}\text { Quantidade de } \\
\text { Negócios (QN1) }\end{array}$ & 0,64 & 0,92 & & & & & & & & & & \\
\hline $\begin{array}{l}\text { Quantidade de } \\
\text { Títulos (QT1) }\end{array}$ & 0,42 & 0,68 & 0,68 & & & & & & & & & \\
\hline $\begin{array}{l}\text { Número de Dias } \\
\text { Sem Transação } \\
\text { (NTD1) }\end{array}$ & $-0,52$ & $-0,78$ & $-0,86$ & $-0,58$ & & & & & & & & \\
\hline $\begin{array}{l}\text { Return-to-Volume } \\
\text { (RtoV1) }\end{array}$ & $-0,02$ & $-0,03$ & $-0,04$ & $-0,02$ & 0,03 & & & & & & & \\
\hline Turnover (TO1) & $-0,03$ & 0,31 & 0,26 & 0,62 & $-0,21$ & 0,02 & & & & & & \\
\hline $\begin{array}{l}\text { Volume Zero } \\
\text { Padronizado (VZP1) }\end{array}$ & 0,02 & $-0,32$ & $-0,27$ & $-0,62$ & 0,22 & $-0,02$ & $-1,00$ & & & & & \\
\hline $\begin{array}{l}\text { Índice de } \\
\text { Negociabilidade } \\
\text { (NEG1) }\end{array}$ & 0,70 & 0,98 & 0,98 & 0,69 & $-0,85$ & $-0,04$ & 0,29 & $-0,30$ & & & & \\
\hline
\end{tabular}




\begin{tabular}{|c|c|c|c|c|c|c|c|c|c|c|c|c|}
\hline \multicolumn{13}{|c|}{ Painel E-3x1 } \\
\hline & VM & $\begin{array}{l}\text { Volume } \\
\text { Financeiro } \\
\text { (VOL3) }\end{array}$ & $\begin{array}{c}\text { Quantidade } \\
\text { de Negócios } \\
\text { (QN3) }\end{array}$ & $\begin{array}{l}\text { Quantidade } \\
\text { de Títulos } \\
\text { (QT3) }\end{array}$ & $\begin{array}{l}\text { Número de } \\
\text { Dias Sem } \\
\text { Transação } \\
\text { (NTD3) }\end{array}$ & $\begin{array}{l}\text { Return-to- } \\
\text { Volume } \\
\text { (RtoV3) }\end{array}$ & $\begin{array}{l}\text { Turnover } \\
\text { (TO3) }\end{array}$ & $\begin{array}{c}\text { Volume Zero } \\
\text { Padronizado } \\
\text { (VZP3) }\end{array}$ & $\begin{array}{c}\text { Índice de } \\
\text { Negociabilidade } \\
\text { (NEG3) }\end{array}$ & $\begin{array}{l}\text { Desvio- } \\
\text { Padrão do } \\
\text { Turnover } \\
\text { (DPTO3) }\end{array}$ & $\begin{array}{l}\text { Desvio- } \\
\text { Padrão do } \\
\text { Volume } \\
\text { (DPVOL3) }\end{array}$ & $\begin{array}{c}\text { Coeficiente } \\
\text { de Variação } \\
\text { do Turnover } \\
\text { (CVTO3) }\end{array}$ \\
\hline $\begin{array}{l}\text { Volume Financeiro } \\
\text { (VOL3) }\end{array}$ & 0,74 & & & & & & & & & & & \\
\hline $\begin{array}{l}\text { Quantidade de } \\
\text { Negócios (QN3) }\end{array}$ & 0,62 & 0,91 & & & & & & & & & & \\
\hline $\begin{array}{l}\text { Quantidade de } \\
\text { Títulos (QT3) } \\
\end{array}$ & 0,41 & 0,67 & 0,69 & & & & & & & & & \\
\hline $\begin{array}{l}\text { Número de Dias Sem } \\
\text { Transação (NTD3) }\end{array}$ & $-0,57$ & $-0,85$ & $-0,93$ & $-0,63$ & & & & & & & & \\
\hline $\begin{array}{l}\text { Return-to-Volume } \\
\text { (RtoV3) }\end{array}$ & 0,02 & $-0,04$ & $-0,08$ & $-0,06$ & 0,06 & & & & & & & \\
\hline Turnover (ТO3) & 0,00 & 0,35 & 0,31 & 0,62 & $-0,28$ & $-0,01$ & & & & & & \\
\hline $\begin{array}{l}\text { Volume Zero } \\
\text { Padronizado (VZP3) }\end{array}$ & $-0,03$ & $-0,37$ & $-0,34$ & $-0,64$ & 0,31 & 0,01 & $-1,00$ & & & & & \\
\hline $\begin{array}{l}\text { Índice de } \\
\text { Negociabilidade } \\
\text { (NEG3) }\end{array}$ & 0,69 & 0,97 & 0,98 & 0,69 & $-0,92$ & $-0,06$ & 0,33 & $-0,36$ & & & & \\
\hline $\begin{array}{l}\text { Desvio-Padrão do } \\
\text { Turnover (DPTO3) }\end{array}$ & $-0,10$ & 0,23 & 0,18 & 0,53 & $-0,15$ & $-0,01$ & 0,95 & $-0,94$ & 0,21 & & & \\
\hline $\begin{array}{l}\text { Desvio-Padrão do } \\
\text { Volume (DPVOL3) }\end{array}$ & 0,70 & 0,97 & 0,86 & 0,64 & $-0,78$ & $-0,05$ & 0,35 & $-0,37$ & 0,92 & 0,29 & & \\
\hline $\begin{array}{l}\text { Coeficiente de } \\
\text { Variação do } \\
\text { Turnover (CVTO3) } \\
\end{array}$ & $-0,42$ & $-0,52$ & $-0,57$ & $-0,40$ & 0,57 & $-0,01$ & $-0,19$ & 0,21 & $-0,56$ & 0,05 & $-0,33$ & \\
\hline $\begin{array}{l}\text { Coeficiente de } \\
\text { Variação do Volume } \\
\text { (CVVOL3) }\end{array}$ & $-0,42$ & $-0,50$ & $-0,55$ & $-0,36$ & 0,55 & $-0,02$ & $-0,16$ & 0,18 & $-0,55$ & 0,07 & $-0,29$ & 0,93 \\
\hline
\end{tabular}




\begin{tabular}{|c|c|c|c|c|c|c|c|c|c|c|c|c|}
\hline \multicolumn{13}{|c|}{ Painel F - 3×3 } \\
\hline & VM & $\begin{array}{c}\text { Volume } \\
\text { Financeiro } \\
\text { (VOL3) }\end{array}$ & $\begin{array}{c}\text { Quantidade } \\
\text { de Negócios } \\
\text { (QN3) }\end{array}$ & $\begin{array}{l}\text { Quantidade } \\
\text { de Títulos } \\
\text { (QT3) }\end{array}$ & $\begin{array}{l}\text { Número de } \\
\text { Dias Sem } \\
\text { Transação } \\
\text { (NTD3) }\end{array}$ & $\begin{array}{l}\text { Return-to- } \\
\text { Volume } \\
\text { (RtoV3) }\end{array}$ & $\begin{array}{l}\text { Turnover } \\
\text { (TO3) }\end{array}$ & $\begin{array}{c}\text { Volume Zero } \\
\text { Padronizado } \\
\text { (VZP3) }\end{array}$ & $\begin{array}{l}\text { Índice de } \\
\text { Negociabilidade } \\
\text { (NEG3) }\end{array}$ & $\begin{array}{l}\text { Desvio- } \\
\text { Padrão do } \\
\text { Turnover } \\
\text { (DPTO3) }\end{array}$ & $\begin{array}{l}\text { Desvio- } \\
\text { Padrão do } \\
\text { Volume } \\
\text { (DPVOL3) }\end{array}$ & $\begin{array}{c}\text { Coeficiente } \\
\text { de Variação } \\
\text { do Turnover } \\
\text { (CVTO3) }\end{array}$ \\
\hline $\begin{array}{l}\text { Volume Financeiro } \\
\text { (VOL3) }\end{array}$ & 0,74 & & & & & & & & & & & \\
\hline $\begin{array}{l}\text { Quantidade de } \\
\text { Negócios (QN3) }\end{array}$ & 0,63 & 0,92 & & & & & & & & & & \\
\hline $\begin{array}{l}\text { Quantidade de } \\
\text { Títulos (QT3) }\end{array}$ & 0,42 & 0,67 & 0,68 & & & & & & & & & \\
\hline $\begin{array}{l}\text { Número de Dias } \\
\text { Sem Transação } \\
\text { (NTD3) }\end{array}$ & $-0,57$ & $-0,84$ & $-0,92$ & $-0,62$ & & & & & & & & \\
\hline $\begin{array}{l}\text { Return-to-Volume } \\
\text { (RtoV3) }\end{array}$ & 0,01 & $-0,05$ & $-0,08$ & $-0,06$ & 0,06 & & & & & & & \\
\hline Turnover (TO3) & $-0,00$ & 0,33 & 0,29 & 0,62 & $-0,25$ & $-0,01$ & & & & & & \\
\hline $\begin{array}{l}\text { Volume Zero } \\
\text { Padronizado (VZP3) }\end{array}$ & $-0,02$ & $-0,35$ & $-0,32$ & $-0,63$ & 0,29 & 0,01 & $-1,00$ & & & & & \\
\hline $\begin{array}{l}\text { Índice de } \\
\text { Negociabilidade } \\
\text { (NEG3) }\end{array}$ & 0,70 & 0,97 & 0,98 & 0,68 & $-0,91$ & $-0,06$ & 0,31 & $-0,34$ & & & & \\
\hline $\begin{array}{l}\text { Desvio-Padrão do } \\
\text { Turnover (DPTO3) }\end{array}$ & $-0,11$ & 0,21 & 0,16 & 0,52 & $-0,13$ & $-0,01$ & 0,95 & $-0,94$ & 0,18 & & & \\
\hline $\begin{array}{l}\text { Desvio-Padrão do } \\
\text { Volume (DPVOL3) }\end{array}$ & 0,70 & 0,96 & 0,86 & 0,64 & $-0,77$ & $-0,05$ & 0,33 & $-0,35$ & 0,92 & 0,27 & & \\
\hline $\begin{array}{l}\text { Coeficiente de } \\
\text { Variação do } \\
\text { Turnover (CVTO3) } \\
\end{array}$ & $-0,42$ & $-0,52$ & $-0,56$ & $-0,39$ & 0,56 & $-0,01$ & $-0,18$ & 0,20 & $-0,56$ & 0,07 & $-0,32$ & \\
\hline $\begin{array}{l}\text { Coeficiente de } \\
\text { Variação do Volume } \\
\text { (CVVOL3) }\end{array}$ & $-0,42$ & $-0,50$ & $-0,55$ & $-0,35$ & 0,54 & $-0,01$ & $-0,15$ & 0,17 & $-0,54$ & 0,08 & $-0,28$ & 0,93 \\
\hline
\end{tabular}




\begin{tabular}{|c|c|c|c|c|c|c|c|c|c|c|c|c|}
\hline \multicolumn{13}{|c|}{ Painel G - 3x6 } \\
\hline & VM & $\begin{array}{c}\text { Volume } \\
\text { Financeiro } \\
\text { (VOL3) }\end{array}$ & $\begin{array}{c}\text { Quantidade } \\
\text { de Negócios } \\
\text { (QN3) }\end{array}$ & $\begin{array}{c}\text { Quantidade } \\
\text { de Títulos } \\
\text { (QT3) }\end{array}$ & $\begin{array}{l}\text { Número de } \\
\text { Dias Sem } \\
\text { Transação } \\
\text { (NTD3) }\end{array}$ & $\begin{array}{l}\text { Return-to- } \\
\text { Volume } \\
\text { (RtoV3) }\end{array}$ & $\begin{array}{l}\text { Turnover } \\
\text { (TO3) }\end{array}$ & $\begin{array}{c}\text { Volume Zero } \\
\text { Padronizado } \\
\text { (VZP3) } \\
\end{array}$ & $\begin{array}{c}\text { Índice de } \\
\text { Negociabilidade } \\
\text { (NEG3) } \\
\end{array}$ & $\begin{array}{l}\text { Desvio- } \\
\text { Padrão do } \\
\text { Turnover } \\
\text { (DPTO3) }\end{array}$ & $\begin{array}{l}\text { Desvio- } \\
\text { Padrão do } \\
\text { Volume } \\
\text { (DPVOL3) }\end{array}$ & $\begin{array}{l}\text { Coeficiente } \\
\text { de Variação } \\
\text { do Turnover } \\
\text { (CVTO3) }\end{array}$ \\
\hline $\begin{array}{l}\text { Volume Financeiro } \\
\text { (VOL3) }\end{array}$ & 0,74 & & & & & & & & & & & \\
\hline $\begin{array}{l}\text { Quantidade de } \\
\text { Negócios (QN3) }\end{array}$ & 0,64 & 0,92 & & & & & & & & & & \\
\hline $\begin{array}{l}\text { Quantidade de } \\
\text { Títulos (QT3) }\end{array}$ & 0,42 & 0,66 & 0,68 & & & & & & & & & \\
\hline $\begin{array}{l}\text { Número de Dias } \\
\text { Sem Transação } \\
\text { (NTD3) }\end{array}$ & $-0,57$ & $-0,83$ & $-0,91$ & $-0,60$ & & & & & & & & \\
\hline $\begin{array}{l}\text { Return-to-Volume } \\
\text { (RtoV3) }\end{array}$ & 0,01 & $-0,05$ & $-0,08$ & $-0,06$ & 0,06 & & & & & & & \\
\hline Turnover (TO3) & $-0,01$ & 0,31 & 0,27 & 0,61 & $-0,23$ & $-0,01$ & & & & & & \\
\hline $\begin{array}{l}\text { Volume Zero } \\
\text { Padronizado (VZP3) }\end{array}$ & $-0,01$ & $-0,34$ & $-0,30$ & $-0,63$ & 0,26 & 0,01 & $-1,00$ & & & & & \\
\hline $\begin{array}{l}\text { Índice de } \\
\text { Negociabilidade } \\
\text { (NEG3) }\end{array}$ & 0,71 & 0,98 & 0,98 & 0,68 & $-0,90$ & $-0,07$ & 0,29 & $-0,32$ & & & & \\
\hline $\begin{array}{l}\text { Desvio-Padrão do } \\
\text { Turnover (DPTO3) }\end{array}$ & $-0,12$ & 0,19 & 0,14 & 0,52 & $-0,11$ & $-0,01$ & 0,95 & $-0,94$ & 0,16 & & & \\
\hline $\begin{array}{l}\text { Desvio-Padrão do } \\
\text { Volume (DPVOL3) }\end{array}$ & 0,70 & 0,96 & 0,86 & 0,64 & $-0,76$ & $-0,06$ & 0,31 & $-0,33$ & 0,92 & 0,25 & & \\
\hline $\begin{array}{l}\text { Coeficiente de } \\
\text { Variação do } \\
\text { Turnover (CVTO3) }\end{array}$ & $-0,41$ & $-0,51$ & $-0,55$ & $-0,39$ & 0,54 & $-0,01$ & $-0,17$ & 0,19 & $-0,55$ & 0,08 & $-0,30$ & \\
\hline $\begin{array}{l}\text { Coeficiente de } \\
\text { Variação do Volume } \\
\text { (CVVOL3) }\end{array}$ & $-0,42$ & $-0,50$ & $-0,54$ & $-0,35$ & 0,53 & $-0,01$ & $-0,14$ & 0,16 & $-0,54$ & 0,09 & $-0,27$ & 0,92 \\
\hline
\end{tabular}




\begin{tabular}{|c|c|c|c|c|c|c|c|c|c|c|c|c|}
\hline \multicolumn{13}{|c|}{ Painel H - 3x12 } \\
\hline & VM & $\begin{array}{l}\text { Volume } \\
\text { Financeiro } \\
\text { (VOL3) }\end{array}$ & $\begin{array}{c}\text { Quantidade } \\
\text { de Negócios } \\
\text { (QN3) }\end{array}$ & $\begin{array}{l}\text { Quantidade } \\
\text { de Títulos } \\
\text { (QT3) }\end{array}$ & $\begin{array}{l}\text { Número de } \\
\text { Dias Sem } \\
\text { Transação } \\
\text { (NTD3) }\end{array}$ & $\begin{array}{l}\text { Return-to- } \\
\text { Volume } \\
\text { (RtoV3) }\end{array}$ & $\begin{array}{l}\text { Turnover } \\
\text { (TO3) }\end{array}$ & $\begin{array}{c}\text { Volume Zero } \\
\text { Padronizado } \\
\text { (VZP3) }\end{array}$ & $\begin{array}{l}\text { Índice de } \\
\text { Negociabilidade } \\
\text { (NEG3) }\end{array}$ & $\begin{array}{l}\text { Desvio- } \\
\text { Padrão do } \\
\text { Turnover } \\
\text { (DPTO3) }\end{array}$ & $\begin{array}{l}\text { Desvio- } \\
\text { Padrão do } \\
\text { Volume } \\
\text { (DPVOL3) }\end{array}$ & $\begin{array}{l}\text { Coeficiente } \\
\text { de Variação } \\
\text { do Turnover } \\
\text { (CVTO3) }\end{array}$ \\
\hline $\begin{array}{l}\text { Volume Financeiro } \\
\text { (VOL3) }\end{array}$ & 0,75 & & & & & & & & & & & \\
\hline $\begin{array}{l}\text { Quantidade de } \\
\text { Negócios (QN3) }\end{array}$ & 0,64 & 0,92 & & & & & & & & & & \\
\hline $\begin{array}{l}\text { Quantidade de } \\
\text { Títulos (QT3) }\end{array}$ & 0,42 & 0,66 & 0,67 & & & & & & & & & \\
\hline $\begin{array}{l}\text { Número de Dias } \\
\text { Sem Transação } \\
\text { (NTD3) }\end{array}$ & $-0,56$ & $-0,81$ & $-0,89$ & $-0,58$ & & & & & & & & \\
\hline $\begin{array}{l}\text { Return-to-Volume } \\
\text { (RtoV3) }\end{array}$ & $-0,00$ & $-0,07$ & $-0,09$ & $-0,06$ & 0,07 & & & & & & & \\
\hline Turnover (ТО3) & $-0,03$ & 0,28 & 0,23 & 0,61 & $-0,18$ & $-0,00$ & & & & & & \\
\hline $\begin{array}{l}\text { Volume Zero } \\
\text { Padronizado (VZP3) }\end{array}$ & 0,01 & $-0,30$ & $-0,26$ & $-0,62$ & 0,22 & 0,01 & $-1,00$ & & & & & \\
\hline $\begin{array}{l}\text { Índice de } \\
\text { Negociabilidade } \\
\text { (NEG3) }\end{array}$ & 0,71 & 0,98 & 0,98 & 0,68 & $-0,87$ & $-0,08$ & 0,26 & $-0,28$ & & & & \\
\hline $\begin{array}{l}\text { Desvio-Padrão do } \\
\text { Turnover (DPTO3) } \\
\end{array}$ & $-0,14$ & 0,16 & 0,10 & 0,51 & $-0,07$ & $-0,01$ & 0,95 & $-0,94$ & 0,13 & & & \\
\hline $\begin{array}{l}\text { Desvio-Padrão do } \\
\text { Volume (DPVOL3) }\end{array}$ & 0,70 & 0,95 & 0,85 & 0,63 & $-0,74$ & $-0,07$ & 0,28 & $-0,30$ & 0,92 & 0,22 & & \\
\hline $\begin{array}{l}\text { Coeficiente de } \\
\text { Variação do } \\
\text { Turnover (CVTO3) } \\
\end{array}$ & $-0,41$ & $-0,51$ & $-0,54$ & $-0,38$ & 0,53 & $-0,01$ & $-0,15$ & 0,17 & $-0,54$ & 0,10 & $-0,29$ & \\
\hline $\begin{array}{l}\text { Coeficiente de } \\
\text { Variação do Volume } \\
\text { (CVVOL3) }\end{array}$ & $-0,42$ & $-0,50$ & $-0,53$ & $-0,35$ & 0,52 & $-0,01$ & $-0,13$ & 0,15 & $-0,54$ & 0,09 & $-0,25$ & 0,92 \\
\hline
\end{tabular}




\begin{tabular}{|c|c|c|c|c|c|c|c|c|c|c|c|c|}
\hline \multicolumn{13}{|c|}{ Painel I-6x1 } \\
\hline & VM & $\begin{array}{l}\text { Volume } \\
\text { Financeiro } \\
\text { (VOL6) }\end{array}$ & $\begin{array}{l}\text { Quantidade } \\
\text { de Negócios } \\
\text { (QN6) }\end{array}$ & $\begin{array}{l}\text { Quantidade } \\
\text { de Títulos } \\
\text { (QT6) }\end{array}$ & $\begin{array}{l}\text { Número de } \\
\text { Dias Sem } \\
\text { Transação } \\
\text { (NTD6) }\end{array}$ & $\begin{array}{l}\text { Return-to- } \\
\text { Volume } \\
\text { (RtoV6) }\end{array}$ & $\begin{array}{l}\text { Turnover } \\
\text { (TO6) }\end{array}$ & $\begin{array}{c}\text { Volume Zero } \\
\text { Padronizado } \\
\text { (VZP6) }\end{array}$ & $\begin{array}{l}\text { Índice de } \\
\text { Negociabilidade } \\
\text { (NEG6) }\end{array}$ & $\begin{array}{l}\text { Desvio- } \\
\text { Padrão do } \\
\text { Turnover } \\
\text { (DPTO6) }\end{array}$ & $\begin{array}{l}\text { Desvio- } \\
\text { Padrão do } \\
\text { Volume } \\
\text { (DPVOL6) }\end{array}$ & $\begin{array}{c}\text { Coeficiente } \\
\text { de Variação } \\
\text { do Turnover } \\
\text { (CVTO6) }\end{array}$ \\
\hline $\begin{array}{l}\text { Volume Financeiro } \\
\text { (VOL6) }\end{array}$ & 0,74 & & & & & & & & & & & \\
\hline \begin{tabular}{|l|} 
Quantidade de \\
Negócios (QN6) \\
\end{tabular} & 0,63 & 0,92 & & & & & & & & & & \\
\hline $\begin{array}{l}\text { Quantidade de } \\
\text { Títulos (QT6) }\end{array}$ & 0,42 & 0,66 & 0,68 & & & & & & & & & \\
\hline $\begin{array}{l}\text { Número de Dias } \\
\text { Sem Transação } \\
\text { (NTD6) }\end{array}$ & $-0,59$ & $-0,85$ & $-0,93$ & $-0,62$ & & & & & & & & \\
\hline $\begin{array}{l}\text { Return-to-Volume } \\
\text { (RtoV6) }\end{array}$ & 0,05 & $-0,04$ & $-0,09$ & $-0,07$ & 0,06 & & & & & & & \\
\hline Turnover (T06) & $-0,01$ & 0,32 & 0,29 & 0,61 & $-0,25$ & $-0,02$ & & & & & & \\
\hline $\begin{array}{l}\text { Volume Zero } \\
\text { Padronizado (VZP6) }\end{array}$ & $-0,04$ & $-0,36$ & $-0,33$ & $-0,64$ & 0,30 & 0,02 & $-0,99$ & & & & & \\
\hline $\begin{array}{l}\text { Índice de } \\
\text { Negociabilidade } \\
\text { (NEG6) }\end{array}$ & 0,70 & 0,97 & 0,98 & 0,68 & $-0,92$ & $-0,06$ & 0,31 & $-0,35$ & & & & \\
\hline $\begin{array}{l}\text { Desvio-Padrão do } \\
\text { Turnover (DPTO6) }\end{array}$ & $-0,11$ & 0,20 & 0,16 & 0,53 & $-0,13$ & $-0,03$ & 0,96 & $-0,94$ & 0,18 & & & \\
\hline $\begin{array}{l}\text { Desvio-Padrão do } \\
\text { Volume (DPVOL6) }\end{array}$ & 0,72 & 0,98 & 0,88 & 0,64 & $-0,80$ & $-0,05$ & 0,32 & $-0,36$ & 0,94 & 0,24 & & \\
\hline $\begin{array}{l}\text { Coeficiente de } \\
\text { Variação do } \\
\text { Turnover (CVTO6) }\end{array}$ & $-0,48$ & $-0,60$ & $-0,64$ & $-0,45$ & 0,64 & $-0,01$ & $-0,20$ & 0,24 & $-0,64$ & 0,01 & $-0,46$ & \\
\hline $\begin{array}{l}\text { Coeficiente de } \\
\text { Variação do Volume } \\
\text { (CVVOL6) }\end{array}$ & $-0,50$ & $-0,60$ & $-0,63$ & $-0,41$ & 0,63 & $-0,02$ & $-0,18$ & 0,22 & $-0,63$ & 0,02 & $-0,44$ & 0,92 \\
\hline
\end{tabular}




\begin{tabular}{|c|c|c|c|c|c|c|c|c|c|c|c|c|}
\hline \multicolumn{13}{|c|}{ Painel J $-6 \times 3$} \\
\hline & VM & $\begin{array}{l}\text { Volume } \\
\text { Financeiro } \\
\text { (VOL6) }\end{array}$ & $\begin{array}{l}\text { Quantidade } \\
\text { de Negócios } \\
\text { (QN6) }\end{array}$ & $\begin{array}{l}\text { Quantidade } \\
\text { de Títulos } \\
\text { (QT6) }\end{array}$ & $\begin{array}{l}\text { Número de } \\
\text { Dias Sem } \\
\text { Transação } \\
\text { (NTD6) }\end{array}$ & $\begin{array}{l}\text { Return-to- } \\
\text { Volume } \\
\text { (RtoV6) }\end{array}$ & $\begin{array}{l}\text { Turnover } \\
\text { (TO6) }\end{array}$ & $\begin{array}{l}\text { Volume Zero } \\
\text { Padronizado } \\
\text { (VZP6) }\end{array}$ & $\begin{array}{l}\text { Índice de } \\
\text { Negociabilidade } \\
\text { (NEG6) }\end{array}$ & $\begin{array}{l}\text { Desvio- } \\
\text { Padrão do } \\
\text { Turnover } \\
\text { (DPTO6) }\end{array}$ & $\begin{array}{l}\text { Desvio- } \\
\text { Padrão do } \\
\text { Volume } \\
\text { (DPVOL6) }\end{array}$ & $\begin{array}{l}\text { Coeficiente } \\
\text { de Variação } \\
\text { do Turnover } \\
\text { (CVTO6) }\end{array}$ \\
\hline $\begin{array}{l}\text { Volume Financeiro } \\
\text { (VOL6) }\end{array}$ & 0,75 & & & & & & & & & & & \\
\hline $\begin{array}{l}\text { Quantidade de } \\
\text { Negócios (QN6) }\end{array}$ & 0,64 & 0,92 & & & & & & & & & & \\
\hline $\begin{array}{l}\text { Quantidade de } \\
\text { Títulos (QT6) }\end{array}$ & 0,43 & 0,66 & 0,68 & & & & & & & & & \\
\hline $\begin{array}{l}\text { Número de Dias } \\
\text { Sem Transação } \\
\text { (NTD6) }\end{array}$ & $-0,59$ & $-0,84$ & $-0,92$ & $-0,61$ & & & & & & & & \\
\hline $\begin{array}{l}\text { Return-to-Volume } \\
\text { (RtoV6) }\end{array}$ & 0,04 & $-0,05$ & $-0,09$ & $-0,07$ & 0,06 & & & & & & & \\
\hline Turnover (TO6) & $-0,01$ & 0,31 & 0,27 & 0,61 & $-0,23$ & $-0,02$ & & & & & & \\
\hline $\begin{array}{l}\text { Volume Zero } \\
\text { Padronizado (VZP6) }\end{array}$ & $-0,03$ & $-0,35$ & $-0,32$ & $-0,64$ & 0,28 & 0,02 & $-0,99$ & & & & & \\
\hline $\begin{array}{l}\text { Índice de } \\
\text { Negociabilidade } \\
\text { (NEG6) }\end{array}$ & 0,71 & 0,98 & 0,98 & 0,68 & $-0,91$ & $-0,07$ & 0,29 & $-0,34$ & & & & \\
\hline $\begin{array}{l}\text { Desvio-Padrão do } \\
\text { Turnover (DPTO6) }\end{array}$ & $-0,12$ & 0,19 & 0,15 & 0,52 & $-0,11$ & $-0,03$ & 0,96 & $-0,94$ & 0,17 & & & \\
\hline $\begin{array}{l}\text { Desvio-Padrão do } \\
\text { Volume (DPVOL6) }\end{array}$ & 0,72 & 0,98 & 0,88 & 0,64 & $-0,79$ & $-0,06$ & 0,31 & $-0,34$ & 0,94 & 0,22 & & \\
\hline $\begin{array}{l}\text { Coeficiente de } \\
\text { Variação do } \\
\text { Turnover (CVTO6) } \\
\end{array}$ & $-0,48$ & $-0,60$ & $-0,64$ & $-0,45$ & 0,63 & $-0,02$ & $-0,19$ & 0,23 & $-0,64$ & 0,02 & $-0,46$ & \\
\hline $\begin{array}{l}\text { Coeficiente de } \\
\text { Variação do Volume } \\
\text { (CVVOL6) }\end{array}$ & $-0,50$ & $-0,60$ & $-0,63$ & $-0,41$ & 0,62 & $-0,01$ & $-0,17$ & 0,21 & $-0,64$ & 0,02 & $-0,44$ & 0,91 \\
\hline
\end{tabular}




\begin{tabular}{|c|c|c|c|c|c|c|c|c|c|c|c|c|}
\hline \multicolumn{13}{|c|}{ Painel $\mathrm{K}-6 \times 6$} \\
\hline & VM & $\begin{array}{l}\text { Volume } \\
\text { Financeiro } \\
\text { (VOL6) }\end{array}$ & $\begin{array}{l}\text { Quantidade } \\
\text { de Negócios } \\
\text { (QN6) }\end{array}$ & $\begin{array}{l}\text { Quantidade } \\
\text { de Títulos } \\
\text { (QT6) }\end{array}$ & $\begin{array}{l}\text { Número de } \\
\text { Dias Sem } \\
\text { Transação } \\
\text { (NTD6) }\end{array}$ & $\begin{array}{l}\text { Return-to- } \\
\text { Volume } \\
\text { (RtoV6) }\end{array}$ & $\begin{array}{l}\text { Turnover } \\
\text { (TO6) }\end{array}$ & $\begin{array}{l}\text { Volume Zero } \\
\text { Padronizado } \\
\text { (VZP6) }\end{array}$ & $\begin{array}{c}\text { Índice de } \\
\text { Negociabilidade } \\
\text { (NEG6) }\end{array}$ & $\begin{array}{l}\text { Desvio- } \\
\text { Padrão do } \\
\text { Turnover } \\
\text { (DPTO6) }\end{array}$ & $\begin{array}{l}\text { Desvio- } \\
\text { Padrão do } \\
\text { Volume } \\
\text { (DPVOL6) }\end{array}$ & $\begin{array}{c}\text { Coeficiente } \\
\text { de Variação } \\
\text { do Turnover } \\
\text { (CVTO6) }\end{array}$ \\
\hline $\begin{array}{l}\text { Volume Financeiro } \\
\text { (VOL6) }\end{array}$ & 0,75 & & & & & & & & & & & \\
\hline $\begin{array}{l}\text { Quantidade de } \\
\text { Negócios (QN6) }\end{array}$ & 0,64 & 0,92 & & & & & & & & & & \\
\hline $\begin{array}{l}\text { Quantidade de } \\
\text { Títulos (QT6) }\end{array}$ & 0,43 & 0,66 & 0,67 & & & & & & & & & \\
\hline $\begin{array}{l}\text { Número de Dias } \\
\text { Sem Transação } \\
\text { (NTD6) }\end{array}$ & $-0,58$ & $-0,84$ & $-0,91$ & $-0,59$ & & & & & & & & \\
\hline $\begin{array}{l}\text { Return-to-Volume } \\
\text { (RtoV6) }\end{array}$ & 0,03 & $-0,06$ & $-0,10$ & $-0,07$ & 0,07 & & & & & & & \\
\hline Turnover (T06) & $-0,02$ & 0,29 & 0,25 & 0,61 & $-0,21$ & $-0,02$ & & & & & & \\
\hline $\begin{array}{l}\text { Volume Zero } \\
\text { Padronizado (VZP6) }\end{array}$ & $-0,02$ & $-0,33$ & $-0,30$ & $-0,63$ & 0,26 & 0,02 & $-0,99$ & & & & & \\
\hline $\begin{array}{l}\text { Índice de } \\
\text { Negociabilidade } \\
\text { (NEG6) }\end{array}$ & 0,71 & 0,98 & 0,98 & 0,67 & $-0,90$ & $-0,08$ & 0,27 & $-0,32$ & & & & \\
\hline $\begin{array}{l}\text { Desvio-Padrão do } \\
\text { Turnover (DPTO6) }\end{array}$ & $-0,13$ & 0,17 & 0,13 & 0,52 & $-0,09$ & $-0,02$ & 0,96 & $-0,94$ & 0,15 & & & \\
\hline $\begin{array}{l}\text { Desvio-Padrão do } \\
\text { Volume (DPVOL6) } \\
\end{array}$ & 0,72 & 0,97 & 0,88 & 0,64 & $-0,78$ & $-0,06$ & 0,29 & $-0,33$ & 0,94 & 0,21 & & \\
\hline $\begin{array}{l}\text { Coeficiente de } \\
\text { Variação do } \\
\text { Turnover (CVTO6) } \\
\end{array}$ & $-0,48$ & $-0,60$ & $-0,63$ & $-0,44$ & 0,63 & $-0,01$ & $-0,18$ & 0,22 & $-0,64$ & 0,03 & $-0,45$ & \\
\hline $\begin{array}{l}\text { Coeficiente de } \\
\text { Variação do Volume } \\
\text { (CVVOL6) }\end{array}$ & $-0,50$ & $-0,60$ & $-0,63$ & $-0,41$ & 0,62 & $-0,01$ & $-0,16$ & 0,20 & $-0,64$ & 0,03 & $-0,43$ & 0,91 \\
\hline
\end{tabular}




\begin{tabular}{|c|c|c|c|c|c|c|c|c|c|c|c|c|}
\hline \multicolumn{13}{|c|}{ Painel L - 6x12 } \\
\hline & VM & $\begin{array}{l}\text { Volume } \\
\text { Financeiro } \\
\text { (VOL6) }\end{array}$ & $\begin{array}{l}\text { Quantidade } \\
\text { de Negócios } \\
\text { (QN6) }\end{array}$ & $\begin{array}{l}\text { Quantidade } \\
\text { de Títulos } \\
\text { (QT6) }\end{array}$ & $\begin{array}{l}\text { Número de } \\
\text { Dias Sem } \\
\text { Transação } \\
\text { (NTD6) }\end{array}$ & $\begin{array}{l}\text { Return-to- } \\
\text { Volume } \\
\text { (RtoV6) }\end{array}$ & $\begin{array}{l}\text { Turnover } \\
\text { (TO6) }\end{array}$ & $\begin{array}{l}\text { Volume Zero } \\
\text { Padronizado } \\
\text { (VZP6) }\end{array}$ & $\begin{array}{l}\text { Índice de } \\
\text { Negociabilidade } \\
\text { (NEG6) }\end{array}$ & $\begin{array}{l}\text { Desvio- } \\
\text { Padrão do } \\
\text { Turnover } \\
\text { (DPTO6) }\end{array}$ & $\begin{array}{l}\text { Desvio- } \\
\text { Padrão do } \\
\text { Volume } \\
\text { (DPVOL6) }\end{array}$ & $\begin{array}{l}\text { Coeficiente } \\
\text { de Variação } \\
\text { do Turnover } \\
\text { (CVTO6) }\end{array}$ \\
\hline $\begin{array}{l}\text { Volume Financeiro } \\
\text { (VOL6) }\end{array}$ & 0,75 & & & & & & & & & & & \\
\hline $\begin{array}{l}\text { Quantidade de } \\
\text { Negócios (QN6) }\end{array}$ & 0,65 & 0,92 & & & & & & & & & & \\
\hline $\begin{array}{l}\text { Quantidade de } \\
\text { Títulos (QT6) }\end{array}$ & 0,42 & 0,66 & 0,67 & & & & & & & & & \\
\hline $\begin{array}{l}\text { Número de Dias } \\
\text { Sem Transação } \\
\text { (NTD6) }\end{array}$ & $-0,57$ & $-0,82$ & $-0,89$ & $-0,58$ & & & & & & & & \\
\hline $\begin{array}{l}\text { Return-to-Volume } \\
\text { (RtoV6) }\end{array}$ & 0,02 & $-0,07$ & $-0,11$ & $-0,07$ & 0,08 & & & & & & & \\
\hline Turnover (T06) & $-0,04$ & 0,26 & 0,22 & 0,60 & $-0,17$ & $-0,01$ & & & & & & \\
\hline $\begin{array}{l}\text { Volume Zero } \\
\text { Padronizado (VZP6) }\end{array}$ & $-0,00$ & $-0,30$ & $-0,26$ & $-0,63$ & 0,22 & 0,01 & $-0,99$ & & & & & \\
\hline $\begin{array}{l}\text { Índice de } \\
\text { Negociabilidade } \\
\text { (NEG6) }\end{array}$ & 0,71 & 0,98 & 0,98 & 0,67 & $-0,88$ & $-0,09$ & 0,24 & $-0,28$ & & & & \\
\hline $\begin{array}{l}\text { Desvio-Padrão do } \\
\text { Turnover (DPTO6) }\end{array}$ & $-0,15$ & 0,14 & 0,09 & 0,51 & $-0,05$ & $-0,01$ & 0,96 & $-0,94$ & 0,11 & & & \\
\hline $\begin{array}{l}\text { Desvio-Padrão do } \\
\text { Volume (DPVOL6) }\end{array}$ & 0,72 & 0,97 & 0,88 & 0,64 & $-0,77$ & $-0,08$ & 0,26 & $-0,29$ & 0,94 & 0,17 & & \\
\hline $\begin{array}{l}\text { Coeficiente de } \\
\text { Variação do } \\
\text { Turnover (CVTO6) } \\
\end{array}$ & $-0,47$ & $-0,60$ & $-0,63$ & $-0,44$ & 0,61 & $-0,01$ & $-0,17$ & 0,21 & $-0,64$ & 0,04 & $-0,45$ & \\
\hline $\begin{array}{l}\text { Coeficiente de } \\
\text { Variação do Volume } \\
\text { (CVVOL6) }\end{array}$ & $-0,49$ & $-0,61$ & $-0,63$ & $-0,42$ & 0,60 & 0,00 & $-0,16$ & 0,19 & $-0,64$ & 0,03 & $-0,43$ & 0,90 \\
\hline
\end{tabular}




\begin{tabular}{|c|c|c|c|c|c|c|c|c|c|c|c|c|}
\hline \multicolumn{13}{|c|}{ Painel $M-12 \times 1$} \\
\hline & VM & $\begin{array}{l}\text { Volume } \\
\text { Financeiro } \\
\text { (VOL12) }\end{array}$ & $\begin{array}{c}\text { Quantidade } \\
\text { de Negócios } \\
\text { (QN12) }\end{array}$ & $\begin{array}{c}\text { Quantidade } \\
\text { de Títulos } \\
\text { (QT12) }\end{array}$ & $\begin{array}{l}\text { Número de } \\
\text { Dias Sem } \\
\text { Transação } \\
\text { (NTD12) } \\
\end{array}$ & $\begin{array}{l}\text { Return-to- } \\
\text { Volume } \\
\text { (RtoV12) }\end{array}$ & $\begin{array}{l}\text { Turnover } \\
\text { (TO12) }\end{array}$ & $\begin{array}{c}\text { Volume Zero } \\
\text { Padronizado } \\
\text { (VZP12) }\end{array}$ & $\begin{array}{c}\text { Índice de } \\
\text { Negociabilidade } \\
\text { (NEG12) }\end{array}$ & $\begin{array}{l}\text { Desvio- } \\
\text { Padrão do } \\
\text { Turnover } \\
\text { (DPTO12) }\end{array}$ & $\begin{array}{l}\text { Desvio- } \\
\text { Padrão do } \\
\text { Volume } \\
\text { (DPVOL12) }\end{array}$ & $\begin{array}{l}\text { Coeficiente } \\
\text { de Variação } \\
\text { do Turnover } \\
\text { (CVTO12) }\end{array}$ \\
\hline $\begin{array}{l}\text { Volume Financeiro } \\
\text { (VOL12) }\end{array}$ & 0,75 & & & & & & & & & & & \\
\hline $\begin{array}{l}\text { Quantidade de } \\
\text { Negócios (QN12) }\end{array}$ & 0,64 & 0,93 & & & & & & & & & & \\
\hline $\begin{array}{l}\text { Quantidade de } \\
\text { Títulos (QT12) }\end{array}$ & 0,43 & 0,65 & 0,67 & & & & & & & & & \\
\hline $\begin{array}{l}\text { Número de Dias } \\
\text { Sem Transação } \\
\text { (NTD12) }\end{array}$ & $-0,60$ & $-0,85$ & $-0,92$ & $-0,60$ & & & & & & & & \\
\hline $\begin{array}{l}\text { Return-to-Volume } \\
\text { (RtoV12) }\end{array}$ & 0,05 & $-0,06$ & $-0,12$ & $-0,09$ & 0,08 & & & & & & & \\
\hline Turnover (T012) & $-0,02$ & 0,29 & 0,26 & 0,60 & $-0,21$ & $-0,04$ & & & & & & \\
\hline $\begin{array}{l}\text { Volume Zero } \\
\text { Padronizado } \\
\text { (VZP12) }\end{array}$ & $-0,06$ & $-0,35$ & $-0,33$ & $-0,64$ & 0,29 & 0,03 & $-0,98$ & & & & & \\
\hline $\begin{array}{l}\text { Índice de } \\
\text { Negociabilidade } \\
\text { (NEG12) }\end{array}$ & 0,71 & 0,98 & 0,98 & 0,67 & $-0,91$ & $-0,09$ & 0,28 & $-0,35$ & & & & \\
\hline $\begin{array}{l}\text { Desvio-Padrão do } \\
\text { Turnover (DPTO12) }\end{array}$ & $-0,13$ & 0,17 & 0,13 & 0,51 & $-0,09$ & $-0,04$ & 0,96 & $-0,93$ & 0,15 & & & \\
\hline $\begin{array}{l}\text { Desvio-Padrão do } \\
\text { Volume (DPVOL12) }\end{array}$ & 0,73 & 0,98 & 0,89 & 0,64 & $-0,80$ & $-0,07$ & 0,29 & $-0,34$ & 0,95 & 0,20 & & \\
\hline $\begin{array}{l}\text { Coeficiente de } \\
\text { Variação do } \\
\text { Turnover (CVTO12) }\end{array}$ & $-0,48$ & $-0,63$ & $-0,65$ & $-0,46$ & 0,65 & $-0,01$ & $-0,19$ & 0,25 & $-0,66$ & 0,02 & $-0,50$ & \\
\hline $\begin{array}{l}\text { Coeficiente de } \\
\text { Variação do Volume } \\
\text { (CVVOL12) }\end{array}$ & $-0,51$ & $-0,64$ & $-0,65$ & $-0,43$ & 0,65 & $-0,00$ & $-0,18$ & 0,24 & $-0,67$ & 0,00 & $-0,49$ & 0,87 \\
\hline
\end{tabular}




\begin{tabular}{|c|c|c|c|c|c|c|c|c|c|c|c|c|}
\hline \multicolumn{13}{|c|}{ Painel $N-12 \times 3$} \\
\hline & VM & $\begin{array}{l}\text { Volume } \\
\text { Financeiro } \\
\text { (VOL12) }\end{array}$ & $\begin{array}{l}\text { Quantidade } \\
\text { de Negócios } \\
\text { (QN12) }\end{array}$ & $\begin{array}{l}\text { Quantidade } \\
\text { de Títulos } \\
\text { (QT12) }\end{array}$ & $\begin{array}{l}\text { Número de } \\
\text { Dias Sem } \\
\text { Transação } \\
\text { (NTD12) }\end{array}$ & $\begin{array}{l}\text { Return-to- } \\
\text { Volume } \\
\text { (RtoV12) }\end{array}$ & $\begin{array}{l}\text { Turnover } \\
\text { (T012) }\end{array}$ & $\begin{array}{l}\text { Volume Zero } \\
\text { Padronizado } \\
\text { (VZP12) }\end{array}$ & $\begin{array}{c}\text { Índice de } \\
\text { Negociabilidade } \\
\text { (NEG12) }\end{array}$ & $\begin{array}{l}\text { Desvio- } \\
\text { Padrão do } \\
\text { Turnover } \\
\text { (DPTO12) }\end{array}$ & $\begin{array}{l}\text { Desvio- } \\
\text { Padrão do } \\
\text { Volume } \\
\text { (DPVOL12) }\end{array}$ & $\begin{array}{l}\text { Coeficiente } \\
\text { de Variação } \\
\text { do Turnover } \\
\text { (CVTO12) }\end{array}$ \\
\hline $\begin{array}{l}\text { Volume Financeiro } \\
\text { (VOL12) }\end{array}$ & 0,75 & & & & & & & & & & & \\
\hline $\begin{array}{l}\text { Quantidade de } \\
\text { Negócios (QN12) }\end{array}$ & 0,64 & 0,93 & & & & & & & & & & \\
\hline $\begin{array}{l}\text { Quantidade de } \\
\text { Títulos (QT12) }\end{array}$ & 0,43 & 0,65 & 0,67 & & & & & & & & & \\
\hline $\begin{array}{l}\text { Número de Dias } \\
\text { Sem Transação } \\
\text { (NTD12) }\end{array}$ & $-0,59$ & $-0,84$ & $-0,91$ & $-0,59$ & & & & & & & & \\
\hline $\begin{array}{l}\text { Return-to-Volume } \\
\text { (RtoV12) }\end{array}$ & 0,05 & $-0,07$ & $-0,13$ & $-0,10$ & 0,08 & & & & & & & \\
\hline Turnover (TO12) & $-0,02$ & 0,28 & 0,25 & 0,60 & $-0,20$ & $-0,04$ & & & & & & \\
\hline $\begin{array}{l}\text { Volume Zero } \\
\text { Padronizado } \\
\text { (VZP12) }\end{array}$ & $-0,05$ & $-0,34$ & $-0,31$ & $-0,64$ & 0,28 & 0,03 & $-0,98$ & & & & & \\
\hline $\begin{array}{l}\text { Índice de } \\
\text { Negociabilidade } \\
\text { (NEG12) }\end{array}$ & 0,71 & 0,98 & 0,98 & 0,67 & $-0,90$ & $-0,10$ & 0,27 & $-0,33$ & & & & \\
\hline $\begin{array}{l}\text { Desvio-Padrão do } \\
\text { Turnover (DPTO12) }\end{array}$ & $-0,13$ & 0,15 & 0,12 & 0,51 & $-0,07$ & $-0,04$ & 0,96 & $-0,93$ & 0,14 & & & \\
\hline $\begin{array}{l}\text { Desvio-Padrão do } \\
\text { Volume (DPVOL12) }\end{array}$ & 0,73 & 0,98 & 0,89 & 0,64 & $-0,80$ & $-0,08$ & 0,27 & $-0,33$ & 0,94 & 0,18 & & \\
\hline $\begin{array}{l}\text { Coeficiente de } \\
\text { Variação do } \\
\text { Turnover (CVTO12) }\end{array}$ & $-0,47$ & $-0,63$ & $-0,65$ & $-0,45$ & 0,64 & $-0,01$ & $-0,18$ & 0,24 & $-0,66$ & 0,03 & $-0,49$ & \\
\hline $\begin{array}{l}\text { Coeficiente de } \\
\text { Variação do Volume } \\
\text { (CVVOL12) }\end{array}$ & $-0,51$ & $-0,64$ & $-0,65$ & $-0,43$ & 0,64 & 0,01 & $-0,18$ & 0,24 & $-0,67$ & 0,00 & $-0,49$ & 0,86 \\
\hline
\end{tabular}




\begin{tabular}{|c|c|c|c|c|c|c|c|c|c|c|c|c|}
\hline \multicolumn{13}{|c|}{ Painel 0-12x6 } \\
\hline & VM & $\begin{array}{l}\text { Volume } \\
\text { Financeiro } \\
\text { (VOL12) }\end{array}$ & $\begin{array}{l}\text { Quantidade } \\
\text { de Negócios } \\
\text { (QN12) }\end{array}$ & $\begin{array}{l}\text { Quantidade } \\
\text { de Títulos } \\
\text { (QT12) }\end{array}$ & $\begin{array}{l}\text { Número de } \\
\text { Dias Sem } \\
\text { Transação } \\
\text { (NTD12) }\end{array}$ & $\begin{array}{l}\text { Return-to- } \\
\text { Volume } \\
\text { (RtoV12) }\end{array}$ & $\begin{array}{l}\text { Turnover } \\
\text { (T012) }\end{array}$ & $\begin{array}{l}\text { Volume Zero } \\
\text { Padronizado } \\
\text { (VZP12) }\end{array}$ & $\begin{array}{l}\text { Índice de } \\
\text { Negociabilidade } \\
\text { (NEG12) }\end{array}$ & $\begin{array}{l}\text { Desvio- } \\
\text { Padrão do } \\
\text { Turnover } \\
\text { (DPTO12) }\end{array}$ & $\begin{array}{l}\text { Desvio- } \\
\text { Padrão do } \\
\text { Volume } \\
\text { (DPVOL12) }\end{array}$ & $\begin{array}{c}\text { Coeficiente } \\
\text { de Variação } \\
\text { do Turnover } \\
\text { (CVTO12) }\end{array}$ \\
\hline $\begin{array}{l}\text { Volume Financeiro } \\
\text { (VOL12) }\end{array}$ & 0,75 & & & & & & & & & & & \\
\hline $\begin{array}{l}\text { Quantidade de } \\
\text { Negócios (QN12) }\end{array}$ & 0,64 & 0,93 & & & & & & & & & & \\
\hline $\begin{array}{l}\text { Quantidade de } \\
\text { Títulos (QT12) }\end{array}$ & 0,43 & 0,65 & 0,67 & & & & & & & & & \\
\hline $\begin{array}{l}\text { Número de Dias } \\
\text { Sem Transação } \\
\text { (NTD12) }\end{array}$ & $-0,59$ & $-0,84$ & $-0,90$ & $-0,58$ & & & & & & & & \\
\hline $\begin{array}{l}\text { Return-to-Volume } \\
\text { (RtoV12) }\end{array}$ & 0,04 & $-0,08$ & $-0,14$ & $-0,10$ & 0,09 & & & & & & & \\
\hline Turnover (TO12) & $-0,03$ & 0,26 & 0,23 & 0,60 & $-0,18$ & $-0,04$ & & & & & & \\
\hline $\begin{array}{l}\text { Volume Zero } \\
\text { Padronizado } \\
\text { (VZP12) }\end{array}$ & $-0,04$ & $-0,32$ & $-0,29$ & $-0,64$ & 0,26 & 0,03 & $-0,98$ & & & & & \\
\hline $\begin{array}{l}\text { Índice de } \\
\text { Negociabilidade } \\
\text { (NEG12) }\end{array}$ & 0,71 & 0,98 & 0,98 & 0,67 & $-0,89$ & $-0,11$ & 0,25 & $-0,31$ & & & & \\
\hline $\begin{array}{l}\text { Desvio-Padrão do } \\
\text { Turnover (DPTO12) }\end{array}$ & $-0,14$ & 0,14 & 0,10 & 0,51 & $-0,06$ & $-0,04$ & 0,96 & $-0,93$ & 0,12 & & & \\
\hline $\begin{array}{l}\text { Desvio-Padrão do } \\
\text { Volume (DPVOL12) }\end{array}$ & 0,73 & 0,97 & 0,89 & 0,64 & $-0,79$ & $-0,09$ & 0,26 & $-0,31$ & 0,94 & 0,17 & & \\
\hline $\begin{array}{l}\text { Coeficiente de } \\
\text { Variação do } \\
\text { Turnover (CVTO12) }\end{array}$ & $-0,47$ & $-0,62$ & $-0,64$ & $-0,45$ & 0,64 & $-0,00$ & $-0,17$ & 0,23 & $-0,65$ & 0,04 & $-0,49$ & \\
\hline $\begin{array}{l}\text { Coeficiente de } \\
\text { Variação do Volume } \\
\text { (CVVOL12) }\end{array}$ & $-0,51$ & $-0,64$ & $-0,65$ & $-0,43$ & 0,64 & 0,01 & $-0,18$ & 0,23 & $-0,67$ & 0,01 & $-0,48$ & 0,86 \\
\hline
\end{tabular}




\begin{tabular}{|c|c|c|c|c|c|c|c|c|c|c|c|c|}
\hline \multicolumn{13}{|c|}{ Painel P - 12x12 } \\
\hline & VM & $\begin{array}{l}\text { Volume } \\
\text { Financeiro } \\
\text { (VOL12) }\end{array}$ & $\begin{array}{c}\text { Quantidade } \\
\text { de Negócios } \\
\text { (QN12) }\end{array}$ & $\begin{array}{l}\text { Quantidade } \\
\text { de Títulos } \\
\text { (QT12) }\end{array}$ & $\begin{array}{l}\text { Número de } \\
\text { Dias Sem } \\
\text { Transação } \\
\text { (NTD12) }\end{array}$ & $\begin{array}{l}\text { Return-to- } \\
\text { Volume } \\
\text { (RtoV12) }\end{array}$ & $\begin{array}{l}\text { Turnover } \\
\text { (T012) }\end{array}$ & $\begin{array}{l}\text { Volume Zero } \\
\text { Padronizado } \\
\text { (VZP12) }\end{array}$ & $\begin{array}{c}\text { Índice de } \\
\text { Negociabilidade } \\
\text { (NEG12) }\end{array}$ & $\begin{array}{l}\text { Desvio- } \\
\text { Padrão do } \\
\text { Turnover } \\
\text { (DPTO12) }\end{array}$ & $\begin{array}{l}\text { Desvio- } \\
\text { Padrão do } \\
\text { Volume } \\
\text { (DPVOL12) }\end{array}$ & $\begin{array}{c}\text { Coeficiente } \\
\text { de Variação } \\
\text { do Turnover } \\
\text { (CVTO12) }\end{array}$ \\
\hline $\begin{array}{l}\text { Volume Financeiro } \\
\text { (VOL12) }\end{array}$ & 0,75 & & & & & & & & & & & \\
\hline $\begin{array}{l}\text { Quantidade de } \\
\text { Negócios (QN12) }\end{array}$ & 0,64 & 0,93 & & & & & & & & & & \\
\hline $\begin{array}{l}\text { Quantidade de } \\
\text { Títulos (QT12) }\end{array}$ & 0,43 & 0,65 & 0,66 & & & & & & & & & \\
\hline $\begin{array}{l}\text { Número de Dias } \\
\text { Sem Transação } \\
\text { (NTD12) }\end{array}$ & $-0,57$ & $-0,82$ & $-0,88$ & $-0,56$ & & & & & & & & \\
\hline $\begin{array}{l}\text { Return-to-Volume } \\
\text { (RtoV12) }\end{array}$ & 0,04 & $-0,10$ & $-0,16$ & $-0,09$ & 0,10 & & & & & & & \\
\hline Turnover (TO12) & $-0,04$ & 0,23 & 0,20 & 0,59 & $-0,14$ & $-0,03$ & & & & & & \\
\hline $\begin{array}{l}\text { Volume Zero } \\
\text { Padronizado } \\
\text { (VZP12) }\end{array}$ & $-0,02$ & $-0,29$ & $-0,26$ & $-0,63$ & 0,22 & 0,02 & $-0,98$ & & & & & \\
\hline $\begin{array}{l}\text { Índice de } \\
\text { Negociabilidade } \\
\text { (NEG12) }\end{array}$ & 0,71 & 0,98 & 0,98 & 0,66 & $-0,87$ & $-0,13$ & 0,22 & $-0,28$ & & & & \\
\hline $\begin{array}{l}\text { Desvio-Padrão do } \\
\text { Turnover (DPTO12) }\end{array}$ & $-0,15$ & 0,11 & 0,07 & 0,50 & $-0,03$ & $-0,02$ & 0,96 & $-0,93$ & 0,09 & & & \\
\hline $\begin{array}{l}\text { Desvio-Padrão do } \\
\text { Volume (DPVOL12) }\end{array}$ & 0,73 & 0,97 & 0,89 & 0,63 & $-0,77$ & $-0,10$ & 0,23 & $-0,28$ & 0,94 & 0,14 & & \\
\hline $\begin{array}{l}\text { Coeficiente de } \\
\text { Variação do } \\
\text { Turnover (CVTO12) }\end{array}$ & $-0,45$ & $-0,62$ & $-0,64$ & $-0,45$ & 0,62 & 0,01 & $-0,16$ & 0,21 & $-0,65$ & 0,05 & $-0,48$ & \\
\hline $\begin{array}{l}\text { Coeficiente de } \\
\text { Variação do Volume } \\
\text { (CVVOL12) }\end{array}$ & $-0,49$ & $-0,65$ & $-0,65$ & $-0,43$ & 0,63 & 0,03 & $-0,17$ & 0,22 & $-0,67$ & 0,01 & $-0,48$ & 0,84 \\
\hline
\end{tabular}




\section{APÊNDICE 2 - EXCESSOS DE RETORNOS MENSAIS DAS CARTEIRAS E RETORNO MENSAL DA CADERNETA DE POUPANÇA}

A tabela abaixo apresenta os excessos de retornos mensais - em relação à taxa de retorno mensal da caderneta de poupança - de cada uma das 10 carteiras formadas com base no decis criados conforme o Índice de Negociabilidade da BM\&FBOVESPA - calculado com base na média dos valores do índice nos 6 meses prévios (NEG6). Os retornos foram calculados equally weighted e as carteiras foram reformuladas semestralmente, nos meses de junho e dezembro de cada ano $t$, de janeiro de 1995 a novembro de 2011. S denota o decil que contém as ações mais líquidas (maiores valores de Índice de Negociabilidade da BM\&FBOVESPA), B denota o decil que contém as ações menos líquidas (menores valores de Índice de Negociabilidade da BM\&FBOVESPA). Rf refere-se a caderneta de poupança. As entradas de dados na tabela são os retornos \%. A coluna Mês sinaliza que os dados vão de janeiro de 1996 a junho de 2011, devido à necessidade de 6 meses anteriores para cálculo das medidas e 6 meses posteriores para retenção das carteiras, conforme descrito em detalhes no Capitulo 3 .

\begin{tabular}{|c|c|c|c|c|c|c|c|c|c|c|c|}
\hline Mês & Rf & $\mathbf{S}$ & D2 & D3 & D4 & D5 & D6 & D7 & D8 & D9 & B \\
\hline Jan.1996 & 1,76 & 18,75 & 20,10 & 21,00 & 21,76 & 9,04 & 14,61 & 9,72 & 9,64 & 8,17 & 4,02 \\
\hline Fev.1996 & 1,47 & $-4,70$ & $-5,56$ & $-3,21$ & 0,90 & 0,34 & 0,06 & 0,95 & 5,05 & $-2,62$ & 1,81 \\
\hline Mar.1996 & 1,32 & 0,59 & $-1,30$ & $-6,40$ & $-3,11$ & $-3,12$ & $-3,29$ & 0,05 & $-2,98$ & $-17,36$ & $-4,12$ \\
\hline Abr.1996 & 1,16 & 0,68 & 1,87 & $-3,29$ & 0,17 & 3,55 & $-2,30$ & 7,17 & 2,15 & $-9,27$ & 3,81 \\
\hline Mai.1996 & 1,09 & 5,85 & 2,78 & $-3,57$ & 11,29 & $-0,49$ & 9,46 & 5,54 & 5,42 & 11,85 & 6,61 \\
\hline Jun.1996 & 1,33 & 3,45 & 1,79 & 1,74 & 4,55 & 0,32 & 4,52 & 6,25 & $-1,25$ & $-0,54$ & $-1,94$ \\
\hline Jul.1996 & 1,09 & $-0,80$ & $-5,55$ & $-6,34$ & $-3,81$ & $-0,66$ & $-1,23$ & $-2,47$ & $-0,02$ & $-3,07$ & $-5,54$ \\
\hline Ago.1996 & 1,13 & 1,39 & $-0,98$ & 5,02 & $-0,91$ & $-1,72$ & 0,27 & $-4,01$ & $-6,38$ & $-1,71$ &, 16 \\
\hline Set.1996 & 1,17 & $-0,26$ & 0,65 & 0,44 & 4,49 & 1,59 & 1,92 & 6,12 & 1,91 & $-2,76$ & 1,05 \\
\hline Out.1996 & 1,25 & 2,22 & 0,87 & 8,21 & $-0,25$ & $-0,90$ & 0,01 & 3,47 & 1,93 & $-1,85$ & 3,70 \\
\hline Nov.1996 & 1,32 & $-2,83$ & $-0,05$ & & & $-4,47$ & 2,14 & 0,83 & 7,62 & 3,44 & 11,84 \\
\hline Dez.1996 & 1,38 & 4,85 & 4,56 & 5,09 & $-3,54$ & $-0,65$ & 3,32 & $-3,08$ & 7,29 & 1,36 & 3,73 \\
\hline Jan.1997 & 1,25 & 12,62 & 9,46 & 6,42 & 9,71 & 6,78 & 14,06 & 21,13 & 17,45 & 3,45 & 8,88 \\
\hline Fev.1997 & 1,42 & & 9,97 & 6,81 & 7,30 & 7,75 & 8,08 & 21,14 & 6,99 & 3,90 & 12,85 \\
\hline Mar.1997 & 1,13 & $-1,65$ & $-3,01$ & $-0,73$ & 5,11 & 0,43 & 2,20 & 3,11 & 0,44 & 2,41 & 1,98 \\
\hline Abr.1997 & 1,12 & 6,94 & 5,23 & 0,46 & 7,63 & 4,58 & 5,23 & 2,95 & 8,81 & $-0,48$ & 1,27 \\
\hline Mai.1997 & 1,14 & 2,63 & & & $0,0 J$ & $-3,35$ & 4,07 & 7,20 & 2,08 & $-1,76$ & 1,63 \\
\hline Jun.1997 & 1,16 & 8,39 & 7,38 & 11,89 & 14,80 & $-1,21$ & 9,76 & 14,73 & 4,28 & 18,93 & 6,48 \\
\hline Jul.1997 & 1,16 & 5,16 & 7,08 & 5,41 & 7,78 & 1,86 & 5,37 & $-3,07$ & 8,77 & 3,07 & $-0,90$ \\
\hline Ago.1997 & 1,13 & $-18,40$ & $-9,68$ & $-13,42$ & $-10,91$ & $-6,62$ & $-8,51$ & $-6,66$ & $-6,02$ & $-3,93$ & 3,42 \\
\hline Set.1997 & 1,15 & 11,54 & 5,98 & & 4,15 & 1,38 & $-1,05$ & $-0,09$ & $-3,38$ & 4,96 & 9,34 \\
\hline Out.1997 & 1,16 & $-27,54$ & $-24,32$ & $-27,20$ & $-24,65$ & $-21,25$ & $-12,75$ & $-2,80$ & $-11,34$ & $-3,45$ & $-2,40$ \\
\hline Nov.1997 & 1,36 & 6,95 & 1,14 & $-5,29$ & $-19,60$ & $-14,21$ & $-12,13$ & $-24,31$ & $-15,02$ & $-10,33$ & $-17,73$ \\
\hline Dez.1997 & 1,82 & 8,16 & 2,24 & 0,64 & 1,81 & 0,83 & $-3,03$ & $-4,68$ & $-7,00$ & 4,24 & $-0,35$ \\
\hline Jan.1998 & 1,65 & $-9,78$ & $-10,68$ & $-11,99$ & $-4,87$ & $-9,12$ & $-10,98$ & $-16,42$ & $-8,79$ & $-5,98$ & $-7,03$ \\
\hline Fev.1998 & 1,56 & 5,53 & 6,08 & 10,17 & 9,01 & 9,19 & 7,97 & 11,46 & $-0,86$ & $-4,40$ & $-2,76$ \\
\hline Mar.1998 & 1,40 & 9,03 & 20,66 & 28,15 & 21,78 & 21,04 & 21,18 & 12,96 & 10,45 & 12,74 & 15,04 \\
\hline Abr.1998 & 0,97 & $-2,99$ & 1,60 & $-1,70$ & 3,57 & 9,28 & 11,04 & 1,20 & 11,81 & 5,63 & 14,25 \\
\hline Mai.1998 & 0,96 & $-18,37$ & $-18,95$ & $-21,99$ & $-15,99$ & $-13,09$ & $-14,29$ & $-12,37$ & $-7,13$ & $-0,75$ & $-6,50$ \\
\hline Jun.1998 & 0,99 & $-2,91$ & $-9,68$ & $-11,43$ & $-7,93$ & $-4,47$ & $-9,00$ & $-6,05$ & $-7,95$ & $-6,40$ & $-5,28$ \\
\hline Jul.1998 & 1,05 & 5,88 & 15,12 & 4,16 & 4,78 & 4,79 & 3,80 & 0,40 & $-1,26$ & $-5,63$ & $-0,94$ \\
\hline Ago.1998 & 0,88 & $-36,01$ & $-37,31$ & $-26,77$ & $-31,87$ & $-22,02$ & $-13,34$ & $-29,48$ & $-15,74$ & $-20,23$ & $-10,96$ \\
\hline
\end{tabular}




\begin{tabular}{|c|c|c|c|c|c|c|c|c|c|c|c|}
\hline Mês & Rf & $\mathbf{S}$ & D2 & D3 & D4 & D5 & D6 & D7 & D8 & D9 & B \\
\hline Set.1998 & 0,95 & 6,09 & $-5,24$ & $-9,53$ & $-12,81$ & $-15,08$ & $-22,14$ & $-8,89$ & $-5,26$ & $-7,90$ & $-12,51$ \\
\hline Out.1998 & 1,39 & $-2,47$ & $-0,79$ & 3,44 & 3,24 & $-4,19$ & $-5,41$ & $-4,94$ & $-4,22$ & $-6,02$ & $-4,88$ \\
\hline Nov.1998 & 1,12 & 21,71 & 17,33 & 17,49 & 19,07 & 14,73 & 14,95 & 21,28 & 10,48 & 7,13 & 24,52 \\
\hline Dez.1998 & 1,25 & $-15,14$ & $-15,80$ & $-10,87$ & $-11,17$ & $-6,13$ & 2,27 & $-3,05$ & 6,32 & $-1,70$ & $-4,03$ \\
\hline Jan.1999 & 1,02 & 1,92 & $-7,30$ & 7,59 & 17,82 & 9,32 & 21,23 & $-1,33$ & 1,64 & $-1,82$ & $-0,49$ \\
\hline Fev.1999 & 1,67 & 9,37 & 2,88 & 5,38 & 9,03 & 4,20 & $-0,63$ & 3,35 & $-5,18$ & 9,12 & $-2,21$ \\
\hline Mar.1999 & 1,67 & 24,57 & 41,43 & 16,94 & 24,15 & 35,83 & 18,30 & 115,47 & 11,18 & $-4,53$ & 9,50 \\
\hline Abr.1999 & 1,11 & 6,81 & 7,42 & 6,24 & 10,70 & 4,94 & 8,53 & $-0,73$ & 1,87 & 9,64 & 3,72 \\
\hline Mai.1999 & 1,08 & $-4,40$ & 1,60 & 0,33 & $-1,67$ & 7,19 & 12,04 & 13,54 & $-2,88$ & $-4,37$ & 6,36 \\
\hline Jun.1999 & 0,81 & 2,41 & 8,44 & 1,83 & 5,65 & $-1,78$ & 24,69 & 5,97 & 2,67 & 1,91 & 11,95 \\
\hline Jul.1999 & 0,79 & $-9,42$ & $-9,92$ & $-11,86$ & 3,41 & $-7,44$ & 0,02 & 0,33 & 7,24 & $-0,74$ & 6,40 \\
\hline Ago.1999 & 0,80 & 0,21 & 2,98 & 1,01 & 3,13 & 7,11 & $-1,68$ & $-4,81$ & 0,79 & $-3,02$ & 2,49 \\
\hline Set.1999 & 0,77 & 4,29 & 11,52 & 7,26 & 6,50 & 13,36 & 4,76 & 4,94 & 6,94 & 7,44 & 13,55 \\
\hline Out.1999 & 0,73 & 6,05 & 2,53 & 1,59 & 2,77 & 7,86 & 11,34 & 8,69 & 19,33 & 9,88 & 11,26 \\
\hline Nov.1999 & 0,70 & 15,93 & 23,27 & 20,55 & 14,14 & 16,19 & 14,01 & 19,80 & 18,89 & 19,24 & 19,16 \\
\hline Dez.1999 & 0,80 & 21,85 & 27,49 & 22,80 & 12,51 & 28,24 & 21,23 & 18,89 & 7,35 & 11,13 & 15,66 \\
\hline Jan.2000 & 0,72 & $-8,54$ & $-1,40$ & $-1,63$ & 0,05 & 0,76 & 2,19 & 0,55 & 0,49 & 1,37 & 6,45 \\
\hline Fev.2000 & 0,73 & 1,53 & 4,68 & 3,42 & 4,78 & 1,92 & 4,40 & 6,17 & 3,20 & 0,86 & 6,51 \\
\hline Mar.2000 & 0,65 & 2,61 & 1,40 & 6,57 & 10,69 & 2,94 & 4,05 & 0,17 & 8,68 & 0,39 & $-5,97$ \\
\hline Abr. 2000 & 0,73 & $-8,14$ & $-7,31$ & $-9,80$ & $-13,51$ & $-14,86$ & $-12,84$ & $-7,00$ & $-1,58$ & $-4,98$ & 0,04 \\
\hline Mai.2000 & 0,75 & $-4,61$ & $-3,56$ & 4,12 & $-0,59$ & 0,73 & $-2,73$ & $-4,41$ & $-3,81$ & $-8,24$ & $-4,82$ \\
\hline Jun.2000 & 0,72 & 16,91 & 8,84 & 12,91 & 14,92 & 11,11 & 17,32 & 6,78 & 4,40 & 4,36 & 5,86 \\
\hline Jul.2000 & 0,66 & $-3,34$ & $-1,39$ & 3,23 & 5,18 & 6,27 & 8,12 & 7,66 & 3,78 & 5,16 & 4,85 \\
\hline Ago. 2000 & 0,70 & 3,93 & 9,76 & 7,19 & 1,46 & 1,79 & 7,01 & 7,37 & 7,32 & 14,61 & $-0,62$ \\
\hline Set.2000 & 0,60 & $-9,00$ & $-8,69$ & $-12,36$ & $-3,25$ & $-0,92$ & $-2,87$ & $-3,37$ & $-4,11$ & $-5,68$ & 1,75 \\
\hline Out.2000 & 0,63 & $-8,97$ & $-5,17$ & $-7,27$ & $-6,56$ & $-3,04$ & $-4,76$ & $-7,90$ & $-4,50$ & $-2,97$ & $-5,34$ \\
\hline Nov. 2000 & 0,62 & $-11,17$ & $-10,86$ & $-11,91$ & $-6,39$ & $-2,99$ & $-7,51$ & $-6,09$ & $-2,10$ & $-1,42$ & 5,40 \\
\hline Dez.2000 & 0,60 & 16,75 & 14,25 & 14,27 & 11,23 & 3,73 & 3,25 & 10,21 & 4,49 & 8,68 & 11,96 \\
\hline Jan.2001 & 0,64 & 15,73 & 17,34 & 17,45 & 21,09 & 14,99 & 15,13 & 11,86 & 14,59 & 17,64 & 6,71 \\
\hline Fev.2001 & 0,57 & $-11,20$ & $-11,85$ & $-5,30$ & $-5,87$ & 2,18 & $-4,27$ & $-2,67$ & 2,56 & $-1,88$ & $-0,56$ \\
\hline Mar.2001 & 0,67 & $-11,92$ & $-6,20$ & $-6,34$ & $-8,85$ & $-3,73$ & $-5,29$ & $-5,50$ & $-3,63$ & $-7,32$ & $-4,36$ \\
\hline Abr.2001 & 0,66 & 4,24 & 4,07 & $-3,32$ & $-0,31$ & $-1,68$ & $-0,14$ & $-0,40$ & $-2,87$ & $-4,29$ & $-0,43$ \\
\hline Mai.2001 & 0,68 & $-5,10$ & 1,14 & $-0,52$ & $-2,43$ & $-5,94$ & $-7,92$ & $-4,03$ & $-0,62$ & 1,82 & $-1,25$ \\
\hline Jun.2001 & 0,65 & 0,58 & $-0,44$ & 2,86 & 3,55 & 8,05 & $-0,30$ & 1,83 & 4,42 & 0,02 & 7,16 \\
\hline Jul.2001 & 0,75 & $-4,51$ & $-7,68$ & $-2,67$ & $-4,32$ & $-7,52$ & $-1,03$ & $-2,49$ & $-3,27$ & $-6,08$ & $-3,51$ \\
\hline Ago.2001 & 0,85 & $-9,81$ & $-6,16$ & $-0,32$ & $-2,70$ & $-6,42$ & $-1,47$ & $-4,21$ & $-0,17$ & 3,80 & 6,72 \\
\hline Set.2001 & 0,78 & $-16,72$ & $-27,82$ & $-19,69$ & $-19,71$ & $-14,83$ & $-14,11$ & $-15,36$ & $-13,15$ & $-8,06$ & $-12,28$ \\
\hline Out.2001 & 0,79 & 5,28 & 9,24 & 9,76 & 6,00 & 16,42 & 5,64 & 4,53 & $-0,15$ & 7,97 & 7,91 \\
\hline Nov.2001 & 0,69 & 12,56 & 16,43 & 13,44 & 12,28 & 9,24 & 2,89 & 11,11 & 12,11 & 2,97 & 10,82 \\
\hline Dez.2001 & 0,70 & 4,15 & 4,40 & 4,53 & 9,74 & 1,07 & 7,20 & 2,25 & $-0,70$ & 5,77 & $-4,04$ \\
\hline Jan.2002 & 0,76 & $-5,16$ & $-5,98$ & $-1,88$ & $-1,83$ & 0,29 & 0,25 & 2,66 & 2,23 & 6,10 & $-0,22$ \\
\hline Fev.2002 & 0,73 & 8,63 & 7,46 & 8,86 & 6,34 & 5,86 & 6,10 & 5,35 & 1,64 & 2,08 & 6,30 \\
\hline Mar.2002 & 0,68 & $-4,56$ & $-4,41$ & $-2,18$ & 1,89 & 2,90 & $-0,99$ & 0,13 & 0,02 & $-1,18$ & $-1,43$ \\
\hline Abr.2002 & 0,74 & 0,20 & $-3,91$ & 3,47 & $-1,15$ & 2,56 & $-2,91$ & 3,78 & $-4,73$ & $-0,02$ & 0,69 \\
\hline
\end{tabular}




\begin{tabular}{|c|c|c|c|c|c|c|c|c|c|c|c|}
\hline Mês & $\mathbf{R f}$ & $\mathbf{S}$ & D2 & D3 & D4 & D5 & D6 & D7 & D8 & D9 & B \\
\hline Mai.2002 & 0,71 & $-3,90$ & $-1,37$ & $-3,98$ & $-6,07$ & $-3,40$ & $-4,49$ & $-2,76$ & $-2,16$ & $-2,99$ & $-3,08$ \\
\hline Jun.2002 & 0,74 & $-13,10$ & $-11,98$ & $-6,35$ & $-11,27$ & $-5,78$ & $-7,44$ & $-8,38$ & $-3,04$ & $-5,61$ & $-0,37$ \\
\hline Jul.2002 & 0,77 & $-13,52$ & $-9,92$ & $-6,72$ & $-7,27$ & $-5,65$ & $-2,45$ & $-5,52$ & 2,87 & 1,54 & $-4,56$ \\
\hline Ago.2002 & 0,75 & 13,25 & 2,83 & 1,56 & 8,77 & 4,89 & 5,94 & 8,69 & $-0,50$ & $-2,46$ & 4,73 \\
\hline Set.2002 & 0,70 & $-17,07$ & $-15,82$ & $-6,08$ & $-13,43$ & $-5,79$ & $-7,77$ & $-5,74$ & $-2,74$ & $-0,93$ & $-4,03$ \\
\hline Out.2002 & 0,78 & 18,94 & 19,30 & 10,98 & 9,04 & 12,14 & 6,27 & 8,97 & 5,83 & 7,22 & $-5,34$ \\
\hline Nov.2002 & 0,77 & 2,18 & 2,20 & 3,01 & $-0,72$ & 3,40 & 3,78 & 3,89 & 9,86 & 1,69 & 1,86 \\
\hline Dez.2002 & 0,86 & 10,53 & 5,25 & 5,11 & 2,89 & 7,65 & 7,78 & 1,06 & 11,77 & 6,37 & $-2,65$ \\
\hline Jan.2003 & 0,99 & $-5,46$ & $-4,58$ & $-2,35$ & $-7,66$ & $-2,63$ & $-6,02$ & $-0,83$ & $-2,04$ & $-3,02$ & 2,29 \\
\hline Fev.2003 & 1,01 & $-6,06$ & $-5,55$ & $-4,27$ & $-5,98$ & $-1,59$ & $-5,20$ & 0,39 & $-9,61$ & $-7,42$ & $-9,21$ \\
\hline Mar.2003 & 0,88 & 9,60 & 7,55 & 0,99 & 11,90 & 2,25 & 9,11 & 10,30 & 11,12 & 2,24 & 2,44 \\
\hline Abr.2003 & 0,92 & 10,11 & 9,94 & 7,04 & 15,28 & 6,23 & 4,71 & 5,74 & 18,30 & 10,06 & 6,49 \\
\hline Mai.2003 & 0,97 & 6,77 & 5,13 & 1,79 & 5,22 & 0,21 & 8,58 & 5,94 & 3,53 & 0,69 & 0,76 \\
\hline Jun.2003 & 0,92 & $-7,14$ & $-0,78$ & 0,14 & 2,47 & 3,39 & 0,84 & 0,43 & $-2,31$ & $-3,39$ & 3,69 \\
\hline Jul.2003 & 1,05 & 4,53 & 4,95 & 4,37 & 6,47 & $-1,62$ & $-1,81$ & 4,87 & 4,24 & 4,67 & 3,68 \\
\hline Ago.2003 & 0,91 & 10,67 & 12,19 & 12,63 & 14,01 & 9,86 & 7,05 & 13,02 & 6,72 & 26,69 & 6,97 \\
\hline Set.2003 & 0,84 & 3,15 & 8,26 & 4,19 & 8,45 & 8,16 & 3,42 & 14,66 & 7,77 & 17,53 & 13,01 \\
\hline Out.2003 & 0,82 & 13,38 & 12,54 & 10,82 & 5,34 & 5,60 & 7,17 & 6,16 & $-1,59$ & 9,17 & 3,53 \\
\hline Nov.2003 & 0,80 & 8,67 & 18,42 & 12,83 & 8,87 & 6,99 & 6,75 & 3,49 & 16,42 & 5,57 & 4,14 \\
\hline Dez.2003 & 0,62 & 10,31 & 10,00 & 13,09 & 16,85 & 16,03 & 11,19 & 17,01 & 26,15 & 4,33 & 20,54 \\
\hline Jan.2004 & 0,63 & $-4,71$ & $-2,65$ & $-0,62$ & $-3,96$ & 8,64 & 2,78 & 4,19 & 0,93 & 7,35 & 1,96 \\
\hline Fev.2004 & 0,64 & 2,15 & $-0,92$ & $-1,92$ & $-2,99$ & $-3,27$ & $-2,67$ & $-1,31$ & 0,81 & 0,34 & $-0,60$ \\
\hline Mar.2004 & 0,68 & 1,17 & 3,05 & 1,85 & 1,92 & 3,04 & 4,99 & 0,04 & 2,24 & $-3,78$ & $-2,31$ \\
\hline Abr.2004 & 0,59 & $-13,53$ & $-12,32$ & $-13,50$ & $-9,05$ & $-8,53$ & $-1,42$ & $-4,23$ & $-1,35$ & $-1,70$ & 5,21 \\
\hline Mai.2004 & 0,66 & 0,26 & 2,02 & $-1,98$ & $-1,62$ & $-2,33$ & $-2,28$ & $-4,66$ & 1,93 & $-5,07$ & $-8,42$ \\
\hline Jun.2004 & 0,68 & 7,50 & 4,57 & 9,45 & 10,04 & 8,11 & 5,02 & 7,16 & 11,35 & 8,53 & 2,05 \\
\hline Jul.2004 & 0,70 & 6,48 & 8,36 & 8,63 & 6,44 & 11,02 & 3,99 & 8,62 & 5,45 & 8,09 & 7,66 \\
\hline Ago. 2004 & 0,70 & 2,45 & 2,39 & 5,75 & 10,24 & 9,59 & 1,69 & 11,20 & 10,50 & 10,34 & 10,04 \\
\hline Set.2004 & 0,67 & 1,22 & 2,34 & 1,46 & 9,03 & $-0,13$ & 8,17 & 5,85 & 6,42 & 18,91 & 10,47 \\
\hline Out.2004 & 0,61 & $-0,74$ & $-2,66$ & $-0,33$ & $-0,28$ & 1,17 & 0,07 & $-1,06$ & 7,60 & 0,35 & $-4,54$ \\
\hline Nov.2004 & 0,62 & 10,75 & 7,08 & 9,30 & 4,45 & 6,21 & 4,00 & 5,01 & 7,66 & 7,03 & 4,01 \\
\hline Dez.2004 & 0,74 & 2,97 & 1,31 & 10,01 & 8,04 & 11,02 & 5,56 & 5,64 & 10,90 & 17,13 & 79,43 \\
\hline Jan.2005 & 0,69 & $-7,84$ & $-7,46$ & $-9,01$ & $-9,27$ & $-1,15$ & $-2,61$ & $-5,93$ & $-1,80$ & $-3,76$ & $-3,11$ \\
\hline Fev.2005 & 0,63 & 15,89 & 10,17 & 10,58 & 8,87 & 6,00 & 13,84 & 12,06 & 9,08 & 8,33 & 10,59 \\
\hline Mar.2005 & 0,76 & $-7,08$ & $-7,17$ & $-6,78$ & $-5,92$ & $-3,59$ & $-2,02$ & $-0,67$ & $-1,86$ & $-1,00$ & 0,82 \\
\hline Abr.2005 & 0,70 & $-7,80$ & $-6,22$ & $-6,10$ & $-7,77$ & $-8,11$ & $-5,32$ & $-3,58$ & $-4,03$ & $-3,86$ & $-2,50$ \\
\hline Mai.2005 & 0,75 & 0,43 & $-0,47$ & 5,47 & 2,95 & $-5,71$ & $-3,79$ & $-2,31$ & $-1,13$ & 0,80 & 2,34 \\
\hline Jun.2005 & 0,80 & $-3,28$ & $-1,38$ & $-4,21$ & $-1,63$ & $-7,77$ & $-3,21$ & $-0,93$ & $-3,27$ & 2,23 & 0,85 \\
\hline Jul.2005 & 0,76 & 6,54 & 2,57 & $-0,81$ & 0,39 & $-1,69$ & $-2,63$ & $-2,08$ & $-2,77$ & $-0,72$ & $-6,29$ \\
\hline Ago. 2005 & 0,85 & 7,63 & 2,72 & 3,53 & 7,61 & 2,74 & 2,63 & $-2,23$ & 1,86 & 0,52 & 5,60 \\
\hline Set.2005 & 0,77 & 12,30 & 13,57 & 11,73 & 5,74 & 8,84 & 9,74 & 5,23 & 4,86 & 3,37 & $-0,77$ \\
\hline Out.2005 & 0,71 & $-5,18$ & $-5,19$ & $-6,32$ & $-2,74$ & $-3,25$ & $-0,59$ & $-3,30$ & $-2,94$ & $-4,83$ & $-4,52$ \\
\hline Nov.2005 & 0,69 & 6,10 & 3,02 & 6,82 & 10,91 & 1,13 & 6,62 & 1,56 & $-2,13$ & 0,74 & 0,72 \\
\hline Dez.2005 & 0,73 & 3,79 & 5,08 & 6,13 & 3,52 & 7,86 & 5,19 & 8,69 & 13,29 & 7,54 & 6,32 \\
\hline
\end{tabular}




\begin{tabular}{|c|c|c|c|c|c|c|c|c|c|c|c|}
\hline Mês & Rf & $\mathbf{S}$ & D2 & D3 & D4 & D5 & D6 & D7 & D8 & D9 & B \\
\hline Jan.2006 & 0,73 & 15,23 & 8,23 & 9,96 & 15,52 & 12,97 & 18,27 & 11,14 & 11,26 & 8,32 & 14,44 \\
\hline Fev.2006 & 0,64 & $-0,50$ & 4,99 & 4,89 & 0,13 & 4,13 & 10,23 & 3,34 & 6,47 & 0,81 & 3,36 \\
\hline Mar.2006 & 0,71 & $-3,99$ & $-0,49$ & $-4,69$ & $-2,26$ & 1,43 & $-0,08$ & $-3,96$ & 0,78 & 2,77 & 8,90 \\
\hline Abr.2006 & 0,63 & 4,81 & 9,04 & 6,02 & 2,83 & 3,79 & 9,55 & 5,75 & 10,62 & 8,35 & 14,70 \\
\hline Mai.2006 & 0,69 & $-9,11$ & $-11,67$ & $-11,68$ & $-7,32$ & $-7,18$ & $-1,75$ & $-7,64$ & $-3,20$ & $-3,59$ & $-5,84$ \\
\hline Jun.2006 & 0,69 & $-0,29$ & $-0,91$ & 1,46 & $-1,13$ & $-0,29$ & 2,66 & $-2,01$ & $-0,98$ & 1,15 & $-6,16$ \\
\hline Jul.2006 & 0,68 & 0,47 & $-0,37$ & $-3,19$ & 1,49 & $-0,22$ & $-1,90$ & $-0,87$ & $-3,02$ & 1,52 & 5,82 \\
\hline Ago. 2006 & 0,74 & $-2,72$ & 4,40 & 3,92 & 2,37 & 4,41 & $-2,53$ & 1,12 & 3,74 & $-0,80$ & 1,62 \\
\hline Set.2006 & 0,65 & $-0,21$ & 1,07 & $-0,23$ & 1,08 & 2,21 & 1,51 & 1,24 & $-3,71$ & $-0,58$ & 5,04 \\
\hline Out.2006 & 0,69 & 5,50 & 6,35 & 3,69 & 4,48 & 6,01 & 2,86 & 7,52 & 14,40 & 9,36 & $-0,27$ \\
\hline Nov.2006 & 0,63 & 4,55 & 5,82 & 7,41 & 11,05 & 11,03 & 8,27 & 13,50 & 19,06 & 10,58 & 2,23 \\
\hline Dez.2006 & 0,65 & 3,77 & 5,01 & 6,11 & 8,56 & 6,82 & 4,81 & 11,50 & 4,23 & 9,52 & 6,29 \\
\hline Jan.2007 & 0,72 & 1,58 & $-3,82$ & 1,15 & 1,47 & 4,66 & 9,09 & 7,27 & 3,99 & 11,77 & 15,23 \\
\hline Fev.2007 & 0,63 & $-2,95$ & $-0,74$ & $-3,37$ & 3,23 & 0,42 & 4,85 & 5,89 & 9,10 & 5,69 & 8,98 \\
\hline Mar.2007 & 0,69 & 3,09 & 0,08 & 2,09 & 2,25 & 4,59 & 0,86 & 0,59 & 2,81 & 5,58 & $-5,42$ \\
\hline Abr.2007 & 0,63 & 6,47 & 6,78 & 7,93 & 5,48 & 8,36 & 11,24 & 12,15 & 9,66 & 13,07 & 16,73 \\
\hline Mai.2007 & 0,67 & 7,19 & 7,46 & 6,63 & 6,96 & 5,61 & 17,85 & 10,51 & 8,92 & 16,41 & 15,77 \\
\hline Jun.2007 & 0,60 & 2,69 & 4,71 & 3,68 & 2,85 & 8,66 & 8,80 & 3,39 & 10,02 & 12,45 & 20,04 \\
\hline Jul.2007 & 0,65 & $-3,43$ & $-1,63$ & $-1,59$ & 0,18 & 1,42 & 9,87 & $-2,49$ & 4,74 & 5,01 & 19,15 \\
\hline Ago. 2007 & 0,65 & $-1,36$ & $-0,75$ & $-1,36$ & $-3,51$ & $-3,21$ & $-7,55$ & $-4,85$ & $-7,72$ & $-9,79$ & $-4,62$ \\
\hline Set.2007 & 0,61 & 8,73 & 4,37 & 1,93 & 3,60 & 3,68 & 4,69 & $-0,21$ & $-1,54$ & 3,32 & 8,83 \\
\hline Out.2007 & 0,61 & 4,40 & 4,89 & 1,76 & 1,00 & $-1,03$ & 3,18 & 6,45 & 2,68 & $-4,22$ & 13,80 \\
\hline Nov.2007 & 0,56 & $-4,31$ & $-3,94$ & $-11,18$ & $-5,65$ & $-9,66$ & $-5,33$ & $-7,81$ & $-8,06$ & $-6,96$ & $-3,50$ \\
\hline Dez.2007 & 0,56 & & & & & & & 1,38 & & 1,55 & 4,86 \\
\hline Jan.2008 & 0,60 & $-6,55$ & $-5,99$ & $-16,80$ & $-15,84$ & $-9,82$ & $-11,97$ & $-7,37$ & $-9,42$ & $-3,87$ & $-5,62$ \\
\hline Fev.2008 & 0,52 & 7,29 & 5,17 & 6,93 & 7,58 & 5,76 & 2,83 & 9,95 & 6,25 & 12,27 & 1,33 \\
\hline Mar.2008 & 0,54 & $-6,48$ & $-4,18$ & $-10,71$ & $-13,53$ & $-5,60$ & $-5,70$ & $-3,09$ & $-9,77$ & $-7,83$ & $-0,51$ \\
\hline Abr.2008 & 0,60 & 10,76 & 8,71 & 7,59 & 5,82 & 3,29 & $-0,09$ & 1,82 & 0,41 & 4,81 & 4,58 \\
\hline Mai.2008 & 0,57 & 4,56 & 4,01 & 10,38 & 11,23 & 9,67 & 7,66 & 4,74 & 9,92 & 14,81 & 5,82 \\
\hline Jun.2008 & 0,62 & $-11,72$ & $-8,31$ & $-11,04$ & $-11,63$ & $-6,95$ & $-6,29$ & $-2,66$ & $-2,91$ & 1,74 & $-5,97$ \\
\hline Jul.2008 & 0,69 & $-6,02$ & $-4,95$ & $-6,28$ & $-5,37$ & $-10,93$ & $-10,09$ & $-8,49$ & $-8,29$ & $-7,71$ & $-5,99$ \\
\hline Ago. 2008 & 0,66 & $-7,76$ & $-7,26$ & $-9,84$ & $-13,88$ & $-10,44$ & $-7,37$ & $-4,07$ & $-6,74$ & $-6,45$ & $-3,27$ \\
\hline Set.2008 & 0,70 & $-15,26$ & $-15,69$ & $-21,22$ & $-25,38$ & $-20,98$ & $-20,85$ & $-16,04$ & $-17,04$ & $-12,57$ & $-9,90$ \\
\hline Out.2008 & 0,75 & $-26,71$ & $-20,39$ & $-25,81$ & $-27,62$ & $-30,06$ & $-25,94$ & $-30,29$ & $-23,58$ & $-20,49$ & $-12,75$ \\
\hline Nov. 2008 & 0,73 & $-1,16$ & 0,36 & 2,85 & 0,72 & 6,75 & 1,47 & $-1,02$ & 1,17 & 0,96 & 0,10 \\
\hline Dez.2008 & 0,72 & 2,63 & 2,76 & 0,36 & 0,90 & 9,10 & 7,90 & 0,59 & 2,59 & 6,71 & 3,24 \\
\hline Jan.2009 & 0,68 & 0,29 & 2,35 & 1,49 & 5,48 & 2,31 & 4,09 & 7,74 & 0,11 & $-0,61$ & 2,01 \\
\hline Fev.2009 & 0,67 & $-5,25$ & $-3,84$ & $-0,06$ & $-2,14$ & 0,13 & 4,57 & 0,60 & $-0,18$ & 4,65 & $-2,99$ \\
\hline Mar.2009 & 0,64 & 7,69 & 0,74 & 4,45 & 2,26 & 0,76 & 0,73 & 0,74 & $-1,48$ & 4,92 & $-4,25$ \\
\hline Abr.2009 & 0,55 & 20,35 & 24,64 & 22,61 & 26,44 & 33,74 & 25,23 & 21,20 & 13,46 & 15,04 & 12,20 \\
\hline Mai.2009 & 0,55 & 10,66 & 9,10 & 8,00 & 10,47 & 10,49 & 13,01 & 14,28 & 3,48 & 5,29 & 19,36 \\
\hline Jun.2009 & 0,57 & $-3,48$ & $-0,60$ & $-3,61$ & 4,47 & 2,42 & 4,16 & 1,38 & 1,11 & $-0,23$ & $-0,44$ \\
\hline Jul.2009 & 0,61 & 8,54 & 10,83 & 8,39 & 14,79 & 16,29 & 15,24 & 9,56 & 8,56 & 6,82 & 5,61 \\
\hline Ago.2009 & 0,52 & 2,93 & 5,63 & 4,11 & 8,65 & 8,89 & 9,72 & 3,40 & 10,35 & 1,25 & 7,65 \\
\hline
\end{tabular}




\begin{tabular}{|c|c|c|c|c|c|c|c|c|c|c|c|}
\hline Mês & Rf & S & D2 & D3 & D4 & D5 & D6 & D7 & D8 & D9 & B \\
\hline Set.2009 & 0,50 & 8,20 & 6,04 & 5,24 & 6,48 & 9,30 & 8,20 & 6,55 & 8,64 & 5,62 & 3,95 \\
\hline Out.2009 & 0,50 & $-0,88$ & 0,65 & $-0,06$ & 2,80 & 0,21 & 2,63 & 4,17 & 1,55 & 0,16 & 2,76 \\
\hline Nov.2009 & 0,50 & 8,66 & 9,47 & 5,99 & 3,40 & 6,20 & 7,82 & 6,01 & 3,51 & 7,20 & 4,77 \\
\hline Dez.2009 & 0,55 & 3,43 & 6,13 & 4,59 & 3,59 & 4,26 & 5,29 & 10,87 & 2,96 & 1,91 & 1,28 \\
\hline Jan.2010 & 0,50 & $-5,95$ & $-5,02$ & 1,05 & 4,70 & $-0,77$ & 4,64 & 16,82 & 4,08 & 6,68 & 3,13 \\
\hline Fev.2010 & 0,52 & 2,41 & $-0,59$ & 0,30 & 0,44 & $-0,66$ & 3,35 & 6,16 & $-1,64$ & 4,30 & 1,38 \\
\hline Mar.2010 & 0,58 & 5,19 & 1,10 & $-1,04$ & $-4,66$ & 0,28 & $-3,25$ & $-2,31$ & 2,71 & 0,21 & 7,58 \\
\hline Abr.2010 & 0,50 & $-3,19$ & $-2,30$ & $-1,57$ & $-0,48$ & $-1,66$ & $-3,47$ & $-4,70$ & 0,10 & $-4,31$ & $-5,48$ \\
\hline Mai.2010 & 0,55 & $-7,26$ & $-6,37$ & $-2,02$ & $-6,54$ & $-5,99$ & $-9,08$ & $-8,64$ & $-3,95$ & $-7,02$ & $-6,36$ \\
\hline Jun.2010 & 0,56 & $-3,84$ & 2,36 & 1,81 & $-0,03$ & 2,96 & 4,26 & 0,99 & 2,18 & 5,82 & 5,26 \\
\hline Jul.2010 & 0,62 & 12,10 & 6,86 & 9,76 & 9,04 & 10,68 & 10,87 & 8,79 & 5,94 & 3,91 & 1,07 \\
\hline Ago.2010 & 0,59 & $-6,40$ & $-2,80$ & 1,44 & $-1,17$ & 2,04 & 1,31 & 7,60 & 0,18 & 9,25 & 2,59 \\
\hline Set.2010 & 0,57 & 4,62 & 5,19 & 3,51 & 3,85 & 3,71 & 4,32 & 5,64 & 4,54 & $-1,04$ & 2,52 \\
\hline Out.2010 & 0,55 & 1,47 & 5,45 & 2,51 & 7,63 & 7,32 & 6,80 & 5,12 & 6,99 & 1,24 & 0,03 \\
\hline Nov.2010 & 0,53 & $-5,44$ & $-4,44$ & $-2,22$ & $-4,55$ & $-0,86$ & 0,56 & 0,53 & 0,90 & 1,12 & 0,28 \\
\hline Dez.2010 & 0,64 & 0,03 & 0,44 & 3,80 & 0,58 & 1,61 & 3,14 & 2,70 & 4,55 & $-0,86$ & 4,10 \\
\hline Jan.2011 & 0,57 & $-7,53$ & $-2,80$ & $-5,31$ & $-4,70$ & $-7,99$ & $-3,59$ & $-8,65$ & $-2,73$ & 0,22 & 0,58 \\
\hline Fev.2011 & 0,60 & $-0,03$ & $-0,81$ & $-0,14$ & 0,13 & $-0,91$ & $-3,85$ & $-5,57$ & $-1,63$ & $-2,11$ & $-3,12$ \\
\hline Mar.2011 & 0,62 & 2,12 & 2,04 & 6,42 & 1,53 & 3,47 & $-4,23$ & 0,81 & $-0,38$ & 3,37 & $-0,59$ \\
\hline Abr.2011 & 0,54 & $-2,81$ & $-1,95$ & $-1,53$ & 0,14 & 1,33 & 3,02 & 0,65 & 5,38 & 6,97 & 2,24 \\
\hline Mai.2011 & 0,66 & $-2,90$ & $-1,03$ & 2,53 & $-2,27$ & 0,02 & $-0,36$ & $-4,98$ & 0,45 & $-1,87$ & 2,87 \\
\hline Jun.2011 & 0,61 & $-1,01$ & $-1,45$ & $-1,29$ & $-1,90$ & $-1,91$ & $-2,45$ & $-2,71$ & $-2,37$ & $-2,09$ & $-3,14$ \\
\hline
\end{tabular}




\section{APÊNDICE 3 - VALORES (PRÊMIOS) MENSAIS DOS FATORES DE RISCO}

A tabela abaixo apresenta os valores (prêmios) mensais dos fatores de risco - beta de mercado, liquidez, tamanho, índice $\mathrm{B} / \mathrm{M}$ e momento. $\mathrm{O}$ fator liquidez foi calculado, essencialmente, conforme procedido por Liu (2006). Os fatores de beta de mercado, tamanho e índice B/M foram calculados conforme procedido por Fama e French (1993). O fator momento foi construído, essencialmente, da forma sugerida por Carhart (1997). MKT (Rm - Rf) representa o fator beta de mercado. Os fatores liquidez, tamanho, índice B/M e momento são identificados na tabela abaixo por LIQ, SMB, HML e WinMLos, respectivamente. O rebalanceamento das carteiras para cômputo dos fatores foi feito semestralmente, nos meses de junho e dezembro de cada ano $t$, de julho de 1995 a novembro de 2011. As entradas de dados na tabela são os prêmios \% para cada fator. A coluna Mês sinaliza que os dados vão de janeiro de 1996 a junho de 2011, devido à necessidade de 6 meses anteriores para cálculo das medidas e 6 meses posteriores para retenção das carteiras, conforme descrito em detalhes no Capitulo 3.

\begin{tabular}{|c|c|c|c|c|c|}
\hline Mês & MKT (Rm - Rf) & LIQ & SMB & HML & WinMLos \\
\hline Jan.1996 & 15,08 & $-8,78$ & $-2,14$ & $-7,10$ & $-2,36$ \\
\hline Fev.1996 & $-4,26$ & 3,48 & 4,51 & 0,43 & 1,75 \\
\hline Mar.1996 & $-1,67$ & $-2,60$ & $-4,31$ & 1,73 & 2,64 \\
\hline Abr.1996 & 0,14 & 1,42 & 6,54 & $-3,29$ & 1,86 \\
\hline Mai.1996 & 5,87 & 4,07 & 12,77 & $-8,31$ & 15,04 \\
\hline Jun.1996 & 4,47 & $-1,83$ & 2,88 & 0,56 & 3,69 \\
\hline Jul.1996 & $-1,75$ & 0,72 & 0,26 & 1,42 & 2,93 \\
\hline Ago.1996 & 0,39 & $-2,76$ & $-3,22$ & 2,73 & 4,44 \\
\hline Set.1996 & 1,32 & $-0,49$ & 3,40 & $-2,94$ & $-2,29$ \\
\hline Out.1996 & 3,62 & 0,04 & $-6,51$ & 9,90 & $-0,33$ \\
\hline Nov.1996 & 0,06 & 4,95 & 3,95 & 1,78 & 0,72 \\
\hline Dez.1996 & 6,41 & 0,76 & $-5,84$ & 1,78 & $-1,73$ \\
\hline Jan.1997 & 11,96 & 4,10 & 1,26 & 1,80 & 7,70 \\
\hline Fev.1997 & 9,98 & 2,00 & 4,09 & $-9,89$ & 2,14 \\
\hline Mar.1997 & $-1,58$ & 2,20 & 6,14 & $-1,66$ & 5,55 \\
\hline Abr.1997 & 6,34 & $-1,31$ & $-1,17$ & 3,05 & 4,97 \\
\hline Mai.1997 & 7,04 & $-1,09$ & 3,85 & $-3,44$ & 5,78 \\
\hline Jun.1997 & 8,57 & 2,56 & 4,44 & 3,60 & 6,40 \\
\hline Jul.1997 & 3,13 & $-2,28$ & 2,03 & 3,74 & $-4,30$ \\
\hline Ago.1997 & $-15,43$ & 7,11 & 10,10 & 3,12 & $-3,26$ \\
\hline Set.1997 & 9,53 & $-3,11$ & $-8,16$ & 4,74 & 1,37 \\
\hline Out.1997 & $-23,67$ & 18,08 & 11,42 & $-1,49$ & $-1,20$ \\
\hline Nov.1997 & 0,97 & $-9,23$ & $-15,90$ & 4,32 & 9,40 \\
\hline Dez.1997 & 6,81 & $-4,63$ & $-10,23$ & $-1,74$ & $-2,64$ \\
\hline Jan.1998 & $-8,72$ & $-0,33$ & $-2,41$ & $-1,78$ & $-3,10$ \\
\hline Fev.1998 & 5,02 & $-5,96$ & $-2,58$ & $-1,61$ & $-3,53$ \\
\hline Mar.1998 & 10,62 & $-6,22$ & 9,27 & 7,10 & $-10,49$ \\
\hline Abr.1998 & $-0,96$ & 5,93 & 10,62 & $-1,59$ & 2,98 \\
\hline Mai.1998 & $-16,21$ & 9,50 & 4,47 & 3,86 & 5,93 \\
\hline Jun.1998 & $-6,09$ & 0,50 & 0,70 & $-2,82$ & 2,89 \\
\hline Jul.1998 & 9,60 & $-6,98$ & $-10,38$ & $-3,57$ & 1,06 \\
\hline Ago.1998 & $-39,71$ & 12,99 & 18,15 & 1,74 & 5,86 \\
\hline
\end{tabular}




\begin{tabular}{|c|c|c|c|c|c|}
\hline Mês & MKT (Rm - Rf) & LIQ & SMB & HML & WinMLos \\
\hline Set.1998 & 4,28 & $-3,65$ & $-15,35$ & 8,12 & $-9,80$ \\
\hline Out.1998 & 5,71 & $-4,83$ & $-12,63$ & 1,96 & 1,02 \\
\hline Nov.1998 & 17,80 & $-1,72$ & $-3,95$ & $-0,70$ & $-3,63$ \\
\hline Dez.1998 & $-18,45$ & 11,93 & 18,21 & $-1,30$ & 6,58 \\
\hline Jan.1999 & 9,58 & $-2,24$ & $-2,41$ & 1,31 & $-17,60$ \\
\hline Fev.1999 & 6,13 & $-5,42$ & $-7,61$ & 3,04 & 3,61 \\
\hline Mar.1999 & 28,56 & 0,74 & $-18,97$ & 3,75 & $-7,77$ \\
\hline Abr.1999 & 4,97 & $-2,80$ & 1,20 & 6,54 & $-6,60$ \\
\hline Mai.1999 & 1,33 & 4,34 & 5,67 & $-5,90$ & 1,13 \\
\hline Jun.1999 & 4,71 & 5,88 & $-1,34$ & $-0,50$ & $-0,94$ \\
\hline Jul.1999 & $-5,32$ & 10,27 & 5,11 & $-1,11$ & $-0,29$ \\
\hline Ago.1999 & 1,27 & $-3,95$ & 3,60 & $-3,09$ & 10,79 \\
\hline Set.1999 & 7,99 & $-0,68$ & 7,73 & $-7,72$ & 3,79 \\
\hline Out.1999 & 4,78 & 8,19 & 4,29 & $-1,75$ & $-1,51$ \\
\hline Nov.1999 & 16,56 & $-0,06$ & $-0,55$ & 14,12 & $-3,94$ \\
\hline Dez.1999 & 20,04 & $-7,58$ & 3,80 & $-5,18$ & $-0,53$ \\
\hline Jan.2000 & $-6,47$ & 4,44 & 6,57 & 0,72 & $-0,95$ \\
\hline Fev.2000 & 4,38 & 0,98 & $-2,82$ & $-0,66$ & 0,33 \\
\hline Mar.2000 & 3,06 & $-3,35$ & 16,48 & $-20,03$ & 6,00 \\
\hline Abr. 2000 & $-9,46$ & 5,42 & $-0,15$ & 3,94 & $-0,42$ \\
\hline Mai.2000 & $-0,96$ & $-3,98$ & $-3,52$ & 0,88 & 0,07 \\
\hline Jun.2000 & 14,11 & $-5,24$ & $-1,13$ & 0,38 & $-0,04$ \\
\hline Jul.2000 & $-2,11$ & 2,38 & 5,48 & 7,89 & 0,13 \\
\hline Ago. 2000 & 7,64 & 2,56 & $-3,52$ & $-2,61$ & 1,98 \\
\hline Set.2000 & $-6,64$ & 3,84 & 1,74 & 3,09 & $-0,52$ \\
\hline Out.2000 & $-5,37$ & 1,43 & 0,08 & $-2,57$ & $-0,37$ \\
\hline Nov. 2000 & $-6,88$ & 6,65 & 1,76 & 0,56 & 2,36 \\
\hline Dez. 2000 & 10,76 & $-2,68$ & $-0,32$ & $-0,64$ & $-2,00$ \\
\hline Jan.2001 & 15,26 & $-3,45$ & $-0,83$ & 10,75 & $-5,50$ \\
\hline Fev.2001 & $-7,26$ & 4,85 & 7,72 & 3,46 & $-0,57$ \\
\hline Mar.2001 & $-7,05$ & 2,00 & $-1,59$ & 2,75 & 3,46 \\
\hline Abr.2001 & 5,12 & $-2,42$ & $-3,70$ & $-5,05$ & $-0,63$ \\
\hline Mai.2001 & 0,59 & 0,54 & 0,55 & $-12,58$ & 0,85 \\
\hline Jun.2001 & $-2,04$ & $-0,08$ & 2,79 & 8,04 & $-2,20$ \\
\hline Jul.2001 & $-2,89$ & 2,15 & $-1,18$ & 5,39 & $-2,25$ \\
\hline Ago.2001 & $-4,66$ & 6,24 & 1,64 & 4,32 & $-0,75$ \\
\hline Set.2001 & $-14,98$ & 7,45 & 0,54 & 2,07 & $-1,01$ \\
\hline Out.2001 & 5,73 & $-4,20$ & 1,75 & 3,79 & $-1,37$ \\
\hline Nov.2001 & 7,21 & $-5,09$ & 1,80 & 0,50 & $-5,75$ \\
\hline Dez.2001 & 4,56 & $-2,76$ & $-4,64$ & 1,95 & 0,99 \\
\hline Jan.2002 & $-3,52$ & 5,15 & 2,29 & 2,98 & 2,22 \\
\hline Fev.2002 & 10,17 & $-3,18$ & $-7,81$ & 5,27 & 3,41 \\
\hline Mar.2002 & $-1,11$ & 0,33 & 1,69 & 0,74 & 3,19 \\
\hline Abr.2002 & 0,03 & $-0,87$ & $-1,83$ & 6,41 & 2,67 \\
\hline
\end{tabular}




\begin{tabular}{|c|c|c|c|c|c|}
\hline Mês & MKT (Rm - Rf) & LIQ & SMB & HML & WinMLos \\
\hline Mai.2002 & $-2,01$ & 0,80 & $-1,08$ & $-5,05$ & 5,91 \\
\hline Jun.2002 & $-9,98$ & 4,79 & 4,70 & 0,15 & 2,22 \\
\hline Jul.2002 & $-11,29$ & 6,20 & 6,32 & 0,79 & 4,75 \\
\hline Ago.2002 & 5,78 & $-2,02$ & $-1,77$ & 1,48 & $-3,54$ \\
\hline Set.2002 & $-12,57$ & 7,06 & 9,33 & $-5,03$ & 9,63 \\
\hline Out.2002 & 17,01 & $-8,97$ & $-11,13$ & 1,05 & $-1,34$ \\
\hline Nov.2002 & 0,60 & 2,65 & 4,12 & $-3,09$ & 2,30 \\
\hline Dez.2002 & 6,49 & $-1,09$ & $-3,92$ & 6,33 & $-2,20$ \\
\hline Jan.2003 & $-4,14$ & 3,13 & 0,26 & $-0,30$ & 1,07 \\
\hline Fev.2003 & $-5,65$ & $-1,55$ & 1,32 & 0,38 & 13,15 \\
\hline Mar.2003 & 7,07 & 0,94 & 3,99 & $-5,60$ & $-9,86$ \\
\hline Abr.2003 & 6,80 & $-1,16$ & $-0,59$ & 8,47 & $-5,69$ \\
\hline Mai.2003 & 3,81 & $-0,31$ & $-1,98$ & 6,27 & 3,60 \\
\hline Jun.2003 & $-3,69$ & $-0,34$ & 4,51 & $-2,36$ & 3,68 \\
\hline Jul.2003 & 6,34 & $-0,56$ & $-3,14$ & $-0,61$ & 3,31 \\
\hline Ago.2003 & 8,97 & 0,26 & 4,02 & $-2,07$ & 6,68 \\
\hline Set.2003 & 2,02 & 5,09 & 8,57 & 1,24 & $-3,18$ \\
\hline Out.2003 & 8,59 & $-4,53$ & $-8,06$ & 5,57 & $-6,85$ \\
\hline Nov.2003 & 7,10 & $-3,79$ & 1,73 & 1,13 & $-1,74$ \\
\hline Dez.2003 & 15,38 & 2,59 & 3,16 & 0,84 & $-0,83$ \\
\hline Jan.2004 & $-0,75$ & 3,99 & $-0,25$ & 3,53 & $-8,71$ \\
\hline Fev.2004 & 0,84 & 0,31 & 0,28 & $-0,87$ & 3,65 \\
\hline Mar.2004 & 0,77 & $-2,48$ & 2,19 & $-2,51$ & 6,16 \\
\hline Abr.2004 & $-11,17$ & 10,21 & 7,05 & 0,15 & $-6,38$ \\
\hline Mai.2004 & 0,80 & $-2,97$ & $-2,16$ & $-5,20$ & 2,30 \\
\hline Jun.2004 & 6,02 & $-1,53$ & $-1,79$ & 2,29 & $-2,11$ \\
\hline Jul.2004 & 6,36 & $-1,70$ & $-2,52$ & 8,30 & $-1,91$ \\
\hline Ago.2004 & 2,93 & 2,68 & 2,75 & 3,90 & 7,33 \\
\hline Set.2004 & 4,94 & 6,68 & 4,53 & $-1,69$ & 0,00 \\
\hline Out.2004 & 2,16 & 0,60 & $-1,75$ & $-2,61$ & $-0,58$ \\
\hline Nov.2004 & 5,26 & $-2,27$ & $-0,91$ & 1,89 & $-0,85$ \\
\hline Dez.2004 & 6,99 & 16,40 & 1,84 & $-3,63$ & $-2,38$ \\
\hline Jan.2005 & $-5,52$ & 3,31 & 3,87 & $-3,81$ & 2,81 \\
\hline Fev.2005 & 12,89 & 0,45 & $-2,97$ & 1,26 & 4,56 \\
\hline Mar.2005 & $-5,66$ & 4,99 & 1,73 & 1,67 & $-0,37$ \\
\hline Abr.2005 & $-8,87$ & 3,20 & 3,79 & 1,72 & 0,22 \\
\hline Mai.2005 & 1,02 & $-0,86$ & $-2,85$ & 4,02 & 4,12 \\
\hline Jun.2005 & 0,19 & 3,09 & $-2,64$ & $-1,45$ & $-1,69$ \\
\hline Jul.2005 & 3,37 & $-3,31$ & $-5,30$ & $-1,11$ & $-0,21$ \\
\hline Ago.2005 & 6,60 & $-3,38$ & $-2,02$ & $-1,31$ & 5,36 \\
\hline Set.2005 & 11,64 & $-4,95$ & $-5,24$ & 4,41 & $-2,49$ \\
\hline Out.2005 & $-5,05$ & 1,18 & 1,34 & 3,62 & 4,57 \\
\hline Nov.2005 & 5,53 & $-4,05$ & $-3,66$ & 1,70 & $-0,13$ \\
\hline Dez.2005 & 4,47 & 2,74 & 3,56 & 0,89 & 3,11 \\
\hline
\end{tabular}




\begin{tabular}{|c|c|c|c|c|c|}
\hline Mês & MKT (Rm - Rf) & LIQ & SMB & HML & WinMLos \\
\hline Jan.2006 & 15,68 & 0,06 & 3,02 & 2,40 & 11,02 \\
\hline Fev.2006 & $-0,41$ & 2,15 & 0,27 & 6,63 & $-3,14$ \\
\hline Mar.2006 & $-2,11$ & 3,84 & 1,74 & 1,75 & 2,55 \\
\hline Abr.2006 & 6,31 & 4,39 & $-4,50$ & 0,17 & 1,20 \\
\hline Mai.2006 & $-7,49$ & 5,12 & 5,65 & $-1,68$ & 0,84 \\
\hline Jun.2006 & $-1,21$ & $-0,84$ & $-1,11$ & 2,97 & 0,92 \\
\hline Jul.2006 & 0,48 & 0,63 & 1,49 & $-0,11$ & 3,96 \\
\hline Ago.2006 & $-1,83$ & $-1,78$ & 3,56 & 1,80 & $-4,77$ \\
\hline Set.2006 & $-0,44$ & $-0,10$ & $-0,81$ & 1,73 & $-2,33$ \\
\hline Out.2006 & 5,36 & 1,37 & 0,69 & $-0,23$ & $-0,61$ \\
\hline Nov.2006 & 7,39 & 2,58 & 2,59 & $-0,62$ & $-2,29$ \\
\hline Dez.2006 & 5,60 & 1,07 & 2,39 & $-1,40$ & 2,92 \\
\hline Jan.2007 & 0,93 & 8,37 & 5,49 & $-1,58$ & 2,26 \\
\hline Fev.2007 & $-3,39$ & 7,47 & 7,00 & 0,52 & 2,77 \\
\hline Mar.2007 & 3,78 & $-1,51$ & $-1,00$ & 0,95 & 0,68 \\
\hline Abr.2007 & 6,07 & 5,61 & 3,25 & 4,95 & 2,93 \\
\hline Mai.2007 & 6,35 & 7,16 & 4,98 & 7,24 & $-0,03$ \\
\hline Jun.2007 & 5,08 & 6,69 & $-0,70$ & 2,39 & $-1,93$ \\
\hline Jul.2007 & 0,40 & 7,43 & 6,28 & $-1,63$ & 0,53 \\
\hline Ago. 2007 & $-0,15$ & $-5,04$ & $-2,17$ & 5,32 & $-4,76$ \\
\hline Set.2007 & 8,69 & $-1,30$ & $-1,62$ & $-4,38$ & 0,35 \\
\hline Out.2007 & 7,91 & 1,77 & $-3,92$ & $-1,79$ & $-0,68$ \\
\hline Nov.2007 & $-4,09$ & 0,25 & $-2,24$ & 0,72 & $-2,30$ \\
\hline Dez.2007 & 1,48 & 5,93 & $-0,78$ & $-0,06$ & $-1,78$ \\
\hline Jan.2008 & $-9,73$ & 3,59 & $-4,67$ & 5,28 & 2,38 \\
\hline Fev.2008 & 7,61 & 0,01 & $-2,39$ & $-1,92$ & $-4,45$ \\
\hline Mar.2008 & $-6,05$ & 3,06 & $-3,02$ & 0,57 & 2,83 \\
\hline Abr.2008 & 9,15 & $-5,12$ & $-5,69$ & 1,08 & 1,95 \\
\hline Mai.2008 & 5,89 & 0,64 & 4,18 & 2,04 & 0,69 \\
\hline Jun.2008 & $-9,37$ & 6,77 & $-1,41$ & 5,29 & $-1,91$ \\
\hline Jul.2008 & $-11,19$ & $-1,47$ & 0,92 & 3,26 & 0,24 \\
\hline Ago. 2008 & $-6,04$ & 4,16 & $-3,77$ & $-1,36$ & 1,68 \\
\hline Set.2008 & $-8,35$ & 4,23 & $-9,73$ & $-6,07$ & 1,70 \\
\hline Out.2008 & $-25,72$ & 3,16 & $-2,84$ & 2,30 & 2,70 \\
\hline Nov. 2008 & $-1,42$ & $-1,38$ & $-5,53$ & 4,73 & $-8,24$ \\
\hline Dez.2008 & 4,59 & 1,10 & 1,10 & $-0,81$ & 0,27 \\
\hline Jan.2009 & 5,04 & 0,43 & 1,15 & $-3,26$ & $-5,92$ \\
\hline Fev.2009 & $-0,87$ & 3,64 & 0,68 & 1,75 & 3,09 \\
\hline Mar.2009 & 5,66 & $-3,41$ & $-3,57$ & $-3,23$ & 2,54 \\
\hline Abr.2009 & 13,57 & $-8,25$ & 9,99 & 5,19 & $-16,08$ \\
\hline Mai.2009 & 10,92 & 1,47 & $-2,61$ & 0,64 & $-7,74$ \\
\hline Jun.2009 & $-4,31$ & 1,31 & 3,68 & 3,46 & $-3,04$ \\
\hline Jul.2009 & 3,61 & $-2,58$ & 9,79 & 2,73 & 1,45 \\
\hline Ago. 2009 & 2,01 & 0,45 & 7,13 & 3,78 & 0,87 \\
\hline
\end{tabular}




\begin{tabular}{|c|c|c|c|c|c|}
\hline Mês & MKT (Rm - Rf) & LIQ & SMB & HML & WinMLos \\
\hline Set.2009 & 8,52 & $-0,47$ & 2,97 & $-1,50$ & 2,09 \\
\hline Out.2009 & 0,50 & 1,72 & 2,48 & $-2,60$ & $-2,67$ \\
\hline Nov.2009 & 7,78 & $-0,90$ & $-2,01$ & $-0,88$ & 2,86 \\
\hline Dez.2009 & 1,60 & 0,07 & $-0,82$ & 4,71 & $-1,34$ \\
\hline Jan.2010 & $-4,15$ & 7,94 & 6,10 & 0,32 & $-0,19$ \\
\hline Fev.2010 & 0,20 & 1,91 & 2,66 & $-3,29$ & 3,58 \\
\hline Mar.2010 & 3,67 & 0,94 & $-6,35$ & 2,54 & $-1,27$ \\
\hline Abr.2010 & $-3,89$ & $-1,74$ & 3,42 & $-1,87$ & 2,96 \\
\hline Mai.2010 & $-6,01$ & $-1,50$ & $-1,36$ & $-0,76$ & 2,50 \\
\hline Jun.2010 & $-4,56$ & 2,70 & 3,58 & 1,97 & 0,54 \\
\hline Jul.2010 & 9,29 & $-3,11$ & 0,84 & $-1,46$ & $-1,54$ \\
\hline Ago.2010 & $-3,55$ & 5,21 & 5,66 & $-1,46$ & 2,84 \\
\hline Set.2010 & 5,22 & $-0,93$ & $-1,26$ & $-2,04$ & 0,73 \\
\hline Out.2010 & 1,61 & $-0,88$ & 5,12 & $-0,32$ & 1,09 \\
\hline Nov.2010 & $-3,31$ & 3,84 & 4,49 & $-0,88$ & 1,73 \\
\hline Dez.2010 & 3,80 & 1,34 & 0,12 & $-1,37$ & $-0,85$ \\
\hline Jan.2011 & $-3,81$ & 2,84 & 0,51 & 0,98 & $-2,80$ \\
\hline Fev.2011 & 1,37 & $-2,91$ & $-5,18$ & 2,98 & 0,27 \\
\hline Mar.2011 & 1,28 & $-3,31$ & $-1,37$ & 1,76 & 1,27 \\
\hline Abr.2011 & $-3,11$ & 4,63 & 3,54 & $-0,55$ & 3,46 \\
\hline Mai.2011 & $-2,86$ & $-0,03$ & 0,89 & $-0,18$ & 0,47 \\
\hline Jun.2011 & $-3,12$ & 0,99 & 0,65 & 0,66 & 0,40 \\
\hline & & & & & \\
\hline
\end{tabular}




\section{APÊNDICE 4 - TESTES DE NORMALIDADE, AUTOCORRELAÇÃO E (MULTI)COLINEARIDADE DAS VARIÁVEIS}

O Painel A da tabela abaixo apresenta os resultados dos testes de autocorrelação de Durbin-Watson (D- W) e dos testes de (multi)colinearidade - Fator de Inflação da Variância (FIV) das regressões/variáveis testadas na presente pesquisa. O Painel B, por sua vez, apresenta os resultados dos testes de normalidade das séries Kolmogorov-Smirnov (K-S) - tanto para as variáveis dependentes quanto para as independentes utilizadas nos modelos. As variáveis de S a B são variáveis dependentes dos modelos - as carteiras formadas com base nos decis baseados na liquidez medida pelo Índice de Negociabilidade da BM\&FBOVESPA (NEG6). MKT é a variável independente beta de mercado. LIQ é a variável independente liquidez. SMB, HML e WinMLos são as variáveis independentes tamanho, índice B/M e momento, respectivamente.

\begin{tabular}{|c|c|c|c|c|c|c|}
\hline \multicolumn{7}{|c|}{ Painel A - Durbin-Watson (DW) e Fator de Inflação da Variância (FIV) } \\
\hline \multirow[b]{2}{*}{ Modelo } & \multirow[b]{2}{*}{ D-W } & \multicolumn{5}{|c|}{ FIV } \\
\hline & & $b$ & $l$ & $s$ & $\boldsymbol{h}$ & $W$ \\
\hline CAPM & De 1,54 a 2,21 & 1,00 & & & & \\
\hline 2-fatores & De 1,62 a 2,16 & 1,38 & 1,38 & & & \\
\hline 3-fatores & De 1,60 a 2,18 & 1,19 & & 1,28 & 1,08 & \\
\hline 4-fatores & De 1,64 a 2,16 & 1,24 & & 1,28 & 1,17 & 1,16 \\
\hline \multicolumn{7}{|c|}{ Painel B - Kolmogorov-Smirnov (K-S) } \\
\hline Variável & \multicolumn{3}{|c|}{ Kolmogorov-Smirnov Z } & \multicolumn{3}{|c|}{ P-Value } \\
\hline S (dependente) & \multicolumn{3}{|c|}{1,14} & \multicolumn{3}{|c|}{0,17} \\
\hline D9 (dependente) & \multicolumn{3}{|c|}{0,76} & \multicolumn{3}{|c|}{0,61} \\
\hline D8 (dependente) & \multicolumn{3}{|c|}{0,81} & \multicolumn{3}{|c|}{0,52} \\
\hline D7 (dependente) & \multicolumn{3}{|c|}{1,19} & \multicolumn{3}{|c|}{0,13} \\
\hline D6 (dependente) & \multicolumn{3}{|c|}{0,66} & \multicolumn{3}{|c|}{0,77} \\
\hline D5 (dependente) & \multicolumn{3}{|c|}{1,12} & \multicolumn{3}{|c|}{0,16} \\
\hline D4 (dependente) & \multicolumn{3}{|c|}{0,96} & \multicolumn{3}{|c|}{0,32} \\
\hline D3 (dependente) & \multicolumn{3}{|c|}{1,05} & \multicolumn{3}{|c|}{0,22} \\
\hline D2 (dependente) & \multicolumn{3}{|c|}{1,05} & \multicolumn{3}{|c|}{0,22} \\
\hline B (dependente) & \multicolumn{3}{|c|}{0,62} & \multicolumn{3}{|c|}{0,83} \\
\hline MKT (Rm - Rf) (independente) & \multicolumn{3}{|c|}{0,83} & \multicolumn{3}{|c|}{0,50} \\
\hline LIQ (independente) & \multicolumn{3}{|c|}{0,77} & \multicolumn{3}{|c|}{0,60} \\
\hline SMB (independente) & \multicolumn{3}{|c|}{0,94} & \multicolumn{3}{|c|}{0,34} \\
\hline HML (independente) & \multicolumn{3}{|c|}{1,01} & & 0,26 & \\
\hline WinMLos (independente) & 1,1 & & & & 0,14 & \\
\hline
\end{tabular}




\section{APÊNDICE 5 - SENSIBILIDADE DOS EXCESSOS DE RETORNOS AOS FATORES DE RISCO CONSIDERANDO AS AMOSTRAS WITHIN-SAMPLE}

A tabela abaixo apresenta os resultados das regressões procedidas em séries temporais considerando os diferentes períodos de within-sample, indicados no Quadro 8 do Capítulo 3, para as 10 carteiras formadas com base em decis conforme o Índice de Negociabilidade da BM\&FBOVESPA (NEG6). O excesso de retorno mensal equally weighted de cada carteira calculado em relação ao retorno do ativo livre de risco - caderneta de poupança - foi considerada a variável dependente das regressões temporais. $\mathbf{S}$ denota o decil que contém as ações mais líquidas (maiores valores de Índice de Negociabilidade da BM\&FBOVESPA) e B denota o decil que contém as ações menos líquidas (menores valores de Î́ndice de Negociabilidade da BM\&FBOVESPA). As variáveis independentes foram os prêmios pelos fatores beta de mercado, liquidez, tamanho, índice B/M e momento, nos respectivos modelos em que cada fator é incluído. $\mathrm{O}$ fator liquidez foi calculado, essencialmente, conforme a metodologia de Liu (2006). Os fatores beta de mercado, tamanho e índice B/M foram calculados, essencialmente, conforme procedido por Fama e French (1993). Por sua vez, o fator momento foi estimado conforme os métodos de Carhart (1997). Para cálculos que envolvam o índice B/M foram excluídas as ações de empresas financeiras e com Patrimônio Líquido negativo. A coluna Teste referencia o nome do teste que indica o período de within-sample utilizado, conforme indicado no Quadro 8 do Capítulo 3. Os coeficientes dos fatores beta de mercado, liquidez, tamanho, índice $\mathrm{B} / \mathrm{M}$ e momento são identificados na coluna Coef. da tabela por $b, l$, $s, h$ e $w$, respectivamente, em cada um dos modelos testados: CAPM (Painel A), 2-fatores (Painel B), 3-fatores (Painel C) e 4-fatores (Painel D). As entradas de dados são os coeficientes dos fatores obtidos nas regressões temporais.

\begin{tabular}{|c|c|c|c|c|c|c|c|c|c|c|c|}
\hline Teste & Coef. & $\mathbf{S}$ & D9 & D8 & D7 & D6 & D5 & D4 & D3 & D2 & B \\
\hline \multicolumn{12}{|c|}{ Painel A - CAPM } \\
\hline Original & b & 1,05 & 1,09 & 0,90 & 0,91 & 0,74 & 0,65 & 0,98 & 0,47 & 0,43 & 0,40 \\
\hline Alternativo 1 & b & 1,04 & 1,09 & 0,90 & 0,89 & 0,74 & 0,64 & 0,99 & 0,42 & 0,39 & 0,38 \\
\hline Alternativo 2 & $b$ & 1,02 & 1,10 & 0,93 & 0,90 & 0,76 & 0,65 & 1,04 & 0,44 & 0,41 & 0,40 \\
\hline Alternativo 3 & $b$ & 1,05 & 1,09 & 0,91 & 0,91 & 0,74 & 0,64 & 0,97 & 0,48 & 0,44 & 0,44 \\
\hline Alternativo 4 & b & 1,06 & 1,08 & 0,91 & 0,91 & 0,74 & 0,65 & 0,95 & 0,48 & 0,45 & 0,43 \\
\hline Alternativo 5 & $b$ & 1,01 & 1,06 & 0,91 & 0,88 & 0,73 & 0,64 & 1,04 & 0,42 & 0,41 & 0,38 \\
\hline \multicolumn{12}{|c|}{ Painel B - 2-fatores } \\
\hline \multirow{2}{*}{ Original } & $b$ & 0,96 & 1,09 & 0,81 & 0,99 & 0,81 & 0,88 & 1,58 & 0,81 & 0,65 & 0,76 \\
\hline & $l$ & 0,26 & 0,00 & 0,24 & 0,24 & 0,21 & 0,66 & 1,72 & 0,96 & 0,64 & 1,03 \\
\hline \multirow{2}{*}{ Alternativo 1} & b & 0,96 & 1,06 & 0,85 & 0,99 & 0,82 & 0,82 & 1,42 & 0,75 & 0,69 & 1,00 \\
\hline & $l$ & 0,27 & $-0,09$ & 0,16 & 0,21 & 0,21 & 0,52 & 1,29 & 0,79 & 0,73 & 1,66 \\
\hline \multirow{2}{*}{ Alternativo 2} & $b$ & 0,96 & 1,05 & 0,86 & 0,98 & 0,82 & 0,83 & 1,40 & 0,76 & 0,70 & 1,00 \\
\hline & $l$ & 0,27 & 0,09 & 0,16 & 0,19 & 0,22 & 0,53 & 1,29 & 0,81 & 0,74 & 1,64 \\
\hline \multirow{2}{*}{ Alternativo 3} & b & 0,95 & 1,11 & 0,81 & 0,97 & 0,82 & 0,91 & 1,67 & 0,74 & 0,61 & 0,73 \\
\hline & $l$ & 0,26 & 0,05 & 0,24 & 0,21 & 0,21 & 0,73 & 1,86 & 0,88 & 0,60 & 0,98 \\
\hline \multirow{2}{*}{ Alternativo 4} & $b$ & 0,93 & 1,11 & 0,83 & 0,97 & 0,83 & 0,90 & 1,69 & 0,74 & 0,62 & 0,74 \\
\hline & $l$ & 0,25 & 0,04 & 0,28 & 0,18 & 0,20 & 0,71 & 1,86 & 0,85 & 0,58 & 0,96 \\
\hline \multirow{2}{*}{ Alternativo 5} & $b$ & 0,94 & 1,10 & 0,82 & 0,96 & 0,83 & 0,89 & 1,70 & 0,73 & 0,62 & 0,72 \\
\hline & $l$ & 0,23 & 0,11 & 0,26 & 0,23 & 0,27 & 0,74 & 1,94 & 0,90 & 0,62 & 1,01 \\
\hline
\end{tabular}




\begin{tabular}{|c|c|c|c|c|c|c|c|c|c|c|c|}
\hline Teste & Coef. & $\mathbf{S}$ & D9 & D8 & D7 & D6 & D5 & D4 & D3 & D2 & B \\
\hline \multicolumn{12}{|c|}{ Painel C - 3-fatores } \\
\hline \multirow{3}{*}{ Original } & $b$ & 1,06 & 1,18 & 1,06 & 1,13 & 0,94 & 0,91 & 1,12 & 0,75 & 0,67 & 0,66 \\
\hline & $s$ & 0,03 & 0,24 & 0,46 & 0,65 & 0,58 & 0,76 & 0,40 & 0,80 & 0,70 & 0,77 \\
\hline & $h$ & 0,13 & 0,10 & 0,32 & 0,24 & 0,28 & 0,28 & 0,19 & 0,36 & 0,43 & 0,38 \\
\hline \multirow{3}{*}{ Alternativo 1} & $\bar{b}$ & 1,06 & 1,18 & 1,07 & 1,12 & 0,95 & 0,93 & 1,14 & 0,69 & 0,63 & 0,65 \\
\hline & $s$ & 0,03 & 0,24 & 0,49 & 0,63 & 0,59 & 0,80 & 0,40 & 0,73 & 0,66 & 0,75 \\
\hline & $h$ & 0,11 & 0,08 & 0,33 & 0,23 & 0,28 & 0,29 & 0,21 & 0,31 & 0,41 & 0,37 \\
\hline \multirow{3}{*}{ Alternativo 2} & $b$ & 1,04 & 1,18 & 1,10 & 1,12 & 0,96 & 0,93 & 1,17 & 0,69 & 0,65 & 0,65 \\
\hline & $s$ & 0,04 & 0,24 & 0,49 & 0,62 & 0,59 & 0,80 & 0,36 & 0,73 & 0,67 & 0,73 \\
\hline & $h$ & 0,10 & 0,11 & 0,35 & 0,22 & 0,28 & 0,27 & 0,23 & 0,32 & 0,42 & 0,38 \\
\hline \multirow{3}{*}{ Alternativo 3} & b & 1,06 & 1,17 & 1,06 & 1,14 & 0,94 & 0,90 & 1,12 & 0,75 & 0,69 & 0,72 \\
\hline & $s$ & 0,02 & 0,23 & 0,46 & 0,66 & 0,58 & 0,76 & 0,42 & 0,79 & 0,73 & 0,83 \\
\hline & $h$ & 0,13 & 0,11 & 0,33 & 0,25 & 0,31 & 0,26 & 0,23 & 0,34 & 0,45 & 0,31 \\
\hline \multirow{3}{*}{ Alternativo 4} & $b$ & 1,06 & 1,16 & 1,07 & 1,13 & 0,94 & 0,90 & 1,10 & 0,76 & 0,69 & 0,72 \\
\hline & $s$ & 0,02 & 0,23 & 0,46 & 0,64 & 0,60 & 0,76 & 0,45 & 0,81 & 0,73 & 0,84 \\
\hline & $h$ & 0,13 & 0,11 & 0,34 & 0,25 & 0,30 & 0,27 & 0,24 & 0,34 & 0,43 & 0,30 \\
\hline \multirow{3}{*}{ Alternativo 5} & $b$ & 1,02 & 1,13 & 1,08 & 1,11 & 0,94 & 0,94 & 1,17 & 0,68 & 0,65 & 0,64 \\
\hline & $s$ & 0,03 & 0,20 & 0,47 & 0,63 & 0,57 & 0,82 & 0,37 & 0,72 & 0,68 & 0,70 \\
\hline & $h$ & 0,10 & 0,11 & 0,33 & 0,22 & 0,28 & 0,28 & 0,25 & 0,33 & 0,41 & 0,37 \\
\hline \multicolumn{12}{|c|}{ Painel D - 4-fatores } \\
\hline \multirow{4}{*}{ Original } & $b$ & 1,06 & 1,17 & 1,05 & 1,10 & 0,92 & 0,88 & 1,10 & 0,73 & 0,68 & 0,64 \\
\hline & $s$ & 0,03 & 0,24 & 0,47 & 0,65 & 0,59 & 0,76 & 0,41 & 0,81 & 0,70 & 0,77 \\
\hline & $h$ & 0,14 & 0,10 & 0,31 & 0,18 & 0,23 & 0,22 & 0,14 & 0,32 & 0,46 & 0,34 \\
\hline & $w$ & 0,04 & $-0,01$ & $-0,06$ & $-0,22$ & $-0,15$ & $-0,18$ & $-0,16$ & $-0,13$ & 0,10 & $-0,15$ \\
\hline \multirow{4}{*}{ Alternativo 1} & $b$ & 1,07 & 1,18 & 1,06 & 1,09 & 0,93 & 0,91 & 1,11 & 0,68 & 0,65 & 0,63 \\
\hline & $s$ & 0,03 & 0,24 & 0,50 & 0,65 & 0,60 & 0,81 & 0,41 & 0,74 & 0,66 & 0,76 \\
\hline & $h$ & 0,14 & 0,08 & 0,29 & 0,15 & 0,21 & 0,22 & 0,13 & 0,29 & 0,45 & 0,33 \\
\hline & $w$ & 0,09 & 0,00 & $-0,13$ & $-0,26$ & $-0,24$ & $-0,22$ & $-0,25$ & $-0,05$ & 0,12 & $-0,14$ \\
\hline \multirow{4}{*}{ Alternativo 2} & $b$ & 1,05 & 1,18 & 1,08 & 1,09 & 0,93 & 0,91 & 1,14 & 0,69 & 0,66 & 0,64 \\
\hline & $s$ & 0,03 & 0,24 & 0,50 & 0,64 & 0,61 & 0,81 & 0,38 & 0,74 & 0,66 & 0,74 \\
\hline & $h$ & 0,14 & 0,11 & 0,29 & 0,14 & 0,20 & 0,21 & 0,15 & 0,30 & 0,44 & 0,34 \\
\hline & $w$ & 0,14 & 0,02 & $-0,19$ & $-0,25$ & $-0,29$ & $-0,22$ & $-0,28$ & $-0,07$ & 0,09 & \begin{tabular}{|l|}
$-0,14$ \\
\end{tabular} \\
\hline \multirow{4}{*}{ Alternativo 3} & $b$ & 1,07 & 1,17 & 1,06 & 1,12 & 0,92 & 0,87 & 1,10 & 0,73 & 0,70 & 0,69 \\
\hline & $s$ & 0,02 & 0,23 & 0,46 & 0,66 & 0,59 & 0,76 & 0,43 & 0,79 & 0,73 & 0,84 \\
\hline & $h$ & 0,15 & 0,11 & 0,32 & 0,20 & 0,26 & 0,21 & 0,18 & 0,30 & 0,45 & 0,23 \\
\hline & $w$ & 0,07 & 0,01 & $-0,04$ & $-0,17$ & $-0,15$ & $-0,20$ & $-0,16$ & $-0,12$ & 0,03 & $-0,27$ \\
\hline \multirow{4}{*}{ Alternativo 4} & $b$ & 1,07 & 1,16 & 1,06 & 1,11 & 0,92 & 0,88 & 1,08 & 0,75 & 0,69 & 0,69 \\
\hline & $s$ & 0,01 & 0,23 & 0,46 & 0,65 & 0,61 & 0,76 & 0,45 & 0,81 & 0,73 & 0,85 \\
\hline & $h$ & 0,15 & 0,11 & 0,33 & 0,20 & 0,26 & 0,22 & 0,19 & 0,31 & 0,44 & 0,23 \\
\hline & $w$ & 0,08 & $-0,01$ & $-0,03$ & $-0,16$ & $-0,16$ & $-0,18$ & $-0,18$ & $-0,11$ & 0,02 & $-0,25$ \\
\hline \multirow{4}{*}{ Alternativo 5} & $b$ & 1,04 & 1,14 & 1,06 & 1,08 & 0,91 & 0,91 & 1,14 & 0,67 & 0,66 & 0,62 \\
\hline & $s$ & 0,02 & 0,20 & 0,48 & 0,64 & 0,59 & 0,84 & 0,38 & 0,73 & 0,67 & 0,71 \\
\hline & $h$ & 0,15 & 0,11 & 0,27 & 0,14 & 0,19 & 0,20 & 0,17 & 0,32 & 0,43 & 0,33 \\
\hline & $w$ & 0,17 & 0,03 & $-0,18$ & $-0,27$ & $-0,30$ & $-0,26$ & $-0,28$ & $-0,06$ & 0,07 & $-0,13$ \\
\hline
\end{tabular}


